

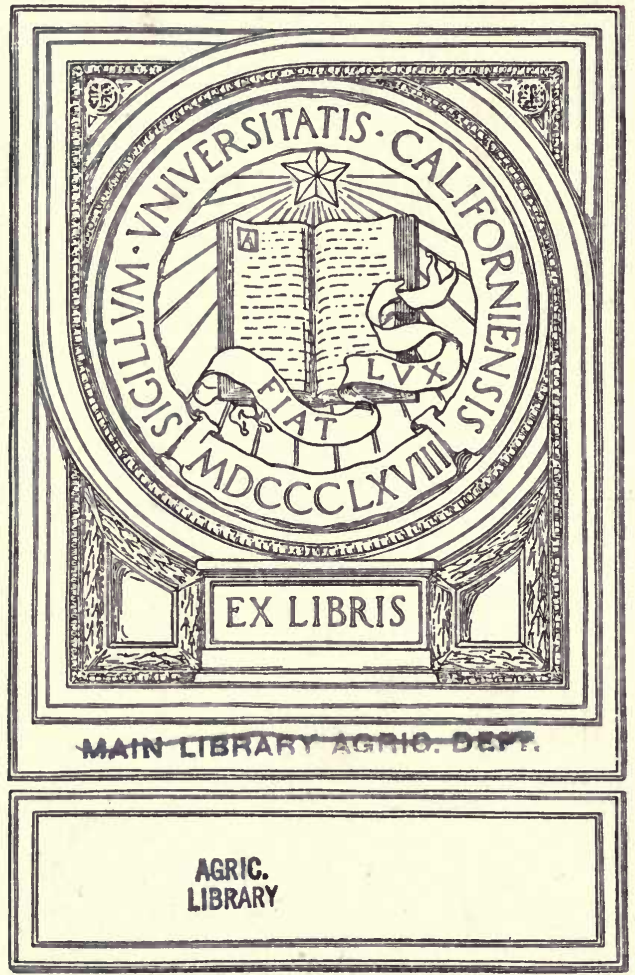



a 






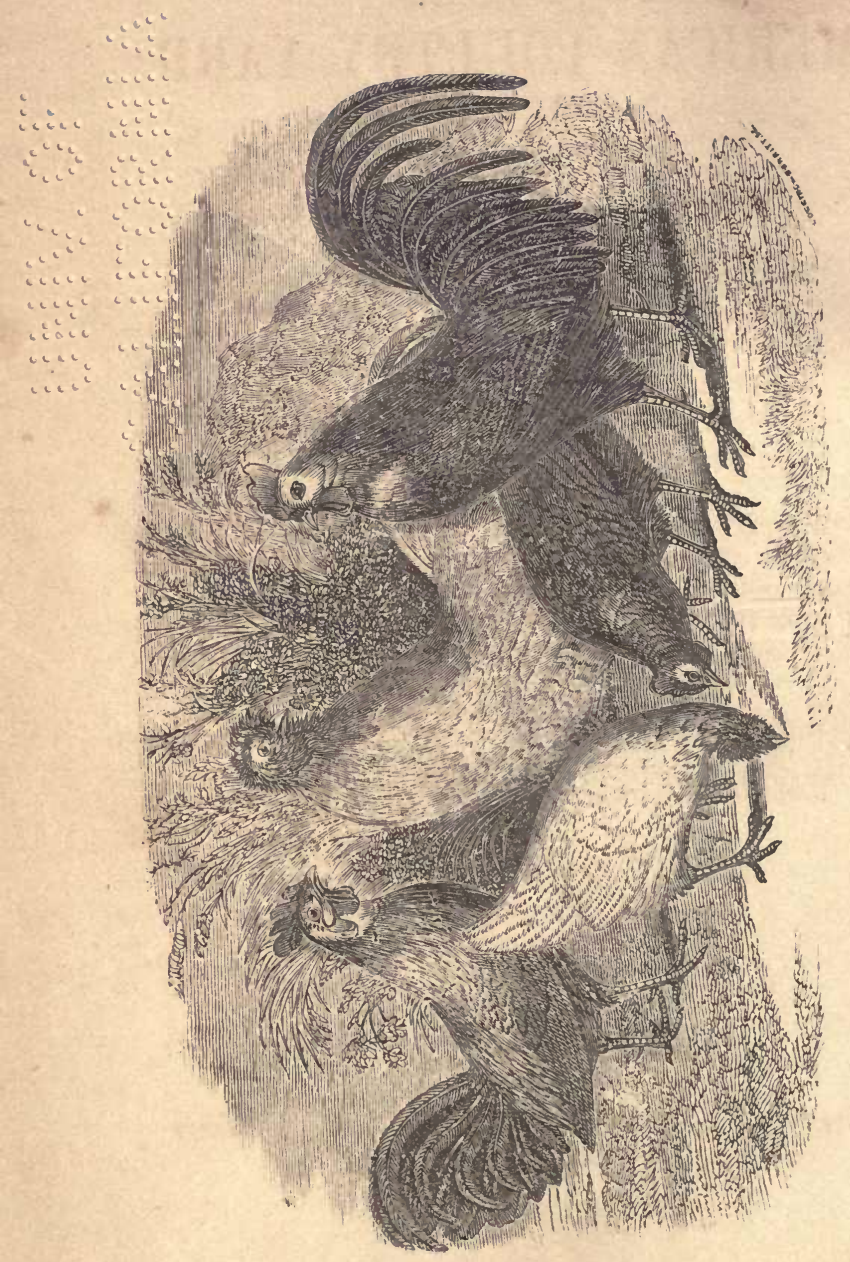




\section{THE}

\section{AMERICAN POULTRY YARD;}

conprassise THв

ORIGIN, HISTORY, AND DESCRIPTION

OF THE DIFFERENT BREEDS

of

DOIMSTIC POULTRY;

WITH

COMPLETE DIRECTIONS FOR THEIR BREEDING, CROSSING, REARING FATTENING, AND PREPARATION FOR MARKET; INCLUDING SPECIFIC DIRECTIONS FOR CAPONISING FOWLS, AND FOR

THE TREATMENT OF THE PRINCIPAL DISEASES TO .WHICH THEY ARE SUBJECT; DRAWN FROM AUTHENTIC SOURCES AND PERSONAL OBSERVATION;

\section{ILLUSTRATED WITII NUMEROLS ENGRAVINGS.}

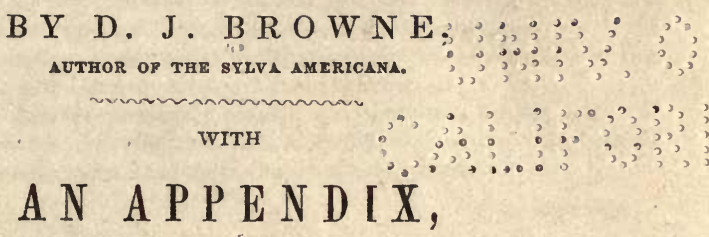

EMBRACING THE COMPARATIVE MERITS OF DIFFERENT BREEDS OF FOWLS,

BY SAMUEL ALLEN.

\section{NEW YORK :}

P UBLISHED BY C. M. SAXT $O N$. 1850 . 


\section{$S F 487$ \\ 8785 1850 \\ AGRIC. \\ LBBDAII}

\section{MAIN LIBRARY AGRIC. DEPT.}

Entered according to Act of Congress, in the year 1849 , by EPHRAIM BLANCHARD,

In the Clerk's Office of the District Court of the United States for the Southern District of New York.

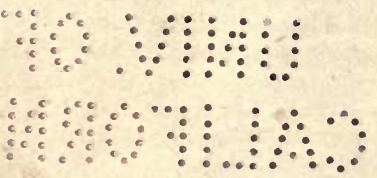




\section{A D VERTISEMENT.}

TnE "American Poultry Yard" being now completed, the publisher has thought proper to offer a few preliminary remarks on its design and the manner in which it has been got up.

Actuated by the most liberal motives, he has, in the first place, endeavored to keep pace with the improvements of the age, in obtaining the best information on the subject, that could be procured, suited to the general reader, and answering, at the same time, the purposes of practice and economy.

Mr. Browne, the ostensible author of this work, was bred and brought up a practical farmer, and was favorably known as editor of "The Naturalist," a monthly periodical, published in Boston some twenty years ago, and more recently as a civil engineer on our public works, and as the writer of a treatise on American trees. He is an enthusiastic devotee to the natural and exact sciences, particularly to agriculture and rural economy, having travelled and resided for a considerable time in various parts of North and South America, the West Indies, Europe, and Western Africe, with the express object of practically investigating the agriculture and natural features of those countries. From his intimate knowledge of the history and habits of our domestic animals, having devoted, probably, more attention to the subject, as a whole, by reading and observation, than any other individual in the country, the task of preparing this work was assigned to him.

Mr. Allen, who has very generously looked over the proof sheets, and favored the public with a valuable Apppendix, is well known as the father and co-laborer of the editors of the "American Agriculturist," and as an experienced and successful breeder of stock, as well as of the choicer varieties of domestic fowls.

The publisher, therefore confidently presents the "American Poultry Yard" to the public with the full belief that it combines the utmost economy and utility, united, at the same time, with elegance and the facility of obtaining the desired end.

C. M. SAXTON.

Now YoRK, January 2, 1850. 


\section{P R E F A C E.}

Tre scope and intention of the present treatise, pertaps, is sufficiently declared in the title page. Therefore, to waste the reader's time by further details would be as impertinent as unnecessary. The hasty manner in which these pages have been compiled, the want of a more intimate knowledge of the history and pedigree of the various breeds of our domestic birds, of which but few records are to be found, together with the limited nature of the work itself, are the only apologies the author has to offer for any errors and deficiencies with which he doubtless may be charged. Without great aid from those who have written before him, the volume, though not large, never could have appeared; yet, most of the current books on poultry are but compilations of matter, valuable only to those practically acquainted with the subject, and many of them unsuited to our economy as weli as to our climate, and full of errors and confusion, that would be obvious to the attentive reader, even though he never had seen a fowl in his life.

In order to write a perfect work on poultry, two important desiderata would be required for its attainment; one or the other of them would be indispensable-the first, a complete set of full-sized colored figures of every variety, giving both the male and female, the egg, and the newly-hatched chick, with accurate and technical descriptions of their plumage and their characteristic properties; the second, a collection of stuffed specimens of the representatives of every breed for comparison and reference. The first of these might be accomplished by a person, or an association of persons of fortune, by procuring a complete collection of all the varieties whose characters are decidedly distinct, both of this country and from abroad, and breeding them in-and-in for a series of years, as well as by judicious crossing with one another. An enterprise of this kind, conducted with proper intelligence and experience, however trivial it may appear in the eyes of many, would be worth millions to the country, and prove a boon to mankind.

In order that he may not be accused of the reproach of "strutting in borrowed plumes," the author has the candor to confess that he has made a free use of the labors of Pliny, Columella, Cuba, Aldrovandi, Mascall, Réaumur, Moubray, Parinentier, Flourens, W. B. Dickson, J. J. Nolan, W. C. L. Martin, and the Rev. Edmund S. Dixon, particularly of those of the four gentlemen last named, without giving them, in numerous instances, such credit as the punctilious critic would scem to demand. Be this as it may, the author has endeavored not to deviate from established custom, except in cases where he deemed it expedient to change the language, in part, for the sake of brevity, elucidation, or Americanising the subject, or adapting it to our climate, economy, and social condition. Much of the matter, however, and several of the illustrations, he claims to be original. With this avowal, he will declare no more than his full trust in a candid consideration of whatever merit his book may deserve.

D. J. B.

Newo York, December 26th, 1849. 


\section{THE DOMESTIC FOWL}

ORIGIN AND HISTORY.

" fowls were prepared for me, and also once in ten days, store of all sorts of wine."

HoLY WRIT.

The Common Fowl, as well as the pea fowl, are of Indian-origin, and we learn nothing respecting them till within a comparatively recent epoch. It will naturally be asked, What is the earliest date of poultrykeeping? Nobody knows. It is thought by some to be cöeval with the keeping of sheep by Abel, and the tilling of the ground by Cain-a supposition which cannot be far from probability, if there is any foundation for the legend that Gomer, the eldest son of Japhet, took a surname from the cock. Indeed, it would be to him that Western Europe stands indebted for a stock of fowls from the ark itself. For, it is supposed by the erudite, and shown by at least probable arguments, that the descendants of Gomer settled in the northern parts of Asia Minor, and then spread into the Cimmerian Bosphorus and the adjacent regions, and that from them the numerous tribes of the Gauls, Germans, Celts, and Cimbrians descended. It is true that there is no mention of fowls by name in the Old Testament, except a doubtful allusion in the Vulgate 
translation of the book of Proverbs, (xxx. 31,) which is lost in the authorised version. There is another equally disputable passage in Ecclesiastes, xii. 4. "And the doors shall be shut in the streets, when the sound of the grinding is low, and he shall rise up at the voice of the bird, (that is, at cock-crowing,) and all the daughters of music shall be brought low." A still less certain evidence occurs in the book of Job, xxxviii. 36. "Who hath put wisdom in the inward parts? or who hath given understanding to the heart?"

The apparent omission of the name of the domestic fowl from the Old Testament may possibly have arisen from this cause, namely, that tending them would be the occupation of women, whose domestic employments are less prominently brought forward by oriental writers than the active enterprises of men; and, also, that the birds specially named there are the unclean birds, which are to be avoided, whereas those which may be eaten are classed in a lump as "clean." See Leviticus, xi. 13, and Deuteronomy, xiv. 11.

That the fowl was domesticated and extensively spread at a very remote period, is very evident; but it does not seem clear whether it was possessed by the Israelites before the consolidation of the nation under Solomon, when commerce began to flourish, and the arts of life to be strenuously cultivated. After the Babylonish captivity, we cannot doubt that the fowl was among the domestic animals of Palestine, and it is to this bird, most probably, that Neherniah, (в.с. 445 ,) alludes, when in his rebuke he says, "Now that which was prepared for me daily was one ox, and six choice sheep, also fowls were prepared for me, and also once in ten days, store of all sorts of wine" (v. 18). Antecedently to this period, the fowl was abundant in Persia. Thus Peisthetærus relates why the cock is called the "Persian bird," and how it reigned over that country before Darius and Megabazus (в.c. 521). Not only do the classic poets and historians speak of the high antiquity of the fowl, but medals and coins 
proclaim the same, and bear its figure stamped upon them. Nor is its delineation absent on other relics of remote periods. In Camparini's "Etruscan Tombs," we see several persons reclined on a sort of couch, taking wine and bread after the burial of some friend. Under one of the tables a cock and hen are depicted, and under another a cat is seen insidiously creeping towards them. Figures of the domestic fowl are carved in relief on the marbles lately brought into England from Lycia, in Asia Minor, by Sir C. Fellows, and their outlines are represented to be remarkable for accuracy.

Among the Greeks and Romans the fowl figured in the public shows. It was dedicated to Apollo, to Mercury, to Essculapius, and to Mars ; and its courage and watchfulness were well appreciated. The Rhodian fowls, and those of Delos, Chalcis, Media, and Persia, were celebrated for their superiority in fight, and for the excellence and delicacy of their flesh. Cock-fighting, as might be expected, was a diversion in consonance with the tastes of the Romans, and they were as much devoted to it as the Malays of the present day, who will stake all upon the issue of the battle. To the rearing of these birds for the table, the greatest attention was paid by the luxurious. They had their gallinaria, and were accustomed to cram their fowls with meal, and keep them in the dark that they might the more readily fatten; nor were the capon, (gallus spado,) and the poularde, (gallina spadonia,) unknown.

Herodotus does not mention the fowl as among the domestic birds of Egypt, though he speaks of the goose, the vulpanser, or chenalopex, the duck, the quail, small birds, and two sorts of ibis; neither does it occur on any of the ancient monuments of that country.

Aristotle, who wrote about 350 years before Christ, speaks of them as familiarly as a natural historian of the present day would. It is unnecessary more than to allude to the beautiful comparisons taken from them in the New Testament. The Roman authors of tho 
commencement of the Christian era record that they were classed into such a number of distinct varieties as could oniy have been the result of long cultivation. Whether we suppose that different breeds were collected and imported from different native stations, or assume that the differences of those breeds were the artificial result of domestication, - whichever case we take, domestic fowls must have been held in familiar esteem for many, many ages before we have any clear record of them. Either supposition attaches to them a highly interesting and quite mysterious degree of antiquity.

When the Romans, under Julius Cæsar, invaded the shores of Britain, they found both the fowl and the goose in a state of domestication; but these, as well as the hare, were forbidden as food. "They deemed it not lawful to eat the hare, the fowl, and the goose ; nevertheless, they bred these animals for the sake of fancy and pleasure." 'Through what channel, it may be asked, did the fowl reach this ultima Thule?

At the time of the discovery of the American continent by Europeans, the domestic fowl was not found in any part of it, neither was it found on any of the Atlantio Isles, although the Canaries, the supposed Fortunate Islands of the ancients, were inhabited by a half-civilized people, who held in subjugation sheep, goats, hogs, and dogs.

Dr. Kidd, in his "Bridgewater Treatise," doubts whether the camel ever existed in a wild and independent state. But others do not go quite so far as that in scepticism in the case of fowls, but still believe that those, who, at this epoch, hunt for cocks and hens of the same species as our tame ones, either on the continent of Asia, or throughout the whole inhabited vast Indian Archipelago, will have undertaken but a fruitless search. For certain writers have been at great pains, for some years past, with but little success, except in their own conceit, to pitch upon the wild origin of our domestic fowls. The first decided 
attempts to do this, appear to have been made by Sonnerat, and to have been followed up by succeeding French writers, whose errors are glaring, and in whose praise little can be said.-Réaumur, whose writings are really philosophical and valuable, devoted his inquiries to more practical objects, but Sonnerat was merely a blind leader of the blind, if there is justice in the criticism of Mr. Swainson, who pronounces that "Sunnerat's works, although often cited by the French authors, are very poor; the descriptions vague, and the figures, particularly of the birds, below mediocrity." Buffon, who did not die till 1788, had therefore an opportunity of adopting Sonnerat's jungle fowl as the parent of cocks and hens, and his vivid imagination made him very likely to have adopted so apparently clear an account, ready telegraphed for his reception. But instead of that, he speaks hesitatingly and doubtfully of the derivation of our domestic fowls from wild cocks, and seems to despair of indicating their origin. He says, "Amidst the immense number of different breeds of the gallinaceous tribe, how shall we determine the original stock? So many circumstances have operated, so many accidents have concurred; the attention, and even the whim of man have so much multiplied the varieties, that it appears extremely difficult to trace them to their source."

A difficulty, which speaks volumes, is, that those birds which have been pointed out as the most probable ancestors of the domestic fowl, do not appear to be more tameable than the partridge, the American grouse, or the golden pheasant ; moreover, so remarkable an appendage as the horny expansion of the feather stem, as seen in Sonnerat's cock, would, according to what is generally supposed to take place, be increased rather than diminished and obliterated by domestication; and even if got rid of by any course of breeding for a few generations, would be sure, ultimately, to reappear.

Still, our own cocks and hens must have had some 1* 
progenitors, and if an opinion may be offered, it is this: that the wild race, that which once ranged the primeval woods and jungles, unsubdued oy man, is now extinct, for ever gone, with the Dodos and the Deinornithes. Such an idea quite agrees with what we now see going on in the world. At no very distant period, the turkey will be in exactly the same position in which we are supposing our cocks and hens to be now placed. The race will continue to survive, only from having submitted itself to the dominion of man. Wild turkeys are becoming every year more and more scarce with us, and as population increases, and penetrates deeper into the wilds, till the whole face of the country is overspread, occupied, and cultivated, this bird must share the fate of the bustard in England; and where shall we find it then, except under the same circumstances as we now see our domestic fowls? How long existing literature will endure it is impossible to say; but should it be swept away by any social convulsion, our descendants, two thousand years hence, will have as much difficulty in determin. ing the origin of the turkey, as we have in deciding upon that of the cocks and hens.

Man has the power of trampling under foot, and sweeping every living thing before him in his progress ; but in some cases, at least, he is likely, for his own sake, to rescue the most valuable part of the spoil from destruction, if it will only submit to be rescued, and not refuse to accept a continued existence on such conditions. A family of savages would soon consume and destroy a whole province of wild cocks and hens, if it were ever so well stocked; but civilised man can see his interest in their preservation, and it is lucky for fowls that their destiny threw them in contact with the Caucasian race instead of Australian aborigines. But the increase of knowledge and humanity may even yet do something to extend a merciful and forbearing conduct toward existing animals.

But the common hen has one peculiar habit, which 
would alone ensure the destruction of her progeny in an unprotected state, in spite of all her fruitfulness and her great maternal virtues. Her delight at having laid an egg, expressed by loud cackling, which is joined in by all her companions that are at hand, would, by itself, be sufficient to prevent much increase of her young. How the squaws and their picaninnies would chuckle to have wild birds abounding around them, that not only produced an excellent egg every day, but told them where to find it !

The habit which so large a bird as the fowl has of retiring to roost by daylight, too, and composing itself to repose before it is hidden and protected by the shades of night, would also be a certain source of danger in a wild state. The craving hunter who wanted a meal, need not fatigue himself by a search during the noontide heats. $\mathrm{He}$ would have but to bear the pangs of appetite till evening approached, and then stealing with no great caution under the outstretched branches, he would find a ready prey distinctly apparent between himself and the ruddy glare of sunset. No wild race could survive a few years of such facile, such tempting capture. Those who would reply by saying that when cocks and hens were wild they had not fallen into the imprudent fashion of roosting before dark, and cackling when they dropped an egg, beg the question which we are not disposed to grant them, unless they can positively establish their claim.

The common cock, (Gallus gallinaceus,) would at first sight appear to have received one or two remarkable changes of form subsequent to its having been saved from annihilation by becoming dependent on the care of man, if we can believe domestication to be capable of producing such chainges. The crest of feathers on the head is an extraordinary metamorphosis to have occurred from an original fleshy comb. There is no instance, that I am aware, of any wild-crested breed. Aristotle makes such a pointed and so clear a 
distinction between the feathered crests of birds in general, and the combs of cocks, as to lead to a strong suspicion that he was unacquainted with fowls with topknots; which he could hardly have avoided seeing in the course of his unequalled opportunities for research, had they existed in his day. "Certain birds," says he," "have a crest; in some consisting of actual feathers; but that of cocks alone is peculiar, being neither flesh, nor yet very different from flesh in its nature." Neither can there be found a passage in the classical authors which implies that the cocks and hens of their day bore a feathered topknot. Cirrus is the Latin word used by Pliny to denote the tuft of feathers on the head of certain ducks, (fuligulæ,) and also properly adopted by Aldrovandi to express the topknot of Polish fowls. The earliest notice of crested fowls that I am aware of, occurs in Aldrovandi, where he says, "Our common country hen, all white, and with a crest like that of a lark," a very useful comparison that will serve to distinguish such-like from the Polish fowls ; the other, what he calls the Paduan, evidently a variety of the Polish or Poland.

If birds with such peculiarities were unknown to the ancients, it will be asked through what agency they have made their appearance in our days. Are they new races, the result of judicious combination and nurture, or of mere chance? Not conceiving that they are anything " new under the sun," although long unknown to us, I answer, at once, No. The mercantile enterprize and trading voyages of the English, Dutch, Spaniards, and Portuguese, are quite sufficient to explain their arrival, without having recource to a new creation. The lately-introduced Cochin-China fowl, about which there is no mystery, is a case in point. But it is not strange nor anlikely that gentlemen who have succeeded in obtaining some exotic rarity, should choose to conceal the source and the channel by which it came into their hands, nor even take credit for having themselves raised and generated a breed which 
excites the curiosity and admiration of their neighbors. There are several varieties that are extinct, or not to be obtained in England, as the Duke of Leeds' fowl, and the white Poland fowl with a black topknot. Attempts have been made to reproduce them, both by the most promising systems of crossing, and by acting on the imagination of breeding fowls, after the manner of Jacob's experiments with Laban's flocks; all in vain. We can easily understand how certain points in any race can be confirmed and made more conspicuous by selection and breeding in-and-in, but we are at a loss to know how to go to work to produce something quite original and new. If these lost varieties do re-appear, and they are both worth the trouble they may give, it will probably be by a fresh importation from their original Indian home.

The addition of a fifth toe to the foot, as in the Dorking variety, is more likely than the crest to have supervened in the course of time. This appendage is said not to be mentioned by any earlier writer than Columella, since whose time, to the present day, a fifth toe has been the well-known and distinctive character of a certain breed.

A Cochin-China cock in the possession of Rev. E. S. Dixon, of Norwich, England, has the outer toe of each foot furnished with two distinct claws, which we may take to be the earliest indication of a fifth toe. His chickens inherit the same peculiarity. A correspondent of the same gentleman, says, "I had a cock of the golden Polish variety that lost two of his claws by accident, and in their place two smaller joints grew from the end of each toe, both provided with little claws. This became hereditary, for next season there were two chicks hatched, both having the aforesaid peculiarity." Analogous instances may be seen in museums, of lizards with two tails; the original single one hav- . ing been lost by accident, two grew in its place.

Could we analyse the migrations of our own species from clime to clime; could we trace the progress of 
the human swarms which in the obscurity of time have successively advanced from various points, spreading as they have proceeded, sometimes mingling with other nations, sometimes driving the older occupants of the land before them; could we develop the history of man, the relationship of race to race, and point out their original seats and starting places, then might we be able to throw a clearer light on the history of our domestic animals; but I will now maintain unhesitatingly, that it was not man nor his domestication, nor any inherent tendency in the creatures themselves, that gave feathered crests to the Poland fowl, dwarfed the Bantam, expanded the Dorking, enlarged the Malay and Cochin-China fowl, inspired courage to the gamecock, nor made the hen, next to woman, the most exemplary of mothers; unless we believe it was man who arranged the strata in the ribs of the earth, and prescribed to the sea its everchanging boundaries. Man is powerful to have dominion; God alone is potent to create-His Providence to overrule. Not by man, nor chance, nor by generative force of an idol called Nature, have the things which we see, and the diversities in our living fellow creatures, been brought about. No; most thankfully, no! Then would matters have been far less harmoniously, far less benignantly arranged. It is our greatest consolation to feel assured that all the physical changes which this earth has undergone, and every renovation of its inhabitants, has been from the beginning foreordained by that Allwise and All-powerful Being, in whose presence the best and greatest of us would be crushed into nothingness, did we not, to our comfort, believe that $\mathrm{He}$ is not the Creator merely, but the Father and Protector of every animated creature. "These wait all upon Thee, that Thou mayest give them meat in due season. When - Thou givest it them, they gather it, and when Thou openest thy hand, they are filled with good. When Thou hidest Thy face, they are troubled. When Thou 
takest away their breath they die, and are turned again to their dust."-Dixon.

\section{GEOGRAPHICAI DISTRIBUTION.}

In a wild state, the speoies of the genus gallus are at present restricted to India, Malaya, Sumatra, Java, and perhaps other islands of the neighboring groups, as well as those scattered over the vast Pacific. How far to the west, in remote ages, some of these species may have spread, we know not; some may have been distributed from India through Persia, even to Mingrelia and Georgia, anciently Colchis, whence the Greeks derived the pheasant, which they found on the banks of the Phasis.

Oliver de Serres, on his return from a first voyage to Guiana, in 1795, published a note on the subject of the wild cock and hen of that country, which he had every reason to believe were indigenous. "In travelling over the gloomy and inextricable forests of Guiana," says he, "when the dawn of day began to appear, amidst the immense woods of lofty trees, which fall under the stroke of time only, I had often heard a crowing similar to that of our cocks, but only weaker. The considerable distance which separated me from every inhabited place, could not allow one to think this crowing was produced by domesticated birds; and the natives of those parts, who were in company with me, assured me it was the voice of wild cocks. Every one of the colony of Cayenne, who have gone very far up the country, give the same account of the fact. Some have met with a few of these wild fowls, and I have seen one myself. They have the same forms, the fleshy comb on the head, the gait of our fowls, only they are smaller, being hardly larger than the common pigeon ; their plumage is brown, or rufous."

In a domestic state, next to the dog, the fowl has been the most constant attendant upon man in his 
migrations and his occupation of strange lands. The carniverous diet of the dog is one main cause of this pre-eminence. But search where you will, except in the very highest latitudes, you will find in New Zealand, Australia, the American continents, the West Indies, and in islands innumerable, fowls sharing in the possession and settlement obtained by man. As we approach the poles, difficulties arise in the way of their further companionship. In Greenland, they are occasionally kept only as curiosities and rarities. And Sir Wm. Hooker tells us that poultry of all kinds is quite unknown to the Icelanders, except that a few are now and then conveyed to the country by the Danes, who are obliged at the same time to bring with them a sufficient supply of necessary food, that is, grain, for their support, of which the island furnishes none. Fowls, however, would get on very well with a fish and meat diet with grass and vegetables, assisted by a little imported corn, were there sufficient inducement to make the inhabitants take pains about their maintenance.

But the most mysterious, though not the most ungenial localities in which fowls have hitherto been found are the islands scattered over the vast Pacific Ocean. How they got there is as great or a greater puzzle than to divine the origin of their human population. The earliest discoverers found the people to be possessed of pigs, dogs, and fowls, all domesticated for the sake of being eaten.

The domestic fowl was found in the Sandwich Islands by their first discoverer, although seldom used by the natives as an article of food; and, according to tradition, it has existed there as long as the people, and it is supposed they came there with the first colonists by whom these islands were settled, or that they were created by Taarva, at the same time that their men were supposed to have been made.

This account would assign an unfathomable antiquity to the domestication of fowls, confirmed by the 
following legend:-Among the many traditionary accounts of the origin of the island and its inhabitants, was one, that in former times, when there was nothing but sea, an immense bird settled on the water and laid an egg, which soon bursting, produced Hawaii. Shortly after this, a man and woman, with a hog and a dog, and a pair of fowls, arrived in a canoe from the Society Islands, took up their abode in the eastern shores, and were the progenitors of the present inhabitants.

Captain Cook found fowls on islands that had never before been visited by civilized man, and the very wide range over which they are distributed, precludes the supposition of their having been introduced by Tasman or any of the other early voyagers. "There is only one tame species of birds, properly speaking," says his journalist, "in the tropical isles of the South Sea, namely, the common cock and hen. They are numerous at Easter Island, where they are the only domestic animals; they are likewise in great plenty in the Society Isles and Friendly Isles, at which last place they are of a prodigious size ; they are also not uncommon at the Marquesas, Hebrides, and New Caledonia; but the low isles, and those of the temperate zone, are quite destitute of them."

The pigs of that quarter have been affirmed to differ specifically from our own domestic breeds-less has been said about the poultry. It appears that there are different varieties in the different islands, some of very large size. Our great commercial intercourse with the Pacific makes that the quarter from whence our importations of fowls are frequently drawn, either as curious specimens, or for the sake of improving our stock ; but it would certainly be interesting, and might prove useful, could we obtain a few new sorts, such as the Friendly-Island breed, from the less frequented spots in the South Seas. Our missionaries in the Sandwich Islands, Tahiti, and other places, might surely send us a ferv cocks and hens in return for the substantial 
benefits the inhabitants of those islands have derived from us. And should this little book ever penetrate so far into the other hemisphere, let it persuade the Sandwich Islanders to preserve, by domestication, and by transmission to this country, a stock of their most interesting, pretty, and unique little geese, before the race is quite swept out of existence.

\section{CLASSIFIOATION.}

THE correct mode of classifying domestic fowls, doubtless would be to arrange them with the wild ones, in natural order and sequence; but in the present state of our knowledge, this is impossible, except by a comparatively unsatisfactory, rough approximation. A half century hence, when the Indian Archipelago and the islands of the Pacific shall have been more fully explored, such a thing, perhaps, may be successfully attempted.

It is evident, that, if our common fowls are believed to be merely altered forms of one or two wild races, under the influence of altered food and climate, they must be arranged on different principles to what they would be if we allow them to take rank as original and independent varieties or species. In the one case, we have to search out the wild bird nearest resembling any one domestic breed, and form our series from that as a beginning, as well as we can; in the other, we have to become well acquainted with all the wild and all the domestic species of gallus, and then arrange them in groups or in a continuous line, according to their resemblances and relationships, without any reference to the circumstance of their domestication or their untameability. The former plan can be carried out by a little theory and bold guess work; the latter requires industry, accurate observation, and opportunities which few individuals, if any, have at present at command. In the meanwhile, I will attempt some- 
thing like an artificial arrangement, which may afford a temporary assistance to the fancier, till a more scientific scheme is worked out by wiser heads than my own. Let us first proceed, then, to enumerate the principal species known to exist in a wild state, from which it is any way probable our domestio races were derived.

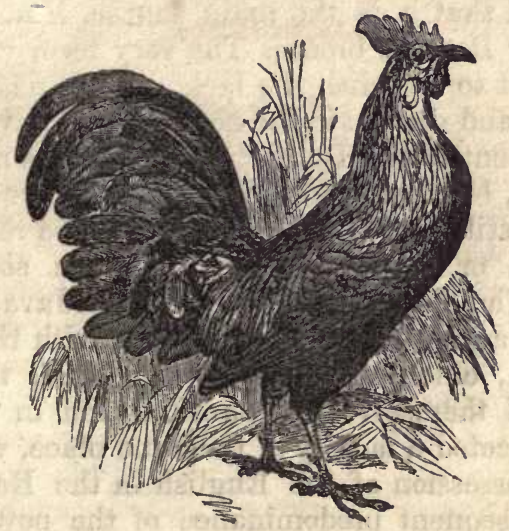

THE JAVANESE JUNGLE FOWL.

Syronrmes.-Gallus bankiva, of Temminck ; Ayam-utan, or Brooga, of the Malays ; Javan Cock, of Latham ; Bankiva Fowl, Javanese Jungle Fowl, Bankivn Jungle Fovol, of the English and Anglo-Americans.

This beautiful bird is found wild in Java, and i. about equal in size to an ordinary Bantam-the blackbreasted, red varieties of which, with a dark steel-blue band across the wings, it closely resembles. The space round the eyes and the throat are bare, the comb is much developed and deeply serrated along the upper ridge, the wattles are rather large. L Long, clear, brilliant, golden orange hackles, (plumes,) cover the neck and rump. The upper part of the back, over which the hackles of the neck are continued, is bluish-black. The middle and lesser wing coverts are of a rich deep 
chestnut, with the webs of the feathers disunited; greater coverts, steel-blue; secondaries, also steel-blue, with a border of chestnut. The quills are brownishblack, edged with pale reddish-yellow. Tail black, glossed with changeable green and blue. Breast and under parts black. Contour very graceful, and every action animated and lively.

With regard to the Bankiva jungle fowl, it cannot be doubted that it is the main source, if not the only one, of our Bantam breeds. The very term "Bantam" is sufficient to establish the fact. Bantam is the name of a town and district in the northwest of Java, belonging at present to the Dutch. The town is now fallen into decay, but was formerly a place of great importance, and still boasts of a governor, whose residence is at Sirang, or Ceram, a thriving town some miles inland. The Portuguese, who visited Java, in 1511, carried on a great trade from Bantam with Hindoostan and China, chiefly in pepper. In 1595, the Dutch established themselves at Bantam, and in 1602, the English erected a factory in the same place, which was the first possession of the English in the East Indies. Of the subsequent predominance of the power of the Dutch, who built the town of Batavia, not far distant from Bantam, this is not the place to speak. From this statement, however, it is evident that the beautiful Bankiva jungle fowls, reclaimed by the natives, and sold to the British, at Bantam, while their factory was established there, were imported into England under the very natural appellation of Bantam fowls. Their elegance and diminutive size rendered them favorites, and in due time the name, belonging exclusively to these birds, came to be conferred on all small or dwarf fowls indiscriminately, whether of this pure breed or otherwise. The domestic Bantam stock, as every one knows, breeds freely with ordinary fowls, the mixed offspring being intermediate in size between their parents ; and that the Bankiva jungle fowl will breed with our domestic Bantam race, and with other 
races, the progeny being fertile, as has been fully proved. Such birds are common in the gardens of the London Zoological Society, and so closely do the offspring of the Bankiva jungle cock and a brown domestic Bantam hen resemble the wild, or original breed, that on more than one occasion have the best of judges been in doubt; nor is this to be wondered at-as on both sides was the lineage the same.

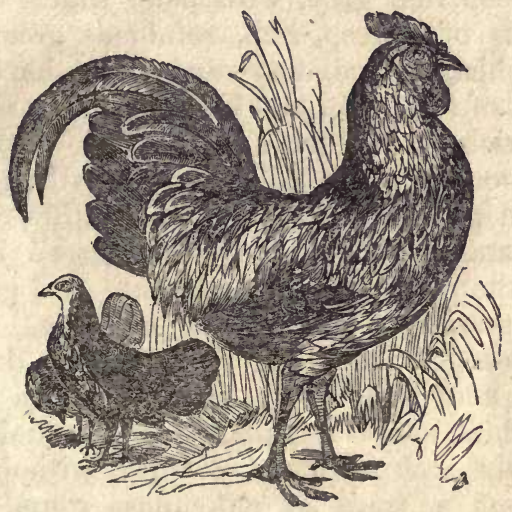

SONNERAT'S JUNGLE FOWL.

Srronymes.-Gallus sonneratti, of Temminck; Rahn Komrah, of the Mahrattas ; Coq sauvage, of Sonnerat; Jungle Cock, of the British Sportsmen in India; Sonnerat's Jungle Fowl, Stanley's Jungle Fowl, of the English and Anglo-Americans.

The size of the male of this species is intermediate between that of the Bantam and game cock; but the general contour is peculiarly light and graceful, and vigor and alertness are displayed in every action. The comb is large, with a sub-serrated ridge, that is, the ridge is but slightly dentated, in comparison with the comb of the Bankiva. The wattles are large and double. The hackles of the neck, the wing coverts on the shoulders, and the tail coverts are dark-greyish, with bright golden orange shafts, dilating in the centre 
and towards the tip into a flat, horny, and very glossy plate. In some of these feathers, the shaft takes an elliptical or oar-like shape, in others it puts on the appearance of a long inverted cone, from the centre of the base of which a battledore-like process arises. The effect produced by this expansion of the shafts is at once singular and exquisitely beautiful. The feathers of the middle of the back, breast, belly, and thighs, are of a deep rich grey, with paler shafts and edges. The tail is of a deep, rich, refulgent green, but the feathers which immediately succeed the hackles of the lower part of the back, and lie against the sides of the tail, are rich purple with a pale-yellow edge; those next in succession are golden-green, with grey edges, and all are glossed with brilliant metallic reflections; bill, legs, and toes yellowish. When seen in a bright sunlight, the plumage of this elegant bird glitters like gold, and presents a most rich appearance.

The female is generally described as destitute of those expanded ornaments to the hackles and wing coverts, which are so conspicuous in the male. She is less than the cock by about a third, without comb or wattles, but a trace of nakedness round the eye. Plumage without the horny structure which distinguishes that of the male. Upper parts uniform brown; neck feathers with dark edges; those of the back and wing coverts with a pale streak along the shaft; and those of the wings, tail coverts, and tail, waved and mottied with darker pencillings; throat and front of the neck white; feathers of the rest of the lower parts greyish-white, edged with dark-brown; legs bluishgrey.

Under the term "Sonnerat's jungle fowl," two species of jungle fowl appear to have been confounded together-at least, by most naturalists - although there can be no doubt of their real distinctness. Colonel Sykes, speaking in reference to the Gallus sonneratii, says: "Very abundant in the woods of the Western Ghauts, where there are either two species, or two 
very strongly marked varieties. In the valleys, at 2,000 feet above the sea, Sonnerat's species is found slender, standing high on the legs, and with the yellow cartilaginous spots on the feathers even in the female. In the belts of wood on the sides of the mountains, at 4,000 feet above the sea, there is a short-legged variety. The male has a great deal of red in his plumage, which Sonnerat's-has not ; the female is of a reddish-brown color, and is without cartilaginous spots at all."

Sonnerat's jungle fowl, the jungle cock of the British, is noted for its prowess and resolution, insomuch that it is anxiously sought after by the cock fighters in Hindoostan, who rely on it for victory when pitted against larger game cocks. It does not appear, however, that the Mussulman cock fighters breed this bird in its purity; they seek after the wild birds, which soon become tame.

In general habits and manners, the jungle fowl resemble their domestic relatives; the cock proudly leads his train of females, and vigilantly watches over their safety. On being suddenly disturbed the troop scatters in all directions, seeking safety under covert of the dense brushwood. In spots where they are numerous, the challenging of the cocks to each other may be heard on every side around, and yet such is their cunning, and keenness of sight, that the sportsman, unless he is well acquainted with their habits, is often disappointed in his attempts to get a fair shot.

Sonnerat and many other naturalists have contended, that, to this species alone are our breeds of domestio fowls to be traced. Most probable, notwithstanding the peculiarity of the plumage, and the circumstance of the throat of the female being covered with feathers, instead of being naked and wattled, it has intermingled with other breeds, or contributed to improve themand among them inay be enumerated the high-spirited game fowls kept for fighting by the Mussulmans of India, and which have been long celebrated; but it cannot be admitted that Sonnerat's jungle fowl is the 
sole origin of the domestic race. The Bankiva and the great Malay present stronger claims to our notice, nor can we doubt they contribute the groundwork of some of our most remarkable varieties. Those writers, who, by a pleasant legerdemain, so easily transform one of the wild Indian cocks into a barn-door fowl-who put the jungle cock, the Bankiva cock, or the gigantic jago bird under a bushel, hocus pocus a little, lift up the cover, and then exhibit a veritable chanticleer-write as if they had only to catch a wild bird in the woods, turn it into the yard for three or four weeks, and make it straightway become as tame as a spaniel. On such a notion comment is now supererogatory.

There are several other species of jungle fowl, to which I shall here only briefly allude, as they are not likely to have contributed to the establishment of the domestic race. One of these is the "bronzed cock" of Sumatra, (Gallus anus, ) a fine species, remarkable for a large comb, smooth along the ridge. The neck is not covered with true hackles. Another is the Ayam-alas jungle fowl or fork-tailed cock of Java (Gallus furcatus). This species has no true hackles on the neck, and the throat is adorned with a single large wattle only, springing from a central line. An intermediate form between the genera phasianus and gallus, is presented by the fire-backed pheasant of Sumatra (Euplocamus ignitus). It is a very splendid bird, and might perhaps be domesticated.

So much, then, for the remote history of the domestic fowl, as far as obscure hints, notices, or delineations enable us to decipher it; and it has been shown to what wild species its origin is, in all probability, to be attributed. It is evidently the oldest, and perhaps the most important of man's acquisitions from among the feathered tribes, its flesh and its eggs being in all countries regarded partiy as delicacies always acceptable, and partly as staple articles of food, at once nutritious and digestible. That a bird which has passed in a 
domestic state generation after generation for several thousand years, in one country or another, should have branched out into many varieties, will not be surprising-perhaps rather it is surprising that it has not undergone more changes. The varieties, however, are sufficiently numerous, every country having some peculiar to itself, and every breeder founding crosses according to his own fancy - to say nothing of those resulting from accidental intermixture in Europe and in our own country. It is to the principal of these varieties only, in their

VALUE IN AN ECONOMICAL POINT OF VIEW,

that I shall pay any further attention; nor from the limits of this little treatise, shall I be able to dwell at much length upon them at that.

In the size of our domestic fowls; in the color and quality of their skin and plumage; in the form of the tail, or its utter absence; in the form of the comb; in the presence or absence of a plume or crest on the head; in the number of the toes ; in disposition; and in the qualities of the hens as layers or sitters, differences more or less striking are universally to be found. Yet, amidst all these modifications, the characters of the genus are rigidly preserved.

Let us take, then, the serrated upright fleshy comb, to be the typical distinction of the cock-a feature which Aristotle has pointedly indicated, as well as Columella and others of more modern date. The sickle feathers of the tail are perhaps equally characteristic of the genus, but they differ little in the respective varieties. Neither mark nor distinction has, it is true, any functional office in the organization of the animal; but it would be difficult to find one which had. In the Spanish fowl, the comb is more developed than in any other breed; we will therefore take that bird as our type, and suggest, with diffidence, the following pro tempore arrangement :- 


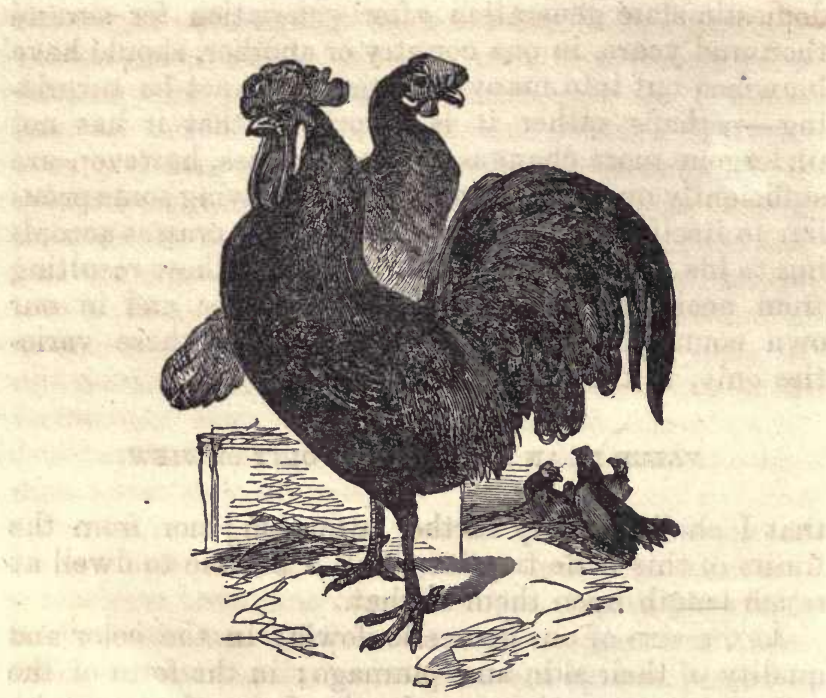

THE SPANISH FOWL.

Srxorrmxs.-Gallus gallinaceus, of Naturalists; Gallo andaluz, of the Spaniards ; Minorcas, in North Devon, in England; Portugal Fowl, Spanish Fowl, Bluck Spanish Fowl, of the English and Anglo-Americans.

This is a noble race of fowls, possessing many great merits; of spirited and animated appearance, of considerable size, excellent for the table, both in whiteness of flesh and skin, and also in flavor, being juicy and tender, and laying exceedingly large eggs, in considerable numbers. Amongst birds of its own breed, it is not deficient in courage ; though it yields without showing much fight to those which have a dash of game blood in their veins. It should be a general favorite in all large cities, for the additional advantage that no soil of smoke or dirt is apparent on its plumage.

The thorough-bred birds of the fancy should be cntirely black, as far as feathers are concerned, and when in high condition display a greenish metallic lustre. The combs of both cock and hen are exceed- 
ingly large, of a vivid and most brilliant scarlet, that of the hen drooping over on one side. Their most singular feature is a large white patch, or ear lobe, on the cheek, of a fleshy substance, similar to the wattles, which are small in the hens, but large and very conspicuous in the cocks. This marked contrast of black, bright-red, and white, makes the head of the Spanish cock as handsome as that of any other variety; and in the genuine breed, the whole form is equally good; but the scraggy, long-legged, mis-shapen mongrels are often met with enough to throw discredit on the whole race. Some birds are occasionly produced handsomely streaked with red on the hackles and back. This is no proof of bad breeding, if other points are right.

Spanish hens are also of large size and good figure, and are celebrated as good layers, producing very large, quite white eggs, of a peculiar shape, being very thick at both ends, and yet tapering off a little at each. They are by no means good mothers of families, even when they do sit, which they will not often condescend to do, proving very careless, and frequently trampling half their brood underfoot. But the inconveniences of this habit are easily obviated by causing the eggs to be hatched by some more motherly hen.

It has been noticed that this variety of fowl frequently loses nearly all the feathers on the body, besides the usual quantity on the neck, wings, and tail ; and if they moult late, and the weather is severe, they feel it much. Nothing else can reasonably be expected to take place with an "everlasting layer." It often happens to the Guinea fowl ; and the reason of it is plain. If the system of a bird is exhausted by the unremitting production of eggs, it cannot crntain within itself the wherewithal to supply the growth of feathers. The stream that will fill but one channel cannot be made to keep two at high-water mark ; and therefore, Mr. Leonard Barber, an English author, justly observes: "With regard to an anxiety about 
their constant laying, in my opinion nature ought not to be forced, as it requires a rest." But some people think it cannot be right if their hens do not lay every day.

It is doubtful whether they would readily bécome acclimatized in the northern part of the United States, for continued frost, at any time, much injures their combs ; frequently causing mortification in the end, which has terminated in death. A warm poultry house, high feeding, and care that the birds do not remain too long exposed to severe weather, are the best means of preventing this disfigurement.

The chicks are large, as would be expected from such eggs, entirely shining black, except a pinafore of white on the breast, and a slight sprinkling under the chin, with sometimes also a little white round the beak and eyes; legs and feet black. They do not get perfectly feathered till they are three fourths grown; and, therefore, to have these birds come to perfection, it is preferable to have them hatched early in spring, so that they may get well covered with plumage before the cold autumnal rains.

The black, however, is not the only valuable race of Spanish fowls, although certain London dealers, who have no right to offer an opinion, if they do not choose to give information on the subject, presume to affirm that there can be no such breed as "speckled Spanish," it being characteristic of that breed to be perfectly black. Still there are some breeds, in Spain, closely allied to these, which are of a blue, grey, or a slaty color. Their growth is so rapid, and their eventual size so large, that they are remarkably slow in obtaining their feathers. Although well covered with down when first hatched, they look almost naked when half-grown, and should, therefore, be hatched as early in the spring as possible.

The crass between the pheasant-Malay and the Spanish produces a particularly handsome fowl, and probably very much resembling the old Hispanic type, 


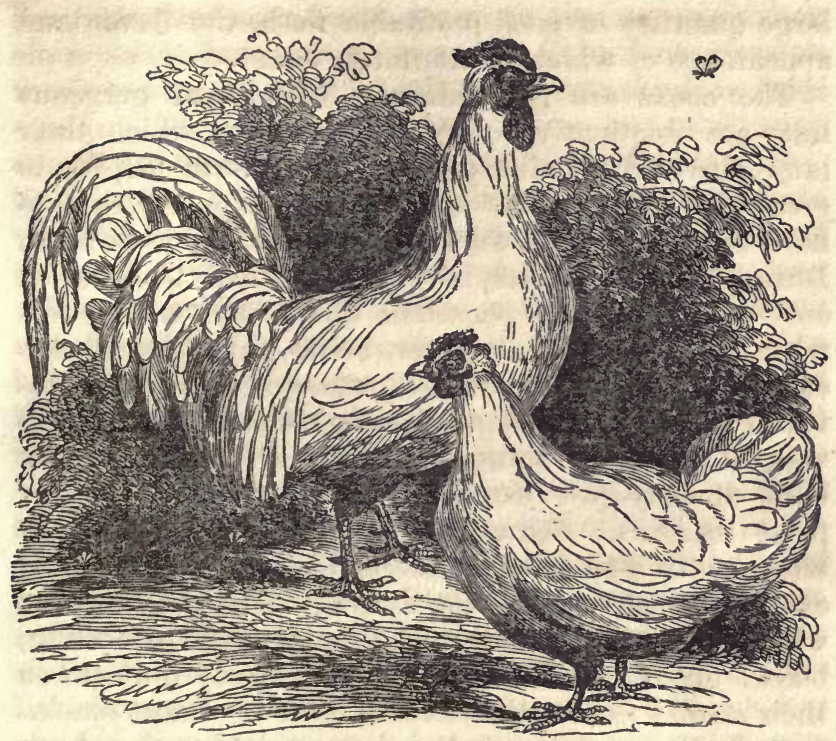

THE DORKING FOWL.**

Sxnonrmes.-Gallus pentadactylus (?), Temminck; Le Coq et la Poule a cinq doigts (?), of Buffon; Dìs Funfzehiger Huhn (?), of Bechstein ; Dorkings, Speckled Dorkings, of the English and Anglo-Americans.

For those who wish to stock their poultry yards with fowls of most desirable shape and size, clothed in rich and variegated plumage, and, not expecting perfection, are willing to overlook one or two other points, the Dorkings are the breed, above all others to be selected. They are larger-bodied, and of better proportions, according to their size, than any other variety 1 have yet seen, their bodies being rather long, plump, and well-fleshed; and the breeder, as well as the housewife, generally beholds with delight their short legs, full, broad breasts, little waste in offal, and the

* So called from Dorking, a town in Surrey, England, which brought them into modern repute. 
large quantity of good profitable flesh, the flavor and appearance of which is inferior to none.

The cocks are magnificent. The most gorgeous hues are frequently lavished upon them, which their large size and peculiarly square-built form display to great advantage. The original Dorkings are said to have been white, but such are now seldom to be seen. During all my rambles, in various parts of the country, only on one or two occasions did I meet with purewhite birds. In all, however, as far as my knowledge extended, when pure-blooded, more or less white prevailed; but the cloudings, and markings of the plumage were unlimited. Many were marked with bands, or bars, of ashy-grey, running into each other at their paler margins. Some had the hackles of the neck white, with a tinge of yellow, and the body of a darker or brownish-red, intermixed irregularly with white; while others were beautifully variegated with white, black, green, and brown, or were nearly uniform in their shades from a light-cream color to almost black.

Both the cocks and the hens are usually shortlegged, thickly-feathered, having fine, delicate heads, with single, double, or large, flat rose-like combs, which, when they are in high health, adds very much to their appearance, particularly if seen in the bright rays of the sun. Their legs are invariably white, or flesh-colored, each often armed with one or more toe-like claws; and, instead of four toes to each foot, a fifth one protrudes from the same root as the heel toe in the common varieties, which is generally regarded as a distinguishing mark of the breed.

The weight of the Dorkings, at maturity, varies from five to eight pounds, and full-grown capons have been known to weigh ten or twelve. Their eggs are usually of a clear white, but sometimes of an ashygrey color, rather large in size, very much rounded at both ends, and of an excellent flavor. The hens are not "everlasting layers," although they produce eggs in reasonable abundance, but at due or convenient 
intervals they manifest a desire to sit, in which they often most strenuously persevere. In this - respect, they are steady and good mothers when the little ones appear. They are better adapted than any other fowl, except the great Malay, to hatch superabundant tur key's eggs. Their size and bulk enable them to afford warmth and shelter to the turkey poults for a long time. For the same reason, spare goose eggs may safely be entrusted to their motherly care. Their young, in this country, have thus far proved very hardy and easy to rear. The chicks are generally brownish-yellow, with a broad, brown stripe down the middle of the back, and a narrow one on each side.

Although pure-bred Dorkings are still deservedly in high repute, a cross is generally regarded more profitable than the true breed. A showy, energetic game cock, with Dorking hens, produces chickens, in size and beauty little inferior to their maternal parentage, and more robust. This race has the peculiarity in having a supernumerary toe on each foot, and, as has already been said, often one or more toe-like protrusions above their heels resembling claws. These characteristics almost always disappear with the first or second cross; and as they are points that can well be spared without any disadvantage, it is now a common practice, in England, thus to breed them off. The first cross produces a fine bird, which is large, though less prolific; but if the mongrel progeny be crossed with each other, they soon dwindle to nothing. Therefore, one has no further guarantee of the cross breed being good further than the first result.

The Dorking breed, more or less crossed, or at least a race nearly allied to them, is to be found in Sussex, England, the bodies of which are more elongated than in the Dorkings, and many of them have five toes. They are represented as very fine, and worthy of a trial in the United States. The "Old Sussex," or Kent variety, is closely related to these, if not absolutely identical. 
It is a question how the variety known in England. under the name of "speckled Dorkings," was lirst produced. Some maintain that the pure-white Dorkings are the original breed with five toes, and that the speckled Dorking is a recent and improved cross, by which the size was much increased, between the original white breed and the Malay, or some other large fowl. From this opinion, I must entirely dissent, on the ground of strong, though not absolutely conclusive, evidence to the contrary. It seems to me that Columella's favorite sort of hen could not differ much from the speckled Dorkings, as they at present exist. $\mathrm{He}$ says: "Let them be of a reddish or dark plumage, and with black wings. ****** Let the breeding hens, therefore, be of a choice color, a robust body, square-built, full-breasted, with large heads, with upright and bright-red combs. * * * * Those are believed to be the best bred which have five toes." Except that there is no mention of speckles, (and he never describes minute markings, ) the whole description almost exactly tallies with our birds of the present day. Pliny's account, also, agrees with this : "Superiority of breed in hens is denoted by an upright comb, sometimes double, black wings, ruddy visage, and an odd number of toes." It appears that Columella had the white sort, but he rejected them; for he advises: "Let the white ones be avoided, for they are generally both tender and less vivacious, and also are not found to be prolific," faults which are still attributed to them by some. I cannot, therefore, avoid believing, that, from the robust dark-colored, five-toed fowl, white individuals have been from time to time produced and propagated, exactly as we see in other species of gallinaceous birds that have long been in domestication-pea fowls, turkeys, and Guinea fowls, for instance. I think, also, that there is no instance of any white species of cocks and hens having been found wild; which is some argument that dark and gaudy colors are the hues originally characteristic of the genus. 
The first Dorkings brought into the United States, were introduced in about the year 1840 , by L. F. Allen, of Black Rock, New York, and Dr. Eben Wight, of Boston, Massachusetts, both of whom continue to breed them in their utmost purity. Other importations have since been made by Mr. Rotch, of Butternuts, and Messrs. Chadwick and Beach, of the city of New York.

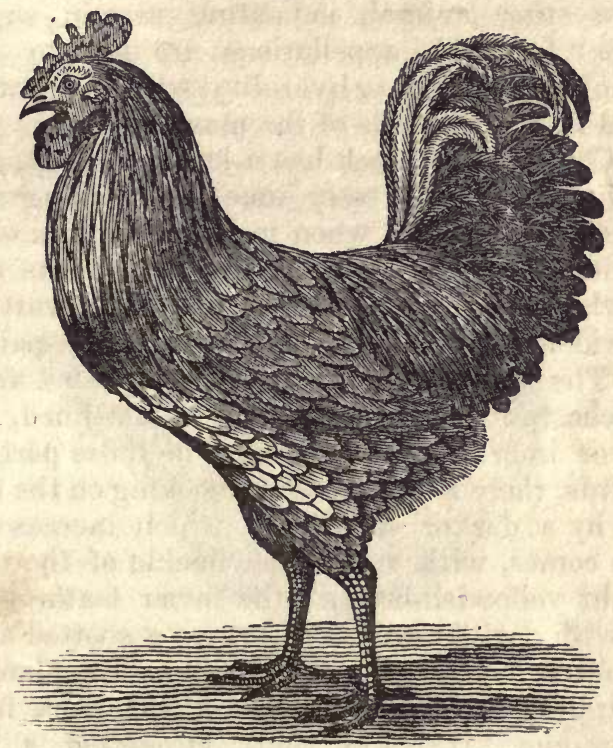

TIE COCHIN-CHINA FOWL.

Synonymes-Gallus giganteus (var.?), of Temminck ; Cochin-Chına Fowl, Ostrich Fowl, of the English and Auglo-Americans.

Whether the breed now under consideration did really come from Cochin-China or not, is probably known only to the party who imported them, if to him. But from whatever oriental region derived, it is a valuable variety for some purposes, and the only fear is, that statements of its merits have been set forth so 
highly exaggerated, that they must lead to disappointment, and cause the breed to be as much undeservedly underrated, as it had been before foolishly extolled. The size and weight ascribed to them, too, are enormous. To give an idea of their height and magnitude, they have been styled the "ostrich fowl." This is an old, but very bad system of giving names, to affix that of some other animal, indicating certain supposed qualities; for such appellations are apt to induce notions of relationship, or hybridity, which are not easily removed from the minds of the many.

The Cochin-China cock has a large, upright, single, deeply-indented comb, very much resembling that of the black Spanish, and when in high condition of quite as brilliant a searlet; like him, also, he has a very large, white ear lobe on each cheek. The wattles are large, wide, and pendant. The legs are of a pale-flesh color. The feathers on the breast and sides are of a bright chestnut-brown, large and well defined, giving a scaly or imbricated appearance to those parts. In some birds, there is a horse-shoe marking on the breast, caused by a darker shade, and which increases, and perhaps comes, with age. The hackle of the neck is of a light yellowish-brown; the lower feathers being tipped with dark-brown, so as to give a spotted appearance to the neck. The tail feathers are black, and darkly iridescent; back, scarlet-orange; back hackle, yellow-orange. It is, in short, altogether a flamecolored bird. Both sexes are lower in the leg than either the black Spanish or the Malay, and they are remarkably full feathered.

It has incorrectly been asserted, that "the disposition of the feathers on the back of the cock's neck is reversed, these being turned upwards; the wing is jointed, so that the posterior half can, at pleasure, be doubled up, and brought forward between the anterior half and the body ;" the only foundation for which absurdity, is, that in some of the half-grown cockerels, certain feathers, the wing coverts, curl forwards; but the 
curling disappears with the complete growth of the plumage.

The hen approaches in her build more nearly to the Dorking than any other, except that the tail is very small, and proportionately depressed, being more horizontal, I think, than in any other fowl. Her comb is moderate-sized, almost small; she has also a small white ear lobe. Her coloring is flat, being composed of various shades of very light-brown, with light-yellow on the neck. Her appearance is quiet, and only attracts attention by its extreme neatness, cleanness, and compactness. Her legs and thighs are thick and stout. The tail short, thin, and not the usual length

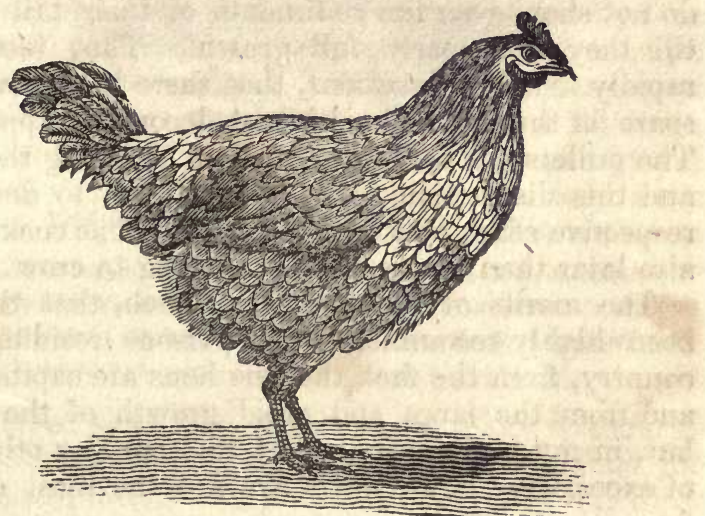

COCHIN-CHINA HEN.

It was stated in the London Agricultural Gazette, of the 30 th of September, 1848, the male birds of these fowls weighed from 12 to $15 \mathrm{lbs}$., live weight, and the hens from 9 to $10 \mathrm{lbs}$. ' This, certainly, is very extraordinary, if the account is not fabulous ; for, out of a large number of cocks and hens, of various breeds, and among them the Cochin-China, varying from five minnths to four vears old, not one of the former exceeded 
the weight of $7 \frac{1}{2}$ lbs., nor the latter that of $6 \frac{1}{2} \mathrm{lbs}$. It is possible, nevertheless, that capons of this, or some allied variety, might arrive at double these weights.

The average weight of the eggs of the Cochin-China fowl is about 2oz. each. They are smooth, of an oval, nearly equally rounded at each end, and usually of a rich buff color, but sometimes white. The newlyhatched chicks appear very large in proportion to the size of the eggs. They have light flesh-colored bills, feet, and legs, and are thickly covered with down, of the hue vulgarly called "carrotty." They are not less thrifty than other chickens, and feather somewhat more uniformly than either the black Spanish or the Malay. A peculiarity in the cockerels is, that they do not show even the rudiments of their tail feathers till they are nearly full grown. They increase so rapidly in other directions, that there is no material to spare for the production of these decorative appendages. The pullets are less backward in shooting their tails, and this distinction alone is sufficient to denote the respective sexes at a very early age. The cockerels are also later than others in commencing to crow.

The merits of this breed are such, that they have been highly recommended to persons residing in the country, from the fact, that the hens are capital layers, and from the large and rapid growth of the chicks; but, in my humble judgment, this nor any other breed of excessively large fowls are not the most desirable for general use.

The Cochin-China fowl is said to have been presented to her Majesty, Queen Victoria, of England, from the East Indies, and, by her liberality, imparted to such persons in her dominions as were likely properly to appreciate them.

In the United States, there are numerous individuals who possess large fowls bearing the name of "CochinChina," which have been crossed with the Dorking and other large breeds; but such a course is believed to be of doubtful atility. 


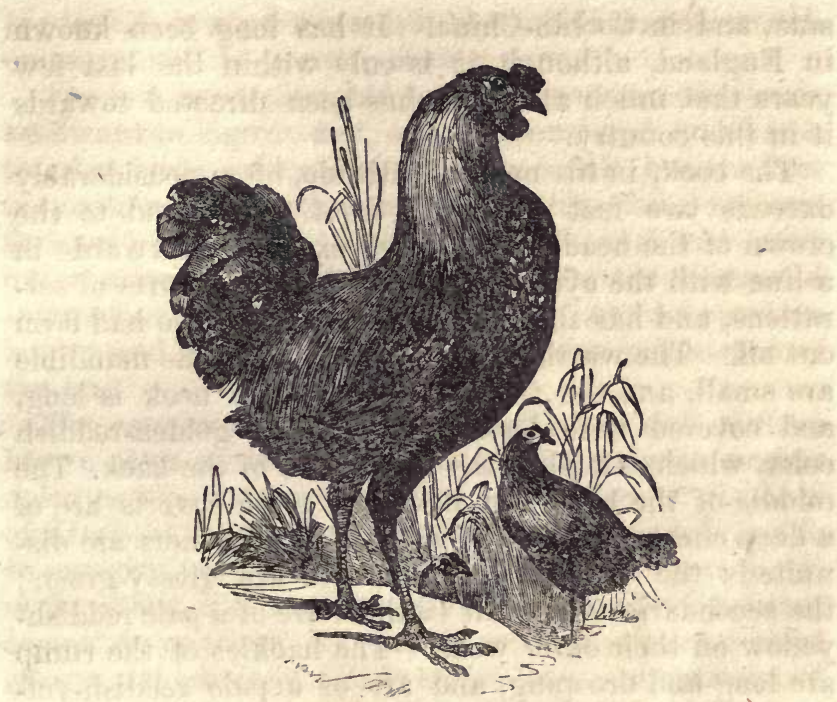

THE KULM, OR GREAT MALAY FOWL.

Srnonrmes.-Gallus giganteus, of Temminck; Grand Coq des Malaies, of the French; Kulm Hahn, Maluischer Hahn, of the Germans; Kulm Fowol, Malay Fowl, Great Malay Fowl, Chittagong Fowl, of the English and Anglo-Americans.

This breed is in high repute with many writers, as a supposed connecting link between the wild and the tame races of fowls. Indeed, something very like them is still to be found in the East; and it would be useful to kuow, as a certain test, whether the kulm cock be indocile, like the pheasant, or tameable, like the fowl. Their flesh is condemned by common prejudice, as coarse, stringy, oily, and ill-flavored. The pure breed is undoubtedly game; but, as far as size is concerned, has little to recommend it. The hens, however, are cxcellent layers, and the eggs remarkable for their delicacy.

'The kulm fowl is kept in a domestic state, not only in India, Java, and Sumatra, but in the Malay penin- 
sula, and in Cochin-China. It has long been known in England, although it is only within the last few years that much attention has been directed towards it in this country.

The cock, in his natural attitude, often considerably exceeds two feet in height, from the ground to the crown of the head. The comb extends backwards in a line with the eyes; it is low, thick, destitute of serrations, and has the appearance as if its ridge had been cut off. The wattles hanging from under the mandible are small, and the throat is bare. The neck is long, and covered with hackles of a pale golden-reddish color, which extend to the upper part of the back. The middle of the back and the lesser wing coverts are of a deep chestnut, and the webs of the feathers are disunited; the greater wing coverts are glossy-green; the secondaries and quill feathers are of a pale reddishyellow on their outer webs. The hackles of the rump are long and drooping, and are of a pale reddish-yellow. The tail feathers are of a glossy-green. The under parts generally are of a glossy greenish-black, with high reflections, each feather being of a deepchestnut at the base, producing somewhat a mottled appearance, especially if the plumage be a little deranged. The body is stout, and the legs are long, but very robust. In proportion to the size of the body, and length of the neck and limbs, the head seems small, and is far from being pleasing in appearance, the curtailment of the comb and wattles seeming the result of injury or malformation. The gait is heavy and destitute of alertness, and the bird often reposes resting on his shanks, their whole length being applied to the ground. The attitude is uncouth, and gives the idea of the bird being oppressed with its own weight. It is very probable that this gigantic fowl is less dis- posed to mount the trees and roost on the branches than most others of the genus ; and this strange attitude may be the ordinary mode of taking repose.

The voice of the cock, instead of being a clear ring- 
ing tone, heartily delivered, is short, hoarse, and monotonous, more like a croak than a crow.

The hen is considerably less in size than the cock, awkward in figure, and often ill-tempered and harsh to other birds. The comb is very small, but the face is much covered with a red skin. The bill, legs, and feet are yellew; the head, neck, back, tail, and quills are of a rich brown; the lower parts of the thighs of a lighter hue; the neck long; the stature and carriage lofty; and the head small in proportion to the size of the bird.

The eggs are of a good size, and of a rich buff or brown color, which are much prized by the numerous epicures who believe that this hue indicates richness of flavor-a fact which has not yet been made sensible to my own palate. The chicks are at first very strong, with yellow legs, and are thickly covered with. lightbrown down; but, by the time they are one third grown, the increase of their bodies has so far outstripped that of their feathers, that they are half naked about the back and shoulders, and extremely susceptible of wet and cold.

The hens are sometimes employed to hatch the eggs of turkeys, a task for which they are well adapted, in every respect but one ; that is, they will follow their natural instinct in turning off their chicks at the usual time, instead of retaining the charge of them as long as the mother turkey would. Goslings would suffer less from such untimely desertion.

With regard to the kulm fowl, the jago fowl, (improperly called the "St. Jago fowl," from the supposition that they came from an island of that name, one of the Cape Verds, ) and the Cochin-China fowl, may be looked upon as so many domestic off-sets, not uncrosised with others, of the Gallus giganteus, of Temminck. And here, let it be remarked, that in the jago fowl, so famous for height and weight, the comb, both of the cock and hen, is large and often double, added to which there is sometimes a crest of feathers. 
Domestication always produces some modifications of structure in animals, and more especially in organs of minor importance, as in the length of the tail and ears, and in the development of various appendages. That the comb of the jago fowl should be large, and often double, is not surprising. Mnst of our ordinary breeds have a rose crown, yet this development is never found in any wild species. It is the result of domestication, and occurs in a part most liable, as might be anticipated, to change.

\section{THE PHEASANT-MALAY FOWL.}

Synonymps.-Gallus giganteus (var. ?), Temminck ; Pheasant-Mulay

Fowl, Pheasant Fowl, Pheasant Breed, of the English Poulterers.

This variety may claim the sad pre-eminence of having given occasion to more disputes than any bird of its tribe, always excepting the game cock. It is highly valued by many English farmers, not on account of its intrinsic merits, which are considerable, but because they believe it to be a cross between the pheasant and the common fowl, than which nothing can be more erroneous. The pullets and cockerels are rcpresented as excellent for the table, and when brought to market meet with a ready sale, less because they are really fine birds, than because the seller assures his customers, in perfect sincerity, that they are halfbred pheasants; and the buyer readily pays his money down, thinking that he has got a nice fowl, and a taste of pheasant into the bargain - something like the Paddy who was delighted, at breakfast, on finding that he was "ateing a little hen" when he had only paid for an egg.

Let it be clearly and distinctly known, then, that the "pheasant breed" of the English poultry fancier is no more a mule between the common hen and the cock pheasant, than the Cochin-China, or ostrich fowl, is a half-bred ostrich. Yet, hybrid birds produced between 
the pheasant and common fowl are of frequent occurrence. The London Zoological Society have possessed several, which were for a time kept together, but showed no signs of breeding; they are considered, like other hybrids, to be unproductive among themselves, all being half-bred; but when paired with the true pheasant or the fowl, the case is different. The society has had exhibited at the evening meetings two instances of success in this sort of second cross. The first was in 1831 ; the second instance in 1836. Two cases only, and those in the second cross, ascertained during all the time that the society has had extraordinary means at command, are exceptions so rare, as to confirm the rule that such mules are barren, and incapable of founding a family, and becoming the ancestors of a distinct race. A correspondent in the London Agricul.tural Gazette, a most successful breeder of them, also admits, that, after many trials of these paired hybrids, he had "never brought up but two to be a'most hens," and that they took the megrims (staggers,) and died.

And yet, an evidently sincere writer in the publication last referred to, declares: "From what I have seen of the plumage of birds casually produced at the wood side, (from crossing with pheasants,) I believe a judicious and scientific selection would lead to the production of very fine varieties, and that, among others, the dark pheasant-plumed breed, both of Bantams and common poultry, would reward the patient inquirer."

The pheasant-Malays are described as large, wellflavored, good sitters, good layers, good mothers, and in many points an ornamental and desirable stock. The eggs vary in size, some very large, in summer, smooth but not polished, sornetimes tinged with lightbuff, balloon-shaped, and without the zone of irregalarity. Six eggs of these hens weigh very nearly 12 ounces.

This breed is very graphically described by a late 
English writer, nearly in the following words.- "The cock is a large-sized bird, of a dark-red color, with a small comb; but the beauty of the breed is with the hens, which are of a pheasant-color in all parts of the body, with a velvety-black neck. The shape of both male and female is good. The neck is long and highcrested, giving them an appearance quite superior to other fowls in that particular. The color of the hens varies from the warmth of the plumage of the cock pheasant to the colder bue of the hen pheasant, but as I have always bred from the high-colored birds, I now have the better color generally predominating. The legs are white, and also the skin. They are excellent birds on table, both as to quality, shape, and size. They have no resemblance to the Malay, except that the cocks are rather high on the legs, the hens being the reverse. The combs of the hens are very small. The hens never have a foul feather, but I have never seen a cock which does not show some small mark of white on one of his tail feathers. You will observe in the hens of the pheasant-Malay that the two longest tail feathers are somewhat curved, which, when the bird is full grown, and in full feather, materially improve the appearance. They do not arrive at their full size until the second season. They lay well, but late. Their eggs are very small in proportion to the size of the birds. I should say that their weight was, on the average, above that of the black Spanish, while their eggs are a third smaller. * * * * * The hens have scarcely any comb. The cocks always have a comb extending but a very little way backward, but standing up so high as always to fall a little over on one side. I have never seen any variation as to the combs nor the color of the neck and tail feathers, either of males or females, which indicates them to be a real variety. The only variation I have observed is in the body color of the hens, and this is not in the marking, but merely in the ground color. * * * * * The eggs are quite small, but of excellent flavor, neither 
very white nor brown; the shape varies considerably. The chicks are of a yellowish color, with sometimes two brown stripes down the back and a few specks about the head, but more usually without either. They have, however, invariably the hinder part of the back of an intenser or browner yellow, almost amounting to a warm fawn-color. * * * * My male birds have a-very peculiar feathering on the neck-the neck feathers being very long and full, dark-red, and black at the tips, but the under part of a downy white. The consequence is, an appearance of mixed dark-red and white about the neck, which is the more peculiar from its being so particularly at variance with the glossy-black neck feathering of the female. The feathering of the back and wings is rather scanty, and the tail is not very full. The bird has a good, erect carriage. * * * * * The chickens of this breed are very small at first, and but scantily supplied with down. As they begin to grow, they have a very naked appearance from the slow development of their feathers, and this renders them very susceptible of cold. At six weeks old, they are not above half the size of Dorkings of the same age, but after two months, they grow very fast, and the pullets feather well and show indications of their permanent color. The cocks are ragged in appearance until five months old, after which they get their permanent plumage, and grow fast. As a sort of profitable growth, I cannot recommend them, but the ornamental figure and color of the hens, I think, is beyond question. The flesh, at table, is extremely good and white; and they lay abundantly, though late. I have a strong suspicion, from various peculiarities, that they are of comparatively recent introduction into this country, from a much warmer climate. ***** Baker, of London and Chelsea, (one of the best fancy dealers,) told me that they were a breed from Calcutta. They are certainly tender, and are apt to die in the moulting." 


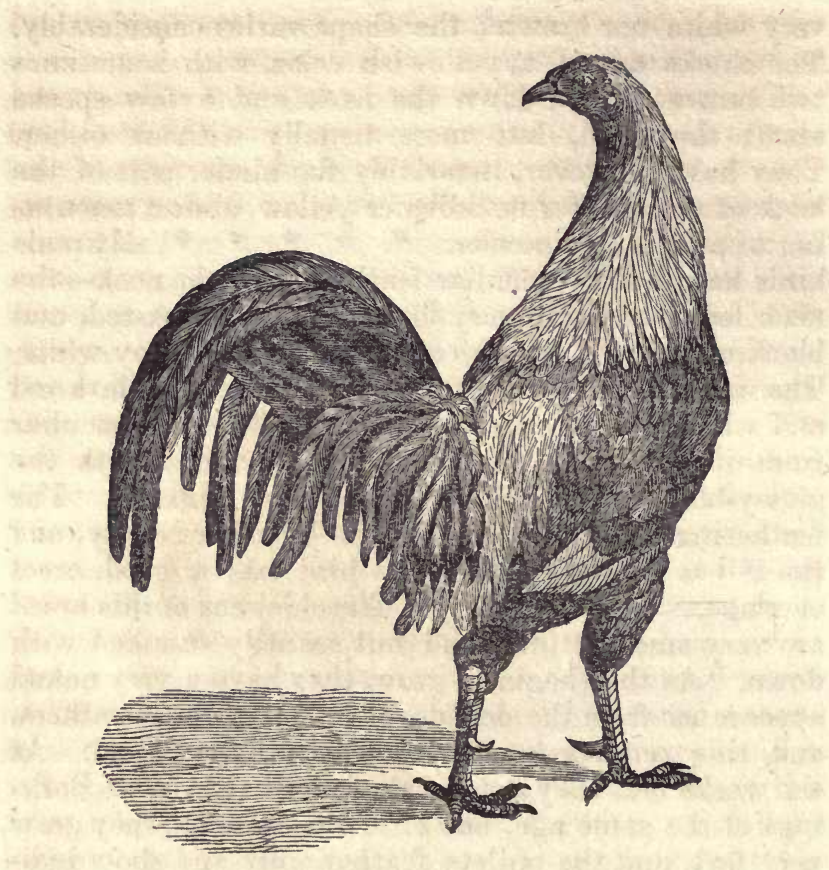

THE GAME FOWL.

SYronymes.-Gallus gallinaceus (var.?), of Naturalists ; Coq anglais, of Buffon; Gallo peleador, of the Spaniards ; Game Fowl, Game Cock, Fighting Cock, of the English and Anglo-Americans.

It is not within the range of the present little treatise to kunt up the distinctions of the sporting fancy, particularly cock-fighting, which, it is hoped, will soon become obsolete; yet an allusion to those distinctions might excite the curiosity of the naturalist. It is the temperament which gives the bird its value in the eye of the sportsman; its physical qualities deserve the notice of the ornithologist. But even now, many of the handsomest game cocks to be seen, are already 
trimmed, (in the comb at least,) in case they should be wanted in a hurry for a private spar.

The game cock approaches nearer to the Malay and pheasant-Malay than to any other variety of fowl. As I have made the Spanish fowl, on account of his well-developed single comb, the type of the genus, so,

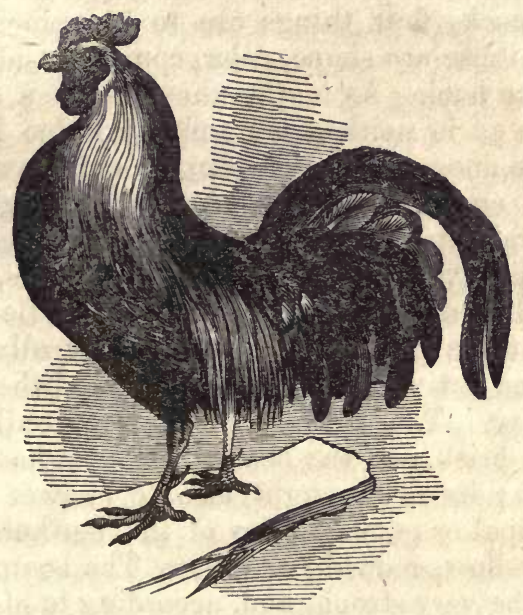

THE ENGLISH GAME COCK.

in any circular arrangement of the genus itself, I should make the game fowl the centre from which the rest, in one way or another, diverge. There are the white-legged, the yellow-legged, and the leaden or black-legged game fowl, all of which vary in the color of their plumage. No other breed runs off into so many varieties, which still are all "true game fowls." The eatalogue of sorts is a long one; and many of them have been preserved in various noble and gentle families, in Europe, distinct. At present, the Earl of Derby possesses a breed which has been in possession of that noble family for many generations, and which is sedulously preserved from base alloy. It 
is a black-breasted red, with a purple band across the wing, and, though superior in size to the Bankiva jungle fowl, it closely resembles that bird in plumage and in elegance of contour.

The exterior qualifications of a male bird of this variety, is described by an anonymous writer in the following words:- "In the choice of the game or fighting cock, four things are to be principally considered ; these are shape, color, courage, and the sharpness of the heel. As to the shape, such a one should be chosen as is neither too small nor too large; the very large ones are always clumsy and unwieldy, and the small ones are slow and tedious in fighting, and are generally too weak to stand a very tight battle; another disadvantage to these extremes, is, that they are very difficult to be matched; the middle size ought: therefore to be preferred, as he is generally the must nimble and active with his strength, and the matching him is easy. The head ought to be small, the eyes large and brisk, and the beak strong and hooked at the setting on; its color ought also to answer to that of the principal or general color of the feathers, whether they be yellow, reddish, or grey. The beam of his leg ought to be very strong, and, according to his plumage, either blue, grey, or yellow; and the spurs ought to be rough, long, and sharp, a little bending and pointing inward. The three colors esteemed in the game cock are grey, yellow, and red, with a black breast. The perfection of a cock is not, however, tied down to these colors absolutely, for experience has shown that there are cocks of other colors which have proved excellent ones, but these are, in general, the best. The pied cock sometimes turns out good, but the white and dun are seldom of any value. If the neck of a cock be invested with a circle of scarlet complexion, it is a sign that he is strong and vigorous, and has great courage; but if it be pale and wan, it denotes him to be defective in these material particulars."

The game cock is by no means the aggressive san- 
guinary tyrant that he is commonly represented to be. He will submit to no insult nor intrusion within his own domain ; but neither does he offer any unprovoked assault. If his antagonist flee, he is satisfied, and loes not pursue him in order to perpetrate any bloody revenge. Other poultry that are killed by game cocks generally draw down the punishment upon themselves, by their own impudent and continued aggression. The bird, too, is as enduring of pain, as he is bold in combat. But though I wish to clear the game breed from the charge of blood-thirsty cruelty, I cannot hold them out as patterns of gentleness and forbearance. "Might with them, makes right." None but the brave, however well they may deserve, or how muchsoever they may long for, are likely to enjoy any favor from the present class of rusty-fusty colored beauties. "Quiet people," says a late writer, "unless they have studied phrenology, or kept game fowls, have little idea how close a connexion there is said to be between love and murder. But the ladies have long found it out; there is no sweetheart like a soldier. A constantly pacific male is despicable in their eyes. ' Eh! si je veux qu'il me batte!' 'If I choose my husband to beat me, what business is that of yours? A pretty state of things, when a woman may not permit her own husband to beat her!' So wrote the great Molière, in the high-heeled, periwigged reign of Louis XIV. But civilised and uncivilised nature is alike. The southern she savage, when her brute lifts his waddy, to give her a tap on the head that would fell an English ox, bows thankfully to receive the caress on her indurated noddle, and triumphs that the compliment was not bestowed upon either of the other squaws."

The game hens, as well as the cocks, also vary in color, and some breeders think the darkest to be of the purest blood; a deep-brown hen, with dark legs and small leaden comb, is thought to be the model bird; but in most, if not all game hens, the tail will be found 
to be large, vertical, fan-like, and well carried over. the back-a distinction which continues to be very apparent in the first cross with any other breed. The flesh, even of the yellow-legged, yellow-skinned breeds, is justly, in high repute; their eggs, also, are much prized for the table, but my own palate is not sufficiently discriminating to detect their particular superiority to the eggs of other hens. They are comparatively small, contain a somewhat larger proportion of yolk, are generally tapering, unequally elliptic, and mostly, though not always, tinged with buff.

Another general merit of the hens, is their excellence as incubators and nurses; a virtue in them which is no new discovery. "Florentius," says Aldrovandi, " is the authority, that in the Alexandria which faces Ægypt, certain hens, from which the fighting cocks are produced, are called Monositæ, (that is, one-mealers, or such as eat only once a day,) and that these will go on sitting for the second or third time, in consequence of their chicks being smuggled away as soon as hatched and brought up elsewhere. It thus happens that a single hen may hatch forty, and even sixty or more, at one sitting." When they are at length permitted to receive their reward in the shape of a brood of chicks, nothing can exceed their admirable conduct. The very young hens, with their first clutch, are apt to be over-anxious, and not at all forbearing to other fowls that come in their way; but that is a fault on the right side, and if the feathers of intruders are now and then made to fly abroad, they must grow again. The delicate proportions of the game hen adapt her to take charge of even the most fragile gallinaceous birds; while her courage and determination render her equal to the most robust. Every breeder or experimenter should have a nursery of game hens.

"The nest for the hen," says the same anonymous writer, referred to above, "should be made of sweet and clean straw, and should be placed in some warm corner, out of the way of disturbance from any other 
fowl, for this sort of interruption provokes this quarrelsome bird in such a manner as to endanger the eggs. That she may never have occasion to leave the eggs so long as to cool them, it will be proper to lay all sorts of food that she is likely to approve of before her, and to put clean water every day not only for her to drink but to wash and trim herself in; some ashes, sand, and gravel should also be sifted on the ground near the nest. The chickens are hatched in about three weeks, and the nest is to be carefully watched about this time, for there are always some of the chickens hatched before the others; these should be taken away as soon as out of the shell, and laid before the fire, or in some warm place in wool, and as soon as the rest are hatched these should be given back to the hen. They are not to be suffered to go abroad for the first fortnight, and the room they are kept in must be boarded, all other floors being too cold and too moist. At about a month old, the chickens may be turned out into a walk of some fresh grass, that they may feed at liberty and eat worms and other insects; but there must be no puddle of water near the place, for they are apt to get into such, and it occasions them a number of diseases.

"As soon as the comb and wattles appear on the cocks, they must be cut away, and the sore place anointed with fresh butter till it is well-(the cock fighter only will act in this cruel manner, the fancier will not thus disfigure his birds). The chickens may be all suffered to run together till they begin to peck one another, then the cocks are to be separated ; each must have his particular walk, and the more freed from disturbance this is the better. The place of feeding them must either be a boarded floor, or a very soft and dry piece of ground. If the place be hard, as a stony pavement, or a plastered floor, the taking up their food will injure and blunt their beaks, so that they will never be able to hold fast afterwards. Any white oorn is good for the young game cook in his 
walks; and so is a white bread toast steeped in ale. There should never be allowed more than three hens to one game cock in his walk; and care is to be taken also as to his roosting-place, that the perch be not too small in the gripe, and be so placed that he may sit upon it without straddling. Game cocks are brought to the greatest state of their strength and activity in about ten days, but they will. scarcely remain twentyfour hours in this condition; nay, some have been known to change for the worse in twelve hours."

Many of the foregoing directions bear rather upon the rearing of the game cock for the purpose of fighting, than for ordinary utility; but others are of general import.

It is not only for its pugnacious qualities that the game fowl is to be noticed-it yields to no breed, nay, perhaps is superior to most in the whiteness and sapidity of its flesh; the hens are excellent layers, and the eggs, though of moderate size only, are remarkable for the delicacy of their flavor, as has already been stated.

Of all the breeds, the game fowl is considered the most beautiful, whether we look to contour or to coloring ; the cock carries himself proudly and yet gracefully, his port and bearing proclaim his fiery spirit, his undaunted mettle, which endures even to his last breath, for while prostrate and mortally wounded he will answer the insulting crow of his victorious rival, and make a last effort to revenge himself before the spark of life is extinct. No wonder that the gallant cock should have been chosen as the emblem of courage.

Poultry fanciers, who keep only a small number of fowls, may manage to rear a young brood of this variety by precautions which the farmer cannot put into practice. The principal objection to them, in these respects, is their impatience of confinement to a yard or coop; and from their lightness on the wing, it is difficult to prevent them from flying out at will. 


\section{THE GOLDEN AND SILVER HAMBURGH FOWL.}

Synonymes.-Gallus gallinuceus (var.?), of Ray ; Gallina turcica (?), of Aldrovandi ; Coral Grey, Botton Grey, Bolton Bay, of Lancashire; Pencilled Dutch Fowl (?), Turkish Fowl (?), of Dickson ; Chittiprats, Cheveprats (?), at Keighley, in Yorkshire, England ; Golden Hamburgh, Silver Hamburgh, of Dixon; Creoles, of Wiltshire and other parts of the South of England.

It is no easy task to reconcile the synonymes of this breed. Aldrovandi, in describing a Turkish cock and two Turkish hens, says : "The cock, whose likeness we now give, is called the Turkish cock. His whole body was, in a manner, inclined to white. Still the wing feathers were partly black, the belly also was black; the tail consisted of feathers that were partly green, partly black, some also half green, some half black. His whole body was exquisitely adorned with lines that were sometimes golden and sometimes silver, and it is wonderful what a beautiful effect this produced. His legs and feet were tinged with blue. The hen, which in like manner is called Turkish, was all white, sprinkled over with black spots; the feet tinged with blue; the wattles were short, when compared with those of the male. The next hen would seem the same, except that her/neck was yellowish, and she had a sharp point on the top of her head, her feet altogether blue, and an immaculate tail, * * * * * I have observed another hen of this kind, whose feet were entirely blue, spotted in the same manner as the foregoing with black and white, but behind its fieshy crest it had another of white feathers like a lark, and that part of the neck and shoulders which in the other is black, in this changing from ash color to dirty yellow."

The figures given in Aldrovandi's large wood cuts are evidently the golden Hamburgh; the hens, one golden, and one silver. The very peculiar form of the comb, so recognisable at the present time, is clearly 
marked in these old characters. The fleshy rose comb of the golden Hamburgh terminating in a sharp point behind, like the corner of a cocked hat turning upwards, and which is seen in no other variety of fowl, is well described.

A writer in the London Agricultural Gazette, of October 14th, 1848, in speaking of this breed, says : "The silver (Hamburgh) fowls are worthy of notice, both on account of their beauty and productiveness; they are small-bodied, have short blue legs, a very pretty head, with a full comb, and a remarkably short bill, rounded, and shaped somewhat like a sparrow's ; their color white, with very regular black dots or moons on their wings and tail. They lay well ; mine commenced early in February, and are laying now (Oct. 3$)$; they do not show any inclination to sit, but in a hatch their eggs are very productive. I have had fourteen chicks out of fifteen eggs. It is necessary to keep a game hen or two, to perpetuate the breed (by hatching the eggs, which they will not do for themselves.) I find rice, at 12s. to $14 s$. per cwt., soaked all night in water, and then rolled in Indian meal, a very economical and fattening food, occasionally mixed with a little barley. My hens would have commenced laying earlier in the season, if their roosting place had been warmer."

Moubray, to whom the merits, at least, of originality and practical knowledge ought to be conceded, appears to have been acquainted only with the English stock of this breed. He says of the Coral, or Bolton Greys, "This variety, apparently the crack breed of their vicinity, but entirely unknown in the metropolis, is described by the Rev. Mr. Ashworth, Vicar of Tamworth, as follows:- 'Small-sized, short in the leg, and plump in the make. The color of the genuine kind, invariably pure white in the whole lappel of the neck; the body white, thickly spotted with bright black, sometimes running into a grizzle, with one or more black bars at the extremity of the 
tail ; they are chiefly esteemed as very constant layers, though their color would mark them for good table fowl.' Certain other breeds, (in Lancashire,) are described, but they do not appear to possess any title to distinction." In his eighth edition, a colored figure is given, which quite corresponds with the silver Hamburghs. Why they are called "corals," it is difficult to say, unless it be on account of their red comb ; which, however, is not redder than that of other fowls.

"Bolton bays" is another provincial name for the "golden Hamburghs," as "Bolton greys" is for the "silver." In order to fix more clearly the nomenclature, by the comparison of individual specimens of different localities, Rev. E. S. Dixon, of Norwich, England, purchased in Hungerford Market, some birds that had been imported from Holland; another specimen from Herring, on the New Road, and was supplied with a pair of "bays," and also of "greys," from Bolton, in Lancashire ; likewise, with a "Creole" hen from Wiltshire. The result of the comparison, and of the unanimous opinion of the London poulterers, was, that the two varieties of Hamburghs, the "golden" and "silver," are of the same breed.

The "Bolton bay," from Lancashire, says Mr. Dixon, "differed most in her markings from the normal type, which we will suppose represented by Aldrovandi's Turkish hen; but all the main points were correct, and for this difference I had been prepared. The bay hen I received was marked very like a golden Poland, (the crest, of course, being quite absent,) but that the ground of the plumage was of a much richer and browner hue. Those persons, therefore, who wish to procure golden Hamburgh fowls, from Lancashire, should state to their agents whether they desire them to be of barred or marginated markings. The Bolton fowls average, in Liverpool, $3 s$. each, which is cheap for those who wish to obtain a stock of this very distinct variety. All the birds that I received were very good specimens. The male golden Hamburgh is a particu- 
larly beautiful creature; nothing but a full-sized colored drawing can give an adequate idea of the extremely rich coloring and brilliant lustre of his plumage. It has been mentioned in the previous note that the males of the Bolton greys differ somewhat in the quantity of black or dark grey which they wear; the hens also very slightly, some having a tendency to linear markings of black and grey, and others to spots of the same colors, but the difference is hardly more than would be seen amongst a brood of chickens reared from the same pair of fowls. The Creole from the south of England was a very well-bred specimen, having the peculiar comb, pointed behind, described and figured by Aldrovandi.

"The Bolton-bay cock, from Lancashire, has a large very double comb pointed behind upwards, flat on the top, but covered with small upright points; the wattles are large, and there is a small white ear patch. The bill is short and lead-colored; feet and legs also leadcolored. Irides orange-brown. The hackle is composed of a mixture of brown, black, yellow, and green; back the same, only darker. Tail, black glossed with green, and having grey down at the base of the feathers. Quills of the wings, chestnut; wing coverts, metallic black ; breast and under part of the body, black."

The golden and silver Hamburgh, when pure bred, are commonly looked upon as "everlasting layers," but no strictly universal rule that will apply without fail to every case, can be laid down for fowls any more than for quadrupeds or men. The term "everlasting" receives its name from the circumstance that the hens, if properly fed, and kept in a warm situation protected against the cold, will continue to lay throughout the whole of the year, or nearly so, and thus afford an unfailing supply of eggs. In general, fowls after laying for a certain length of time become "broody" - they cease to lay, and evince an uncontrollable desire, an instinctive propensity to devote themselves to the task of incubation. They are impelled by the law of nature, which urges them to this essential mode of continuing their race; but in the present breed, in which the season of 
laying is preternaturally lengthened out, or is almos continuous from spring to spring, this natural desire is greatly weakened, or indeed altogether subdued. The hen betrays but little anxiety to incubate, and continues to lay eggs as if for no other purpose than to repay her keeper. Hence, to obtain a brood of this stock, (and it should be kept in its purity,) the eggs must be put under a good sitter, of any common breed, a few of which may be kept for the express purpose, and thus the fancier may replenish his stock. It is not often that pure everlasting fowls are to be seen, and this renders it the more desirable that those who possess breeds should sedulously preserve them from admixture; a cross will spoil the hens as "everlasting layers," without rendering them enduring, patient sitters.

\section{THE CUCKOO FOWL.}

Srnonymes.-Gallus gallinaceus (var.?), of Ray ; Cuckoo Fowl, of tho Norfolk Farmyards, England; Barn-Door Fowl, of the English and Anglo-Americans.

This variety, there is good reason to believe is old and distinct, though it is generally looked upon as a mere "barn-door fowl ;" that is, the accidental result of promiscuous crossing. But there are several forms among the "bain-door fowls," so called, that are seen to be repeated generation after generation, the counterparts of which are to be met with scattered here and there over this country as well as Europe. So constant a repetition of corresponding features would seem to declare, that there are several unnoticed and undistinguished varieties of fowl, which deserve to be regarded and treated as we do other distinct sorts.

The objection to the adoption of this view and mode of practice is, that it would inconveniently multiply the number of species, and give additional trouble to naturalists and poultry fanciers. But the multiplicity of Nature's works always has been infinite, in reference to man's power of understanding them. The only won- 
ar, if we reflect, is, that he has had the courage to srapple with them at all. The subject is certainly deserving of consideration, and may be the means of affording important service to natural history. Dr. Bechstein, of Germany, seems to have been not far from suspecting that several distinct varieties might be detected amongst the ordinary fowls of the farmyard. It might answer the purpose of the dealer to rear a pure stock of some of the handsomest and most useful of these, and send them forth with appropriate names, determined by competent persons, fixing the appellation of the variety.

The "cuckoo fowl," it may be supposed, was so called from its barred plumage, resembling the breast of the cuckoo. The prevailing color is a slaty blue, undulated and softly shaded with white all over the body, forming bands of various widths. The comb is very small; irides, bright orange; feet and legs, light flesh color. The hens are of a good size, the cocks are large, approaching the heaviest breeds in weight. The chickens, at two or three months old, exhibit the barred plumage even more perfectly than the full-grown birds. The eggs average about two ounces each, are white and of porcelain smoothness. The newly-hatched chicks are grey, much resembling those of the silver Polands, except in the color of the feet and legs. This breed supplies an unfailing troop of good layers, good sitters, good mothers, and good feeders, and is well worth promotion in the poultry yard.

\section{THE LARK-CRESTED FOWL.}

Srкокумes.-Gallus gallinaceus (var.?). of Ray; Copplecrowns, in Norfolk, England; Lark-Crested Fowl, of the English and AngloAmericans.

Here again, as with the cuckoo fowl, is a breed, which, until of late, has been treated with undeserved regard. They have, no doubt, been looked upon by many as ill-bred Polands, but the shape of the crest, as 
well as the proportions of the bird are different. Aldrovandi perceived the distinction. He calls the one "our farmyard hen, known to everybody, entirely white and crested like a lark ;" the other is his Paduan fowl. The first, of whatever color, is of a peculiar taper form, inclining forwards, as Aldrovandi's old-fashioned woodcut well represents, with a moderate, depressed, backward-directed crest, and deficient in the neatness of the legs and feet so conspicuous in the Polands; the latter are of more upright carriage and a more squarely-built frame. Set the two side by side, and their discrepancy will be apparent.

Lark-crested fowls are of various colors; pure snowwhite, brown with yellow hackles, and black. How far these sorts require to be subdivided, has not yet been investigated. The first of these are perhaps of a more brilliant white than is seen in any other domesticated gallinaceous bird, and the color is much more dazzling than that of the white Guinea fowl, or the white pea fowl. This white variety is in great esteem with many farmers' wives, in England, who will keep it to the entire exclusion of any other sort. They are represented to have a remarkably neat and lively appearance when rambling about a homestead, and look very clean and attractive when dressed for market. An old bird, cleverly trussed, will be apparently as delicate and transparent in the skin and flesh as an ordinary chicken. The feathers are also more saleable than those from darker-colored fowls. By some, this breed is thought to be more tender than other kinds, yet they are considered, on every account, preferable to the white Dorkings.

In the cocks, a single upright comb sometimes almost entirely takes the place of the crest. The hens, too, vary in their degree of crestedness, some not having above half a dozen feathers in their head dress. If they were not of average merit as to their laying and sitting qualifications, they would not retain the favor they do with the thrifty housewives by whom they are chiefly reared. 


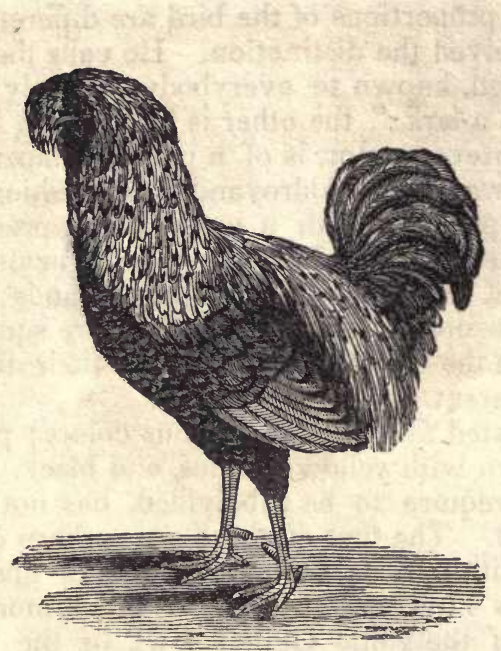

THE SPANGLED HAMBURGH FOWL.

SrNonrMes.-Gallus giganteus (var. ?), of Temminck ; Spangled Hamburgh Fowl, Golden Spangled Hamburgh, Silver Spangled Hamburgh Fowl, of the English and Anglo-Americans.

The spangled Hamburghs may be comprised under two varieties, ("golden" and "silver,") the distinctive characteristics being slight, and depending nearly altogether upon color. In the "spangled Poland fowl," of pure strain, there is no comb; but the spangled Hamburgh has a small one, rising up into two, and sometimes more, conical eminences, or horns, behind which is a full pendent topknot. Under the insertion of the lower mandible, or that portion of the neck corresponding to the chin in man, is a full, dark-colored tuft, somewhat rese mbling a beard.

The wattles of the cock are small, and under the throat as just observed, is a full, dark-colored tuft of feathers. His general color is golden or orange-yellow, each feather having a glossy, dark-brown or black tip, 
(not white,) particularly remarkable on the hackles and wing coverts, and also on the darker feathers of the breast. The thighs are of a dark-brown, or blackish shade, and the legs and feet are of a bluish-grey.

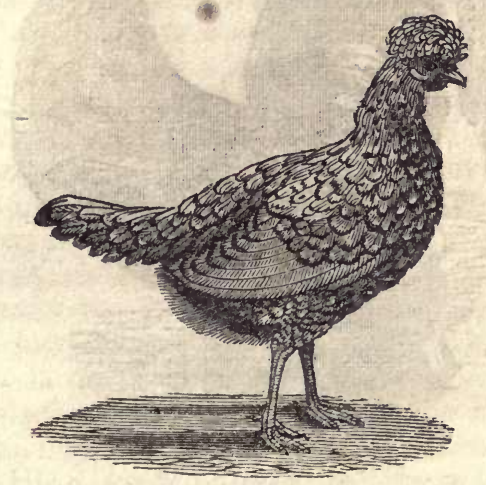

THE SPANGLED HAMBURGH HEN.

The hen is yellow or orange-brown, with the feathers margined with black, after the manner of those of the cock. Birds thus colored are called "golden spangled."

In the "silver-spangled" variety, the only perceptible difference is, that the ground color is a silvery white, with perhaps a tinge of straw-yellow, every feather being margined with a semi-lunar mark of glossy black. In other words, when the fowls are at rest, the feathers present the appearance of regular semi-circular spots or spangles. Hence the name of "spangled Hamburghs," the varieties being called "golden" or "silver," according to the prevailing color, being bright-yellow or silvery white.

Both varieties are extremely beautiful, having full, plump bodies, a tender skin, and but little offal; and the hens lay freely an abundance of good-sized eggs.

These fowls gained the prize at a late show of the Royal Agricultural Improverhent Society of Ireland. 


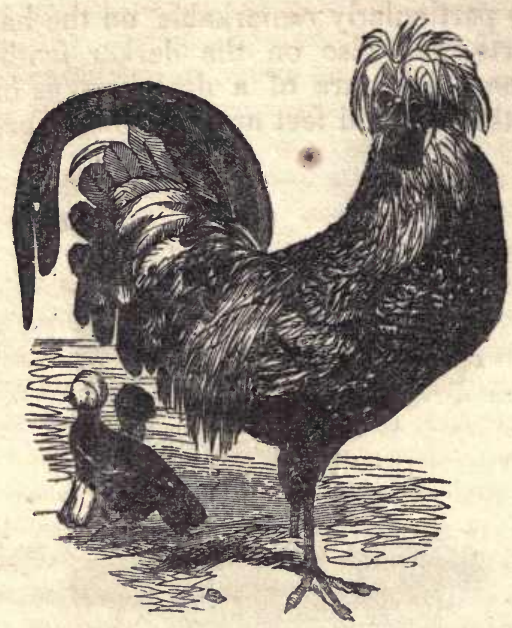

THE POLAND, OR POLISH FOWL.

8rxorymes.-Gallus giganteus (var. ?), of Temminck, Paduan Fowl, of Aldrovandi ; Copplecrowns, in Norfolk, England; Polish Fowl, Polan. ders, Black Polish Fowl, Golden Polands, Silver Polunds, White Polish Fowl, Spangled Polish Fowl, Poland Topknots, of the English and Anglo-Americans.

Certain fowls, with topknots, are called by the names indicated above. Whence the cognomen of "Polands" was derived, it is difficult to trace. Those who doubt the likelihood of any new breed of poultry coming from Poland, are inclined to think the word a corruption of some term derived from the poll, or head; the word "polled," which we now apply to eattle without horns, would be more suitable to fowls with topknots. Or, it might possibly be given in allusion to the plica polonica, or Polish disease, in which the hair in the human subject grows into an immense matted mass. Whether the climate of Northern Europe has any tendency to develop the growth of crests, " muffs," \&c., (as in what are called Siberian fowls, or muffed Dorkings,) on the heads 
of fowls, in a similar way in which that of Angora is said to soften and lengthen the hair of various animals, from the fur of cats and goats, to the hair and beard of men; and whether, poultry being unknown to the Teutonic tribes before their conquest by the Romans, the growth of a topknot or a muff be the result of an introduction to trans-alpine influences, is a speculation which we have no present means of pursuing.

There is no evidence that any breed of fowls with topknots was known to the ancients; but we first meet with them in the middle ages. Aldrovandi, quoted by Willoughby, in his "Ornithology" gives us many kinds, or rather rarities, of hens, among which was one white and "copped," but this is believed to be the lark-crested barn-door fowl of the present day. Aldrovandi also gives two large spirited figures, each occupying the whole of his folio page, which he calls the Paduan fowls, but in which we recognize what would now be called Polands. His description reads as follows :-

"There exist cocks for the most part larger than our own, which the common people call Paduan, even as such hens are larger than our own hens. We exhibit the likeness of the male and the female. The male was most beautiful to behold highly decorated with five colors, namely, black, white, green, red, and ochre. For the whole body was black. The neck was covered with very white feathers. But the wings and the back consisted partly of black, and partly of green. Tho tail likewise was of the same color, but the roots of the feathers were whitish. Some of the quill feathers, (remigibus,) were white above. Its head was adorned with a very handsome crest ; but the roots of the crest were white. A red spot encircled the eyes. The comb was very small; the bill and feet yellowish. But in the whole hen, there was not the least white, except that white skin, which is usual about the openings of the ears, but she was altogether black, shining with green. The feet were light-yellow; the comb very small, and scarcely of a red color."

A difficulty about such varieties recorded so long ago 
is the doubt whether the cock and hen were really of the same breed.

The Paduan fowl has been continually mentioned as something distinct and primitive, by those who have quoted Aldrovandi, but let us for the present discard the term, and sweep the birds into the class of Polands. Whether they were really first brought from Poland it is difficult to know; but the fact is quite possible. Fowls brought alive from India to Europe, by the overland journey, would suffer less than such as were sent by -sea round the Cape of Good Hope. At the end of each day's journey, they could be let loose immediately, that the spot for the night bivouac was fixed upon; they would soon learn to return at dusk to their travelling hen house, and would be well refreshed against the next day's fatigue. In Russia, the finest teas are received overland from the East; nor is it improbable that a few fowls may have been carried as far as the neighboring country of Poland, after having accompanied some wealthy merchant, as live stock to be eaten by the way in case of sickness, or short commons. But whether correct or not, it would be difficult now to alter their nomenclature. Moubray says, "Perhaps the genuine sort, (of Polish,) has always five claws ;" and he proceeds to derive the famous Dorking breed from them, with the reservation, however, that such a speculation may be groundless, which it decidedly is. For the fifth toe vanishes from the Dorkings at a very early stage of crossing with any other breed.

The Black Polish Fowls are of a uniform black, both cock and hen, glossed with metallic green. The head is ornamented with a handsome crest of white feathers springing from a fleshy prtuberance, and fronted more or less deeply with black. The comb is merely two or three spikes, and the wattles are rather small. Both male and female are the same in color, except that the cock has frequently narrow stripes of white in the waving feathers of the tail ; a sign, it is said, of true breeding. The hens also have two or three feathers on each side of the tail, tinged in the tip with white. They 
do not lay quite so early in the spring as some varieties, especially after a hard winter; but they are exceedingly good layers, continuing a long time without wanting to sit, and laying rather large, very white sub-ovate eggs. They will sit, however, at length, and prove of very diverse dispositions; some being excellent sitters and nurses, others heedless and spiteful. The chicks, when first hatched, are dull, black, with white breasts, and white down on the front of the head. They do not always grow and get out of harm's way so quickly as some other sorts, but are not particularly tender.

In rearing a brood of these fowls, one may observe some of the hens with crests round and symmetrical as a ball, and others in which the feathers turn all ways, and fall loosely over the eyes; and in the cocks, also, some have the crest falling gracefully over the back of the head, and others have the feathers turning about and standing on end ; these are to be rejected, the chief beauty of the sort depending on such little particulars. One hen, noticed by Mr. Dixon, laid just a hundred eggs, many of them on consecutive days, before wanting to incubate ; after rearing a brood successfully, she laid twenty-five eggs before moulting in autumn.

The Black-topped White Polish are now, it seems, run out in England, if, indeed, there is any evidence of their having ever existed there. Buffon mentions them as if extant in France in his time. These and the "Shackbags" are probably recoverable only by importation from Asia.

The Golden Polands are sometimes called "gold spangled," but surely not correctly, because, although the bird has spots, those markings are not universal, but many of the finest specimens have the feathers merely fringed with a darker color, and the cocks, much more frequently than the hens, exhibit a spotted or spangled appearance. Many of them are disfigured by a muff or beard; but no such birds should be allowed the entrée to the poultry yard, but be dispatched at once to the fatting coop.

The golden Polands, when well bred, are exceedingly 
handsome; the cock having golden hackles, and gold and brown feathers on the back; breast and wings richly spotted with ochre and dark-brown; tail darker; large golden and brown crest, falling back over the neck; but little comb and wattles. The hen is richly laced with dark-brown or black on an ochre ground; dark-spotted crest; legs light-blue, very cleanly made, and displaying a small web between the toes, almost as proportionally large as that in some of the aquatic birds called "waders." They are good layers, and produce fair-sized eggs. Many of them make excellent mothers, although you cannot always get them to sit early in the season. The chicks are rather clumsy-looking little animals, of a dingy brown, with some dashes of ochre about the head, breast, and wings. They are sometimes a little apt to die in the first week of their existence, but afterwards get tolerably hardy, although liable to make a stand-still when about half grown.

It has been observed as a peculiarity in the temper of this breed, that if you catch one of them, or if one is attacked by any animal, the rest, whether cocks or hens, will instantly attack the aggressor with fury, and endeavor to rescue their unfortunate companion.

The Silver Polands are similar to the preceding in shape and markings, except that white, black, and grey, are exchanged for ochre or yellow, and various shades of brown. They are even more delicate in their constitution, more liable to remain fixed at a certain point of their growth, and still more require and will repay extra care and accommodation. Their topknots are not, perhaps, in general, so large ; but they retain the same neat, bluish legs and slightly-webbed feet. It is curious that a bird which is quite incapable of swimming should have webs on its feet, while the gallinule, which swims and dives well, has none.

The hens of the silver Polands are much more ornamental than the cocks; though even they are sure to attract notice. They may certainly be ranked among the choicest of fowls, whether we consider their beauty or their rarity. They lay moderate-sized, French-white 
eggs, much pointed at one end, in tolerable abundance, and when they sit, acquit themselves respectably.

The new-hatched chicks are very pretty; grey, with black eyes, light, lead-colored legs, and a swelling of down on the crown of the head, indicative of the future topknot, which is exactly the color of a powdered wig, and indeed gives the chick the appearance of wearing one. They are easily enough reared for the first six weeks or two months, the critical time with them being the interval between that age and their reaching their fifth or sixth month. At a very early age, they acquire their peculiar distinctive features, and are then the most elegant little miniature fowls it is possible to imagine. The distinction of sex is not very manifest till they are nearly full grown, the first observable indication being in the tail. That of the pullet is carried uprightly, as it ought to be, but in the cockerel it remains depressed, awaiting the growth of the sickle feathers. It is remarkable that the golden Polish cock brings as true silver chicks, and those stronger, with the silver Polish hen, as the silver Polish cock would.

The silver Polands have all the habits of their golden companions; the main difference being the silvery ground instead of the golden. The silver variety will sometimes even make its appearance if you breed merely the golden sort, exactly as the black Polish produce now and then some pure white chicks that make very elegant birds. An attempt has been made in England to obtain the black topknotted, white, Polish from these, by acting on the imagination of the parents. The experiment failed, though similar schemes have been said to succeed with animals; it proved, however, one thingnamely, that it will not do to breed from the white Polish as a separate breed. Being albinos, the chicks come very weakly, and few survive. On the other hand, trust to chance for an occasional white one among the black, and you may get a fine bird.

There is a singular variety of the Polish, which has the entire plumage of a uniform slaty dun color. Other curious combinations of color are probably to be found 
here and there in the hands of careful breeders. One has been lately raised in England, in which the golden plumage has been crowned by a large glube-shaped white crest of dense feathers; how long this will continue permanent, remains to be tested. There was also a breed called after Lord Erdley, which obtained a prize at one of the poultry shows in the Surry Zoological Gardens.

The Polish fowls are chiefly suited for keeping in a small way, and in a clean and grassy place. They are certainly not so fit for the yard of the farmer, becoming blinded and miserable with dirt. It is a main point to procure them genuine; for there is no breed of fowls more disfigured by mongrelism than this. The Polish will, without any cross-breeding, occasionally produce white stock that are very pretty, and equally good for laying, \&c. It is singular, however, that if you attempt to make a separate breed of them, they become puny and weak. It is better for those who wish for them to depend upon chance, as every brood almost of the black produces one white chick strong and lively as the rest.

The Polish fowls are excellent for the table, the flesh being white, tender, and juicy; but they are quite unsuitable for being reared in any numbers, or for general purposes ; they are capricious in their growth, frequently remaining "stuck," for a whole month, without getting bigger, and this, too, when about a quarter or half grown, the time of their life when they are most liable to disease. As aviary birds, they are unrivalled among fowls. Their plumage often requires a close inspection to appreciate its elaborate beauty; and the confinement and petting seem not uncongenial to their health. It is recommended that persons whose accommodations for poultry is very limited, select some pretty family of Polanders, and keep them on the aviary system; when it will be found that their plumage improves in beauty with almost every moult.

Polish fowls are also currently reported as "everlasting layers," which further fits them for keeping in small 
enclosures; but, as in the Hamburghs, individual exceptions are often met with, however truly the habit may be ascribed to the race.

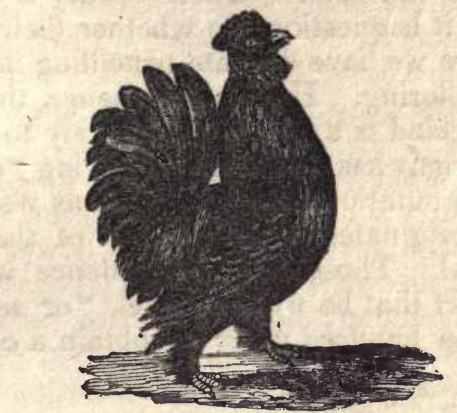

THE BANTAM FOWL.

Srnonyse.-Gallus bankiva (var. ?), of Temminck; Cog de Bantam, of Buffon; Bantamischer Hahn, of the Germans ; Bantam Fowl, of tho English and Anglo-Amoricans.

Our little friends, the Bantams, as their name clearly implies, came from Bantam, a town and kingdom in the island of Java, famous for its trade in pepper. Since their introduction into Europe, this breed has ramified into many varieties, none of which are destitute of elegance, and some remarkable for beauty. All are, or ought to be, of small size, but lively and vigorous, exnibiting in their movements both stateliness and grace.

The Yellow or Nankin Bantams are about the most useful of their tribe, and not the least ornamental. The hens are mainly tinted with a ginger-yellow, and have dull-blue legs and feet, and small comb. There is a subvariety, in which they are more brown, after the fashion of some game hens. The cocks are decked in red, orange, and scarlet, mostly with the false speculum,or iridescent wing coverts, altogether of a flashy appearance ; and, indeed, when good specimens of their kind, they are really beautiful little birds. Their eggs are large in proportion to the size of the layer, very rounded and full at both ends, and of excellent flavor. The hens are ex- 
cellent mothers, particularly for such delicate things as Guinea fowls.

The Sebright Bantam has very much thrown the preceding into the shade. Their beauty is of a different class, but it is questionable whether their merits are greater. Here we have delicate pencilling in the shape of brilliant coloring. How and whence they first appeared in England is a mystery and likely to remain so. Sir J. S. Sebright has the credit of having "originated" the breed, a reputation believed to be as well deserved as that he "originated" the creation of the feathered race in general. Those in his confidence were accustomed to report that he would travel, "or send," as far as two or three hundred miles to obtain a choice bird,

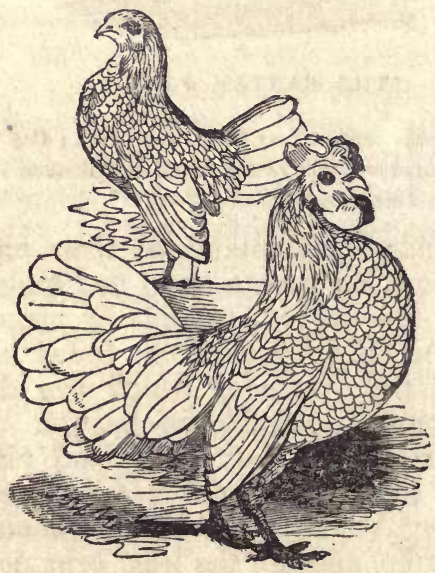

SEBRIGHT BANTAMS.

which was doubtless true; but had they added many thousands of miles to the two or three hundred in the "sending" part of the story, they would, we believe, have been still nearer to the truth. That Sir John treated his birds, when procured, with jealous care and skilful nature will be readily granted. But while breeders continue to be so anxious, not merely to conceal their system of management, (in the earliest stages at 
least,) but even to mislead inquirers, those who cultivate natural history for its own sake, will not be justified in arriving at hasty conclusions from such information.

"We are at once struck with surprise at the impudence of the Sebright Bantams. Oh! the consequential little atom! That such a contemptible minikin as that should have the assurance to parade his insignificant person in the presence of great ladies, the female members of families of weight and substance, before the Misses, and still worse, the Mistresses Dorking, CochinChina, and Malay, to presume to show marked attention, nay even, I declare! to —. Well, there is no knowing to what lengths impudence will go, so long as Bantams survive extermination.

"Here is a little whipper-snapper! Pretty, certainly, and smart, but shamefully forward in his ways. His coat is of a rich, brownish-yellow ; almost every feather is edged with a border of a darker hue, approaching to black. His neat, slim legs are of a light, dull-lead color; his ample tail is carried well over his back. His dependent wings nearly touch the ground. $\mathrm{He}$ is as upright as the stiffest drill serjeant, or more so, for he appears now and then as if he would fall backwards, like a horse that over-rears himself. His full, rose comb and deep-depending wattles are plump and red; but their disproportionate size affords a most unfortunate hold for the beak of his adversary; but he cares not for that ; a little glory is worth a good deal of pecking and pinching, and it is not a slight punishment, nor a merely occasional infliction of it that will make him give in. The great hens, too, that look down upon him, and over him, think proper to do battle with him on a first introduction, though they afterwards find out that they might as well have received him in a more feminine style." Dixon.

The plumage of the hens is similar to that of the cocks. They are very good layers, most excellent sitters, assiduous and affectionate mothers, but most murderous step-mothers ; that is, if you attempt to change, or add to, the number of the brood they have hatched 
themselves, they will welcome the little strangers by making raw head and bloody bones of them, before you can return from fetching a pan of water to set before the coop. Their own chickens are dark-brown when first hatched, with no particular marks about them whilst young. This is the variety figured by Moubray as the "Bantam or pheasant fowls."

The Black Bantam is a most beautiful example of a great soul in a little body. It is most pugnacious of its whole tribe. It will drive to a respectful distance great dunghill cocks five times its weight. It is more jealous, irascible, and domineering, in proportion to its size, than the thorough-bred game cock himself. Its combativeness, too, is manifested at a very early period. Other chickens will fight in sport, by the time they are half grown, but these set to work in good earnest.

The black Bantam, in his appearance, is a pleasing little fellow. He should have a full rose comb, clean and sinewy legs, glossy plumage with almost metallic lustre, of a different tint to the glancing green of the Spanish fowl, arched and flowing tail, waggish, impudent eye, self-satisfied air and gait.

The hens are of a duller jetty black, less knowing in their manner, and, in every way, of inferior capacity. They have great credit for fulfilling their maternal duties well; but they are found to be less affectionate and careful than other Bantams. They are great stayers at home, prowling very little about, and therefore are desirable in many situations, such as suburban villas that are surrounded by captious neighbors. They will remain contented with the range of a moderate stable yard, and the least bit of shrubbery; and will do much good by the consumption of numerous insects. They are reputed gond layers during winter; but that will depend on the liberality with which they are fed. Cooks say that their eggs, though small, are "very rich," which means, perhaps, that they contain a greater proportion of yolk than those of larger fowls. Guinea fowls' eggs are prized for the same quality; and any one may, at breakfast, observe how much less a proportion of white 
there is in them, than in those of the turkey. Black Bantam's eggs are smooth, tinged with buff, decidedly long-oval in most individuals, and with a zone of irregularity towards the smaller end in some.

The new-hatched chicks are covered with black down, which occasionally has a greyish cast under the belly; bill, eyes, feet and legs black. The female chicks are not bigger than the queen of the black and yellow humble bees, and their slender, little legs appear fitter to belong to an insect than a chicken.

When brought up by their own mother, a spent cucumber frame covered with a net, is a good place to keep them the first month. The hottest and finest part of the season should be selected for them to pass their chickenhood in. When full grown and plumed, they are not more tender than other poultry, though they are better suited for confinement in yards.

Those who keep any other variety of domestic fow], and are desirous of having plenty of chickens as well as eggs, had better not permit a black Bantam cock to enter upon their premises.

The White Bantam very much resembles the one preceding in every respect except color; the rose comb may perhaps in some specimens be a little more exuberant. But they are not much to be coveted. The white of their plumage is not brilliant, and is sure to be un-neat in the places where they are usually kept. Were they really guilty of the savage, objectless, and unnatural ferocity that is attributed to them, they would all deserve to have their necks wrung; but the tale wants confirmation.

Creepers, so called from the shortness of their legs, and Jumpers, from their halting gait, are rather to be considered as accidental deformities collected from unhealthy families of Bantams, than as constituting any distinct variety. A sufficient proof of which is, that many of them are scarcely able to propagate their kind. Some of these are the very smallest of their genus, being not larger than pigeons, and not so tall. They are now much out of fashion, and are rarely seen. They were 
well known, however, to the middle-age curiosity collectors. Aldrovandi, in discoursing on them, says: "But the hens which Longolius calls pigmy, and renders into German 'Kriel,' those, as I have just said, exist here and there, creep along the ground by limping rather than walking." Again, he says: "Although we declared that we would not give another figure of common hens, we have thought right, on account of their rarity to exhibit one of the pigmy or dwarf sort, which we have said that many people unadvisedly consider as the Hadrian hen, (of classical authors,) although it belongs to the same kind. But this hen was all black except the larger feathers of the wings, which were whitish at the tips; she had likewise white spots all round about her neck emulating the full moon, and lastly, a round spot of an ochrey color encircled her eyes. Her head was topknotted. The wattles and comb, which was very small, were of a rather intense red; the feet were bright yellow ; the claws small, exceedingly white."

Aldrovandi also gives a rich collection of three-footed, four-footed, double-headed, and double-bodied fowls, that occurred to him in the course of his laborious researches.

\section{MONGRELS AND BARN-DOOR FOWLS.}

IT is now generally conceded, and the best judges agree, that there is no such variety as the "barn-door fowl," unless we appropriate that name to some one variety which has hitherto been scarcely distinguished with precision; and that the collections usually known under the name, are merely a rabble of mongrels, in which the results of accidental or injudicious crosses have become apparent in all kinds of ways.

From observation and strict inquiry, it is now regarded as an established principle, that the most careful breeding will only fix, and make prominent, certain peculiar features, or points, which are observed in certain families of the same aboriginal species, or subspecies; and that the whole world might be challenged to bring evidence that any permanent intermediate variety of quadruped or bird, generated by the crossing 
of any two wild species, that would continue to reproduce offspring, like itself, and not finally revert back to one or other original type.

As to the great question of the "immutability of species," so closely allied to the investigation of the different varieties of poultry, as far as the limited researches of physiologists and naturalists have goneand they have been confined almost entirely to birds under the control or influence of man-I have been led to the conclusion that sub-species, and even varieties, are much more permanent, independent, and ancient, than is currently believed at the present day. My conviction is, that the diversities which we see even in the most nearly-allied races of birds, are not produced by any transmuting influence of time, variation or increase of food, change of climate, (except in some instances in their feathers,) nor by hybridization;* but that each distinct variety, however nearly resembling any other, has been produced by a Creative Power. Moreover, facts would seem to prove that hybrids, possessed of the power of reproduction, are even then saved from being barren only by their progeny more or less rapidly reverting to the type of one parent or the other; so that no intermediate race is founded. Things sooner or later go on as they went before, or they cease to go on at all. This is the case with our domestic animals generally; and is well known to breeders as one of the most inflexible diffi-

* The prevalence of bright colors in the animals of polar and cold regions is well known, and is ascribed to the influence of climate: the arctic fox, the polar bear, and the American snow bird, are striking instances. The same character is remarkable in some species which are more darkly colored in warmer situations. A similar fact is also observable in those birds and animals which change their color in the same country, at the winter season, to whiteor grey, as the ermine, (Mustela ermina,) and weasel, (M. nivalis,) the varying hare, squirrel, reindeer, the white game bird of Lapland, (Tetrao lagopus,) and the American snow bunting (Emberiza nivulis.) In cold regions, too, the fur and feathers are thicker, and more copious, so as to form a much more effectual defence against the climate than the coarser and rarer textures which are seen in warm countries.

Difference of food might be naturally cxpected to produce considerable corresponding modifications in the color, form, and size of animals. For instance, oxen become very large and fat when reared for many generations on rich soils, but are distinguished by shortness of the legs; while, on drier situations, their whole bulk is less, and the limbs more muscular and strong. Some singing birds, too, chlefly of the lark and finch kinds, are known to become gradually black if they are fed on hemp seed alone. 
culties they have to contend with, technically called by them "crying back." Thus it is that half the mongrels that one sees among our domestic fowls are only transition forms, passing back to the type of one or other progenitor.

The mongrels and barn-door fowls are so numerous and so variously mixed, that it is impossible to give even a catalogue of all the intermediate shades of character among them. I shall, therefore, only notice those which have some pretensions to distinctness of character, and have been propagated either for ornament or profit. Their names and chief characteristics, are as follows :-

The Jago Fowl, (see vignette,) also erroneously called the "Paduan" and the "great St. Jago fowl," is the offspring of an absurd quotation from Marsden's "History of Sumatra," which has run the rounds of most compilations on the domestic fowl. Jago, the native Sumatran or Malay word for a particular breed, has been mistaken for St. Jago, the name of one of the Cape Verd Islands. Marsden was, doubtless, well acquainted with his subject, as will appear from his own words: "There are in Sumatra the domestic hen, (ayam,) some with black bones, and some of the sort we call Freezland or Negro fowls; hen of the woods (ayam baroogo); the jago breed of fowls, which abound in the southern end of Sumatra, and western of Java, are remarkably large; 1 have seen a cock peck off a common dining-table; when fatigued, they sit down on the first joint of the leg, and are then taller than the common fowls. It is strange if the same country, Bantam, produces likewise the diminutive breed that goes by that name."

This fowl, which was formerly in very high repute, in England, is said to have been as large and as finelyflavored as a turkey; but now, it is rarely to be met with, if at all. It was probably nothing more than a cross between the Cochin-China, and some other large eastern fowl, which, at present, has nearly or quite "cried-back." There are numerous other races or 
varieties bearing this and other names found in different parts of Europe and this country, one of the most interesting of which is called the "Spanish fowl" (see vignette). The body and tail feathers are of a rich black, with occasionally a little white on the breast. The deportment of the cock is grave and stately, and his eyes are encircled with a ring of brownish feathers, from which rises a black tuft that covers the ears. Behind the comb, there are other similar feathers, as well as beneath the wattles. The legs and feet are of a leaden color, except the soles of the feet, which are yellowish.

The famous "shack-backs," "shack-bags," or "Duke of Leeds' fowl," in vogue in England some years ago, were supposed to have been a cross between the jago and Dorking fowls.

The Shanghae Cochin-China Fowl.-This breed is said to have been carried from the eastern part of Cochin-China to the city of Shanghae ; thence to Liverpool, in England, whence they were conveyed to Boston, in Massachusetts, by Captain Forbes, in 1848.

In general shape and appearance, these fowls resemble the true Cochin-Chinas, of which they are doubtless a cross, though they have a greater depth of quarter, less depth of breast, and are lighter in their color. Their legs invariably are large and heavily feathered. The general plumage is of a bright-yellow, or gold color, variegated with dark-brown or red. Their eggs, also, are of a lighter mahogany color than those of their congeners, the Ccchin-Chinas, but are equally large and as good in flavor. It is stated in the Massachusetts Ploughman, that Mr. Phillips, of Marshfield, had a pullet of this breed, which laid 120 eggs in one hundred and twenty-five days; then stopped six days; recommenced, and laid 16 eggs more; ceased laying four days, and then continued to lay again.

The chickens are said to be quite uniform in size, healthy, hardy, of rapid growth, early maturity, tenderfleshed, and of excellent flavor. In their present form 
and character, they are well adapted for caponizing, by which means they, undoubtedly, would attain an extraordinary large size.

The Plymouth Rock Fowl.-This is the name of a mongrel breed of some notoriety, lately produced by Dr. J. C. Bennett, of Plymouth, Massachusetts, which he describes in the Boston Cultivator, (of Aug. 25, 1849 ,) in the following words :-

"I have given this name to a very extra breed of fowls, which I produced by crossing a cockerel [?] of Baylies' importation of Cochin-China, with a hen, a cross between the fawn-colored Dorking, the great Malay, and the wild India. Her weight is six pounds and seven ounces. The Plymouth Rock fowl, then, is in reality, one half Cochin-China, one fourth fawncolored Dorking, one eighth great Malay, and one eighth wild India-having five primitive bloods, Shanghae, Malay, game, Turkish, and India, traceable by referring to the history of those breeds and their crosses respectively. There are several of this breed, (the Plymouth Rock, in Plymouth, from my original stock, belonging to Messrs. Perkins, Drew, Harlow, and myself, that are now a little over one year old ; the cockerels [?] measure from thirty-two to thirty-five inches high, and weight about ten pounds, and the pullets from six and a half to seven pounds each, forming, in my opinion, the best cross that has ever been produced.

"The pullets commenced laying when five months old, proving themselves very superior layers. Their eggs are of medium size, rich, and reddish-yellow in color. Their plumage is rich and variegated; the cockerels, usually red or speckled, and the pullets darkish-brown. They are very fine fleshed, and easily fit for the table. Their legs are very large, and usually blue or green, but occasionally yellow or white, generally having five toes upon each foot. Some have their legs feathered, but this is not usual. They have large and single combs and wattles, large dewlaps, [?] rather short tails, and small wings, in proportion to their bodies. They are domestic, and not so destruo- 
tive to gardens as smaller fowls. There is the same uniformity in size and general appearance, at the same age of the chickens, as in those of the pure bloods or primary races.

"The demand for this breed has exceeded all others during this season, and they have been sent into most of the New-England States and Western New York. And all, who may hereafter purchase from persons who have been supplied by myself, or either of the gentlemen above-named, may rely on the fowls being genuine and of pure blood. I never sell to the same individual a cockerel and pullet of the same parentage, so they need not fear that the breed will be deteriorated by ' close' breeding; nor do I sell at any price, for breeders, any but those of the very first quality. This is the only way in which breeds can be retained in their purity and excellence."

How far the above doctrine corresponds with the principles advocated in this humble little treatise, the candid and intelligent reader can judge, But, should these fowls be "bred in the line ;" that is, uncrossed with any other race, before the lapse of many years, their progeny will revert to the type of one or other of the original parents, or they will cease to breed of themselves at all. They are undoubtedly a valuable fowl for some purposes, and if judiciously crossed, alternately, year after year, with pure-bred Dorkings, game fowls, and the great Malays, their value and utility would probably be maintained or enhanced.

The Jersey-Blue Fowl. - This is another large mongrel of a bluish cast, probably made up of crosses of the great Malay, jago, Javanese, or other cognate breeds, and some of our native varieties. Their legs are long, their thighs large, and their flesh less savory than that of the Dorking, the Bucks-County or the Dominique fowl ; neither are they particularly remarkable for hardiness nor for laying.

They are produced in considerable abundance in 
New Jersey, and usually are found in the Philadelphia and New-York markets.

The Ostrich Fowl.-This variety is said to have originated in Bucks county, Pennsylvania, and hence is sometimes called the "Bucks-County breed." The color of the cock, as described by Mr. Bement, is a dark blue-black, with the ends of his feathers tipped with white; wings tinged with a bright yellow, or gold color; hackles dark, glossy blue ; rose or double comb, and wattles large; bold, lively carriage, and a stately walk.

The hens do not differ much from the cock in color, and are similar in form, being deep, short, plump, and thick-set in body; legs short, of a dark color and medium size; they have high, single, serrated combs, generally falling over on one side; wattles large. They are esteemed good layers, their eggs weighing $4_{2}^{1}$ ounces ; and for a large breed, they are good sitters as well as good mothers; the eggs large and nutritious ; the flesh, unlike that of the Malay, white, firm, tender, and fine-flavored.*

The Booby Fowl.-This is a large breed, doubtless of Asiatic origin, procured by Dr. R. Kitridge, of Portsmouth, New Hampshire, from Montgomery county, Pennsylvania. Their color is a black ground, spotted all over with white ; the legs, black, and general shape like that of a turkey. The cocks, when full grown, are represented to weigh 9 or $10 \mathrm{lbs}$., and the hens 7 or $8 \mathrm{lbs}$. They are said to be prolific layers, and not inclined to sit like the common varieties; sometimes laying forty or fifty eggs before they become broody. Some of their eggs weigh over $3_{2}^{1}$ ounces each, and measure three inches in circumference.

The Bucks-County Fowl.-Here is another mongrel monstrosity, first brought into notice in Bucks county, Pennsylvania, and has little to recommend it except great size, and a few large, well-flavored eggs. The 
hens are enormous eaters, poor layers, and miserable sitters, seldom laying more than ten or twelve at a litter. They are only profitable to breed from, should the race not run out, for making capons which are sometimes sold in the Philadelphia market for $\$ 5$ to $\$ 10$ per pair.

In corroboration of the above opinion, I insert the following extract from the American Agriculturist, written by L. F. Allen, of Black Rock, a practical farmer, and late President of the New-York State Agricultural Society :-

"The Bucks-County breed has received some celebrity in the neighborhood of Philadelphia as a valuable variety of fowl, principally on account of its enormous size. I have seen many specimens of this fowl, paid some attention to its habits, and learned from those who have tried them their principal merits. It is a large bird, weighing, at maturity, 8 and even $10 \mathrm{lbs}$., rather thinly feathered, of various colors from grey to black, and frequently speckled, black, and white. They are coarse in their legs, tall and bony, and have evidently a cross of the Malay in their composition. They are but moderate layers; their eggs are very large and good. They are bad sitters, frequently breaking their eggs, on account of their great weight and size, by crushing them ; they are not hardy, and on the whole, will not compare with the common dunghill fowl for ordinary uses. They do not breed equally in size and appearance, showing them, evidently, to be a cross from other breeds; but from what they are derived, other than the Malay, it is difficult to say. A gentleman of my acquaintance, who is very curious as well as nice in the selection of his fowls, tried them effectually for his poultry yard, and they disappointed him. He then crossed them with the game breed, and has succeeded finely, the cross being reduced in size, fuller feathered, hardier, and better layers, with an excellent carcass, and finer flesh. As a fancy fowl, or to make up a variety, they are very well, but they can 
never become of great utility, except to cross with the common or the game fowl, to the farmer."

The Dominique, or Dominica Fowl.This is the name of a beautiful variety, very common, at present, in the New-York markets, and is highly esteemed for its laying and breeding qualities, as well as for the excellent flavor of its flesh and eggs. Both the males and the females are of a medium size, rather longbodied, having yellow -legs and feet, single or double combs, and with or without copplecrowns. Their general plumage is of a light-grey color, each feather barred crosswise by bands of a darker shade, which gives them a beautiful pheasant-like appearance, as they are paraded in the farmyard, or confined in a crate. The hackles on the necks and backs of the cocks are often variegated with gold yellow, or reddish-brown.

The Blue Dun Fowl.-This breed, at present in vogue in Dorsetshire, England, is under the average size, and rather slenderly made, of a soft and pleasing bluish-dun color, the neck being darker, with high, single, deeply-serrated combs. The cock is of the same color as the hen, but has in addition some handsome dark stripes in the long feathers of the tail, and sometimes a few golden, and even scarlet marks on the wings, which, by the contrast, give the bird a very exotic look.

The blue duns are represented as exceedingly familiar, impudent, and pugnacious; so much so, that it is suspected, also from their shape, they have a dash of game blood in their veins.

The hens are good layers, wanting to sit after producing a moderate number of eggs, and proving attentive and careful rearers of their own chickens, but rather savage to those of other hens. The eggs are small and short, tapering slightly at one end, and are perfectly white.

The hackles of the cock are always in great request, in England, for making artificial flies for fishing. If kept perfectly unmixed with any other fowl, one 
will seldom obtain more than half the number of the proper "blue duns," the rest being either black or white. The chickens on the latter color, however, are afterwards sprinkled with dun feathers. Perhaps the original sort may have been either black or white, as it is known that animals will, after many cross-breedings, "cry back."

\section{ANOMALOUS FOWLS.}

Anomalies have been called "finger points that point the way to unsuspected truths." Hence the strange irregularities which we often meet with in our domestic fowls better deserve the attention of naturalists than any favor of poultry keepers. They may safely be pronounced worthless as a stock, and have a more appropriate place in the menagerie or museum than in the poultry yard or lawn. Just as well might the farmer propagate "Manx cats," well known for the peculiarity of having no tails, the "woolly horses," (caballos chinos,) of Mexico, or the "wingless birds" of New Zealand, as "frizzled," "rumpless," or "negro" fowls.

Among the monstrosities of the domestic fowl, which are particularly curious, and worthy of the attention of the student of nature, may be mentioned the "rumkin," or tailless cock, (Gallus ecaudatus,) believed at present to be found wild in the island of Ceylon; and the "silky" and "negro", fowls, with white silky plumage, and with skin, combs, and bones which areblack.

\section{RANGE AND DOMESTIC ACCOMODATION OF FOWLS.}

Whatever number or breed of fowls one may have selected for keeping, provision must be made for their comfort and safety. Those attached to houses in the country, lead, in many respects, a happy life. They have good air and plenty of room, and generally with no lack of food. They wander about the farmyard, the orchard, and the lawn, visit the adjacent gardens 
and fields, travel over the pastures, through the highways or lanes, troop around the barn, and enjoy total freedom. To the advantage of pure air, they usually have that of pure water, and the opportunity of varying their diet by picking up insects and their larvæ; and a store of pebbles, gravel, old mortar, and other calcareous matter, which they require, is always at their command. So far, they lead a comfortable and natural life; but how are they housed at night? In many instances, in a proper and well-built poultry house, with perches judiciously arranged, with boxes lined with straw for the laying and sitting hens; but often in places utterly unfitted for them. For instance, numerous flocks of hens will be lodged under the roof of some large, open shed, above the cattle, wagons, or carts, which receive an abundance of their droppings; others take shelter in the barns, stables, cider mill, pig pen, out-houses, \&c., while not a few may be found roosting on the branches of some favorite tree. This want of order cannot be ton strongly condemned, as hens, having no proper laying places, select such situations as chance may offer them, not unfrequently in obscure places of concealment, so that their eggs are devoured by vermin or are lost.

Those who intend to rear fowls, should have a distinct yard, with a warm aspect, well fenced, secure from vermin and thieves, sufficiently inclined to be always dry, and supplied with gravel, old mortar, (not quick lime,) or chalk, soot, brick dust, and with sand or ashes for the fuwls to bask or roll in. If possible, a stream of running water should pass through the yard; but if this cannot be done, a trough filled with fresh water every morning may be substituted. A want of water, of which all kinds of poultry are fond, produces constipation of the bowels and inflammatory diseases. A contiguous field or pasture, however, whenever it can be had, would, in all cases, he preferred.

A fowl house should be dry, well roofed, and fronting the east or south; and if practicable, in a cold climate, it should be provided with a stove, or some other means 
for heating, warmth being very conducive to health and laying, though extreme heat has the contrary effect. The dormitory, or roost, should be well ventilated by means of two lattice windows, at opposite ends of the building; and it would be desirable to have one or more apertures through the roof for the escape of foul air. The sitting apartment, also, should be well ventilated by means of a large lattice window, in the side of the house, and holes through the ceiling or roof. If kept moderately dark, it will contribute to the quietude of the hens, and thus favor the process of incubation. The sitting room should be provided with boxes or troughs, well supplied with fresh water and proper food for the hens, during the hatching period, from which they can partake at all times, at will. The laying room, in winter, should have similar boxes or troughs, containing old mortar, broken oyster shells, soot, brick dust, gravel, and ashes, as well as a liberal supply of proper drink and food. The perches, or roosting poles, should be so arranged that one row of fowls should not rest directly above another. They should be so constructed as to enable the fowls to ascend and descend by means of ladders, or steps, without making much use of their wings; for, heavy fowls fly up to their roosts with difficulty, and often injure themselves by descending, as they alight heavily upon the ground.

The following cut represents a hen house, in perspective, 20 feet long, 12 feet wide, 7 feet high to the eaves, with a roof having a 7 -foot pitch, a chimney top, a ventilator on the peak, twelve feet in length and one foot or more in height, and openings in the gable ends for the admission of fresh air. In the easterly end, there are two doors, one leading into the laying apartment and loft, and the other into the hatching room. In the same end there is also a wooden shutter, or blind, which may be opened, whenever necessary, to let air or light into the roost. In the back, or northerly -side, there is a large lattice window, three feet above the floor or ground, 4 by 12 feet, for the purpose of affording fresh air to the sitting hens. In the front, or 
southerly side, there is a large glazed window, 4 by 12 feet, and another in the southerly side of the roof, of a corresponding size, designed to admit the light and heat of the sun, in cold weather, to stimulate the laying hens. In the southerly side, there are also two small apertures three feet above the floor or ground, for the ingress and egress of the fowls. These openings may be provided with sliding shutters, as well as with "lighting boards," inside and out, and may be guarded by

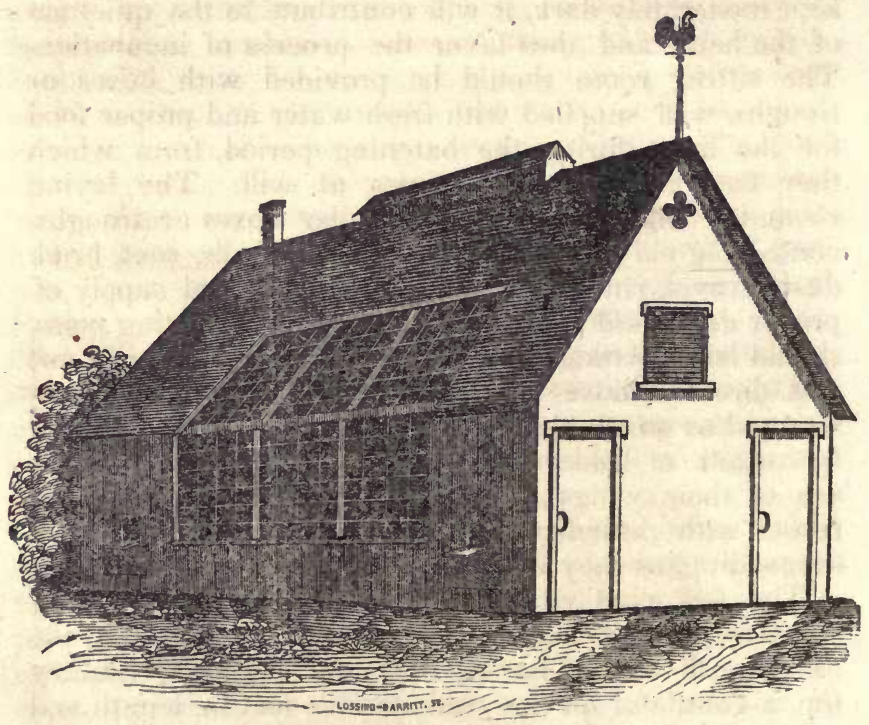

PERSPECTIVE VIEW OF A HEN HOUSE.

sheets of tin, nailed on below them, to prevent the intrusion of rats, weasels, or skunks.

The building may be constructed of wood or other materials, and in such style, or order of architecture, as may suit one's taste, only preserving the internal arrangements and proportions, in reference to breadth and height. As a general rule, as regards the length of the building, each hen, irrespective of the cocks, may be allowed a foot. 
In the ground plan, $L$ denotes the laying apartment ; $H$, the hatching room, each 6 by 20 feet; $n, n, \& \cdot c$., nest boxes for laying, 14 by 14 inches, and 10 inches deep; $0,0, \& c$., nest boxes for the sitting hens, of the

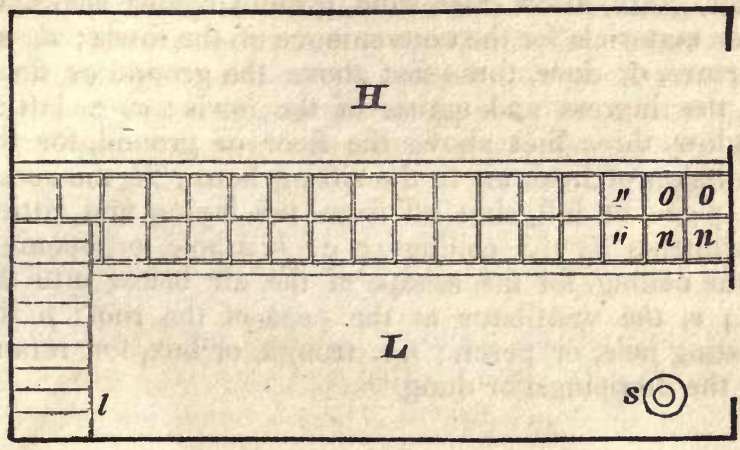

GROUND PLAN.

same size; $l$, a ladder, or steps, leading into the loft ; and $s$, a stove for warming the apartment, if desirable, when the weather is cold.

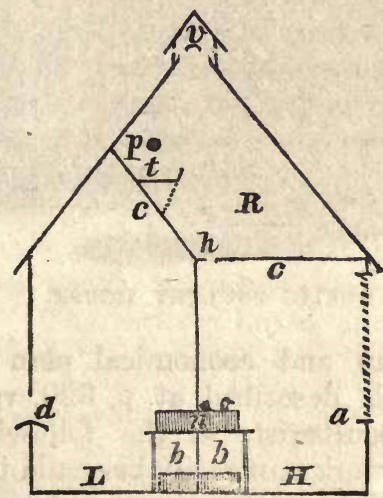

TRANSVERSE SECTION.

The transverse, or cross section, shows the building, from the bottom to the top, with the internal arrange- 
ments. $L$, denotes the laying apartment, and $H$, the hatching room, divided in the middle by a partition; $n$, the nest boxes, resting on tables, three feet above the floor or ground; $b, b$, boxes, or troughs, containing water, grain, brick dust, sand, ground oyster shells, or other materials for the convenience of the fowls ; $d$, an aperture, or door, three feet above the ground or floor, for the ingress and egress of the fowls; $a$, a lattice window, three feet above the floor or ground, for the admission of fresh air to the sitting hens; $R$, the roosting place, or loft, shut off from the laying and sitting apartments by the ceilings, $c, c ; h$, a hole, or opening, in the ceiling, for the escape of the air below into the loft; $v$, the ventilator at the peak of the roof; $p$, the roosting pole, or perch; $t$, a trough, or box, for retaining the droppings, or dung.

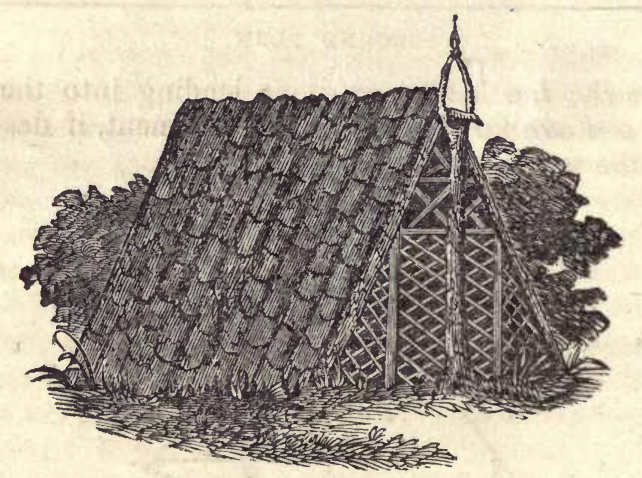

RUSTIC POULTRY HOUSE.

A very cheap and economical plan for a rustic poultry house is described at p. 320 , vol. viii. of the American Agriculturist, in the following words:"'This kind of work can easily be made by any person accustomed to the use of the saw and axe. All that is required is a little taste, having your plan well digested before commencing, so as to require no alterations. "For the construction of a piece of rustic work like 
the above figure, after selecting the situation, join four pieces of saplings in an oblong shape for the sills; confine them to the ground; erect at the middle of each of the two ends a forked post, of suitable height, in order to make the sides quite steep; join these with a ridge pole; rough-board it from the apex downward by the sills to the ground; then cover it with bark, roughly cut in pieces a foot square, laid on and confined in the same manner as ordinary shingles; fix the back end in the same way; and the front can be latticed with little poles with the bark on, arranged diamond fashion as shown in the sketch-a part to be made with hinges for a door."

Something after this style, placed on the bank of a lake or small stream, and half covered with climbing plants, would make a very pretty home for aquatic fowls.

The size of the building may vary according to the wants or taste of the owner. Towards the apex of the interior, rough roosting poles should run parallel with the sides of the house, so arranged that one set of fowls shall not perch directly above the others. Troughs or boxes should be placed under the poles, in order to catch the manure; and ladders, or steps, should be provided for the fowls to ascend and descend from their roost. Laying and sitting boxes may be placed at either side of the building, under the roofing on or just above the ground. They should be about 14 inches square, 10 inches deep, and concealed by bundles of corn stalks, wheat or rye straw, faggots, or pine boughs. The sitting boxes should be partly filled with wood ashes, pulverized charcoal, or soot. These are slow conductors of heat or cold, and when once warm, they will impart a proper temperature to the eggs during the absence of the hen. They will also ward off lice and other small vermin, as well as contribute to her health. Directly above the ashes, \&c., should be the nest. It may be made of finel:- 
chopped hay or straw, dried grass, or the leaves of trees.

Where the fowls have the range of an orchard, or a wide, dry, sandy pasture, or field, and are able to procure clean water, a good poultry house is all that is essential, though even then an enclosure, or yard, is desirable for the safety and better management of the young broods. It shoutld be open and airy, its soil dry, and sheltered from cold, wintry winds. A simple shed, moreover, should be erected in some suitable spot, in order to afford a screen to the fowls from the hot rays of the mid-day sun in summer, and from heavy rain storms and showers. Should there be no access to a pasture, orchard, or field, it is desirable that a portion of the yard should be laid down with turf; and the larger the yard, the better the accommodation.

Cleanliness, both in the poultry house and in the yard, is indispensable. Hence, all rubbish should be frequently swept out of both apartments, and the whole interior of the building white-washed, at least once a year. This, with as free a circulation as possible, and a proper space for the fowls to run in, is necessary to insure success; as in narrow and confined situations they never do so well. A sickly fowl ought to be separated immediately from the rest of the flock, and removed to some proper place, where it can remain in seclusion, not only because the disease may be contagious, but for the sake of safety and quietude of the fowl itself. Meagre, pining fowls are frequently objects of dislike, not only to the cock, which is apt to maltreat them, but even to the hens, that evir se their hostility and rancor to such a degree, that, snnetimes, they actually destroy their more unfortunate companions.

Every poultry house, as before observed, should be pro. vided with nest boxes, filled with hay or straw, \&c. If the plan be adopted, as recommended above, sliding boxes, or drawers, $n$, $o$, may be constructed twenty-eight inches long, fourteen inches wide, and ten inches deep, partitioned in the middle, so as to leave two compart- 
ments in each, fourteen inches square. On a level with the tables, each of which is designed to be two feet wide, and extending three feet above the ground, let there be cut through the partition between the laying and sitting apartments, an aperture the whole length of the rooms, ten inches high, or sufficiently large to receive these nest boxes, or drawers, so that one half of each will be in the laying room, and the other half in the sitting apartment, leaving a space nine or ten inches wide on each table for the hens to alight upon, and deliberately enter their nests, without breaking their eggs. When a hen is disposed to sit, the eggs may be put under her, and one or two nights after, the ends of the nest box may be shifted, so that she will be in the sitting room, where she may remain in perfect quietude till she hatches her brood. It is not at all required to have as many-nests as hens, as one might suppose, because they have not all occasion to occupy them at the same time; besides, they are so far from having a repugnance to lay in a common receptacle, that the sight of an egg stimulates them to lay. It is true, nevertheless, that the most secluded and darkened nests are those which the hens prefer, particularly when they are inclined to sit. T herefore, it would be advisable to set up around and between the sitting boxes, small bundles of corn stalks, faggots, or straw.

\section{SELECTION OF THE COCK.}

"The courage of the cock," says a modern writer on Ornamental Poultry, "is emblematic ; his gallantry admirable; his sense of discipline and subordination most exemplary. See how a good game cock, of two or three years' experience, will, in five minutes, restore order in an uproarious poultry yard. He does not use harsh means of coercion, when mild will suit the purpose. A look, a gesture, a deep, chuckling growl gives the hint that the turbulence is no longer to be permitted; and if these are not effectual, severe punishment is fearlessly administered. Nor is he aggressive to birds of other species. He allows the turkey to strut before 
his numerous dames, and the Guinea fowl to court his single mate, uninterrupted; but if the one presumes upon his superior weight, and the other on his cowardly tiltings from behind, he soon makes them smart for their rash presumption. His politeness to females is as marked as were Lord Chesterfield's attentions to old ladies, and much more unaffected. Nor does he merely act the agreeable dangler; when occasion requires, he is also the brave defender."

Much has been said relative to the selection of the cock; but all, in the end, come to one point. Whatever be the breed to which he belongs, he should exhibit the distinctive characters of that breed in full perfection. He should be bold, lively, clean made, with close, glossy plumage, a high head, short bill, and a bright eye; the color of his comb and wattles of a rich, shining vermilion; his crow should be clear, loud, shrill, and long-drawn; his breast, broad and fleshy; his thighs, muscular, firm, and covered with feathers; his insteps and ankle joints, stout ; his claws and spurs, strong, pointed, and slightly hooked; and lastly, he should carry himself with a proud, yet graceful air, and should be in perfect health.

Some cocks, especially when they are getting past their prime, say at the age of five or six years, are unsocial, vicious, and tyrannical. Instead of scraping up delicacies for the hens, and collecting them around him by a clucking note of invitation, the surly bird attacks them without provocation, tears their combs, and otherwise injures them. Let such a despot be dethroned from his proud eminence as soon as possible. On the other hand, a young cock, in his prime, will sometimes take a hatred to some particular hen, and treat her with marked antipathy, although he will conduct himself towards the rest of his coterie with a grace becoming to a gallant cavalier. The entire life of the domestic cock, however, shows that he is a most excellent family man, placing his whole care and study in providing all necessaries for his household. For this bird devotes whatever energy he has, the live-long day, 
to the good of his dependents, and is solicitous about nothing else than self.

\section{CHOICE OF HENS.}

THE hen is deservedly the acknowledged pattern of maternal love. When her passion of philoprogenitiveness is disappointed by the failure or separation of her own brood, she will either go on sitting, till her natural powers fail, or she will violently kidnap the young of another fowl, and insist upon adopting them. But all hens are not alike. They have their little whims and fancies, likes and dislikes, as capricious and unaccountable as those of other females. Some are gentle in their manners and disposition, others sanguinary ; some are lazy, others energetic almost to insanity. Some, by their very nature, are so mild and familiar, and so fond of the society of man, that they can scarcely be kept out of his dwelling; others seem to say, "Thank you, but I'd rather be left to myself."

The good qualities of hens, whether intended for laying or for breeding, are of no less importance to be attended to, than those of the cock. To gratify the curious reader, and show what the ancients thought of the points of a hen, we give a quaint passage from old Leonard Mascall. Following Columella and Stephanus, he says, "The signes of a good henne are these : to be of a tawnye colour, or of a russet, which are counted the cheefest colours, and those hennes nexte which hath the pens of their winges blackishe, not all blacke, but parte. As for the gray and the white hens, they are nothing so profitable. The henne with a tuft of feathers on her head is reasonable good; and the low featherde henne also. Their heads oughte not to be great and their tails ought to be in a meane, and her brest large, and her body deepe and long, for the greatest hennes of body, are not the aptest hennes to lay, nor yet for that purpose so naturale. As for those hennes which have hinder clawes, they will commonly breake their egges in sitting thereon, and they sit not so surely as others, and will ofttimes eat their egges. As for those hennes which doe call or crowe lyke the cocke, 
or doth creke and scrape to help the same, ye shall pluck off the greatest fethers of her wings and give her millet-wheat to eat." To this I will add, they should be of middling size, of robust constitution, with bright eyes, pendent combs, yellow or bluish legs and feet, and not over three or four years old. As regards the color of hens, except for appearance' sake, it is quite immaterial, unless we discard white on the ground that they are less hardy, and are in an abnormal state.

\section{PAIRING.}

W ITH good management, peace, and plenty, just before they are full-grown, the combs of both the young cocks and pullets will be observed to become of a more brilliant red; the former will crow more lustily; and the pullets will grow animated, restless, and full of busy importance, as if a new idea had lately broke in upon their minds. By-and-by, they will commence prating and cackling, and in a few days the delighted pullet will lay her first egg. And when, time after time, this first instalment is followed by similar deposits, she thinks herself, and is thought by her amateur owner, a perfect paragon. Such are the pleasures of productiveness.

\section{RELATIVE NUMBER OF HENS TO BE ALLOTTED TO EACH COOK.}

IN order to keep fowls with advantage, attention must be paid to the relative number of cocks and hens composing the flock. On this point, there is some differ. ence of opinion. M. Parmentier considers that one cock is sufficient for twenty hens, which, in France, perhaps, may be the case, but not in the cold and variable climate of many parts of the United States. Indeed, it has been found by experience, that if a cock be placed over a numerous flock of hens, the chickens produced are feeble, and the breed soon degenerates, or runs out. The old breeders of game fowls allowed only three hens to one cock; and where renovation of a breed is required, this proportion, it is thought, should not be exceeded.

As a general rule, from eight to twelve hens may be 
assigned to one cock, but no more; nor, indeed, even so many, if the fowls are kept in a confined yard, where the depressing influence of captivity will be more or less experienced. In a cold or humid climate, perhaps, this number is the best; but in a warm, dry climate, or where the fowls are healthy and have a free range, a greater number may safely be allowed.

When there are two or more cucks of the same age, a little management will be required to prevent them from fighting, which it will be almost impossible to avoid; but one cock may be brought up under another, each, in turn, gaining the ascendency over the male portion of the successive broods. For instance, a stock of fowls, intended to be increased, may consist of twelve hens, with a single cock at the head. Out of the young chickens hatched, a certain number will be selected for keeping. Among these should be the most promising and beautiful of the young cocks. When this new comer is a twelvemonth old, his progenitor will have arrived at the age of two years. In like manner, the number may again be added to, till the stock is sufficiently numerous. When the old cock is past his fourth year, however, it will be advisable, generally speaking, to get rid of him; as he then becomes lazy, violent in temper, and excessively jealous. Should it be deemed necessary to procure a new cock, a young bird should be selected, and introduced to the hens at the period of moulting, when his older rival will take but little notice of him, and ultimately become reconciled to him by the time that the laying season commences; and, during the interim, he will ingratiate himself with a certain number of the hens, which will appreciate his marked politeness, and acknowledge him as their brave defender.

Where numerous fowls are kept, it has generally been observed that each cock has his own female train, which follow him, and is always at his call; and that they are divided into coteries, or groups, and have each their favorite places of resort; but should a strange cock make a sudden appearance on the premises, he will have many a hard fight before he can establish 
himself, either in the character of a conqueror, or a defeated champion.

\section{ON THE LAYING PROPENSITIES OF HENS.}

THE act of laying is not voluntary on the part of a hen, but is dependent upon her age, constitution, and diet. If she be young, healthy, and well-fed, lay she must; if she be aged and half-starved, lay she cannot. All that is left to her own choice is, where she shall deposit her egg, and she is sometimes so completely taken by surprise, as not to have her own way even at that. The poultry keeper, therefore, has only to decide which is the more convenient-that his hens should lay here and there, as it may happen, about his premises, or in certain determinate places, indicated to the hens by nest eggs. Yet it is quite a mistake to suppose that the presence of a nest egg causes a hen to sit earlier than she otherwise would. The sight of twenty nest eggs will not bring on the hatching fever; and when it does come, the hen will take to the empty nest, if there be nothing else for her to incubate. Any one, whose hens have from accident been deprived of a male companion, cannot be ignorant of the fact, that they have not done so well till the loss has been supplied. During the interregnum matters get all wrong. The poor deserted creatures wander about dispirited, like soldiers without a general. It belongs to their very nature to be controlled and marshalled by one of the stronger sex, who is a kind, though a strict master, and a considerate though stern disciplinarian.

\section{QUALITIES AND SEX OF EGGS.}

To every hen belongs an individual peculiarity in the form, color, and size of the egg she lays, which never changes during her whole lifetime, so long as she remains in health, and which is as well known to those who are in the habit of taking her produce, as the handwriting of their nearest acquaintance. Some hens lay smooth cream-colored eggs, others rough, chalky, granulated ones. Then, there is the buff, the snowwhite, the spherical, the oval, the pear-shaped, and the emphatically egg-shaped egg. A farmer's wife who 
interests herself in the matter, will tell you with precision, in looking over her stores, "this egg was laid by such a hen," a favorite perhaps; "this one by such another;" and it would be possible that she should go on so throughout the whole flock of poultry. Of course, the greater the number kept, the greater becomes the difficulty in learning the precise marks of each. If four dozen eggs, laid by no more than four different hens, were put at random on a table, the chances are that it would be as easy to sort them as the four suits in a pack of cards.

It has been copied and re-copied from quarto to octavo, through duodecimo and pamphlet, that "small, round eggs produce female, and long pointed ones male chicks." Now I assert that the hen which lays one round egg, will continue to lay all her eggs round; and the hen that lays one oblong, will lay all oblong. Consequently, one hen would be the unceasing mother of cocks, another must remain the perpetual producer of pullets; which is absurd, as daily experience proves. Every poultry maid knows that when a hen steals a nest, and hatches her own eggs only, the brood she brings home contains a fair proportion of either sex.

There is nothing so instructive as a "case," whether in law, physic, or poultry-raising. Here is an experiment in point. An old lady, whose. fowls were all white, gave Mr. Dixon, of England, a small globular egg, as round as a ball, which was added to a clutch of speckled Dorkings. The result was, the due number of Dorkings, and one white cockerel, which he kept till it began to crow. It ought to have been a pullet, according to the old stereotyped rule.

Another supposed test is the position of the air bag at the blunt end of the shell. We are told that " if it be a little on one side, it will produce a hen; if this vacuity be exactly in the centre, it will produce a cock." But, take a basket of eggs, examine them as directed, by holding them between your eye and a candle, and you will find very few indeed in which you can say that the air bubble is exactly concentric with the axis of the egg. A cock ought thus to be, like 
Orid's black swan, a rare bird. But in many broods, the cockerels bear a proportion of at least one third, sometimes two thirds; especially in those hatched during winter or in unfavorable seasons; the immediate cause being, doubtless, that the eggs producing the robuster sex possess a stronger vitality; the more remote cause being the same wise law of Providence, through which, in the human race, more males are born into the world than females, to meet the wear and tear of war, labor, and accident.

In short, the "bubble theory" is properly described by its name; and, it is believed, there is no known means of determining beforehand the sex of fowls, except, perhaps, that cocks may be more likely to issue from large eggs, and hens from small ones. Knowing, however, that the eggs of each hen may be recognised, we have thus the means of propagating from those parents the race of which we deem most desirable to continue.

Horace, Columella, and Pliny had the same notions respecting the shape of eggs as are current now, but they applied them to eating, rather than hatching purposes. The long eggs were better-tasted, according to them, because they contained cocks. Those which are laid round, according to Pliny, produce a female; the rest, a male.

\section{Again, Doctor Philip Francis quaintly says, after Horace-}

"Long be your eggs, far sweeter than the round, Cock eggs they are, more nourishing and sound."

The popular notion now is, that eggs with buff and brownish shells have a higher flavor, and are more nutritious, than those which the shells are white. Be this as it may, the finest are those having small, brightorange yolks, like those of the Bantam and game breeds; but large eggs, like those of the Polands and Spanish fowls, often have pale yolks, with but little flavor. Aristotle's opinion is exactly the reverse of that of the Romans. He says that "long and sharp eggs are females, but that those that are spherical, and have a 
convexity close to the sharp end are males." One rule is just as good as the other; that is, good for nothing. When any one will produce a brood consisting entirely of pullets hatched from eggs selected with that view, then, and not till then, will it be admitted that there exist practical criteria of judging beforehand of the sex of an egg.

\section{PRESERVATION OF EGGS FOR COOKERY.}

"Preserved eggs," says Cobbet, " are things to run from not after." Perhaps so, perhaps not, as the case may be. At any rate, many articles of cookery, which cannot be made without eggs, are not things to run from ; and, therefore, preserved eggs must be had, unless you choose to disappoint the little folks of their Christmas plum pudding, and the ladies of their " egg-nog." A large proportion of the eggs brought to market during winter, are certainly displeasing enough, quite uneatable as, eggs, but only not offensive to the smell. They are saved from putrefaction by immersion in lime water, to which salt is added by some housewives. When wanted, they are fished out of the tub, wiped, and sometimes rubbed with a little sand to give a fresh-looking roughness to the shell. Cooks say they answer their purpose; but it is assuredly worth while to try for something better.

The three following are cheap and easy modes of preserving eggs for culinary use :-

Recipe, No. 1.-Pack the eggs to be preserved in an upright water-tight cask, with their small ends downwards. Take eight quarts of unslaked lime, one half pound of common salt, two ounces of cream tartar; mix in water so as to bear up an egg with its top just above the surface; pour the mixture into the cask con. taining the eggs, and they will keep sound and good for two years.

Recipe, No. 2.-Pack the eggs to be preserved in an upright earthen vessel or tub, with their small ends downwards. Procure, melt, and strain a quantity of cheap tallow or lard, and pour, while warm, not hot, 
over the eggs in the jar till they are completely covered. When all is cold and firm, set the vessel in a cool, dry place, till required for use. After the eggs are taken out, the grease need not be wasted, as it will serve for making soap, or many other household purposes.

Recipe, No. 3.-Pack the eggs to be preserved in common salt, with the small ends downwards, and they will keep tolerably good for eight or nine months.

It has been stated by Réaumur, who is a high authority, that clear or unfertile egors will keep good longer than those that would be productive; but it is doubtful whether the difference is so great as to make it worth while keeping the hens in a melancholy widowhood on this account.

\section{PRESERVATION OF EGGS FOR HATCHING.}

EGGs for hatching should be as fresh as possible; if laid the very same day, so much the better. This is not always possible when a particular stock is required to be increased; but if a numerous and healthy brood is all that is wanted, the most recent eggs should be selected. Some books tell us that eggs to be hatched should not be more than a fortnight, others say not more than a month old. It is difficult to fix the exact term during which the vitality of an egg remains undistinguished; it undoubtedly varies from the very first, according to the vigor of the parents of the inclosed germ, and fades away gradually till the final moment of non-existence. But long before that moment, the principle of life becomes so feeble, as to be almost unavailable for practical purposes. The chicks in stale eggs have not sufficient strength to extricate themselves from the shell; if assisted, the yolk is found to be only partially absorbed into the abdomen, or not at all; they are too faint to stand, the muscles of the neck are unable to lift their heads, much less to peck; and although they may sometimes be saved by extreme care, their usual fate is to be trampled to death by their mother, if they do not expire almost as soon as they begin to draw their breath. Thick- 
shelled eggs, like those of geese, Guinea fowl, \&c., will retain life longer than thin-shelled ones, as those of hens and ducks.

In the meanwhile, air should be excluded from the eggs as much as possible; it is best to set them on end, and not to suffer them to lie and roll on the side. Dry sand or hard-wood sawdust, (not pine, on account of the turpentine,) is the best packing. But when choice eggs are expected, it is more prudent to have a hen waiting for them than to let them wait for her. A good sitter may be amused for two or three weeks with a few, addled eggs, and so be ready to take charge of those of value immediately upon their arrival.

Eggs sent any distance to be hatched, should be tightly inclosed in a cork or wooden box, and arranged so as neither to touch each other, nor the sides of the box. Mr. Cantelo, in his little pamphlet, has recommended oats as a packing, and no doubt they form an excellent vehicle, taking little time to pack, filling all interstices, and moreover being useful at the journey's end. The eggs should be shaken as little as possible, for fear of rupturing the ligaments by which the yolk is suspended in the centre of the egg, and mixing the true strata of albumen surrounding it and letting the yolk loose. Nor should they be suffered to come in contact with any greasy substance that would close the pores of the shell, so as to exclude the air from the chick.

\section{THE STRUCTURE OF EGGS.}

Upon opening, after death, the body of a laying hen, a cluster of eggs, or rather the rudiments of eggs, may be observed, from twenty to a hundred or more, from the size of a pin's head to that of a boy's marble, according to the different stages of their growth. This batch of rudimental eggs, or egg cluster, is termed by anatomists the ovarium, and the rudimental eggs themselves are called ova.

It is necessary to observe here, that a rudimental egg, or ovum, has no shell nor white, which are acquired in 
an after stage of its progress, but consists wholly of yolk, on whose surface the germ of the future chick lies; both the yolk and the germ being wrapped round with a very thin membrane.

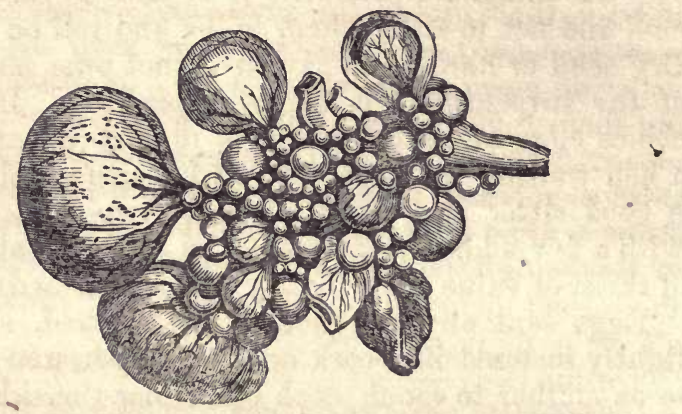

EGG CLUSTER, OR OVARIUM.

When the rudimental egg, still attached to the ovarium, becomes larger and larger, and arrives at a certain size, either its own weight, or some other efficient cause, detaches it from the cluster, and makes it fall into a sort of funnel, leading to a pipe which anatomists term the oviduct.

Here the yolk of the rudimental egg, hitherto irnperfectly formed, puts on its mature appearance of a thick yellow fluid, while the rudimental chick or embryo, lying on the surface, at the point opposite that by which it had been attached to the ovarium, is white, and somewhat paste like.

The white, or albumen, of the egg now beosmes diffused around the yolk, being secreted from the blood vessels of the egg pipe, or oviduct, in the form of a thin, glairy fluid; and it is prevented from mixing with the yolk and the embryo chick, by the thin membrane which surrounded them before they were detached from the egg cluster, while it is strengthened by a second and stronger membrane, formed around the first, immediately after falling into the 
oviduct. It is proper to mention, also, that this second membrane, enveloping the yolk and the germ of the chick, is thickest at the two ends, having what may be called bulgings, termed chalazes by anatomists; these bulgings of the second membrane pass quite through the white at the ends, and being thus as it were embedded in the white, they keep the inclosed yolk and germ somewhat in a fixed position, preventing them from rolling about within the egg when it is moved. The white of the egg being thus formed, a third membrane, or rather a double membrane, much stronger than either of the first two, is formed around it, becoming attached to the bulgings, or chalazes, of the second membrane, and tending still more to keep all the parts in their relative positions.

During the progress of these several formations, the egg gradually advances about half way along the oviduct. It is still, however, destitute of the shell, which begins to be formed by a process similar to the formation of the shell of a snail, as soon as the outer layer of the third membrane has been completed. When the shell is fully formed, the egg continues to advance along the oviduct, till the hen goes to her nest and lays it.

Reckoning, then, from the shell inwards, there are six different envelopes, one of which only could be detected before the descent of the egg into the oviduct:-

1. The shell. 2. The external layer of the membrane lining the shell. 3. The internal layer of the same lining. 4. The white, composed of a thinner liquid on the outside, and a thicker and more yellowish liquid on the inside. 5. The bulgings, or chalaziferous membrane. 6 . The proper membrane.

One important part of the egg is the air bag, or folliculus aeris, of anatomists, placed at the larger end, between the shell and its lining membranes. According to Dr. Paris, it is about the size of the eye of a small bird in new-laid eggs, but is increased as much as ten times in the process of hatching. 
This air bag is of such great importance to the development of the chick, probably by supplying it with a limited atmosphere of oxygen, that if the blunt end of an egg be pierced with the point of the smallest needle the egg cannot be hatched, but perishes.

From the air bag being thus placed at the blunt end of the egg, important signs may be taken to distinguish the freshness of an egg ; for, as the air in the cell will not abstract heat from without, like a more solid substance, it is a usual practice to apply the tongur to the blunt end of an egg, and if it feels rather warm, it is stale, but if cold, it is fresh. This, however, is a much more uncertain test than the comparative size of the small circle seen by the transmitted light of a candle or otherwise, a small circle being a proof of freshness, and a large one of staleness.

The shell of an egg, chemically speaking, consists chiefly of carbonate of lime, similar to chalk, with a small quantity of phosphate of lime and animal mucus. When burnt, the animal matter and the carbonic acid gas of the carbonate of lime are separated, the first being reduced to ashes or animal charcoal, while the second is dissipated, leaving the decarbonised lime mixed with a little phosphate of lime.

The white of the egg, (albumen,) is without taste or smell, of a viscid, glairy consistence, readily dissolving in water, coagulable by acids, by spirits of wine, and by a temperature of $165^{\circ} \mathrm{F}$. If it has once been coagulated, it is no longer soluble either in cold or hot water, and acquires a slight insipid taste. Experiments show that it is composed of 80 parts of water, $15_{2}^{1}$ parts of albumen, and $4_{2}^{1}$ parts of mucus, besides giving traces of soda, benzoic acid, and sulphuretted hydrogen gas.

The yolk has an insipid, bland, oily taste, and when agitated with water, forms a milky emulsion. If it be long boiled, it becomes a granular, friable solid, yielding upon expression a yellow, insipid, fixed oil. It consists, chemically, of water, oil, albumen, and gela- 
tine. In proportion to the quantity of albumen, the egg boils hard.

The white of the egg is found to be a very feeble conductor of heat, retarding its escape and preventing its entrance to the yolk; a contrivance of Providential Wisdom, nol only to prevent speedy fermentation and corruption, sut as Dr. Paris remarks, to avert the fatal chills which might occur in hatching, when the mother hen leaves her eggs from time to time in search of food. Eels, tench, and other fish, which can live long out of water, secrete a similar viscid substance on the surface of their bodies, furnished to them, no doubt, for a similar purpose.

\section{BREEDING.}

THE breeding of the common fowl, with a view to improvement, like that of our domestic quadrupeds, may be said to be founded on nature's established law, that "like begets like." This, however, is only true in part, for there is a constant tendency to change, arising from a variety of causes; such as living in a different climate, or on a different kind of food. The management to which they are subject has, also, its influence. While these may be looked upon as the chief causes in operation, that produce this change, they are the means, at the same time, in connection with other causes, which are used to effect an improvement.

In order to perpetuate or improve an animal, there are two modes advocated and pursued by practical breeders. One is commonly called the "in-and-in system," and the other that of " crossing." As a general rule, the first-named system has a tendency, after a time, to deteriorate the breed, unless the utmost care is observed in selecting such animals as will be likely to unite in the offspring the qualities sought. From their progeny, again, must be selected only such animals as more. com letely exhibit those qualities, 
and so on from generation to generation, until the desired points are fully developed.

The importance of continuing this process for a number of successive generations is obvious, from the fact, that peculiar traits of character often disappear in the first, and reappear again in the second or third generation. A desirable property may be found in the parent, and inherited by only a part of the offspring, and the requisite point can only be uniformly developed by a careful selection through several consecutive generations. By this process, it is apparent that this system must be adopted; yet, at the same time, it is desirable to avoid too close alliances. Hence, it is considered better to breed more distant members of the same family together than those that are more nearly related. Thus in "breeding in the line," with a view of perpetuating a particular race of fowls, the Dorkings, for instance, the best birds of that breed should be selected, both males and females, and allow them to propagate in their utmost purity from one generation to another, changing from one family of Dorkings to another, as often as circumstances or necessity may require.

The system of " crossing" is founded on a principle just as secure, as regards care in selection, as that adopted in breeding in-and-in. For, it is well known that certain diseases are hereditary, none of which can be changed nor got rid of except by crossing. This system, therefore, requires great care in selection, as well as in management.

A fact respecting fowls, that has not been sufficiently regarded, but which goes far to prove their high antiquity, is the permanent character of the different varieties. Before attending much to the subject, some people fancy that crossings and intermixtures may be infinitely multiplied and continued, restricted only by the algebric law of permutation and combination; and such is the current opinion among many who are accustomed to see the diverse colors and appearance of 
fowls promiscuously bred in a farmyard. But the observant breeder knows that such is not the case. Nothing is more difficult than to establish a permanent intermediate race even between nearly-allied varieties. In a few generations, the character reverts to that of one or other of the parents; the peculiarities of an old type reappear, and the new cross, on which the fancier was beginning to glorify himself, vanishes. The more heterogeneous are the parents, the more sudden is the return to old established characters. The hybrid progeny are either utterly barren, or their young exhibit the likeness of their grandfather or grandmother, not of their actual parents.

As a general rule, domestio animals of all kinds, which have been produced by crossing, are the most profitable both for meat and milk. But in all cases, where a cross is attempted, with the object of improving a breed, be sure to have pure blood on one side. In raising fowls, then, for laying, for the fatting coop, or for the market, a convenient number of hens, either pure bred or mongrels, may be obtained, which possess such properties as may be desirable, as regards size, shape, color of the skin, tenderness of the flesh, size and flavor of the eggs, hardiness, aptitude to lay, sit, and rear their young, together with a requisite number of pure-blooded cocks of such a breed as is known from experience to be fixed in its character, and whose progeny have proved profitable to the owner. Allow these to run promiscuously together, and breed from year to year, for four or five seasons, killing off, or separating all the chickens as fast as they arrive at maturity. In the meantime, however, should any of the hens be lost from accident or disease, their places may he filled with others of a similar breed, or with the pullets of the first, or at farthest of the second cross. Should the cocks die before they arrive at the age of five years, or become quarrelsome in their disposition, or disabled in any way, they should be killed, and others of pure blood and of the same breed, placed in 
their stead. At the end of five years, the whole may be killed, or otherwise disposed of, when you may commence anew, with fresh young fowls.

In breeding "in-and-in" for the purpose of perpetuating any particular variety, the utmost care must be observed in selecting healthy birds, cocks as well as hens, of pure blood on both sides, and if possible, of distantly-related families, which have been kept separate from all other breeds from their infancy. By this means, the purity of a race may be maintained.

\section{INCUBATION.}

As in case of other birds, nature designs that every hen shall sit upon her own eggs, and hatch her own progeny; but the domestic fowl is in an artificial state, and deviations from the laws of nature are, therefore, to be expected. A wild hen will lay no more eggs than she can conveniently cover, and her periods for laying and for incubation will be fixed and regular. On the contrary, domestic hens lay many more eggs than they can cover. Some lay every day, or every other day, for nine months out of the twelve, and never or rarely evince a desire to incubate; while others manifest this desire, some at one period, and others at another period. Among a flock of hens, these diversities will show themselves, and advantage may be taken of them with benefit to their owner.

A hen prompted by instinct to the task of incubation, asks only for eggs suited to her size, be they those of her own production er not, (those even of a duck will be accepted,) a nest, and undisturbed solitude. At this juncture, she utters an instinctive cluck, ruffles her feathers, wanders about, searches obscure corners and recesses, and is evidently ill at ease. She is feverishly hot, impatient, and anxiously restless. In high-fed hens this instinctive desire comes on sooner than in such as are not supplied with food in abundance, and it may be induced by stimulating diet, a little raw liver or fresh meat, chopped small, potatoes mashed warm, with milk and Indian meal. Some farmers recommend a fomenta- 
tion of vinegar in which pepper has been steeped, to be applied to the under parts, as a means of inducing this desire; and others even advise that some of the feathers of the abdomen be plucked off, and the skin stung with nettles! Such means may induce fever, and a desire to cool the inflamed skin by applying it to cool substances, but not a genuine natural impulse to fulfil the great law of nature. Let them never be put into practice. They are barbarous and contemptible. By high feeding, some hens, especially of the Dorking breed, which, as sitters, take the pre-eminence over all other breeds, may be induced to sit in October, especially if they have moulted early. Advantage may be taken of this circumstance at the South, and chickens may be obtained fit for the table by Christmas-not, however, without great care and trouble. The incubation must take place, and the chickens be reared and fed, in a warm room, if necessary, kept at an equal temperature. Generally speak ing, spring chickens are more desirable, which should be hatched in January, so as to be ready for the market in the latter part of March, and through the months of April, May, and June. They require great care, but they return an ample profit.

The most usual time in which hens manifest a desire to incubate, extends from March to May or June, and at this season chickens may be reared without any extraordinary precautions.

When the determination to sit becomes fixed,-there is no need to indulge the first faint indications immediately-let her have the nest she has selected well cleaned and filled with fresh straw. The number of eggs to be given to her, will depend upon the season, and upon their and her own size. The wisest plan is not to be too greedy. The number of chickens hatched is often in inverse proportion to the number of eggs sat. I have known only three to be obtained from eighteen. Hens will, in general, well cover from eleven to thirteen eggs laid by themselves. A Bantam may be trusted with about half a dozen eggs of a large breed, such as the Spanish. A hen of the largest size, as a Dorking, will successfully hatch, at the most, five goose eggs. 
But if a hen is really determined to sit, it is useless, as well as cruel, to attempt to divert her from her object. The means usually prescribed are such as no humane person would willingly put in practice. If the season is too early to give a hope of rearing gallinaceous birds, the eggs of ducks or geese may generally be had; and the young may be brought up with a little pains-taking, as well as by their natural parent. And if it be required to retain the services of a hen for expected valuable eggs, she may be beguiled for a week or ten days with four or five old addled ones, till the choicer sort arrive.

Three weeks is the period of incubation of the common hen. Sometimes, however, when she does not sit close for the first day or two, or in early spring, it will be some hours longer; more frequently in our southern climate, when the hen is assiduous and the weather hot, the time will be a trifle shorter. But in cases of artificial incubation, where the eggs are uniformly kept at a temperature of from $101^{\circ}$ to $102^{\circ} \mathrm{F}$., the period is sometimes hastened forty-eight hours. The range of temperature, within which the eggs will hatch, varies from $95^{\circ}$ to $106^{\circ} \mathrm{F}$. Towards the close of incubation, the process may be suspended for one or two hours, or even for a longer period, according to the degree of extraneous heat which the eggs may derive from their situation, without fatal consequences to the embryo chick.

The growth of the chick in the egg has been so fully and so well described by many writers, from Aristotle down to Réaumur, that I need merely refer the reader to them. The observations of the latter, particularly, have appeared in almost every compilation that has been published on the subject; and I think it much better taste for common inquirers to betake themselves to such sources of information, illustrated as they are by good engravings, than to desire that a set of half-hatched eggs should be -broken to gratify their curiosity. A shattered and imperfectly-formed chick, struggling in vain in the fluid that ought to perfect its frame, till it sinks in a gradual and convulsive death, is a horrible 
spectacle, though on a small scale. To gratify the curious reader, I present below three cuts illustrating the first, middle, and last stages of incubation.

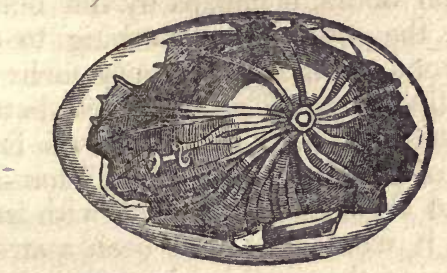

FIRST STAGE OF INCUBATION.

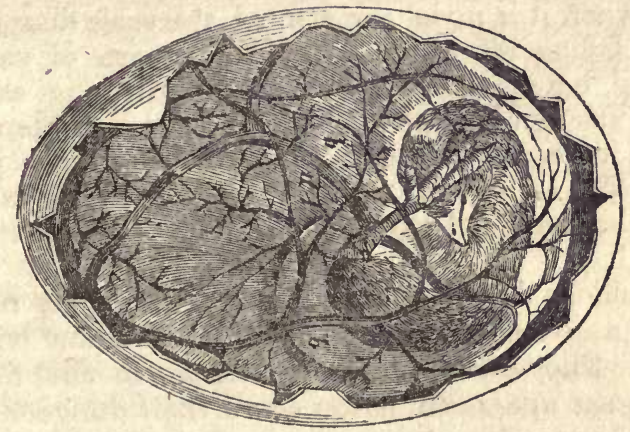

MIDDLE STAGE OF INCUBATION.

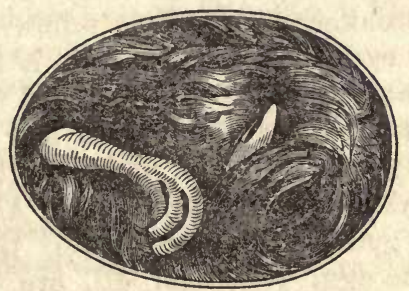

CHICK JUST BEFORE HATCHIN்G.

Shortly before the time of hatching arrives, the chickens may be heard to chirp and tap against the walls of their shell. Soon a slight fracture is perceived towards the upper end, caused by force from within. 
The fracture is continued around the top of the egg, which then opens like a lid, and the little bird struggles into daylight. The tapping which is heard, and which opens the prison doors, is caused by the bill of the included chick; the mother has nothing to do with its liberation, beyond casting the empty shells out of the nest. At the tip of the bill of every new-hatched chick, on the upper surface, a whitish scale will be observed, about the size of a pin's head, but much harder than the bill itself. Had the beak been tipped with iron to force the shell open, it would not have been a stronger proof of Creative Design than is this minute speck, which acts as so necessary an instrument. In a few days after birth, when it is no longer wanted, this scale disappears ; not by falling off, which would be a waste of valuable material, but by being absorbed and becoming serviceable in strengthening the bony structure, minute as the portion of earthy substance is. And yet some people direct, that as soon as the chick is hatched, this scale should be forced off with the finger nail, because it is injurious!

All chicks do not get out so easily, but may require a little assistance. The difficulty is, to know when to give it. They often succeed in making the first breach, but appear unable to batter down their dungeon walls any further. A rash attempt to help them by breaking the shell, particularly in a downward direction towards the smaller end, is often followed by a loss of blood, which can ill be spared. It is better to wait awhile and not interfere with any of them, till it is apparent that a part of the brood has been hatched some time, say twelve hours, and that the rest cannot succeed in making their appearance. After such wise delay, it will generally be found that the whole fluid contents of the egg, yolk and all, are taken up into the body of the chick, and that weakness alone has prevented its forcing itself out. The causes of such weakness are various ; sometimes insufficient warmth, from the hen having sat on too many eggs ; sometimes the original feebleness of the vital spark included in 
the egg, but most frequently staleness of the eggs employed for incubation. The chances of rearing such chicks are small, but if they get over the first twentyfour hours they may be considered as safe. But all the old wives' nostrums to recover them are to be discarded; the merest drop of ale may be a useful stimulant, but an intoxicated chick is as liable to sprawl about and have the breath trodden out of its body as a fainting one. Pepper corns, gin, rue, and fifty other ways of doctoring, are to be banished afar.

The only thing to be done, is to take the chicks from the hen till she is nestled at night, keeping them in the meanwhile as snug and warm as possible. If a clever, kind, gentle-handed little girl could get a crumb of bread down their throats, it would do no harm. Animal heat will be their greatest restorative. At night, let them be quietly slipped under their mother ; the next morning they will be either as brisk is the rest, or as "flat as pancakes."

Now I am on the subject of hatching, I may as well refer to the perplexity to which poultry keepers are sometimes subjected, when hens will sit, at seasons of the year at which there is little chance of bringing up chickens. Some advise the hens to be soaked in a pail of water, cold from the pump ; but if they have a mind to kill her, it is more cruel to do so by giving her fever and inflammation of the lungs, than by simply knocking her on the head. A less objectionable remedy, is the following:- "I have known one or two doses of jalap relieve them entirely from a desire to sit ; and in my opinion it is far better than the cold-water cure. I have known English fowls lay in three weeks afterwards."* But why not let the poor creatures obey their natural propensity? Or, surely, some neighbor would gladly exchange a laying hen for one that wanted to sit. Others, borrowing an ancient piece of barbarism, recommend a large feather to be thrust through the nostrils; that she may rush here and 
there in terror, and give up all thoughts of sitting. The wisest way is to guide, instead of thwarting the impulses of nature. Let your good hen indulge the instinct implanted in her by a Wiser Being than you ; give her a sitting of duck's eggs, and unless the winter or spring be extraordinarily severe, you must be a bungler if you do not rear them by the aid of bread crumbs, Indian meal, and a kitchen fire.

\section{ARTIFICIAL INCUBATION.}

The process of bringing the vitalised embryo of the egg through all its stages of development until the chick makes its exit from the shell, by the judicious administration and management of artificial heat, has long been practised in China and Egypt, nor have experiments both in our own country and France been unsuccessful; but whether the plan will ever become general, so that a supply of apparatus-hatched chickens may be in constant readiness to meet the public demarid, is very questionable. Our changeable climate is not favorable for the process on a large scale; the least change of temperature is fatal ; for it is indispens. able that an equable temperature of from $95^{\circ}$ to $106^{\circ} \mathrm{F}$. be maintained. At a higher or a lower temperature the development of the embryo cannot be perfected. Hence, although in Egypt, which enjoys a favorable atmospheric state for the accomplishment of the experiment, success in our climate is far from certain.

Let us be content, then, with our poultry yards and their feathered inmates as they are, and be grateful to Providence for the fowls of the air, which are peculiarly the pensioners upon our bounty.

The apparatus, latterly employed for this purpose, has been described 'under the names of eccaleobion, (literally the invoker of life,) polotokian, and hydroincubator. The former was an ingenious contrivance, for hatching chickens by means of heated air. It presented the appearance of an oblong box, nine feet in 
length, three feet in breadth, and three feet in height. It had no connexion with the walls against which it was placed, nor the table on which it stood; its regulating power was within. According to Mr. Bucknell, the English inventor and proprietor of this machine, which some years ago excited great attention, the eccaleobion possessed a perfect and absolute command over temperature from $300^{\circ} \mathrm{F}$. to that of cold water, so that any substance submitted to its influence was uniformly acted upon over its whole surface at any required intermediate degree within the above range, and such heat maintained unaltered without trouble or difficulty for any length of time. Hence, by means of this absolute and complete command over the temperature obtained by this machine, the impregnated egg of any bird, not stale, placed within its influence at the proper degree of warmth, at the expiration of its natural time, was elicited into life without the possibility of a failure, which is sometimes the case with eggs subjected to the caprice of their natural parent. During the public exhibition of this instrument thirty or forty thousand chickens, perhaps more, were stated to have been brought into existence by a single machine, which was constructed to contain two thousand eggs at a given time. These chickens, with proper attention and under suitable treatment, were said to grow as healthy and strong as those under a parent's care. Of course, artificial mothers, warmth, a dry soil, and proper buildings would be needed. What might not be expected from a multiplication of these machines, or their formation on a larger scale!

The polotokian, also, was a similar contrivance for hatching, by means of heated air, established in 1843, on an extensive scale, by Mr. E. Bayer, of Brooklyn, New York. He succeeded admirably well, as far as the producing of chickens was concerned, in the process of hatching, not losing over 20 to 25 per cent. of the eggs. The most congenial temperature at which the eggs were exposed, during the process, he found to be 
from $101^{\circ}$ to $102^{\circ} \mathrm{F}$. When uniformly kept in that degree of warmth, the period of incubation was generally hastened two days. The chickens arrived at maturity six weeks earlier than those hatched the natural way, but were more susceptible to the climate. Notwithstanding, they were sweeter, better-flavored, and more tender in their flesh, and commanded a higher price in market than other fowls, the business proved unprofitable, and was abandoned with disgust. Several other establishments were commenced about the same time, on Long Island and elsewhere, on the same plan, which terminated with similar results.

Mr. Cantelo, a year or two since, established in or near London, what he termed a "model poultry farm." In this institution, numbers of chickens, Guinea fowls, and ducks, have been raised by artificial heat most ingeniously applied by "top contact," so as to produce the same effect on the vitalised germ as the heat of the incubating hen. This heat has been proved by Mr. Cantelo to be as high as $106^{\circ} \mathrm{F}$. The eggs were in fact hatched under artificial incubators, which allow the inferior portion of the egg to remain cool until warmed by the inward circulation of the blood, as occurs in natural incubation, but not when eggs are placed in ovens or heated apartments. "The difference," says Mr. Cantelo, "between top-contact heat and that received from radiation as applied to hatching is this: by radiation, or oven heat, the eggs will be hours in arriving at the desired temperature, not only when first put to hatch, but at any time afterwards when they may have been allowed to get cool. The eggs, of course, will heat alike over their whole surface, and consequently evaporate equally from every part. On the contrary, heat applied in top contact penetrates almost instantly and revivifies the germ, and although a much higher temperature is used in this case in imitation of nature; that is $106^{\circ}$ instead of $98^{\circ}$, still, inasmuch as but a small surface is heated, the loss of moisture is much less than by a radiating heat. 
The fowl leaves her nest every day in search of food for twenty or thirty minutes; this must be imitated also, as the temporary loss of heat has the effect of causing the contents of the egg to diminish in bulk, and the vacuum is formed by a fresh supply, (of air,) drawn in for the nourishment of the germ. The eggs must be moved three times a-day, morning, noon, and night, which prevents the adhesion of any part of the fluid to the shell, and gives the small blood vessels better opportunity to spread around the surface of the egg. This is effected by nature; when the fowl leaves her nest or returns to it, she naturally disturbs the eggs, and also from any change she may make in her position while upon her nest."

Mr. Cantelo thus describes the hydro-incubator: "The form, or method considered by the inventor, as best calculated for the application of top-contact heat to eggs during incubation is that of a current of warm water flowing over an impermeable or water-proof cloth, beneath which the eggs are placed. This is effected on a large scale by pumps, and in a small apparatus by the law of gravitation causing the warm particles to rise, and those that have become partially cooled to fall. A tank of water is kept continually at a temperature of $109^{\circ} \mathrm{F}$., from the surface of which it will naturally flow over the water-proof cloth, a return pipe being so placed as to connect the outer end of the cloth with the bottom of the tank. The eggs are placed in drawers having open work or perforated bottoms, and they are laid on a piece of thin woollen cloth. The drawers are placed beneath the incubator, and raised so that the eggs come in contact with the water-proof cloth, but so as to allow a space between the sides of the drawers and the incubating cloth. These sides being lower than the top of the eggs, space is afforded for the air to circulate around them, as it rises through the bottom and passes out over the edges of the drawers."

Within two or three years past, an apparatus has 
been exhibited, from time to time, in the city of New York, called the American egg-hatching machine. It is stated that it has been "examined by a large number of practical and scientific men, who have strongly attested to its usefulness and general adoption."

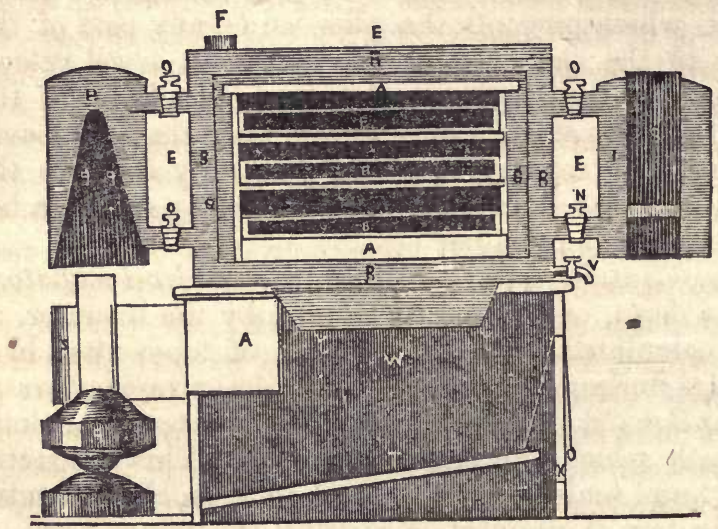

AMERICAN EGG-HATCHING MACHINE.

This machine is constructed of tin, or other materials, with the brooding chamber surrounded by water, warmed to a suitable temperature, by means of a spirit lamp, which, it is said, may constantly be kept burning for less than ten cents a day! The whole apparatus does not exceed two and a half feet in length and depth, and is stated to be capable of hatching from 200 to 600 chickens at a time, with a loss of not more than two per cent., if the eggs are perfect, and if proper attention is paid to the temperature of the machine! But here let us drop the subject. In my humble opinion, all these ingenious imitations of, and interferences with, nature, though they may flourish for a day, (and flourish they cannot bo said to do,) will pass away as things that were. 
NURSING THE YOUNG BROODS.

LET us now suppose that the chick has opened the door of its egg. Feeble trembler, on the verge of an unknown state of existence, what are its sensations! Had it but reason, how applicable to it would be Buffon's eloquent description of man, springing up at the bidding of his Creator into life and light, at once enraptured, perplexed, and bewildered. But the chick is guided by instinct alone; it has nothing to learn, no ideas to be conceived through the medium of the senses, and yet it is interesting to watch it at this juncture. It is free; the first thing it does, while yet on the threshold of the egg, is to draw its head from under its wing, and to direct it forwards, the neck trembling beneath the weight which it has now for the first time to sustain. With its neck stretched forwards, and scarcely able to raise itself on its legs, it rests for a few minutes, till its strength is recruited; the fresh air revives it, it raises itself up, it lifts its head, it turns its neck from side to side, and begins to feel its innate powers. Its downy plumage, the precursor of feathers, being wet with the fluid of the egg, lies close to the skin, in stripes down the body and on the wings; besides, it is not yet fairly free from the sheath in which every plumelet is enclosed. As it dries, every tuft expands, or opens, like a feathery flower; the little membranous sheaths split and fall off; and the chick rises in its nest, clothed with a downy garment of exquisite delicacy!

An experienced poultry maid, in giving directions to her young successor, may be supposed to discourse as follows:- "Do not meddle with the eggs nor the nest; the hen knows better than you, and if they require turning, when, and in what position to place them. She will seldom forsake them, or leave them long enough to be addled, which is caused by the change from heat to cold. Watch patiently and quietly. On the eighteenth or nineteenth day, if you put your ear 
to the egg, you will hear the chick making a gentle piping noise, and at this time the yolk, which has already begun to be taken up into the body, is now in a state of rapid absorption, being destined to supply the chick with nourishment, even after its exit from the shell. You will very seldom have occasion to assist chickens in emerging from the shell, and the chances are, that you will injure them, if you attempt it. Act cautiously, but believe that nature does the business best. Some chickens get out in an hour, others in two or three, and it may happen that some may be a day, or a day and a night at work, by starts. For twenty four hours, you should leave them to themselves; if they are not strong enough to break through their shellwork wall, they will not be stout enough to live; and this is the reason why, even with the gentlest assistance, they very seldom do live, supposing they have not left the egg by their own efforts. It sometimes happens that the feathers are glued to the lining of the shell, which prevents the bird from clearing itself of it. In this case, be very gentle with your fingers, when you draw the feathers from the lining of the shell. You should go to work as if you were removing a blister from your own skin, that is to say, with the greatest tenderness. Be rather tardy than premature ; 'let patience have her perfect work.' Remember that, if the chickens leave the shell before they have taken in, or drunk up all the yolk, which must serve them for food during the ensuing twenty-four hours after they see the light, they, will pine away, and die in a few days. Beware, then, of being premature in any efforts, however well intended, to extricate a feeble chick; nevertheless, be watchful, and ready for every emergency."

So far we may say an experienced poultry maid would give her directions. But now comes another point to be considered. The chickens are all hatched under favorable circumstances; there is no mishap, one after another extricates itself-what is the treat- 
ment to be pursued? Many persons, as the chickens leave the eggs, remove them one by one, and place them in a basket, covered up with flannel, and keep them in a warm place, returning them to the hen when the last has made its appearance. This is not generally necessary ; it is unnatural, and may fret the hen, who delights in hèr young brood, whose piping notes, while the chicks were yet in the egg, she has listened to with complacency. The shells, however, should be cleared from the nest, but unless circumstances render it necessary, the young chickens may be allowed to remain. But suppose that the weather is piercingly cold, and that the hen is restless, then let the chickens have warmth and every attention. Those hatched during the winter, or colder spring months, require comfortable housing, the hen being with them, and the less that interference be made between the hen and her chicks, the better; they troop around her; she protects them, gathers them under her wings, and watches over them with the most earnest solicitude.

Some persons, especially in France, train capons to act as nurses to their broods of chickens which are reared; and some have recourse to artificial mothers, or boxes lined with a soft and warm material for the protection of the brood.

That capons can be taught or trained to hatch a clutch of eggs, and attend to the young, was known to the ancients; and indeed there are cases on record of the cock having laid aside his lordly air, and devoted himself with exemplary patience to the work of incubation; in other cases, he has taken the place of the hen in watching over the chickens when accident has deprived them of her care.

Baptista Porta, in his strange work on Natural Magic, gives instructions as to the mode of taming and training capons for the task of nursing. "In the first place, the bird must be made so familiar as to take food from the hand; this primary step being accomplished, on the evening, when his services are re- 
quired, the feathers must be plucked from off his breast, and the bare skin be irritated by rubbing it with nettles. The chickens must then be put to him; they will naturally huddle under him, and by rubbing with their little downy heads allay the irritation caused by the nettles. This process being repeated for two or three nights, he will gradually conceive an affection for the chickens, and attend to them like a hen. The writer suggests that this attachment may be based on the principle of mutual distress producing mutual sympathy, and that the querulous chirp of the chickens may make the capon, while in pain himself, desirous of allaying their misery. A capon once accustomed to this office will not abandon it, but when one brood is grown up sufficiently, another newly-hatched brood may be substituted in their place, and so on in succession, the last chickens being as carefully attended to as were the first."

With respect to artificial mothers, they are undoubtedly useful when there is no natural parent nor trained capon to protect and warm the chickens; and many persons are great advocates for them. These mothers are nothing more than wooden trays, or boxes, so contrived as to impart the necessary heat to the young chickens, after exclusion from the' egg, till they are sufficiently strong and grown to need no further assistance. When chickens are hatched by artificial means, as by the eccaleobion, or in an oven, these protectors are essential; for, without some substitute for the parent, the ehicks would perish. They are described as being framed of a board ten inches broad and fifteen inches long, resting on two legs in front, four inches in height, and on two props behind, two inches in height. The board must be perforated with many small gimlet holes for the escape of the heated air, and lined with lambskin, dressed with the wool on; the woolly side is to come in contact with the chickens. Over three of these mothers, a wicker basket is to be placed for the protection of the chickens, four feet long, two feet 
broad, and fourteen inches high, with a lid open, a wooden sliding bottom to draw out for cleaning, and a long, narrow trough along the front, resting on two very low stools, for holding their food. Perches are to be fixed in the basket for the more advanced to roost on. A flannel curtain is to be placed in front and at both ends of the mothers, for the chickens to run under, which they soon learn to push outwards and inwards. These mothers, with the wicker baskets over them, are to be placed against a hot wall at the back of the kitchen fire, or in any other warm situa tion, where the heat shall not exceed $80^{\circ} \mathrm{F}$.

When the chickens are a week old, they are to be carried with a mother to a grass plot, for feeding, and to be kept warm by a tin tubo filled with some hot water, which will continue sufficiently warm for about three hours, when the water is to be renewed. Towards evening, the mothers are to be again placed against the hot wall, and thus continued, from day to day, until the chicks are strong enough to take care of themselves.

\section{CHICKEN COOPS.}

THE simplest, and perhaps the most common method employed for confining the hen after hatching her young brood, is to lay a flour barrel on its bilge, knocking out one head, and driving a few small stakes into the ground directly in front. This makes a very comfortable shelter for the hen, protecting her and her chicks from the sun, wind, and rain, and allows the latter to range about the garden or yard, where they are enabled to pick up seeds, insects, worms, \&c., and thereby obtain a large share of their living.

This plan is objected to by many, in this country, on the ground that the chickens are more exposed to the depredations of hawks, minks, rats, \&c., than they would be if protected by their watchful mother by their side. But, as it is necessary in all cases to have the coop near the garden or house, not only on acoount 
of the safety of the young brood, but for the convenience of feeding them, as well as for the security of the flowers and plants, it would be preferable to confine the hen in a coop like that shown in the following cut, and give liberty only to the chicks.

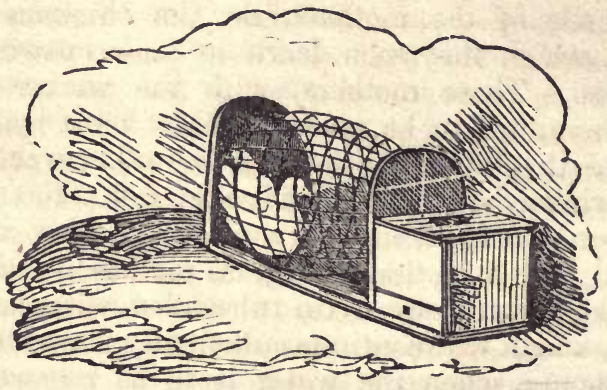

COOP WITH FEEDING BOX ATTACHED.

Those who can well afford it, and wish to display more taste in this delightful branch of rural economy, might build coops in a Gothic or Chinese style, similar to that of the adjoining cut. The size may vary from that of a few feet square to a height sufficient to admit a man.

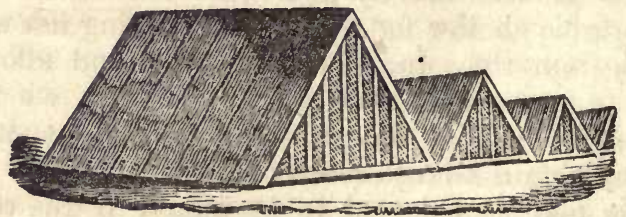

MARQUEE OR TENT-SHAPED COOPS.

Another kind, lately used by Mr. C. N. Bement, author of the "American Poulterers' Companion," answering a very good purpose, is the marquee coop, denoted by the above figure. It is made by nailing 
short pieces of boards together, in such a way as to form two legs of a triangle, the ground answering for the other side. These coops should be at least two feet in height, with one end boarded up tight, and the other secured by nailing strips of boards, or laths, in the form of a grate, leaving sufficient space between them for the free passage of the chicks, without affording liberty to the hen. In front, there should be a broad piece of board, as long as the coop is wide, on which to feed the chickens and hen. This board may be secured to the coop with leather or other hinges, so as to admit of being raised up and closing the coop, towards evening, which will not only answer the purpose of guarding the young brood against rats and other enemies during the night, but will prevent them from wandering about the next morning on the dew and wet grass before it is dry.

The coops should not be located too near each other, as the chickens of different broods are apt to become mixed, or wander to the wrong hen, where they will be repulsed and even killed. Fifty or sixty feet apart will be a sufficient distance, in general, to secure safety to the young broods from injury by other fowls. At the expiration of five or six weeks, the hen may be released from her coop, every morning, when the weather is fair, as soon as the grass is dry, and be made to return again in the evening, if she does not come of her own accord, and there be confined during the night. By the end of two or three weeks more, she may have her entire liberty with her brool, and range at pleasure about the yard.

As the chicks, at first, will hardly be on an equal footing with their older companions, in regard to the distribution of their food, a "feeding coop" may be provided for them by driving small stakes, or laths, into the ground, inclosing a space of two or three yards in diameter, at such distances apart as will admit their entrance, but prevent the ingress of the larger fowls. 
The top of the inclosure must be covered with boards, or otherwise, only having an opening with a lid, sufficiently large to drop through their food.

\section{FOOD OF THE CHICKS PREVIOUS TO WEANING.}

As to the food of the young brood, let them have anything which is not absolutely poisonous. Sloppy matters are better avoided till the little things are old enough to eat a few grains of good wheat, of the best sample, which will then not be thrown away upon them. Meat and insect diet are almost necessary; but raw vegetables chopped small, or Indian-meal dough, containing no salt, so grateful to young turkeys, are caviare to chickens. But whatever be the bill of fare, the meals must be given at short intervals; as much as they can swallow, as often as they can eat. The reader will please to remember that when he came into the world, all that was expected of him was to grow and be good-natured. He had not to provide his long clothes out of his mother's milk, nor to elaborate pinafores from a basin of soaked biscuit; but for poor little chickens, the only known baby-linen warehouse is situated in their own stomachs. And with all their industry, they are only half-clad, till flesh and blood stop growing for a while, and allow down and feathers to overtake them.

The period at which they are left to shift for themselves depends upon the disposition of the hen. Some will continue their attentions to their chicks till they are nearly full-grown, others will cast them off much earlier. In the latter case, it may be as well to keep an eye upon them, for a few days, till they have established themselves as ino pendent members of the gallinaceous community. For $c_{1}$.ickens, in this half-grown state, are at the most critical period of their lives. They are now much more liable to disease than when they were apparently tender little weaklings crowded under their mother's wings. It is just before arriving at this point of growth, that artificially-hatched chickens are so sure to fail, whether hot air, hot water, or sheepskin, be the substitute for the mother's care. 


\section{FATTENING.}

LET it now be assumed that the fowls have got their full growth, or nearly so, as the cocks at least increase somewhat in size till their third year. The breeder, at this period, will have to determine which birds he retains for stock, and which are to enjoy a less extended existence. On the process of fatting fowls, little that is new can be offered, and tastes differ so exceedingly, that almost every family has its own particular mode. Some think a young fowl killed by dislocation of the neck, not by bleeding, and without any fatting, hung up in the feathers a few days in the larder, like game, the greatest luxury; others like them to be brought by confinement and select diet, to the greatest point of delicacy and insipidity. For this purpose, rice may often be obtained at a cheap rate. It should be boiled, not enough to lose its granular form, in milk; meat broth used instead of milk is nourishing and fattening, but diminishes the whiteness of the flesh and the delicacy of the flavor. If fowls were brought to eat uncooked rice, it might prove unwholesome by swelling in the craw. Cram. ming is quite unnecessary; cleanliness in all cases, most expedient. If any coarse or rank food is used, such as tainted meat, greaves, rancid fat, or fish scraps, it will be apt to impart a corresponding taint to the flesh. The purer the diet, the more delicate will be the flavor. Rice, boiled as above directed, barley meal and milk, or boiled potatoes mashed with Indian meal, are all excellent articles for the purpose, and easily obtained. The locality and the cost price must often determine the matters employed, care being only taken to avoid all that is likely to prove hereafter offensive to the palate. For it is an old notion, confirmed by modern experience, that even laying hens should not be allowed to eat unsavory nor strong-tasted substances, lest their eggs become tainted with the flavor.

"Let bitter herbs be avoided, particularly wormwood; for hens that have eaten it lay extremely bitter eggs. Some aver that the eggs from hens that have eaten im- 
pure food, are mostly putrid and even poisonous, and if they have fed filthily, excrementitious. They should also abstain from lupines, (which are bitter,) for the same reason, and also because they produce small swellings under the eyes, as Crescentiensis observed; and Palladius tells us, that unless these swellings are gently opened with the needle and the core extracted, they blind the fowls."* It is certain that a peculiar flavor is perceptible in the eggs of those hens that have fed much about dung heaps, or on grasshoppers.

A well-fatted fowl is undoubtedly a more economical dish than a lean one. But Pliny tells us, with an expression of disapprobation, that the people of Delos were the first inventors of the luxury. He mentions the sumptuary laws, that in old Roman times were passed to restrain such indulgencies, and how they were evaded. This seems, in him, to be very like affectation; for living, as he did, in the best society of a most voluptuous and self-indulgent age, he must often, in the character of an accessory after the fact, have been guilty of the misdemeanor of fatting fowls.

Willoughby is a much more sensible fellow: "No better flesh in the world," says he, "than that of a year-old pullet well fed, or a fat capon; nothing inferior to, not to say better than, that of a pheasant or partridge. Some there are that think, and we also incline to their opinion, that the flesh of those hens is most sweet and delicate which are fed at the barn door, running about and exercising themselves in getting their food, by scraping with their feet. And that the flesh of those is less pleasant and wholesome, that are shut up in coops and crammed. Some are so curious that they think those limbs most wholesome which are most exercised, and, therefore, in wild fowl, they prefer the wings, in tame, the legs."

The old Dutch mode of fatting, as described by Aldrovandi, is by no means a bad one:

"Cardan is the authority, that if you mingle fat lizard, (shred fat?) saltpetre, and cummin, with wheat flour, and feed hens on this food, they will get so fat, and the 
people who eat them will grow so stout, as to burst. John Jacob Wecker records that he learnt the following secret of fatting hens from a certain Hollander:- 'In the kitchen,' he says, 'make to yourself a box, divided into many little boxes, each one with its own opening, through which the hens can thrust their heads out of doors, and take their food. Therefore, in these little boxes, let youthful hens, or pullets, be incarcerated, one in each; let food be offered every hour, drink being interdicted for the time. But let the food be wheat moderately boiled. The little boxes ought to be pervious below, that the excrements may pass through, and be diligently removed every dåy. But the hens ought not to be shut up beyond two weeks; lest they should die from too much fatness. I am told, also, that among some people, they get gloriously fat, and quickly, if beer is offered them for drink, instead of water; also, that if they are fed on brewer's grains, they lay more, as well as larger eggs."

A correspondent of the London Agricultural Gazette thus describes the niethod which he successfully practised for many years in India:- “"The fowl house, or rather feeding house, for only fattening fowls were permitted to be in it, was kept as cool as possible, (in Bengal, remember, ) and almost dark. Each fowl had a separate pen ; they were fed once, and only once a day, with rice, boiled as rice ought to be for Christmas; not to a mash; but so that grain from grain should separate. The quantity to each fowl was about two ounces (before boiling). For the first three days, to each was given about a tea-spoonful of 'ghoor,' a coarse sugar-about half as much again of treacle would be an equivalent. This commencing with sugar was held to be very inportant; it cleansed the birds and disposed them to fatten; no water was given; neither was any chalk nor gravel, both being unknown in the country. In about three weeks, the fowls were generally fat. I never, in England, have seen finer than those I have killed within that time, not even at Mr. Davis's, of Leadenhall Market. If they did not fatten in three weeks, we supposed 
that they did not mean to fatten, but this was of rare occurrence, and proceeded, no doubt, from some ailment beyond my power of discovering; but, fat or otherwise, they were never tough. To boil the rice in buttermilk is by far preferable to boiling it-in water; let the fowls be as young as you can, if of full growth. Many people run away with an impression that fowls fed on rice will go blind; it is dirt and sourness that cause it. How often do we see a trough loaded with meal food, sufficient for two or three days, placed before the unhappy prisoner in the pen, who cannot escape from it, nor seek other and sweeter food! When the fowls have done feeding, the trough should be removed, cleaned, and exposed to the air until the next day's feeding time. At my factory, in India, the troughs were every afternoon thrown into a pond; there they remained until next morning, when, after an hour or two's sunning, they were returned to the coops; no blindness was known there."

\section{EXPERIMENTS WITH BOILED GRAINS IN FATTENING FOWLS.}

IT is the custom of poultry keepers, in France, to cook the grain given to fowls which they intend to fatten, boiling it in water till it is soft enough to be easily bruised between the fingers, the boiling causing it to swell till the farina splits the enveloping membrane, and this they term bursting. Although it is the popular opinion that burst grain is better than when it is dry, for fattening poultry, this opinion has probably not been established on accurate experiments. Be this as it may, it is of no less importance to ascertain whether there is any difference of expense in feeding poultry on dry or on burst grain ; that is, whether, under similar circumstances, fowls eat more or less of one than of the other.

In order to ascertain this, M. Réaumur ordered four pint measures of each of the six common sorts of grain to be boiled till they were well burst, and he found that the increase of bulk in each sort was the following:- 
Pint

measures.

Four pints of oats, after being boiled to bursting, filled..... 7

Four pints of barley, after being boiled to bursting, filled.... 10

Four pints of buckwheat, after being boiled to bursting, filled 14

Four pints of maize, after being boiled to bursting, filled above 15

Four pints of wheat, after being boiled to bursting, filled a

little more than........................ in 10

Four pints of rye, after being boiled to bursting, filled nearly 15

Rice swells considerably more by boiling than any of these six sorts, but it is rarely given to poultry, except for fattening, under the notion that it tends to whiten the flesh.

For the purpose of ascertaining whether the boiling altered the preference of fowls for any of the particular sorts, experiments, varied in every possible way, similar to those detailed above, were made by M. Réaumur. The fowls were furnished with two, three, four, five, and six different sorts, sometimes all the compartments of the feeding box being filled with burst grain, each different from the other, and sometimes each sort of grain filled two of the compartments, one of them having nothing but boiled, and another nothing but dry grain. All that could be collected from these repeated experiments was, that the greater number of fowls prefer boiled grain to raw, though there are many of them which show a preference to the dry grain, on certain days, and no permanency could be discovered in the preference shown for any sort of burst grain. Some fowls, for instance, which one day preferred boiled wheat, would on other days make choice of buckwheat, maize, oats, or barley, and sometimes, though more seldom, even of rye; but rye, either boiled or raw, is the least favorite sort of grain. It follows as an important conclusion from such experiments, that we may make choice of the sort of grain which happens to be cheapest, without much, if any, disadvantage; always excepting rye, when other sorts are to be had on reasonable terms.

Other experiments were required to show whether there is any economy, or the contrary, in feeding poul- 
try with boiled grain, and this was readily ascertained from knowing, first, how much dry grain sufficed one or more fowls, and then boiling the same quantity, and trying how much of that would in like manner be sufficient. The experiments made with the different sorts of grain were as follows :-

Rye, although so very considerably increased in bulk by boiling, so far from being more sufficing, becomes less so, as fowls will eat rather more of it when it is boiled than when it is dry. Seven hens and a ccck consumed only three fourths of a pint measure of dry rye in one day, but ate in the same time three pint measures of the boiled grain; consequently, as three pint measures of boiled rye are equivalent to four fifths of dry, it would cost one twentieth more to feed fowls with boiled than with dry rye, four fifths being one twentieth more than three fourths.

Oats, although increased in bulk by boiling, nearly one half, are not, any more than rye, rendered more sufficing; for the fowls, which, in two days, would have eaten four pint measures of dry oats, consumed in the same time seven pint measures of the boiled grain; consequently it is no saving to boil the oats.

Moubray says, "oats are apt to produce the scour, and chickens become tired of them; but that oats are recommended by many for promoting laying, and in Kent, Sussex, and Surrey, for fattening."

Buckwheat, is increased in bulk by boiling still more than oats, as four pint measures, when well boiled, swell to fourteen; yet is there small benefit obtained by boiling buckwheat; for the fowls consume the fourteen pint measures of the boiled grain nearly in the same time which four pints of the dry would have sufficed them. Moubray says, also, that buckwheat is an unsubstantial food.

Maize, or Indian Corn, is, on the other hand, more profitable when boiled than when given raw; for the fowls which would have got through a pint and a quarter of the dry maize, consumed only three pint 
measures of the boiled grain, which are not equivalent to one of the dry. It was for two days only that they were able to eat in a single day three pint measures of the boiled maize; for after that, they either lost their appetite, or came to dislike it, as they could not get through more than two pint measures of the boiled maize. Even calculating that they were to consume three pint measures a day of the boiled grain, there would be a saving of more than one fifth, and if they were satisfied with two pint measures, the profit would be much more considerable; for this would not be equivalent to two thirds of a pint measure of the dry grain. The saving, in this case, would be one third and one fifth; that is eight fifteenths, or more than one half.

Barley is also much more economical when given boiled than dry; for fowls, which would have eaten two pint measures of dry barley a-day, ate but three pint measures daily of the boiled grain. Therefore, as ten pint measures of boiled barley are produced from four pint measures of dry, three pints of the boiled are equivalent to no more than one and a fifth of a pint of the dry; consequently, the experience in dry barley is to that of boiled as five to three, showing a saving of two fifths, by giving boiled instead of dry barley.

Wheat is shown by the preceding table to increase in bulk by boiling about the same as barley; but experiments prove that the saving to be obtained by feeding fowls with boiled wheat, is not nearly so much as might thence have been anticipated; for the same fowls which consumed three pint measures of boiled barley in one day, ate three pint measures of boiled wheat. Three pints of boiled wheat, however, are not equivalent to two pints of dry wheat, as in the case of the barley, but only one pint and a half of dry wheat, which was found to be the quantity consumed in one day by the same fowls. Now as a pint of boiled wheat is equivalent to no more than two fifths of a pint of 
the dry grain, the three pints consumed a day are equivalent only to one and a fifth of a pint of dry wheat. Consequently, the proportion of what they consumed of dry wheat was, to what they ate of boiled, as five to four; hence there is a saving of one fifth by feeding with boiled wheat, as there is of two fifths, by feeding with boiled barley.

These interesting experiments prove most clearly, that, in every case, when the price of maize, barley or wheat, renders it eligible to feed poultry therewith, there is considerable economy in never giving the grain dry, but well boiled. The expense of fuel, though it must be taken into the account, must be small in comparison with the advantage, particularly in families where large fires are constantly kept up, as a very trifling addition of fuel will be required to burst the grains. It may be well to repeat that there is no saving, but loss in fuel and trouble, by boiling oats, buckwheat, or rye.

\section{KILIING AND PREPARATION FOR MARKET.}

When fowls are in readiness to kill, some people dispatch them simply by wringing their necks, plucking off the feathers, and sending them to market with the intestines in. This is a slovenly practice, doing great injury to the flesh, as it partakes of the flavor of the excrements, when suffered long to remain undressed, and is otherwise impaired from the stagnant blood.

The most approved mode of fitting fowls for market, is to kill them by cutting off their heads, on a block of wood, at a single blow, with a hatchet or an axe, which will deprive them at once of life, and drain their flesh of blood. Then, the feathers and pin feathers should be immediately plucked off, the intestines removed, the blood washed out with cold water, and carefully hung up in a cool, dry room, until ready to convey to market, or otherwise to be used. 


\title{
THE TURKEY.
}

\author{
ORIGIN AND HISTORY.
}

"___ There is no poor animal so beset with ignorant and destructive empicism, on its first introduction into life, as the turkey."

ANon.

IF we call to mind the many and valuable acquisitions, from both the animal and vegetable kingdom, which have been made subservient to the use of man, within comparatively a very recent period, it is not too much to believe that others, of nearly, or quite equal value, still remain to reward the labor and pains of a persevering search. There is the whole of Central Africa, Central Australia, a great part of China and Northern India, and innumerable half-explored or unexplored islands, all waiting to be ransacked for our benefit. And without depending on those distant regions, we know not yet what we may yet find in the unexplored tracts of Oregon, the Rocky Mountains, or other American wilds.

Amongst the living tributaries to the luxury of man, the turkey is an instance of the results yet to be expected from the exploring spirit of our day. It is the most recent, and, except the hen, the most valuable of our domesticated birds. We may, indeed, call it comparatively a new acquisition; for what, after all, is a period of three hundred years, compared with 
the time during which man has had dominion over the earth and its brute inhabitants? The obscurity which hangs over the domestication of this bird, and which there is little chance of clearing away, except by industrious ferreting amongst old family records and memorandum books, shows that those who carried it to the Old World, whence we obtained our stock, doubtless, had no idea of the value of what they were transporting; but probably regarded it like any other remarkable production of nature-a macaw or a tortois. The young would be distributed among friends with the same feeling that golden pheasants and such like are with us; these again would thrive and increase, and the nation would suddenly find itself in the possession of a race, not of pleasing pets, but of a valuable, prolific, and hardy stock of poultry.

That we cannot fix the precise time, nor learn any of the circumstances which relate to the introduction of the turkey into Europe, may cause some astonishment, when we reflect that it must have occurred at some period after the conquest of America, and not probably till after a considerable lapse of years, and the establishment of the Spaniards in Mexico. Cortes, in 1519 , landed at the place where Vera Cruz now stands, but it was not until after two years of laborious warfare that the Spanish power became in the ascendant, and opened the way for Spanish emigration to Mexico. There is, however, reason to believe that previously to the Spanish conquest, the turkey was in a domesticated condition, both in Mexico and in the adjacent islands; for Oviedo, who embarked for the West Indies, in 1514, and resided as governor of the fort and harbor of St. Domingo, in the island of Hayti, then called Hispaniola, published among other works, (some very voluminous,) one entitled Tradado de la Historia Natural de las Indias, which was published at Toledo, in 1526. In this work, he describes the turkey as a kind of peacock, (pavo,) abounding in New Spain, whence numbers had been transported to the 
islands and the Spanish Main, and were domesticated in the houses of the Christian inhabitants. It must be observed that he calls the whole of that part of America "las Indias," (the Indies,) and also "las Indias occidentales," (the West Indies, ) a name still applied to certain islands; hence, probably, the term "coq d'Inde," originally arose, a term, however, which, if it did thus originate, seemed to have conveyed a general idea of this species being the native of Asiatic India; and under this impression, that it was a bird known to the Greeks and Romans, a bird, as the fable states, into which the sisters of Meleagre were transformed, while weeping for the loss of their brother, it obtained, among the learned, the title of "Meleagris."

Belon was one of the first who considered the turkey to be the Meleagris of the ancients, and this is the more extraordinary as he was a scholar of erninence, and the passages in which the Meleagris is mentioned, sufficiently prove that it could not have been a turkey. Aldrovandi, Gesner, and others followed in the wake of Belon. Linnæus, though unfortunately he retains the name "Meleagris," stamping the error thereby with the weight of his authority, well knew that the turkey was a native of the New World, for he places its habitat " in America Septentrionali ;" he was also perfectly aware that it was the parent stock of the domesticated breed; for he gives brief, but excellent directions for the care of the young, and expressly mentions their favorite food- "the young relish the onion and the nettle, and must be taken heed of against hunger and rain." It is generally known that curd, the green part of onions chopped small, and nettles, are among the kinds of food for turkey chicks, whose very existence depends upon regular feeding and protection from rain.

The English name, "Turkey," it is somewhat difficult to account for, except on the supposition that it was generally believed to come from that country; perhaps, however, it was given because the bird was 
a stranger, in the same way as we apply the term "Goth" to men rude and barbarous in their habits, or the term "Turk," to persons of a savage and tyranical disposition; words often become perverted from their original signification and merge into nicknames expressive of supposed qualities or conditions of things. About the time when this bird appears first to have been known in England, the Turkish power was held in dread in Europe. The sultan, Suliman, the Great, reigned from 1520 to 1566 ; his fleet was then the first in the world, and the scourge of the Mediterranean; his ships ravaged the coasts of Italy and Spain, and his armies laid waste the territories of Hungary and some adjacent parts of Germany, and the dread of the Turks was universal over Europe. It might have been that the outlandish aspect of this bird,its deep gutteral notes, its haughty carriage, and irascible disposition, led to the imposition of the name. But, whatever gave rise to this appellation, certain it is that the present species was the subject of much confusion and doubt among the earlier modern ornithologists, whose learned discussions tended to perplex rather than clear up any points of difficulty. John Walcott, a writer on British birds, in 1789, says, "The turkey was first brought to England about the year 1521," but he gives no authority. It is certain that in the reign of Henry VIII. the turkey was pretty general in England. Yarrell, in his "British Fishes," quotes an old couplet which runs thus:

\section{"Turkeys, carps, hops, pickerell, and beer,}

Came into England all in one year."

"The old couplet," adds he, "is certainly erroneous; pike, or pickerell, were the subjects of legal regulations in the time of Edward the First. Carp are mentioned in the Boke of St. Allbans, printed in 1469. Turkeys and hops were unknown till 1524, previous to which wormwood and other bitter plants were used to preserve beer; and the parliament, in 
1528, petitioned against hops as a wicked weed. Beer was licensed for exportation by Henry the Seventh, in 1492, and an excise on bear existed as early as 1284, also in the reign of Edward the First."

About the year 1524, then, it would appear, the turkey was introduced into England, but whether from Spain, or direct from America, we have no means of knowing. Neither can we exactly discover at what period France and Germany received it, but most probably at about the same time as England. Everywhere its intrinsic value would make it acceptable, and cause it to be treated with the most careful attention.

The dispersion of the turkey is not, however, so complete as that of the common fowl. In India, Col. Sykes informs us that it is reared in great numbers by the Portuguese, and that it is met with only in a domestic state. We cannot learn that it is reared-in China, where the fowl and duck abound, nor does it appear to have a place among the domestic birds of Persia, though in Kitto's account of Palestine, both the turkey and the peacock are mentioned. There is a story told in a work called the "Sketches of Persia," which runs to the following effect:- When two English gentlemen, who were on their way to the city of Shiraz, arrived at the town of Kazeroon, they heard so strange an account of two remarkable creatures that were to be seen at a village fifteen miles distant, that they determined to go and see them. "They are very like birds," said their informants, "for they have feathers and two legs ; but then, their head is bare and has a fleshy look, and one of them has a long black beard upon his breast; but the chief point on which they dwelt, was the strangeness of their voice, unlike that of any other bird they have ever heard or seen. An old man, who had gone all the way from Kazeroon to see them, said that the sound was very much like that of the Arabic language, but added, that though he had listened to them with the greatest attention, he had not been able to 
understand a word they said. As it was very unpleasant weather, and the roads were exceedingly bad, the Englishmen were much fatigued by the time they got to the village in which the strange creatures were. The people of the village took them to the house where the animals were kept, the door was opened, and out marched a turkey cock and hen! The former seemed to rejoice much in his release from his confinement, and began to gobble his Arabic with great vehemency. Though vexed at having taken a tedious journey for nothing, yet the travellers could not help laughing at the dénouement. The people were, however, exceedingly surprised, when informed that these strange creatures were very common in India and England. It seemed that the birds had escaped from a vessel which had been wrecked in the Gulf of Persia, and had gradually made their way to the place where they then were.

Although, as before observed, the exact time and eircumstances, under which the turkey was introduced into the various countries of Europe, are in some obscurity, still the wild original of the domestic stock is not only well known, but still abounds in some of the wooded districts of America remote from civilization.

Two species only are known to naturalists, namely, the common wild turkey, (Meleagris gallopavo,) of North America, the origin of our domestie stock, and the Honduras turkey, (M. ocellata,) a bird, which, in the metallic splendor and varying tints of its plumage, outrivals the peacock, if not every other tenant of the air. But, except, perhaps, in some of the dense untrodden woods of Yucatan and of Central America, from Cape Honduras to the tenth degree of north latitude, this bird might be sought for in vain. Of its peculiar $\mathrm{h}$ abits and manners nothing is positively known. We may suppose, however, that it resembles, to a great degree, the common wild turkey of the north.

Could it be domesticated in our Southern States, what a splendid acquisition should we have to our poultry yards and lawns! 


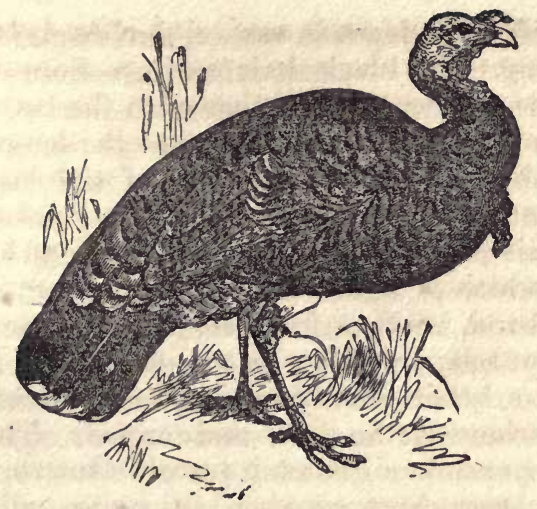

THE WILD TURKEY.

As the common wild turkey is confessedly the origin of all our domestic varieties, a description of it, as it exists in a state of nature, cannot but prove interesting. Bartram, the prince of Canino, (Charles Lucien Bonaparte,) Audubon, and others, have given graphic pictures of its habits, founded on actual observation, of flocks in their native woods, upon which authorities most of the following description is founded :-

The male wild turkey, when full grown, is nearly four feet in length, and more than five in extent of wing. The irides are dark-brown. The head, (which is very small in proportion to the body,) and half of the neck are covered by a naked bluish skin continued over the upper half of the neck and uneven with warty elevations, changeable red on the upper portion, and whitish below, interspersed with a few scattered black hairs. The flaccid and membranous naked skin, also changeable on the lower part of the neck, extends downwards into large wattles. A wrinkled conical fleshy protuberance, capable of elongation and with a pencil of hairs at the tip, takes its rise from the base of the bill, where the latter joins the front. When this excrescence is elongated under excitement, it cov- 
ers the bill and depends several inches below it. A tuft of long rigid black hair springs from the lower part of the neck at its junction with the breast, shooting out from among the plumage to the length of nine inches. The base of the feathers of the body, which are long and truncated, consists of a light fuliginous down; this part of the feather is succeeded by a dusky portion, which is again followed by a broad shining metallic band, varying from copper color or bronze to violet or purple, according to the play of the light, and the tip is a broad velvety band; but this last is absent in the feathers of the neck and breast. The general plumage presents a glancing metallic lustre, which is, however, least glossy on the lower part of the back and tail coverts. The wings are concave and rounded, not extending much if at all beyond the base of the tail. Quills twenty-eight; primaries blackish banded with white, secondaries whitish, banded with blackish, tinged towards the back particularly with brownishyellow. Tail fifteen inches in length at least, rounded at the extremity; the feathers eighteen, broad and capable of expansion and elevation into a fan shape. The general color of these feathers is brown mottled with black, crossed by numerous narrow, undulating lines of the same. There is a broad black band near the tip, then a short mottled portion, and lastly, a broad dingy yellowish band. The bird stands rather high on its robust red legs, the scales of which have blackish margins, and the blunt spurs are about an inch long; the claws are dusky. Bill reddish, but horn-colored at the tip.

The female, at the age of about four or five years, attains her full size and coloring. At this age hens have the pectoral fascicle of hair developed to the extent of four or five inches, which, according to Mr. Audubon, they exhibit a little in the second year if not barren. But this fascicle is much thinner than that of the male. Barren hens do not obtain this distinction until a very advanced age, and, being preferable for the 
table, the hunters single them from the flock, and kill them in preference to the others. The female wild turkey is more frequently furnished wit the hairy tuft than the tame one, and this appendage is gained earlier in life. The great number of young hens without it, has, no doubt, given rise to the incorrect assertion of a few writers that the female is always destitute of it. The irides are similar in color to those of the male. Bill and spurless legs less stout. Head and neck with less of naked skin, being partially covered with dirtygrey feathers. Those on the back of the neck have brownish tips, and so produce a longitudinal band there; the short caruncle on the front is incapabable of elongation. Prevailing hue of plumage, dusky-grey, each feather having a metallic band duller than in the male, then a blackish band, and lastly a greyish fringe. The blackish band, is almost obliterated on the neck feathers and under surface. The whole plumage is more sombre than that of the male; there is less white on the primaries, and there are no bands on the secondaries. The color of the tail is much as it is in the male. Length not exceeding three feet and a quarter.

The young of both sexes resemble each other so closely, before the naked membrane acquires its tinge of red, as to be scarcely distinguishable. The females, however, when a few days old, are somewhat larger than the males, and have a weaker piping note. The males then begin to stand higher on their legs, which are stronger than those of the females, and soon exhibit the rudiments of spurs. On the approach of the first winter, the young males show a rudiment of beard, or fascicle of hairs, on the breast, consisting of a mere tubercle, and attempt to strut and gobble. The second year, the hairy tuft is about three inches long; in the third, the turkey attains its full stature, though it certainly increases in size and beauty for several years longer. The concealed portion of the plumage on the anterior portion of the back is sprinkled with pale fer- 
ruginous down, which disappears as the bird advances in age.

The weight of the hen averages about 9 lbs., but the males far exceed the females, and differ considerably in bulk and weight. "From the accounts," says Bonaparte, "which I have received from various parts of the Union, 15 or $20 \mathrm{lbs}$. may be considered a fair statement of their medium weight; but birds of $30 \mathrm{lbs}$. are not very rare, and I have ascertained the existence of some weighing 40 lbs." Mr. Audubon saw one in the Louisville Market that weighed $36 \mathrm{lbs}$. The pectoral appendage of this bird measured more than a foot in length.

The wild turkey is a noble bird, far exceeding its domestic relative both in size and beauty. Crosses, however, in this country, often take place between the wild and tame race, and are highly valued, both for external qualities and for the table. Indeed, in districts where this bird is common, such crosses are very frequent, the wild male driving a way its domestic rival, and usurping the sultanship of the seraglio.

Eggs of the wild turkey have been frequently taken from their nests, and hatched under the tame hen. The young preserve a portion of their uncivilized nature, and exhibit some knowledge of the difference between themselves and their fostermother, roosting apart from the tame ones, and in other respects showing the force of hereditary disposition.

The domesticated young reared from the eggs of the wild turkey are often employed as decoy birds to those in a state of nature. Mr. William Bloom, of Clearfield, Pennsylvania, caught five of six wild turkeys when quite chickens, and succeeded in rearing them. Although sufficiently tame to feed with his other turkeys, and generally associate with them, yet they always retained some of the original propensities, roosting by themselves, and higher than the tame birds, generally on the top of some tree or of the house. They were also more readily alarmed. On the approach of 
a dog, they would fly off and and seek safety in the nearest woods. On an occasion of this kind, one of them flew across the Susquehanna, and the owner was apprehensive of loosing it. In order to recover it, he sent a boy with a tame turkey, which was released at the place where the fugitive had alighted. This plan was successful. They soon joined company, and the tame bird induced his companion to return home. $\mathrm{Mr}$. Bloom remarked that the wild turkey will thrive more, and keep in better condition than the tame, on the same quantity of food.

The wild turkey is irregularly migratory, as well as irregularly gregarious. Whenever the forest fruits, (or mast, ) of one portion of the country greatly exceeds that of another, thither are the turkeys insensibly led. By gradually meeting in their haunts. with more fruit, the nearer they advance towards the place in which it is most plentiful. Thus, in an irregular manner, flock follows flock, until some districts are deserted, while others are crowded with an influx of arrivals. "About the beginning of October," says Audubon, "when scarcely any of the seeds and fruits have fallen from the trees, these birds assemble in flocks, and gradually move towards the rich bottom lands of the Ohio and Mississippi. The males, or, as they are more commonly called, the 'gobblers,' associate in parties of from ten to a hundred, and search for food apart from the females, while the latter are seen either advancing singly, each with its brood of young, then about two thirds grown, or in union with other families, forming parties often amounting to seventy or eighty individuals, all intent on shunning the old cocks, which, when the young birds have attained this size, will fight with and often destroy them by repeated blows on the head. Old and young, however, all move in the same course, and on foot, unless their progress be interrupted by a river, or the hunter's dog force them to take wing.

"When they come upon a river, they betake them- 
selves to the highest eminences, and there often remain a whole day, and sometimes two, as if for the purpose of consultation. During this time, the males are heard gobbling, calling, and making much ado, and are seen strutting about, as if to raise their courage to a pitch befitting the emergency. Even the females and young assume something of the same pompous demeanor, spread out their tails, and run round each other, purring loudly, and performing extravagant leaps. At length, when the weather appears settled, and all around is quiet, the whole party mounts to the tops of the highest trees, whence at a signal, consisting of a single cluck, given by a leader, the flock takes flight for the opposite shore. The old and fat birds easily get over, even should the river be a mile in breadth, but the younger and less robust frequently fall into the water-not to be drowned, however, as might be imagined; they bring their wings close to their body, spread out their tail as a support, stretch forward their neck, and striking out their legs with great vigor, proceed rapidly towards the shore; on approaching which, should they find it too steep for landing, they cease their exertions for a few moments, float down the stream until they come to an accessible part, and, by a violent effort, generally extricate themselves from the water. It is remarkable that, after immediately crossing a large stream, they ramble about for some time, as if bewildered. In this state they fall an easy prey to the hunter.

"When the turkeys arrive in parts where the mast is abundant, they separate into smaller flocks, composed of birds of all ages and both sexes, promiscuously mingled, and devour all before them. This happens about the middle of November. So genitle do they sometimes become after these long journeys, that they have been seen to approach the farm houses, associate with the domestic fowls, and enter the stables and corn cribs in quest of food. In this way, roaming 
about the forests, and feeding chiefly on mast, they pass the autumn and part of the winter."

The season of courtship begins about the middle of February. The females now separate from the males, whom they endeavor to shun, but by whom they are perseveringly followed.

At this time, the males begin to gobble strenuously, and strut about, making that peculiar whirling jar with their wings, striking the quill feathers smartly on the ground, which all must have observed in the domestic bird. They utter a succession of puffs from the lungs. They spread out and erect the tail, and draw back the head, while the loose skin of the neck swclls and assumes the color of scarlet. Thus they make advances to the females, who roost apart, uttering occasional call notes, to which every male within hearing londly responds, several hastening to the spot whence the call proceeds, eager to pay their homage. Thus it happens that the males frequently meet each other, in which case desperate conflicts ensue, ending often in bloodshed, and often in the loss of life, the weaker falling under the blows inflicted on his head by his stronger rival. In the combat, they use beak, wings, and spurs, striking and pulling each other, the feathers being ruffled, the tail partly raised, and the wings held drooping, ready for a blow.

Old females, when addressed by the male, strut about almost as proudly as he does, and more than half way meet his ardent advances; but females under a year old are not to be won so easily. The solici. tations of the male, under these circumstances, are more pressing and.more energetic, till at length he ingratiates himself in her favor. Thus they are mated for the season, though the male, being polygamous, does not confine himself to one female, but solicits the kindness of as many as he chances to meet. The seraglio follow their favorite sultan, roosting at night near him, if not on the same tree. This unitedness lasts, however, only for a short time; for, as soon as 
they begin to lay, they gradually leave his company, and indeed scdulously avoid him, except for a few hours during the day, and make their nests in some concealed spot, among logs, brushwood, and intertangled foliage, in order that they may escape not only the eye of the crow, which is a great devourer of the eggs of the turkey, who, if he were to find them, would, from jealousy, infallibly break them all. At last, the males find themselves altogether deserted. Their mutual rivalship ceases ; they meet each other in peace, and cease to utter threats of mutual defiance; they seek retired situations in order to rest and recruit their energies; for, at this juncture, like worn-out rakes, they are utterly exhausted, and have lost flesh and activity. When recovered and improved in condition, they draw together again, and commence their wanderings in united parties.

It is generally about the middle of April that the female begins to select a site, and arrange her rude nest, which consists simply of withered leaves, in some depression on the ground amidst dense brushwood, or in such an obscure place as the locality affords. The eggs, like those of the domestic bird, are of large size, and of a dull or cream white, minutely freckled or dotted with reddish-brown; their average number varies from ten to fifteen. While the gradual addition of egg to egg is going on, the hen displays surprising instinctive caution. On leaving her charge, she is careful to cover the whole with dry leaves, so artfully disposed as to render it difficult even for one who has watched her movements to find the nest, and on returning to it, she varies her rout, scarcely ever returning to it twice by the same course. Hence it is mostly by accident that the nest of the hen is discovered. It not unfrequently happens that several hens associate together and form a common nest, probably for mutual aid and assistance, and rear their broods together. Mr. Audubon says that he once found three hens sitting on forty-two eggs. In such cases, one of 
the females at least is ever on guard, no raven nor crow then daring to invade it. While in the act of incubation, the hen is not readily driven from her nest by the appearance of danger. A person walking carelessly along, as if taking no particular notice, may pass a nest within five or six paces, the female crouching low to avoid observation; but, as Mr. Audubon has ascertained, if a person make his approach in a stealthily searching manner, she will quit it while he is yet thirty yards distant, and assuming a stately gait will move away, uttering every now and then a clucking note, probably hoping by this means to draw off the intruder and baffle his search. We learn from the same writer that the hen seldom or never abandons her nest if it has been discovered by man, but that if a snake or any other animal has sucked any of the eggs she leaves it altogether. Under such circumstances, or when the eggs have been removed, she seeks the male, and recommences the preparation of another nest; but as a rule, she lays only a single batch of eggs during the season. When the eggs are on the eve of hatching, the female will not leave her nest under any circumstances while life remains; she will even allow an enclosure to be made around her, and thus be as it were imprisoned, rather than seek her own safety by flight. Mr. Audubon says, "I once witnessed the hatching of a brood of turkeys, which I watched for the purpose of securing them, together with the parent. I concealed myself on the ground within a very few feet, and saw her raise herself half the length of her legs, look anxiously upon the eggs, cluck with a sound peculiar to the mother on such occasions, carefully remove each half-empty shell, and with her bill caress and dry the young birds that already stood tottering and attempting to make their way out of the nest. I have seen them all emerge from the shell, and in a few moments after, tumble, roll, and push each other forward with astonishing and inscrutable instinct." 
Before leaving the nest with her young brood, the female shakes herself, adjusts her plumage, and appears roused to the exigencies of the occasion; she glances upwards and around her, in the apprenension of enemies, and as she moves cautiously along, keeps her brood close about her; her first excursion is generally to a little distance only from the nest, to which she returns with her brood to pass the first night. Subsequently, they wander to a greater distance, the hen leading her charge over dry undulating grounds, as if aware of the danger of damp and humid spots. Wet, indeed, is fatal to young turkeys while covered only with down; hence in very rainy seasons, the broods become greatly thinned, for the young, if once completely wetted, seldom recover; their vital energies sink under the abstraction of caloric during evaporation.

At the age of a fortnight, the young birds begin to use their wings; hitherto they have rested on the ground, but now they begin to roost on the low branches of some large tree, crowding close to each side of the mother, and sheltered beneath her broad wings. They now wander about more freely, visiting the glades and open lands bordering the woods in search of wild strawberries and other fruit, grasshoppers, the larvæ of ants and other insects, and roll themselves in the sand and dust in order to clear their growing feathers of loose scales and parasitic vermin; deserted ants' nests are favorite dusting places.

By the month of August, the young birds have acquired considerable growth, and use their wings and legs with great vigor and readiness, so that they are able to escape the sudden attack of foxes, lynxes, and other beasts of prey, by rising quickly from the ground, and mounting the tallest branches of trees. The young cocks now begin to show their distinctive characteristics, and even to utter an imperfect gobble, while the young hens pur and leap. Several broods now flock together, and s s continue united, till after 
the October migration, and through the winter, when they leave the females, the middle of February bringing a recurrence of the same scenes already described. The young hens, in their turn, are to become parents, and the young cocks will fight for the mastery.

When, during the winter, a sharp frost succeeds a heavy fall of snow, so as to form a hard crust on its surface, turkeys will sometimes remain on their roosts for three or four days or longer, declining to search for food, unless indeed when farms and barns are within a short distance; they then direct their course to the stacks of corn, and enter the barns and stables in quest of grain. During melting snow-falls, turkeys will travel very great distances, and at such extraordinary speed that no hunter can keep up with them. They have then a dangling, straggling way of running, which, awkward as it may seem, enables them to outstrip any other animal. "I have often," says Audubon, "when on a good horse, been obliged to abandon the attempt to put them up, after following them for several hours. This habit of continued running in rainy or very damp weather of any kind is not peculiar to the wild turkey, bnt is common to all gallinaceous birds. In America, the different species of grouse exhibit the same tendency."

\section{GEOGRAPHICAI DISTRIBUTION.}

THe natural habitat of the wild turkey extends from the north-western territory of the United States to the isthmus of Panama, south of which it is rarely found, notwithstanding the statements of authors who have mistaken the curassow for it. In Canada and the now densely-peopled parts of the United States, wild turkeys were formerly more abundant than at present, but, like the Indian and the buffalo, they have been compelled to yield to the destructive ingenuity of the white settlers, often wantonly exercised, and seek refuge in the remotest parts of the interior. Although they relinquish their native soil with slow, 
reluctant steps, yet such is the rapidity with which settlements are extended and condensed over the surface of this country, that we may anticipate a day at no distant period, when the hunter will seek the wild turkey in vain.

The wooded parts of Arkansas, Louisiana, Tennessee, and Alabama, the unsettled portions of the states of Ohio, Kentucky, Indiana, Michigan, and Illinois, the vast expanse of territory north-west of these states, on the Mississippi and Missouri, as far as the forests extend, are more supplied than any other parts of the Union with this valuable game, which forms an important part of the subsistence of the hunter and traveller in the wilderness. It is not probable that the range of this bird extends to, or beyond, the Rocky Mountains. The Mandan Indians, who, a few years ago, visited the city of Washington, considered the turkey one of the greatest curiosities they had seen, and prepared a skin of one to carry home for exhibition.

In some parts of Florida, Georgia, and the Carolinas, the wild turkey is still common, but less so in the western parts of Pennsylvania and Virginia. Some, also, are said to exist in the mountainous districts of Sussex county, New Jersey. In New England and Lower Canada, they were formerly very abundant, but as their places of resort became settled and thickly peopled, they retired and sought refuge in the remotest recesses of the interior, until they entirely disappeared.

Thus far has our sketch applied to the general history and description of the wild turkey; and as the tame variety resembles its unreclaimed progenitor, in most of its marked peculiarities, namely, its rambling habits, its manner of roosting, the antipathy of the males to the eggs, often to the young, in the secrecy in which the female prefers to incubate, and in the tenderness of her young, I will next consider the turkey in a domesticated state. 


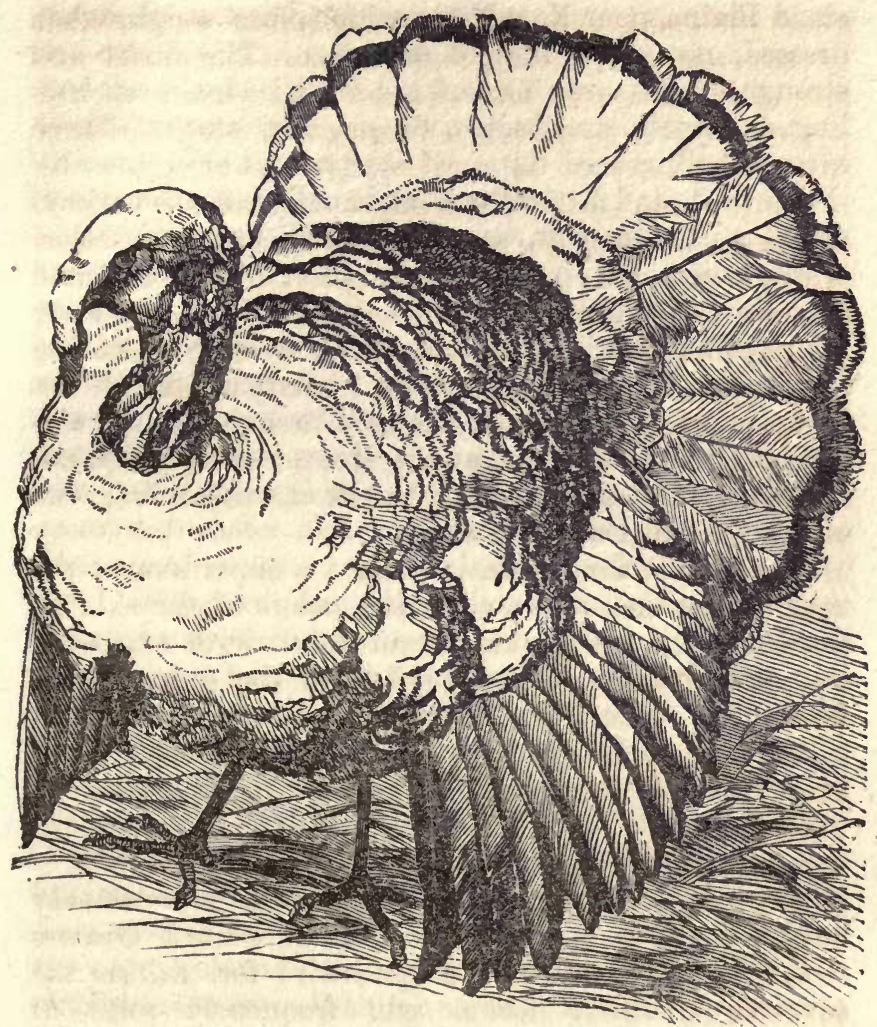

THE DOMESTIC TURKEY.

Synonymes.-Meleagris gallopavo, of Naturalists; Coq d'Inde, Dindon, of the French; Pavo, of the Spaniards; Truthahn, Calcuttischer Hahn, of the Germans; Turkey, Turkey Cock, of the English and Anglo-Americans.

The domestic turkey can scarcely be said to be divided, like the common fowl, into distinct breeds; although there is considerable variation in color, as well as in size, but no Bantam, or dwarf race exists, unless we except the small, delicate-fleshed turkeys of Hemp- 
stead Plains, near New York, which often weigh, when dressed, not more than 4 or 5 lbs. The finest and strongest birds are those of a bronzed black, resemb. ling, as closely as possible, the original stock. These are not only reared the most easily, but are generally the largest, and fatten the most rapidly. Some turkeys are of a coppery tint, some of a delicate fawn-color, while others are parti-colored, grey, and white, and some few of a pure snow-white. All of the latter are regarded as inferior to the black, their color indicating something like degeneracy of constitution, if not actual disease. A variety is said to exist in the aviary of Madame Backer, at the Hague, with a topknot springing from the crown of the head, resembling that of the plumed Poland fowls.

To describe the domestic turkey is superfluous ; the voice of the male; the changing colors of the skin of the head and neck; his proud strut, with expanded tail and lowered wings, jarring on the ground; his irascibility, which is readily excited by red or scarlet colors, are points with which all who dwell in the country are conversant.

\section{RANGE AND DOMESTIC ACCOMMODATION.}

The adult turkey, it is well known, is extremely hardy, and bears the rigors of our coldest winters with impunity even in the open air; for, during the severest weather, flocks, will frequently roost at night upon the roof of a barn, or the branches of tall trees, preferring such an accommodation to an indoor roost. The impatience of restraint and restlessness of the turkey, render it unfit company for fowls in their dormitory; in fact, the fowl house is altogether an improper place for these large birds, which require open sheds and high perches, and altogether as much freedom as is consistent with their safety.

Although, turkeys will roost even during the winter months on trees, it is by no means recommended that this should be allowed, as the feet of these birds are 
apt to become frostbitten from such exposure to the air on the sudden decline of the temperature far below the freezing point. It must be remembered that the domestic turkey, hardy as it is when adult, is not equal in point of endurance to its wild relative breed in the woods and inured to the elements.

-Turkeys are fond of wandering about pastures, hedgerows, and the borders of fields; they love to visit turnip fields, where, besides the leaves of the turnips, which they relish, they find insects, snails, slugs, \&c., which they greedily devour. In the morning, they should have a good supply of grain, and after their return from their peregrinations another feed; by this plan, not only will the due return home of the flock be insured, but the birds will be kept in good store condition, and ready at any time to be put upon fattening diet. Never let them be in poor condition-this is an axiom in the treatment of all poultry-it is difficult, and takes a long time, to bring a bird into proper condition, which has been previously poorly fed or half starved.

\section{CHOICE OF THE TURKEY COCK.}

THE turkey cock should be vigorous, broad in the breast, clean in the legs, with ample wings, and a welldeveloped tail plumage; his eyes should be bright, and the carunculated skin of the neck full, and rapid in its changes of color. Though capable of assuming his legitimate rank among the hens, when a year old, he is not in perfection, (notwithstanding the contrary opinion of some,) until he has attained his third year, and is entering upon his fourth; and he continues in his prime for three or four succeeding years. Thus, for two, three, or four years, or longer, may all the young cocks be devoted to the poulterer, one perhaps of particular beauty being preserved within that space of time for the ornament of the farm yard.

The turkey cocks which are kept for breeding, rather than for the table, "ought not" says Mascall, 
" to be passing a yere, or two yeres old-three yeres is the most, and too much-for, being olde, they are so heavy in treading, they wyll commonlye hurt the hennes, in broosing their backes, and treading off their feathers off their backes. And, also, it is not good to keep two cockes in treading time ; for one will hinder the other, so that your hennes' egges come to small profite in setting."

"Your turkie cock," says Markham, "should be a bird, large, stout, proud, and majesticall, for, when he walketh dejected, he is never good." According to M. Parmentier, both the cock and hen ought to have short legs, a full shape, and great vivacity and energy in all their actions. For breeding, it is peculiarly necessary that both should be well formed, and in healthy condition.

Turkey cocks are pugnacious and vindictive,- and often ill-treat the hens. I have known them to attack children, and have witnessed combats between them and the game cock, in which the latter was more oppressed by the weight of his antagonist than by gladiatorial skill-I have,-in fact, seen the bulky hero worsted; he cannot use his spurs with the address exhibited by the game cock, which, moreover, fights with method.

\section{SELECTION OF THE HEN.}

THE hen turkey should be dark-colored, like the cock-those with white feathers appearing amidst the black plumage should be rejected; her figure should be plump, and her actions lively and animated. The hen breeds when a year old, or rather in the spring succeeding that in which she herself left the egg; but she is not in her prime until the age of two or three years, and will continue for two or three years more in full constitutional vigor. But whether the breeder prefers to keep a store stock for several years, or a yearly or biennial change, will depend on his views and the general practice of the neighborhood 
around him. It is recommended to keep a first-rate cosk for three or four years, or even longer, although one might change his store flock of hens, and, indeed, if these produced first-rate chickens, he should be in no hurry to substitute younger birds in their place. Of course, the stock, whatever its prescribed number may be, should be kept up, deficiencies by death and accidents being duly supplied.

NUMBER OF HENS TO BE ALLOTTED TO EACH COCK.

IT would appear that an almost unlimited number of hens may be allowed to a single male-in fact the caresses of the male only once or twice are required for the fecundation of all the eggs which she will lay during the current season; but, in order to make assurance doubly sure, the number of hens under one lord may be limited to fifteen or twenty; that is, if it is desirable that so many should be kept.

The number of hens, however, which should be put with one cock is disputed amongst several authorities, as we have seen to be the case with the common fowl. M. Parmentier says, that, when one has a certain number of turkeys, it is indispensable to have a proportional number of cocks ; and is of opinion that one cock will be sufficient for twelve females; and in this number he cannot be far wrong, if once treading is, as he seems to think, proved by experiment, efficient to fecundate all the eggs of one laying. So satisfied, indeed, is he of this fact, that he thinks the cock may be dispensed with and sold, after the hen begins to lay.

Lawrence, on the other hand, advises six hens to a cock; though he thinks more may do no harm; and mentions it, as a common practice with breeders, to keep a cock for the use of any neighbors who may. have so few hens as to render it too expensive to keep one.

\section{IAYING.}

Авочт the middle of March, generally speaking, the female commences laving; she indicates this coming 
event by a peculiar cry, by strutting about with an air of self-satisfaction, and often by prying into out-ofthe-way places, evidently in quest of a secret spot of incubation-for her instinctive dread of the male is not removed by domestication, nor has the male lost his antipathy to the eggs. She should now be closely watched, and some management is required to induce her to lay in the nest assigned her. The nest should be prepared of straw and dried leaves; it should be secluded, and to excite her to adopt it, an egg, or a piece of chalk cut into the form of an egg, should be placed in it. When her uneasiness to lay is evident, and symptoms prove that she is ready, she should be confined in the shed, barn, or place in which her nest, (in a large wicker basket,) is prepared, and let out as soun as it is deposited. It is generally in the morning that the turkey hen lays, and mostly every other day; though some lay daily, until the number amounts to from fifteen to twenty. As the eggs are laid, it is as well to remove them, (leaving the decoy egg or piece of chalk,) until the number is complete, as they are liable to be broken, or sucked by rats, weasles, minks, or skunks. They may then be restored to her for incubation.

Some persons are in the habit of giving turkeys stimulating food at the laying period, in order to promote their fecundity, particularly oats and hemp seed; but this is quite superfluous, and may even, perhaps, be injurious, by tending to produce "clear" or in. fertile eggs. By proper food and shelter, during winter, indeed, turkeys may be brought to pair and lay earlier than they otherwise would do ; but, though this might have the advantage of procuring an earlier brood, it must render it more difficult, on account of the cold weather, in spring, to rear it with success.

The habit of laying in the morning may be usefully taken advantage of, where several turkey hens are kept. Their nests may be examined, individually before they go out, and keep back those which 
are about to lay, till they have done so. This will effectually prevent the loss of a single egg, by laying in a secret nest in the hedges, or woods. When they-roost in the open air, as is most natural to them, and sometimes practised for the sake of convenience, and to render the birds healthy, it is nearly impossible to prevent the loss of some eggs.

During the whole time of laying, the cock must be carefully kept apart from the hen, at least in the morning, when she is laying; otherwise, if he find her on the nest, he will ill-treat her, drive her away, and break her eggs.

EGGS.

The eggs of the turkey are larger and more lengthuned than those of the common domestic fowl, of dull cream color, and speckled with reddish dots. They ought to be taken up as soon as laid, lest the hen, which is heavy and awkward in her motions, should break them on returning to lay, and also to keep them from being sucked by rats or skunks. They may be kept in a basket, either with or without dry bran or straw, hung up in a cool, dry, dark place, till the hen leaves off laying, when none of them will be too old to set for hatching, though, when much older, it may be doubtful whether they will hatch at all.

It is recommended, by some, to keep each hen's eggs distinct, that they may be put under those which laid them ; but this appears to be an unnecessary trouble, as a hen turkey will not only successfully hatch the eggs of her own species, wherever they may be procured, but also those of geese, ducks, and common fowls.

It does not appear from Audubon's account, that the wild turkey has usually more than one brood in the year, unless her eggs have been carried off or destroyed; and Buffon says the tame turkey lays only once a year. The latter is wrong in this ; for, under favorable circumstances, when well housed, fed, and 
taken care of, the hen turkey will lay a second time towards the end of summer, sometimes sooner and sometimes later.

In the second laying, there are rarely more than a dozen eggs; and in order to have the brood from these successful, more than ordinary care will be requisite.

When a second laying is expected, the sooner one hen is turned away from her brood, and the brood mixed with that of another, hatched about the same time, the better chance there is of rearing it; as the hen, which is so turned away, will lay again in a fortnight or three weeks, and thus hatch a second time before the month of July is out. Even under these circumstances, the chance of rearing the young ones is very uncertain, as they are hardly strong enough to meet the cold nights in the autumn, when they often become what is called "club-footed," and die.

\section{INCUBATION,}

ThE turkey hen is a steady sitter, and in this respect resembles the wild bird-nothing will induce her to leave the nest; indeed, she often requires to be removed to her food, so overpowering is her instinctive affection; she must be freely supplied with water within her reach; should she lay any eggs after she has commenced incubation; these should be removed-it is proper, therefore, to mark those which were given to her to sit upon. The hen should now on no account, be rashly disturbed : no one except the person to whom she is accustomed, and from whom she receives her food, should be allowed to go near her, and the eggs, unless circumstances imperatively require it, should not be meddled with.

On about the thirty-first day, the chicks leave the eggs. Now, in a state of nature, the wild hen always manages far better than she would do if interfered with by man, were his interference possible, and so we believe will the domestic turkey hen, if her nest be placed 
(and it might in a certain degree,) as it is in nature; this we know, that turkeys which have laid their eggs in out-of-the-way places, and have been allowed to incubate there, have brought their troop of downy younglings into the farm yard with evident pleasure and satisfaction-no extra attention having been paid to them. It is usual, however, in Europe and the northern parts of the United States, to remove the young chicks, one by one, as they make their exit, and place them in a basket of warm flannel, tow, or feathers, until all are out, and then restore them to the hen; this is done as a precautionary measure, lest any accident should happen to them.

In a state of nature, the turkey only rears one brood. during the season, unless her eggs have been destroyed or removed, nor will the domestic hen incubate twice, if allowed to rear her own brood; some, however, which like, as the common phrase is, "to work a free horse to death," recommend that the turkey be induced to hatch a second time in the season. This is effected by taking her young brood from her as soon as possible, and mixing it with another brood of the same age, as nearly as may be ; her cares being no longer required for her young, and her instincts unsatisfied; she seeks the company of the male, and in about three weeks, again commences laying, until the number of eggs is complete. when she re-engages in the task of incubation. But I object to this practice in toto. It is cruel, and it taxes the system; she has already sat patiently for thirty days, that is four weeks and two days, and surely that is quite enough. Besides, the brood thus hatched will be late in the season, and late broods of turkeys cannot be reared without very great care; they cannot stand the chilly mornings of autumn nor the frosty nights; their limbs become swollen and rheumatic, and they die one after another, few surviving, and these few never become fine, healthy bird from which the breeder would select his stock. Let nature alone. Should a hen lay after hatching her clutch of eggs, and should she, (which is very unlike- 


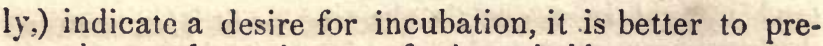
vent her, and use the eggs for household purposes.

\section{TREATMENT OF THE YOUNG BROOD.}

The treatment of the chicks next demands consideration. Some books tell you to plunge them in cold water, to strengthen them; those that survive will certainly be hardy birds. Others say, "make them swallow a whole pepper corn," which is as if we were to cram a Newtown pippin down the throat of a new-born babe. Others, again, say, "give them a little, ale, beer, or wine." We know, unhappily, that some mothers are wicked enough to give their infants gin, and we know the con.sequences. Not a few advise that they be taken away, and kept in a basket by the fire-side wrapped in flannel, for eight or ten hours. Why take them away from her? She has undergone no loss, no pain, nor labor; she wants no rest, having had too much of that already. All she requires is the permission to indulge undisturbed the natural exercise of her owe affectionate instinct.

We have seen that even the wild chicks are delicate, and unable to endure wet. We may say the same with regard to young grouse and partridges, the flocks of which are much thinned by a wet season. But if the wild chicks are tender, much more so are those of the domestic strain. As in the case of young fowls, the turkey chicks do not require food for several hours. It is-useless to cram them, as some do, fearing lest they should starve; and, besides, the beak is as yet so tender that it runs a chance of being injured by the process. When the chicks feel an inclination for food, nature directs them how to pick it up. There is no occasion for alarm if, for thirty hours, they content themselves with the warmth of their parent, and enjoy her care. Yet some food must be provided for them, and this should be, of course, suited to their nature and appetite. Here, too, let the simplicity of nature be a guide. I say this because some have recommended spices, wine, and even bathing in cold water.

Give them nothing; do nothing to them; let them be in the nest under the shelter of their mother's wings at 
least eight or ten hours; if hatched in the afternoon, till the following morning. Then place her on the grass, in the sun, under a roomy coop. If the weather be fine, she may be stationed where you choose, by a long piece of flannel list tied round one leg, and fastened to a stake or a stone. But the boarded coop saves her everwatchful anxiety from the dread of enemies above and behind-the crow, the raven, the hawk, the rat, the weasel; and also protects herself-she will protect her youngfrom the sudden showers of summer. Offer at first a few crumbs of bread; the little ones, for some hours, will be in no hurry to eat; but when they do begin, supply them constantly and abundantly with chopped egg, shreds of meat and fat, curd, boiled rice, mixed with cress, lettuce, and the green of onions. Melted mutton suet poured over barley or Indian-meal dough, and cut up when cold; also, bullock's liver boiled and minced, are excellent things. Barley or Indian meal, mixed thick and stiff with water or milk, nettle tops, leeks, and many other things, might be added to the list; but it is probable that a few of these may now and then be refused by some fanciful little rogues. Little turkeys do not like their food to be minced much smaller than they can swallow it; indolently preferring to make a meal at three or four mouthfuls to troubling themselves with the incessant pecking and scratching in which chickens so much delight. But at any rate, the quantity consumed costs but little; the attention to supply it is everything.

The young of the turkey afford a remarkable instance of hereditary and transmitted habits. From having been tended for many generations with so much care, they appear naturally to expect it almost as soon as they are released from the shell. We are told that young pointers, the descendants of well-educated dogs, will point at the scent of game without any previous training; and so turkey chicks seem to wait for the attention of man before they can have any experience of the value or nature of those attentions. Food which they would refuse from a platter, they will peck greedily from the palm of a hand; a crumb which would be disdained, if seen accidentally on the ground, will be 
relished from the tip of a finger. The proverb that "The master's eye fattens the horse," is applicable to them, not in a metaphorical, but in a literal sense; for they certainly take their food with a better appetite if their keeper stays to distribute it, and see them eat it, than if he merely set it down and left them to help themselves.

I believe this to be the case with more domesticated animals than we are aware of, and appears natural enough if we remember how much more we enjoy a meal in the society of those we love and respect, than if we partook of it in indifferent or disagreeable company.

However, there can be no doubt that young turkeys, pampered and spoiled for about three hundred generations, have at length acquired an innate disposition to rely on the care of man. When the early voyagers discovered new islands, the birds upon them were quite tame, and easily killed by sticks and stones, being fearless of man; but they soon learned to know their enemy, and this newly-acquired sagacity was possessed by their offspring, which had never seen a man. Wild and domesticated turkeys are, in fact, from the same originai type; it is only necessary to compare them, when hatched together under a hen, to be convinced of the principle of hereditary transmission of habits - the wild young ones instantly fly from man, the tame ones are indifferent to his presence. Young of rabbits, wild and tame, show this contrast more strongly than any crea. tures with which I am acquainted.

The turkeys, then, are hatched, and we are rearing them. Abundant food for the mother and her young, constant attention to their wants, are the grand desiderata. An open glade, in a grove, with long grass and shrubs here and there, is the best possible location. A great deal is said about clear and fresh water for turkeys; but I have observed that if left to their own choice, they will be as content and healthy with the rinsings of the scullery, or the muddiest pool, as with the purest spring. The long grass will afford them cover from birds of prey; the hen will herself drive off four-footed enemies with great courage. Insects, too, will abound in such a situation. When the little creatures are three 
or four days old, they will watch each fly that alights on a neighboring flower, fix it with mesmeric intensity, and by slow approach often succeed in their final rush. But in the best position you can station them, forget them not for one hour in the day. If you do, the little turkeys will for a time loudly yelp,

\section{"O then remember me,"}

in notes less melodious than those of a prima donna, and then they will be sulky and silent. When you at length bring their delayed meal, some will eat, some will not. Those that will not, can only be saved by a method at all other times unjustifiable; namely, by cramming; but it must be done most gently. The soft crumb of bread rolled into miniature sausages should be introduced till their crops are full. For drink, many would give wine. I advise milk. The bird wants material, not stimulant. It has been actually wiredrawn. It has grown all the hours you have neglected it, without anything to grow from. Like a young plant in the fine spring season, it will and must grow; but it has no roots in the fertile earth to obtain incessant nourishment. The roots which supply its growth are in its stomach, which it is your office to replenish. "Prevention is better than cure." Such a case ought never to occur in a well-cared-for poultry pard.

The time when the turkey hen may be allowed full liberty with her brood, depends so much on season, situation, \&c., that it must be left to the exercise of the keeper's judgment. Some, whose opinion is worthy of attention, think that if the young are thriving, the sooner the old ones are out with them the better, after the first ten days or so. A safer rule may be fixed at the season called "shooting the red," a "disease," as some compilers are pleased to term it; being about as much a disease as when the eldest son of the turkey's master and mistress shoots his beard. When young turkeys approach the size of a partridge, or before, the granular fleshy excrescences on the head and neck begin to appear ; soon after, the whole plumage, particularly the tail feathers, start into rapid growth, and the "dis- 
ease" is only to be counteracted by liberal nourishment. If let loose at this time, they will obtain much by foraging, and still be thankful for all you choose to give them. Caraway seeds, as a tonic, are a great secret with some professional people. They will doubtless be beneficial, if added to plenty of barley or Indian meal, boiled potatoes, chopped vegetables, and refuse meat. And now is the time that turkeys begin to be troublesome and voracious. What can you expect else from a creature that is to grow from the size of a robin to 12 or $15 \mathrm{lbs}$. in eight or nine months? They will jump into the potato ground, scratch the ridges on one side, eat every grub, wireworm, or beetle that they find, and every half-grown potato. From thence they will proceed to the ruta-bagas; before the bulbs are formed, they will strip the green from the leaves, thereby checking the future growth of the root. At a subsequent period, they will do the same to the white turnips, and here and there take a piece out of the turnip itself. They are seldom large enough before harvest to make so much havoc among the standing grain, as cocks, hens, and Guinea fowls, or they have not yet acquired the taste for it; but when the Indian corn begins to ripen in August or September, and the young wheat comes up in October and November they will exhibit their graminivorous propensities, to the great disadvantage of the farmer. The farmer's wife sees them not, says nothing, but at Christmas boasts of the large amount of her turkey money. One great merit in old birds, (besides their ornamental value, which is our special recommendation,) is, that in situations where nuts, acorns, and mast are to be had, they will lead off their vrood to these, and comparatively, (that is all,) abstain from ravaging other crops. It is, therefore, not fair for a small occupier to be overstocked with turkeys, (as is too ofter the case, and with other things also,) and then let them loose, like so many harpies, to devastate and plunder their neighbors' fields.

FATTENING.

ON the first of October, it will be time to begin to think of fattening some of the earliest broods, in order 
to supply public houses, and such families as require turkeys early in the season; but they are like every other immature production, inferior in quality. To eat turkey poults is a wasteful piece of luxury; those who order them are occasionally deceived by a small hen of the previous year. In the Italian markets, hen turkeys sell for a cent a pound more than the cocks; and there are turkey butchers of whom you may buy the half or a quarter of a bird. A hen will be five or six weeks in fatting; a large stag,* two months, or longer, in reaching his full weight. The best diet is barley or Indian meal, mixed with water, given in troughs, that have a flat board over them, to keep dirt from falling in. A turnip with the leaves attached, or a hearted cabbage, may now and then be thrown down to amuse them. Some use plain oats, but barley or Indian meal is preferable, acting more quickly.

Cramming is unnecessary, though it may hasten the progress. In some forests, where there are immense quantities of mast, turkeys will get perfectly fat upon them; but this, although no doubt profitable to the "gude wife," is by no means pleasant to every palate after the bird has been on the spit. Beech mast, however, in small quantities, and as the substratum of fatting, rather improves the flavor than otherwise. Acorns, which they will often swallow whole, do not come amiss. When they have arrived at the desired degree of fatness, those which are not wanted for immediate use must have no more food given them than is just sufficient to keep them in that state; otherwise the flesh will become red and inflamed, and of course less palatable and wholesome. But with the very best management, after having attained their acmè of fattening, they will frequently descend again, and that so quickly, and without apparent cause, as to become quite thin. Cock birds play this game oftener than hens. The turkey differs from the rest of our poultry in being fit for the table after its youth is past. Many

"When a cock turkey arrives at the age of two yeare, be is called a "stag." 
of the large birds that are brought to market are not less than eighteen months old; some double that age. Nor are they the worse for it, provided the lady of the house be informed of the circumstance, and so enabled to leave a due interim between the killing and the cooking.

Almost every district or country, however, has a peculiar mode of fattening turkeys, and everywhere it depends on local resources. In one place, it is acorns, hickory nuts, beech mast, or chestnuts, sometimes boiled, and mixed with Indian or barley meal; others prefer to feed them, every morning, a month previous to killing, with boiled potatoes mashed with the meal of buckwheat, barley, Indian corn, or beans, according to their cheapness or abundance, made into a paste, of which the turkeys are allowed to eat as much as they please. Every evening, the remains of the paste is removed, and thrown away; the trough, or vessel, in which it was kept, is thoroughly cleaned for the next morning; because, if the weather be warm, the paste is liable to become sour, and endanger their health. For eight days previous to slaughtering time, the turkeys are allowed, in the evening before going to roost, a small quantity of barley or Indian-meal dough, which, in the course of that period, will render them exceedingly plump, delicious, and fat.

It has been asserted, in fact proved, by a late trial made on the farm of Mr. R. L. Colt, of Paterson, New Jersey, that turkeys fatten faster, and with less expense, by caponising them, which, also, produces better and sweeter flesh. But how far this will prove profitable, future experiments will show. 


\section{THE GUINEA FOWL。}

\section{ORIGIN AND HISTORY.}

The Africana, which most people call a Numidica, is like a Meleagris, except that it bears on its head a red helmet and comb, both of which are blue in the Meleagris.

Columella.

The Guinea fowl, in its natural habitat-that is in a state of nature-appears to be exclusively confined to the burning wastes of Central Africa, although it is found wild on the islands of Ascension, Hayti, Cuba, and Jamaica, where they sometimes do much injury to crops and are shot as game. In Africa, it frequents the open glades and borders of forests, the banks of rivers, and other localities where grain, seeds, berries, insects, \&c., offer an abundant supply of food. It is gregarious in its habits, associating in considerable flocks, which wander about during the day, and collect together on the approach of evening. They roost in clusters on the branches of trees, or large bushes, ever and anon uttering their harsh grating cry, till they settle fairly for the night.

The Guinea fowl does not trust much to its wings as a means of escape from danger; indeed, it is not without some difficulty that these birds can be forced to take to flight, and then they wing their way only to a short distance, when they alight, and trust to their swiftnesss of foot. They run with very great celerity, are shy and wary, and seek refuge 
amongst the dense underwood, threading the mazes of their covert with wonderful address. The female incubates in some conceaked spot on the ground; for the male, as in the case of the turkey, will break the eggs if he discovers them. This habit, unnatural as it may be deemed, appears to be very common among gallinaceous birds. The domestic cock, however, evidently shares in the triumph of the hen, when she has laid her eggs, and answers her peculiar note or cackle of joy.

It cannot be for a moment doubted that the ancient Greeks and Romans were well acquainted with two or three species of the Guinea fowl, the descriptions of which hardly answer to those of the present day ; consequently it is not easy to trace out its history. In fact, strange as it may seem, that a bird noticed by Aristotle, Clytus, Pliny, Varro, and Columella, should not ages since have pervaded Europe ; it is not until after the introduction of the turkey from America, that the Guinea fowl became naturalised in Western Europe. Must we not, then, pardon Belon and Aldrovandi for considering the turkey as the Meleagris, seeing, if our suspicions be correct, that they did not know the Guinea fowl ? In short, from ancient times, through the middle ages, and to a comparatively recent period, we lose all trace of this bird, and what is more, it appears that the modern Europeans received it not from Africa, its native country, but from the Western World, to which, with negroes torn from their homes in Guinea and condemned to slavery, it was transported also. This bird is, indeed, so common in several of the West-India Islands, that some have thought it to be indigenous there; but this is a mistake. In fact, in an old work, (Observ. sur les Cout. de l'Asie,) we are informed that, in the year 1508, or about that time, great numbers of these birds were carried into America by the vessels which traded in slaves; but that the Spaniards, instead of attempting 
to tame them, or render them domestic, turned them at large into the wild savannas, where they have in. creased in such prodigious numbers, that they may well appear to be indigenous.

Though extensively spread, the Guinea fowl is not even now a very common bird. It is kept in India, but, according to Colonel Sykes, is to be seen only in a domestic state, and is bred almost exclusively by European gentlemen. It thrives, he adds, as well as in its native country.

In England, the Guinea fowl is less generally kept than the turkey, nor is it abundant in France. In the colder latitudes of Europe, this bird is very rare, and is, in fact, seldom, if ever, to be seen in Sweden, Norway, or Northern Russia. It is not noticed by Linnæus in his "Fauna Suecica," though he was well acquainted with the species. In various parts of North America, it is found, and thrives well.

If, then, in modern days, Western Europe received the Guinea fowl from America, or the adjacent islands, how happens it that, living as it did in the vivaria of the Romans, it should not have spread itself over Europe, and been common in England, from early times ? We are assured that it has been so. Mr. H. D. Richardson says, "it would be difficult to determine the precise period at which the Guinea fowl was first. brought into Great Britain; its introduction must, at all events, have taken place at a remote date, for we are informed, in Kennet's "Parochial Antiquities," that it was known in Fingland as early as the year 1277." If this be the case, how happens it that we see no notice taken of it among such birds as peions, or peacocks, cranes, bustards, and other birds, which figured in the feasts of our British ancestors, nor even at a later time, than the turkey graced the board? Again, had the Guinea fowl been cornmon, would Belon and Aldrovandi have ever regarded the turkey as the Meleagris? 


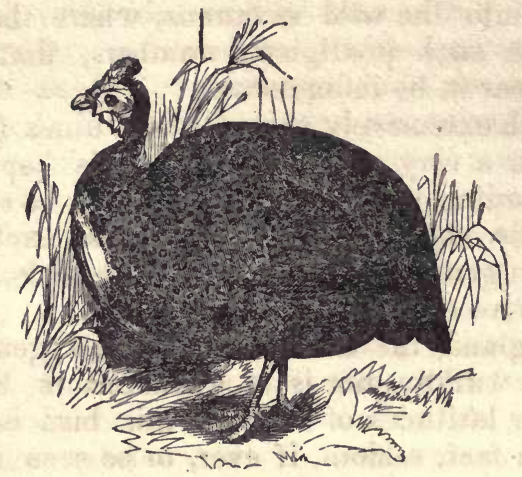

THE GUINEA HEN.

Sycorymes.-Numida meleagris, of Naturalists; Pintade, of the French ; Pintada, of the Spaniards; Perlhuhn, of the Germans ; ComeBack, in Norfold, England ; Guinea Hen, Guinea Fowl, of the English and Anglo-Americans.

The plumage of this bird is singularly beautiful, being spangled over with an infinity of white spots on a black ground, shaded with grey and brown. The spots vary from the size of a pea to extreme minuteness. Rarely, the black and white change places, causing the bird to appear as if covered with a network of lace. A white variety is not uncommon, but is less hardy, and it is doubtful how long either this, or the former one, would remain permanent ; probably but for few generations. Pied birds, blotched with patches of white, are frequent, but are not comparable, in point of beauty, with those of the original wild color. The head and face are remarkable. The scarlet wattles, naked skin, distinct mark of the eye brow, bright, glancing eyes, and comical, quick expression, make, at a front view, a perfect miniature of a clown, dressed and painted for the circus or pantomime.

DISTINCTION BETWEEN THE COCK AND HEN.

IT is not every one who knows a cock from a hen of this species. An unerring rule is, that the hen 
alone uses the call note "come bàck," "come bàck," accenting the second syllable strongly, from which they are often called "come bàcks." The cock has only the harsh, shrill cry of alarm, which, however, is also common to the female.

\section{PAIRING.}

There is one circumstance, in regard to the habits of the Guinea cock, which may not generally be known; that is, he is monogamous, or having one wife only, pairing with his mate, like a partridge, or pigeon, and remaining faithful to her, (perhaps with one or two trifling peccadilloes, ) so long as they continue to live together. It is generally supposed that he, like the common cock, is pleased with a plurality of wives; and the supposition is acted on with bad practical effect. In the case where a Guinea cock and two hens are kept, (a usual number,) it will be found, on close observation, that though the three keep together so as to form one "pack," according to their original instinct, yet that the cock and one hen will be unkind and stingy to the other unfortunate female, keep her at a certain distance, merely suffering her society, and making her feel that she is with them only on sufferance. The neglected hen will lay eggs, in appearance, like those of the other, but not so many, probably, in the same nest. If they are to be eaten, all well and good; but if a brood is wanted and the eggs of the despised one chance to be taken for the purpose of hatching, the result is disappointment and addled eggs. If the produce of the favorite, or rather the lawful wife, are selected, at the end of the month, you have so many strong chicks ; if a mixture of eggs come to hand, the hatch is in proportion Therefore, let all those who wish to succeed with Guinea fowls, match their birds as strictly as the couples in a country dance. The best way to commence keeping them is, to procure a sitting of eggs from some friend, on whom you can depend, for their freshness: and 
also, if possibe, from a place where only a single. pair is kept.

Their amours are conducted with the most strict decorum and privacy. The cock, however, is properly polite and attentive to his own hen, in public, walking very close by her side, so as to touch her wings with his own, offering her tit-bits, now and then a worm, or a grain of corn; he has also a habit of running very quick for a few steps, and then walking affectedly on tiptoe, with a mincing air, like the dandy in a Christmas pantomime, setting up his back and increasing his apparent height. These latter symptoms are less evident in youth, when it is necessary to make the selection, and the call note will be found the safest guide. He attends his own hen to the nest, waits for her close at hand, till she has made her contribution to the treasury already there; and will occasionally betray the situation of the secret hoard, by his extreme solicitude in announcing the approach of intruders.

\section{IAYING.}

OF all known birds, this, perhaps, is the most prolific of eggs. Week after week and month after month see little or no intermission of the daily deposit. Even the process of moulting is sometimes insufficient to draw off the nutriment the creature takes to make feathers instead of eggs. As the body of a good cow is a distillery for converting all sorts of herbage into milk, and nothing else, or as little else as possible, so the body of the Guinea hen is a most admirable machine for producing eggs out of insects, vegetables, garbage, or grain.

Eggs of the Guinea fowl are occasionally produced covered with wrinkles, as if the shell had shrunk in the process of hardening. These sometimes are confined to one end, (the smaller,) and sometimes extend over the whole surface. They are evidently the result of weakness or over-exertion of the egg organs, appearing in young and healthy birds only at the close 
of their long-laying season; in old and weak ones, showing themselves in the first-laid eggs, and increasing in depth and extent as the season advances. The same thing is less frequently seen among turkeys that are about to cease laying. Such eggs are quite good for the table, but should not be taken for the purpose of hatching. They appear to contain a less portion of yolk than the perfect egg.

\section{INCUBATION.}

From their great aptitude for laying, which is a natural property, and not an artificially-encouraged habit, as before observed, and also from the very little disposition they show to sit, it is believed, that these birds, in their native country, do not sit at all on their eggs, but leave them to be hatched by the sun, like ostriches, to which they bear a close affinity. It is certain that the sands of tropical Africa are more than hot enough to hatch them, and that the young birds are unusually vivacious and independent, if they have but a supply of proper food, which they would find in the myriads of insects engendered there.

They are in season from the middle of December till May; and their period of incubation lasts at least twenty-six days.

A Bantam hen is the best mother, being lighter, and less likely to injure the eggs by treading on them than a full-sized fowl. She will well cover nine eggs, and incubation will last about a month. The young are excessively pretty. When first hatched, they are so strong and active as to appear not to require the attention really necessary to rear them. Almost as soon as they are dry, from the moisture of the egg, they will peck each other's toes, as if supposing them to be worms, will scramble with each other for a crumb of bread, and will domineer over any little Bantam, or chicken, that may perhaps have been brought off in the same clutch with themselves. No one, who did not know, would guess, from their appearance, of what species 
of bird they were the offspring. Their orange-red bills and legs, and the dark, zebra-like stripes, with which they are regularly marked, from head to tail, bear nn traces of the speckled plumage of their parents.

\section{FEEDING AND MANAGEMENT.}

HARd-Boiled egg, chopped fine, small worms, maggots, bread crumbs, chopped meat, or suet, whatever, in short, is most nutritious, is their most appropriate food. This need not be offered to them in large quantities, as it would only be devoured by the mother Bantam, as soon as she saw that her little ones had for the time satisfied their appetites; but it should be frequently administered to them in small supplies. Feeding three, four, or five times a day, is not nearly often enongh; every half hour, during daylight, they should be tempted to fill their little craws, which are soon emptied again by an extraordinary power and quickness of digestion. The newly-hatched Guinea fowl is a tiny creature, a mere infinitesimal of the full-grown bird; its growth is consequently very rapid, and requires incessant supplies. A check once received can never be recovered. In such cases, they do not mope and pine, for a day or two, like young turkeys under similar circumstances, and then die; but in half an hour after, being in apparent health, they fall on their backs, give a convulsive kick or two, and fall victims to starvation. The demands of nature for the growth of bone, muscle, and particularly of feather, are so great, that no subsequent, abundant supply of food can make up for a fast of a couple of hours. The feathers still go on, grow ! grow !! grow !!! in geometrical progression, and drain the sources of vitality still faster than they can be supplied, till the bird faints and expires from want of fullness.

This constant supply of suitable food, it is believed, is the great secret in rearing the more delicate birds, turkeys, Guinea fowls, pheasants, \&c., never to suffer the growth of the chick, (which goes on whether it 
has food in its stomach or not,) to produce exhaustion of the vital powers, for want of the necessary aliment. Young turkeys, as soon as they once feel languid, from this cause, efuse their food when it is at last offered to them, (just like a man whose appetite is gone, in consequence of having waited too long for his dinner,) never would eat more, were it not forced down their throats, by which operation they may frequently be recovered; but the little Guinea fowls give no notice of this faintness, till they are past all cure ; and the struggle of a few minutes shows that they have, indeed, outgrown their strength, or rather that the material for producing strength, has not been supplied to them in a degree commensurate with their growth.

A dry, sunny corner in the garden will be the best place to coop them with their Bantam mother. As they increase in strength, they will do no harm, but a great deal of good, by devouring worms, grubs caterpillars, maggots, and all sorts of insects. By the time their bodies are little bigger than those of sparrows, they, will be able to fly with some degree of strength ; and it is very pleasing to see them essay the use of their wings at the call of their fostermother, or the approach of their feeder. It is one out of millinns of instances of the Provident Wisdom of the Almighty Creat , that the wing and tail feathers of young gallinaceous birds, with which they require to be furnished, at the earliest possible time, as a means of escape from their numerous enemies, exhibit the most rapid growth of any part of their frame. Other additions to their complete stature-are successively and less immediately developed. The wings of a chicken are soon fledged enough to be of great assistance to it; the spurs, comb, and ornamental plumage do not appear till quite a subsequent period.

When the young Guinea fowls are about the size of quails, or perhaps a little larger, their mother Bantam, (which we suppose to be a tame, quiet, matronly crea- 
ture,) may be suffered to range loose in the orchard and fields and no longer be permitted to enter the garden, lest her family should acquire a habit of visiting it at a time when their presence would be less welcome than formerly. They must still, however, receive a bountiful and frequent supply of food; they are not to be considered safe till the horn on their heads is fairly grown. Indian meal, as a great treat, cooked potatoes, boiled rice, anything in short, that is eatable, may be thrown down to them. They will pick the bones left after dinner with great satisfaction, and no doubt, benefit to themselves. The tamer they can be made, the less troublesome will those birds be which you retain for stock; the more kindly they are treated, the more they are petted and pampered, the fatter and better-conditioned will the others become, which you design for your own table, or as presents to your friends, and the better price will you get, if you send them to market.

At a certain period, they will have got beyond the management of their good little Bantam mother, and will cast off her authority. They will form what has appropriately been called a "pack ;" prowling about in a body, after insects, and seeds, or grazing together, (for they eat a great deal of grass,) still in a pack; fiercely driving away any intruder on their society, and all giving tongue, in one chorus, at the approach of any danger. When fully grown, they weigh from 3 to 4 lbs.

Birds, thus reared on the spot where they are meant to be kept, are sure to thrive better, and give less trouble than those procured from a distance; they sometimes, will not remain in their new home, but wander about in search of their old haunts till they either find them, or are themselves lost, destroyed, or stolen.

It is of no use to shut up these fowls to fatten, unless, they have previously been made particularly tame, as they would sulk, pine, and die, before they 
became reconciled to confinement, in spite of its extra diet. The only plan, therefore, is to keep them in high condition during the winter, by liberal hand-feeding. The best practice is not to kill them with the knife, like other poultry, but to dislocate their necks, leaving the blood in them to remedy the dryness of their flesh, which is the great fault an epicure would find with them. They should also remain in the larder as long as possible before being cooked. It was formerly the fashion for farmers' wives and daughters to make tippets and muffs of the smaller feathers; which much resemble chinchilli fur in appearance, and were both elegant and useful.

This bird is no great favorite with poultry keepers, in general, but is one of those unfortunate beings, which, from having been occasionally guilty of now and then a trifling fault, has acquired a much worse reputation than it really deserves. Notwithstanding this, it is useful, ornamental, and interesting during life, and a desirable addition to the table, if properly dressed, when dead. 


\title{
THE PEA FOWL.
}

\author{
ORIGIN AND HISTORY.
}

\begin{abstract}
The peacock view, still exquisitely fair, When clouds forsake, or when invest the air , His gems now brightened by a noon-tide ray; He proudly waves his feathers to the day, A strut majestically slow assumes, And glories in the beanty of his plumes.
\end{abstract}

PARAPHRASE OF The BoOK Or JoB.

THE common pea fowl has probably been tamed and domesticated ever since there have existed human eyes to admire it. It is said to have been brought from the barbarians into Greece; and being for a long time rare, it was then exhibited for money to the admirers of beauty in a similar manner as menagerie birds are with us, at the present day. At Athens, both men and women were admitted to examine it every new moon, and profit was made by the show; and, as Antyphon says in his speech against Crasistratus, the male and female were valued at 1,000 drachmæ, or about $\$ 150$ the pair.

The remarkable point in this account is, that the creature was not gratuitously exhibited, like the triumphal spoils of conquered nations, but was made a wild-beast show, for a consideration, and as a matter of gain. It would be interesting to know the price of admission, what sort of "brass band" performed before the doors, and whether the pictorial representations, 
hung outside, at all outrivalled the brilliant display of Barnum's Museum, in Broadway.

So charming is the perfect combination of grace and splendor diplayed by these most lovely creatures, so excellent is their flesh, so hardy are they in their adult state, that were it not for certain inconveniences attendant upon keeping them, and also, perhaps, for the indifference with which everything not rare is apt to be regarded by us, they would be sought after as never-tiring objects wherewith to gratify the sense of sight. Who does not remember the thrill of delight with which, in childhood, he first gazed upon their brilliant gorgeousness? Peacocks and gold fill our youthful imaginations as fit elements of the magnificence of Solomon; and no fable more fitly chose its decorations than that which attached these feathered gems, in association with the many-colored Iris, to the train of the imperial Juno, who adorned its tail with the hundred eyes of Argus - eyes which the poet calls "star-like gems." Even the hen of the pea fowl, though sober in her coloring, is harmoniously shaded, and every movement is coincident with the line of beauty.

But the most extraordinary peacock in the world, altogether unique, and likely to remain so, whose value reduces that of the Athenian birds to a mere nothing, and which is only to be approached in this respect by the goose which lays golden eggs, if we could find her, is kept at Windsor Castle, and long may her Majesty, Queen Victoria, continue in possession of it. Not being larger than an ordinary hen, it consumes but little food; and does no mischief in the gardens, but rarely permitted to go abroad. It would be cheap at $£ 30,000$; for, independent of its worth as a trophy, and the strange history attached to it, its tail is made up of diamonds, and the rest of its body is composed of other costly materials, of which gold is the least precious! It is a specimen of ornamental poultry, and not unsuitable, perhaps, to the monarch 
of Great Britain; but if I may presume to guess at the tastes of the royal owner, more pleasure is derived from the sight of her living models than from the inanimate splendors of this glittering toy, although it does so far-

Outshine the wealth of Ormus and of Ind,

Or where the gorgeons East with richest hand

Showers on her kings barbaric pearl and gold.

Mirton.

That the peacock should, in all times, have been admired for its singular beauty is not surprising. When it moves along in state with its wings lowered to the ground and its tail spread, the rays of the sun glancing upon its gorgeous plumes, iridiscent with metallic effulgence, the eye of every beholder is arrested, and all gaze with admiration on the glorious spectacle. When we talk of the peacock spreading its tail, we use popular language. The gem-adorned plumes, with their loose silken barbs, are not the tail, but the tail coverts. The tail is beneath these, and hidden by them, and consists of rather short, stiff rust-colored feathers, which serve as a support to the train.

I would here willingly give an account of the habits and manners of the wild pea fowls in the jungles of India, parallel to that of the wild turkey of the American forests, but no Wilson, no Audubon, no Bonaparte, has written their history, and, for myself, I have never seen one in its native woods. I might, indeed, transcribe much respecting pea-fowl shooting from the works of various writers, sportsmen in India ; but from all this we gain no positive information. The reader must, therefore, pardon me for the meagre history of the wild bird. However, what it is in captivity in our country, that it is in the forests of India, domestication having little influenced its nature.

There can be little doubt that the splendor of this bird first attracted the notice of the ancients, yet in luxurious Rome, its beauty was not its safeguard; on 
the contrary, it was slaughtered in very wantonness, for the sake of a few parts only deemed worthy of being introduced as small items in the dishes of royal lunatios or noble madmen. The sneer of Martial must, in his day, have been biting; he saw the peacock in its glory, and then beheld it murdered for the sake of its brains. Well might he say-

\footnotetext{
"Oft as the bird his gem-started plumes displays

In admiration dost thou stop to gaze,

And canst thou then, hard-hearted, take its life,

And coolly give it to your hireling's knife."
}

Of the favorite dishes of the Emperor Vitellius, called the buckler of Minerva, was prepared with the livers of a choice fish, the scarus, (Scarus creticus,) the tongues of flamingos, and the brains of peacocks. The bird figured also in the feasts of Hortensius and other sensualists.

GEOGRAPHICAL DISTRIBUTION.

The pea fowl is extensively spread in a wild state, in India and the Indian Islands. It is abundant in the dense woods of the Ghauts, and is readily domesticated, many of the Hindoo temples in the Dukhun, as Colonel Sykes informs us, having considerable flocks of them. On comparing specimens of the wild bird with the domesticated pea fowl of our country, he found no difference in any respect. "Irides intense red-brown," or rather, he should say, blood-red.

The wild pea fowl associates in numbers, and where a favorite feeding ground invites them, hundreds sometimes collect together, but they are very wary, and run with extreme velocity.

Colonel Williamson, in his account of peacock shooting, states that he has seen them in astonishing numbers about the passes in the jungletery district. Whole woods were covered with their beautiful plu. mage, to which the rising sun imparted additiona! brilliancy; he states that small patches scattered about, cultivated with mustard which was then in bloom, induced the birds to collect there for the sake 
of feeding on the plant, and he speaks of the beauty of the scene as enchanting, and so indeed it must have been; for he adds, "I speak within bounds when I assert that there could not be less than twelve or fifteen hundred pea fowls of various sizes within sight of the spot where I stood for near an hour."

The common peacock was, till lately supposed to he the only species of its genus; but both preserved and living specimens of the Aldrovandine pea fowl, which, for a long while, was supposed fabulous, have been recently introduced into England. But there is also a third sort, which, on account of the confusion of synonymes, has not received from naturalists the attention it deserves. The difficulty has been increased by the conversion of "Japan" into "japanned" by some writers. Japonensis, or Japonicus, are not, however, synonymous with Javanensis nor Javanicus; Java and Japan are countries separated by many hundreds of miles of distance, even by many degrees of latitude and longitude. Yet Sir W. Jardine, in the "Naturalist's Library" gives the Pavo javanensis as the same as the Japan peacock. His figure represents the Java bird, as also does that in Griffith's edition of Cuvier's "Animal Kingdom," although the title "Japan Peacock" is added to it. It is possible that both species may be indigenous in one or both of these respective countries, in which case, the specific names are not wrong, but only confused.

The Japan peacock is somewhat less in size than the common, the white patches of naked skin on the cheeks are smaller, the wings are blue-black, edged with metallic-green instead of being mottled like tortoise shell, the imbricated feathers on the back are smaller and less conspicuous, and the whole coloring of the bird is of a darker tone. The hen, on the contrary, is much lighter than the common sort, with a tendency to spangled, perhaps even ocellated, plumage all over her body, and she has scarcely any glistening feathers on the neck; her size is also inferior, and her proportions more slender. 


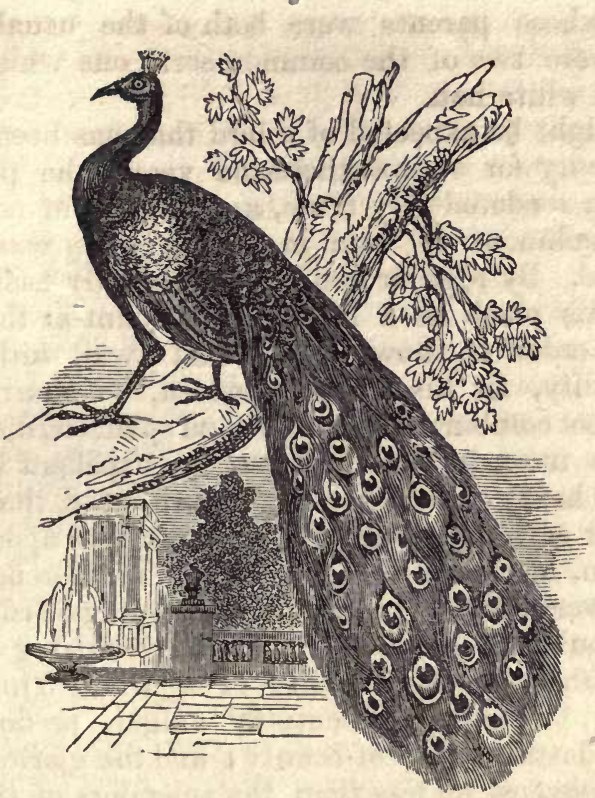

THE PEACOCK.

Synonymss.-Pavo cristatus, of Naturalists ; Mohr, of the Mahrattas ; Paon, of the French; Pavon, Pavo real, of the Spaniards; Pfau, Pfauhahn, of the Germans ; Peacock, of the English and Anglo-Americans.

-The pea fowl is too well known to require a detailed description. There are two varieties of this species, the "pied" and the "white." The first has irregular patches of white about it, like the pied Guinea fowl, the remainder of the plumage resembling the original sort. The white have the ocellated spots on the tail faintly visible. These last are tender, and are much prized by those who prefer rarity to real beauty. They are occasionally produced by birds of the common kind, in cases where no intercourse with other white birds can have taken place. In one instance, in the same 
brood, whose parents were both of the usual colors, there were two of the common sort, one white cock, and one white hen.

As might be expected of a bird that has been reared in captivity for several thousand years, the pea fowl has been rendered very tame, and capable of considerable attachment to man in almost every country in the globe. By regular feeding, it has easily been made to take its place as a liveried attendant at the front door, in order to show himself, and await with great punctuality, for his meals. Indeed, so charming is the perfect combination of grace and splendor, displayed by these most lovely creatures, so excellent is their flesh, so hardy are they in their adult state, that, were it not for certain inconveniences, attendant upon keeping them, and also, perhaps, for the indifference with which everything not rare is apt to be regarded by us, they would be sought after as never-tiring objects wherewith to gratify the sense of sight. "Thus does curiosity, in minds essentially vulgar, predominate over the lasting sense of beauty; and the glories of the visible heavens, no less than the splendors of the peacock, are passed with indifference by unreflecting millions, because both are every-day sights."

The natural disposition of the peacock is selfish and gluttenous, and it is only by pampering this weakness that he can be persuaded into obedience and attachment. $\mathrm{He}$ is vain, and at the same time ungallant. $\mathrm{He}$ is far from manifesting the politeness and attention which the common cock shows towards his mates. The peacock will greedily snatch from the mouth of his hens those tit-bits and delicate -morsels which the cock would either share with his favorites, or yield to them entirely. The peahen, in return, cares less for her lord and master, and is more independent of him, when once her amorous inclinations have been indulged. She then regards the display of his tail, his puffings and struttings, and all the rattling of his 
quills, with the coolest indifference. Nor does he seem to care much about her admiration, or to make all this exhibition of his attractions to secure her notice, but is content, if he can get some astonished hen, or silly bewildered duck, up a corner, to wonder what all this fuss is about. Like other vain coxcombs, he expects the lady to make the first advances. Although occasionally cruel, the peacock is shy of fighting, particularly when in full plumage; nor do these birds so frequently engage with each other as with those of a different species, such as drakes, cocks, \&c. One, out of feather, was seen to keep up a three-hour struggle with a musk drake; had it been in full plumage, it would not have shown fight at all.

Another objection to them, is their alleged wanton destructiveness towards the young of other poultry, a propensity respecting which, the accounts are very contradictory. It is believed, however, that the peacock becomes more cruel as he advances in life, although they often vary in their dispositions. A writer on this point says, "I have known them to kill from twelve to twenty ducklings, say from a week to a fortnight old, during one day; but if they come across a brood of young chicks or ducklings, a few days old, they would destroy the whole of them." And yet, in the face of all this condemnatory evidence, we now and then see a favorite bird, with neck of lapis lazuli, back of emerald, wings of tortoise shell, and tail outshining the rainbow, in some old-fashioned farm yard, the pet of his mistress, who is, perhaps, the most successful poultry woman in the neighborhood, and whose stock shows no sign of any murderous thinning. The peahen, which, when she has eggs or young, seems really a more guilty party, is not, in general, even suspected. So true is it that "one man may steal a horse, while another must not look over a hedge."

Nervous and fastidious persons object to their cry, or call, which, indeed, is not melodious; and a strip of woollen cloth is sometimes hung round their necks 
in the fashion of a collar, to silence them; the appendage, however, is anything but an ornament, and the effect is not permanent. But it must be regarded ats an unhealthy symptom, when any natural or rural sound is displeasing to the ear. The bleating of sheep, the pattering of rain, the hum of bees, the pealing thunder, the laughter of children, the breezy rustling of a grove, the lashing of wintry waves, and the sighing of summer winds, have all been felt by listeners in their happiest moods to be most musical, - to have an effect more touching than any music; and should, therefore, be welcome, instead of distasteful, to the healthy sense. And even the screams of pea fowl, ringing from a distance on a summer's evening, will suggest an abundance of images and recollections that cannot fail to interest any but the most dull and unimaginative minds.

\section{RANGE AND DOMESTIO ACCOMMODATION.}

The causes which disincline many persons from indulging themselves with the daily spectacle of this inapproachable model of beauty, are, in the first place, the depredations that it commits upon gardens. For this, there is no help. The dislike which these birds have to enter a fowl house, and their decided determination to roost on trees, or lofty buildings, prevents our exercising a control which should restrain them from mischief till an eye can be kept upon their movements. At the first dawn, or at the most unsuspected moments, they will steal off to the work of plunder. A mansion, therefore, the fruit and vegetable garden of which is at a distance, is almost the only place where they can be kept without daily vexation. The injury they do to flowers is comparatively trifling; though, like the Guinea fowl, they are great eaters of buds, cutting them out from the axils of the leaves as cleanly as a surgeon's dissecting knife would do. They must also have a dusting hole, which is large and unsightly; but this can be provided for them in some 
out-of-the-way nook ; and by feeding and encouragement, they will soon be brought to dispose themselves into a tableaux vivant, at whatever point of view the tasteful eye may deem desirable. No one with a very limited range should attempt to keep them at all. But where they can be kept, they should be collected in considerable numbers, that their dazzling effect may be as impressive as possible. It should be understood, however, that no vineyard be at hand The greenness and sourness of the grapes, which caused the fox to refrain, would be but a weak argument with them.

Old birds, received at a distance, are difficult to settle in a new home. Housing they do not like, and will scarcely bear. Most liberal feeding is the best bond of attachment, but even with that, they will unexpectedly be off, and will, perhaps, be stopped on the high road, like other suspicious vagrants. It is recommended to procure a sitting of eggs, place them under $q$ hen turkey, and have the pleasure of watching their whole progress, literally $a b$ ovo. Those who are impatient to have a full-grown stock, should still select birds not more than three years old.

LAYING, BROODING, AND SUBSEQUENT TREATMENT.

In general, the peahen makes her nest on the bare ground, amongst nettles, or rank weeds ; sometimes she chooses the shelter of a young fir. The egg very much resembles that of the ostrich in miniature, being smooth, but indented all over with little dimples, as if pricked with a large pin. It is somewhat bigger than a turkey's egg, bulging considerably at the larger end, of a dull, yellowish-white, and occasionally, but not always, spotted, or rather freckled, with a few small reddish-brown marks. The newly-hatched chicks are streaked on the head and neck with alternate stripes of dingy-yellow and pale-brown; the legs are of a dusky-yellowish tinge.

The probable term of life of the pea fowl is eighteen or twenty years; and the young poults may be eaten 
at nine months old. The female does not lay till her third summer; but she then seems to have an in. stinctive fear of her mate, manifested by the secrecy with which she selects the place for her nest; nor, if the eggs are disturbed, will she go there again. She lays from four or five to seven. If these are taken, she will frequently lay a second time, in the course of the summer, which plan is recommended to those who are anxious to increase their stock. She sits from twenty-seven to twenty-nine days. A common hen will hatch and rear the young; but the same objection lies against her performing that office, except in very fine, long summers, for the pea fowl, as for turkeys; namely, that the poults require to be brooded longer than the hen is able conveniently to do. A turkey will prove a much better foster mother in every respect. The peahen should, of course, be permitted to take charge of one set of eggs. Even without such assistance she will be tolerably successful.

The chicks are engaging little things, most elegant in appearance, very tame and confident. They may be made to sit upon the hand to peck flies from the window. The same Wise Provision is evinced by them, as in the Guinea fowl, but still in a greater degree. The demands of nature for the growth of bone, muscle, and particularly of feathers, are so great, that no subsequent abundant supply of food can make up for a fast of a couple of hours. The feathers still go on, grow! grow!! grow!!! in geometrical progression, and drain the sources of vitality still faster than they can be supplied, till the young birds faint and expire from want of fullness.

Their native jungle, in India, tall dense, sometimes impervious, swarming with reptiles, quadrupeds, and even insect enemies, would be a most dangerous habitation for a little tender thing, that can but run and merely squat. Accordingly, they escape from the egg with their quill feathers very highly developed. In three days, they will fly up and perch upon anything 
a yard in height; in a fortnight, they will roost on trees, or the tops of sheds; and in a month or six weeks, you would see them on the ridge of the barn, if there are any intermediate low stables, or other building, that would help them to mount from one to to the other.

If fatted, the pea fowls should be shut up together with any turkeys they may have been in the habit of associating with, and fed exactly the same. If confined alone, they pine. They are, however, an excellent viand at a much more advanced age, and without any more fatting, provided they have been well fed, and killed at a proper season; that is, when they are not renewing their plumage, and are in the larder hung up a sufficient time before cooking. A disregard to these points has probably led to their being so little appreciated as a dainty dish. Pork, in the dog days, and illegal oysters, might, in a similar manner, give a bad repute to other good things, did we not manage them better. When dressed for table, they should be larded over the breast, covered with paper, roasted by a gentle fire, and served with brown gravy, exactly like partridges or pheasants. When moulting; extra diet and varieties of food, including hemp seed and animal sub. stances, are most desirable. 


\section{THE TAME, DUCK.}

ORIGIN AND HISTORY.

It would be curious to know when this species was first domesticated; but, reader, the solntion of such a question is a task on which I shall not renture.

AUduBor.

In regard to the origin of the ordinary farmyard duck, but one leading opinion seems to have prevailed in all the compilations from Aldrovandi down to Audubon, that it is nothing more than the tame descendant of the common wild duck, (Anas boschas,) of Europe, or the old English mallard. It is a pity to disturb so plausible and general a belief; but an attempt to approximate to the solution of Audubon's problem "when this species was first domesticated," has raised some doubts upon the subject, which it is of no use to suppress. One thing, however, is very certain - the wild breed and the tame will freely intermix, and the progeny partake rather more decidedly of the habits and manners of the former, than of the latter.

There are, indeed, many points, irrespective of the varied colors in our domestic breeds, in which the tame and wild ducks differ. For instance, the tame duck is polygamous, but the wild species mates. Again, the feet of the wild duck are black while those of the tame birds are flesh-colored or red. 


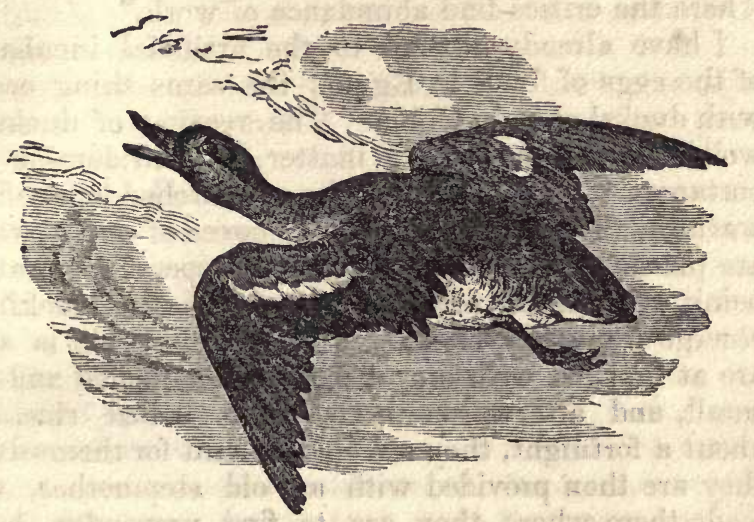

THE WILD DUCK.

As to its history, one thing, I think, may be demonstrated, that is, that the date of its first appearance in domestication on the European continent is not very remote, however high may be its antiquity in India and China. In pursuing this sort of inquiries, which are daily becoming more interesting and more important in their conclusions, one regrets that untranslated works on natural history or farming, (if such there be,) in the oriental languages, are sealed records to almost every one who has the leisure to make use of their contents. It is extremely probable that great light might be thrown on the origin and history of our domesticated animals by a careful inspection of such works. As it is, we are left to obtain our evidence from imperfect and more recent traces, with the ex: ception of geology.

If the swan and the pelican were forbidden to the Israelites, and their carcasses to be held in abomination, (see Leviticus, xi. 18,) the duck would probably be included in the list of unclean birds; or, rather, we may, without violence, suppose that the Hebrew words translated "swan" and "pelican," are used generi- 
cally for all web-footed fowls. But, as Scott says "here the critics find abundance of work."

I have already alluded to the artificial incubation of the eggs of fowls in Egypt; the sams thing occure with ducks' eggs in China. The rearing of ducks as well as pigs there is a matter of considerable importance. Thousands of ducks are hatched by artificial warmth, the eggs being laid in boxes of sand, which are placed on a brick hearth, a proper temperature being maintained around them, until the ducklings emerge from their shells. The ducklings, it is said, are at first fed with cray fish and crabs boiled and cut small, and afterwards mixed with boiled rice. In about a fortnight, they are able to shift for themselves ; they are then provided with an old stepmother, who leads them where they are to find provender, being first put on board a "sampan," or boat which is destined for their habitation, and from which the whole flock, 300 or 400 in number, go out to feed and return at command. This method is used nine months out of the twelve; for, in the colder months, it does not succeed, and is so far from a novelty that it may be seen everywhere, more especially about the time of cutting the rice, when the masters of the duck boats row up and down the rivers, according to the opportunity of procuring food, which, during that season, is found in plenty at the ebb of the tide on the rice plantations which are overflowed at high water. It is curious to see how the ducks obey their master; for, some thousands belonging to different boats, will feed upon the same spot, and on a signal given, follow the leader to their respective crafts, without a stranger being found among them. The communication between the bank and the boat, is by means of a narrow plank; and it is stated by a gentleman long resident in the Celestial Empire that the first duck which gains the boat is ordinarily rewarded with a handful of rice, but that the last undergoes a smart chastisement. Of this discipline, the birds become, from its repetition, 
soon aware, hence each strives to be foremost; one unfortunate must of course be the last, and undergo its punishment.

Among the ancient Egyptians, ducks were in great request, and Herodotus informs us that they were eaten salted, without any other preparation.

"Goose and duck painting, seems to have been a favorite subject among the Egyptians. In Rosellini's plates, (No. iv. M. C.,) there is a picture from a tomb at Thebes, which represents a continuous subject; it lies in one compartment, and is read from right to left. On the extreme right, four men are pulling a long rope attached to a net, in which a num ber of birds, apparently ducks, are caught upon a lake or some water; a fifth man, a little in advance of the four, has also hold of the rope, and seems to be giving a signal to the rest, while a man hid among some plants, (papyri?) appears to be giving a signal and recommending care and silence. Further on the left, are two men carrying the ducks on their shoulders, and a little further, a man putting them into earthern vessels, formed like Roman amphora, after the feathers have been plucked and the legs cut off, the heads of the ducks were kept on, and in this state they seemed to have been put into the amphora, probably containing salt or pickle. In the extreme left of the picture, two men are seated, one of whom seems as if he were rubbing something into a duck; one hand is closed as it would be if it were full of salt, and with the other he is raising one of the wings, apparently for the purpose of rubbing in the salt. The other figure appears to us to be plucking the feathers off the neck of a duck; but Rosellini describes him as sprinkling a handful of salt upon it. These two seated figures are placed near a frame work, formed by two upright poles and a third placed across. From this cross poll, the geese, which are plucked and ready for the amphoræ, are suspended by the neck. This painting, according to Rosellini, is on the tomb of a royal scribe called Titi, who cxercised his art in 
the reigns of Thutmes IV. and of Ameno II., in the beginning of the eighteenth century before the Christian era, and hence, if Rosellini's interpretation of the inscriptions is right, the picture is 3,600 years old."

In other delineations of the same work, ponds in gardens, with tame ducks, geese, and fishes, surrounded by fruit trees, are presented. It is somewhat remarkable, that, esteemed as the duck was by the ancient Egyptians, neither this bird in a tame state, nor the goose, though wild fowls are abundant, is to be seen as of extraordinary occurrence in the villages ; the same observation applies to Syria, and also to Persia and Western Asia in general. These aquatic birds are rarely eaten by the Moslems; and, as there is every reason to believe, were rejected by the ancient $\mathrm{He}$ brews. The wild duck abounds in Syria and other parts of Western Asia, where marshes and lakes afford it a congenial habitation. Wild fowls swarm also on the lake of Tiberias.

It may be shown, however from negative evidence, that the Romans at the time of our Saviour, and subsequently, were not acquainted with the domesticated duck. I can find no passage plainly declaring that they were, but many implying that they were not.

Columella, after having given directions for the rearing of geese, which, with one or two laughable exceptions, are more sensible and practical than are to be found in modern works, proceeds to offer instructions for making the nessotrophion, or duckery. He speaks of it as a matter of curiosity rather than profit; "for ducks, teal, mallard, phalerides," says he, "and such like birds, are fed in confinement." Then it is to be surrounded with a wall fifteen feet high, and roofed with setting, in order "that the domestic birds may have no power of flying out, nor eagles and hawks of flying in." His mcde of increasing his stock shows that ducks had not at that time become naturalised as prolific inmates of the Roman poultry yards. "When any one is desiroue of establishing a duckery," 
continues he, "it is a rery old mode to collect the eggs of the above-mentioned birds, (such as teal, mallard, \&c.,) and to place them under common hens; for the young thus hatched and reared, cast off their wild tempers, and undoubtedly breed, when confined in menageries. For if it is your plan to place freshcaught birds that are accustomed to a free mode of life in captivity, they will be but slow breeders in a state of bondage."

Cicero also speaks of hatching ducks' eggs under hens, (De Naturâ Deorum, II.) but there is nothing in the passage from which to infer that those ducks were domesticated, but rather the contrary ; as he remarks how soon they abandon their foster mother and shift for themsclves.

Pliny describes the flight of ducks, as rising immediately from the water into the higher regions of the atmosphere ; a performance that would make our duck keepers uneasy. The very little mention that he makes of ducks at all, shows that hedid not habitually see them in domestication.

"Suppose it, however, to be proved," says Dixon, "that the tame duck is a comparative novelty in the West, it by no means follows that it is so on the Asiatic continent and islands, nor, as a corollary, that it is a tamed descendant of our mallard. If the skeletons of one and the other were placed side by side, it would require, not a skillful comparative anatomist, but only an observant sportsman, or even an ordinary cook, to point out which was which.* Nor has suffieient weight been attached to the circumstance of one bird being polygamous, and the other monogamous." When I come to speak of the domestic goose, it will be seen how little such a difference is likely to be the result of domestication. Let us not forget, too, that the domestication of wild races is an art that demands quiet, peace, patience, and superabundance, not merely

* "You need not be at a loss to know a wild duck. The claws in the wild species are black-CoL. HAwKra 
for its successful issue, but for its being exercised at all, and was little likely to be much practised by any European nation, in the interva ${ }_{2}$ between the fall of the Roman Empire and the present day, with a creature that required a course of generations to reclaim it. I am inclined, therefore, to consider the race of farmyard ducks as an importation, through whatever channel, from the East, and to point out the discovery of the passage of the Cape of Good Hope, $(1493$,$) as$ the approximate date. The early voyagers speak of finding them in the East Indies exactly similar to ours ; and the transmission of a few pairs would be a much easier task than to subdue the shyness and wildness of the wild mallard, and induce an alteration in its bony structure.

The mallard, though not gone, is fast diminishing as a permanent inhabitant of England ; the tame duok, so much larger and heavier, if its descendant, can hardly be called a degenerate one. The mallard is very widely diffused over the continental part both of the Old and the New World, and therefore its supposed adaptation to domestic life is as likely to have occurred in Asia as in Europe. Its dislike to salt water has made it less cosmopolitan among the islands. Dampier, in his "Voyages," repeatedly mentions that in the East Indies, "the tame fowls are ducks and dunghill fowls, both in great plenty; he does not describe the ducks, except as "the same with ours." He was doubtless correct in believing them to be the same; although we know that the old travellers, and many of the modern emigrants, are not very precise in their zoology, and indeed might sometimes be excusably puzzled. For instance, when Captain Wallis, soon after he had discovered Otaheite, saw animals lying on the shore with their fore feet growing behind their heads, rising every now and then, and running a little way in an erect posture; he was naturally incited with curiosity to inspect them more closely ; and afterwards found that they were dogs. with their fore legs 
tied behind them, brought down by the natives as a peace-offering and a festival dish.

One of the most valid arguments in favor of the derivation of the tame duck from the mallard, is to be found in the readiness with which the former returns to a wild or a half-wild state. In Norfolk, England, there is a breed called "marsh ducks," more from their habits and place of birth than from any peculiarity of race. They are mostly of plumage generally similar to the mallard, though an ornithologist would immediately distinguish them; their size and the firmness of their bones are intermediate between the wild bird and the common farmyard duck. They are turned out on the marshes to forage for themselves ; indeed, it would be next to impossible to keep them at home ; and of the number which are annually lost to their masters, it would seem likely that quite as many assume an independent condition, as are killed by birds, beasts, or men, of prey; but still they do not appear to be ever found actually and entirely wild.

\section{CHOICE OF VARIETIES.}

The variety, at present, most in request, is the "dark-colored Rouen, or Rhone duck," originally from France, but common both in England and in this country. The "English," or "Aylesbury" white variety, though handsome and strong, is inferior in flavor, the flesh being too light-colored and "chickeny," as it is termed. Great numbers of these fowls, however, are fattened in Buckinghamshire, England, for the London markets, where, in consequence of their large size, they command high prices. There is also the "crested," or "topknot duck," a beautiful ornamental tame variety, which breeds early, lays freely, and hatches well. They occur pure white, black, or mixed with black and white. Then there is the "musk" or "Muscovy" duck, which, from its large size, and peculiar habits, demands a more extended notice. 


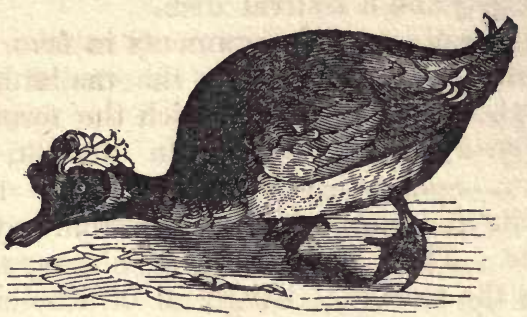

THE MUSK DUCK.

Srronrmes-Anas moschatu, of Linnæus ; Anas sylvestris braziliensis, of Ray ; Cane musquée, of the French ; bisamduftend Ente, of the Germans ; Pata real, Pata grunde, Pata almisclada, of the Spaniards; Musk Duck, Muscovy Duck, of the English and Anglo-Americans.

The musk duck, so termed from the strong scent of musk which its skin exhales, is undoubtedly the type of a genus very distinct from that of the common kind. In this species, the feathers are large, lax, and powdery, the oheeks, are extensively naked, and the base of the bill is carunculated. This duck greatly exceeds the ordinary kind in size, and the male is far larger than the female. The general color is glossy blue-black, varied more or less with white, the head is crested, and a scarlet fleshy space surrounds the eye, continued from scarlet caruncles at the base of the beak. Tail destitute of the curled feathers so conspicuous in the tail of the common drake. In a wild state, the drake is of a brownish-black, with a broad white patch on the wings, the female being smaller and more obscurely colored. But in a state of domestication, it exhibits every variety of colır, like the common duck.

The tropical regions of South America are the native country of the inusk duck, which may account for its dislike to a cold bath in our northern climate. Its frizzled crest is analogous to that of some curassows, natives of the same continent. It is fond of warmth, passing the night, at the north, not in the open air, but, in the fowl house with the cock and hens; 
and selecting by day, the most sunny corner to bask and doze in.

"Can a duck swim ?" is a pert question sometimes asked with little expectation of an answer in the negative. Here, however, is a duck, which, if it can swim, performs that action in such a clumsy way as hardly to deserve the name of swimming. Those who expect that its singular appearance would render it a curious, if not an elegant companion, among our more attractive ducks will be disappointed ; for it will never go near the water, if it can help it, but will prefer the farm yard, the precincts of the kitchen, or even the piggery itself, to the clearest stream that ever flowed. In fact, it hates water, except some dirty puddle to drink and drabble in. When thrown into a pond, it gets out again as fast as it can. It does, indeed, sometimes seem to enjoy an occasional bath, and so does a sparrow or a Canary bird. Its very short leg does not appear to be mechanically adapted for the purpose of swimming. It waddles on the surface of a pond as much as it does on dry land; it is evidently out of its place in either situation. Its proper mode of locomotion is through the air ; its congenial haunts are among the branches of trees.

The female of the musk duck has considerable powers of flight, and is easy and self-possessed in the use of its wings. It is fond of perching on the tops of barns, walls, \&c. Its feet appear by their form to be more adapted to such purposes than those of most other ducks. If allowed to spend the night in the hen house, the female will generally go to roost by the side of the hens, but the drake is too heavy to mount thither with ease. His claws are sharp and long; and he approaches the tribe of "scratchers," (rasores, ) in an un-scientific sense, being almost as dangerous to handle incautiously as an ill-tempered cat; and will occasionally adopt a still more offensive and scarcely describable means of annoyance. He manifests little affection to his femals partner, and none towards her 
offspring. The possession of three or four mates suits him and them, better than to be confined to the company of a single one. He bullies other fowls, sometimes by pulling their feathers, but more frequently by following them close, and repeatedly thrusting his face in their way, with an offensive and satyr-like expression of countenance; or salaciously pursuing them, whether male or female, until he has accomplished his purpose, or at least has made an attempt.

The musk duck, though a voracious feeder, is easily fattened, a prolific breeder, and consequently, may be profitably reared. The male pairs readily with the common tame duck, producing, by the cross, a hybrid, or mongrel, which is incapable of "breeding in a line." The female, however, will pair with the common drake and produce a good sort. The hybrid generally has a deep-green plumage, and is destitute of the red caruncled membrane on the cheeks, as well as of the musky odor of the gland on the rump.

Her eggs are scarcely distinguishable from those of the common duck; they are well flavored. The time of incubation is five weeks; but in all birds that I have observed, the duration of that period varies so much according to circumstances, that a mean of many observations must be taken to arrive at a correct standard. The time required by the hybrid eggs between this and the common duck, is intermediate between the respective periods.

The newly-hatched young resemble those of the common tame duck; they are covered with down, the shades of which indicate the color of the future feathers; and they do not for some time show any appearance of the tuberculated face. They are delicate, and require some care while young, but are quite hardy when full grown. Their food should be anything, that is nutritious, both plenty and a variety of it.

The musk duck is excellent eating, if killed just before it is fully fledged; but it is longer in becoming fit 
for the table than the common duck. The flesh is at first high-flavored and tender, but an old bird would be rank, and the toughest of tough meats. It is strange that a dish should now be so much out of fashion as scarcely ever to be seen or tasted, which, under the name of Guinea duck, graced every feast in England a hundred and fifty years ago, and added dignity to every table at which it was produced.

\section{RANGE AND DOMESTIC ACCOMMODATION OF THE COMMON} TAME DUCK.

IT is not in all situations that common ducks can be kept with advantage; they require water much more, even, than the goose; they are no grazers, yet they are hearty feeders, and excellent "snappers-up of unconsidered trifles ;" nothing comes amiss to themgreen vegetables, especially when boiled, the rejectamenta of the kitchen, meal of all sorts made into a paste, grains, bread, oatcake, animal substances, worms, slugs, and crushed snails, insects and their larvæ, are all accepted with eagerness. Their appetite is not fastidious; in fact, to parody the line of a song, "they eat all that is luscious, eat all that they can," and seem to be determined to reward their owner by keeping themselves in first-rate condition if the chance of so doing is afforded them. They never need cramming-give them enough, and they will cram themselves; yet they have their requirements, and ways of their own, which must be conceded. Confinement will not do for them; a paddock, a pasture, an orchard, a green lane, and a pond; a farm yard, with barns, and water; a common, smooth and level, with a sheet of water, and nice ditches, abounding in the season with tadpoles and the larvæ of aquatic insects, are the localities in which the duck delights, and in such are they kept at little expense. They traverse the green sward in Indian file, (an instinctive habit,) and thus return at evening to their dormitory, 
or emerge from it to the edge of the pond, cr sheet of water, over which they scatter themselves; thus also, they come to the call of their feeder.

Ducks should always have a lodging-place of their own, they should be separate from fowls, and never housed beneath their perches; yet where fowls are kept, a little contrivance will suffice to make their berth, even in a fowl house, tolerably comfortable. In winter, a thin bedding of straw, rushes, or fern leaves should be placed on the floor of their dormitory, and frequently changed.

As respects the accommodation of the tame duck, Mascall says, "Yee must make a ponde of two feete deepe, so long and wyde as the place will serve, and that the water there may run full continuallye to the brimme thereof, that the bankes may not be marde, and also made with plaister, and cimmond, (cement?) in the bottom, and all about the sydes paved with smooth stone, that no weedes do grow therein, but that the fowle may have clear water still run thorow. And in the midst yee shall make a mount of earth, and thereon sowe beannes of Egypt, and such other green herbes as commonly comes in water, to cover and hyde those fowle therein; for some of them loves to be hid in tuftes of grasse, roses, (rushes?) sedge, and such; notwithstanding, yee muste not cover their holes, for the water must be once in the day without weedes."

Where there is much extent of water or shrubbery, within the range of ducks, they are liable to lay and sit abroad, unless they are constantly looked after, and driven home at night, and provided with proper shelter or pens. These may be made of rough boards, or of rustic work, thatched with straw, as denoted in the following cut. They may also be made after the mode of the poultry hortse, at p. 86 . 


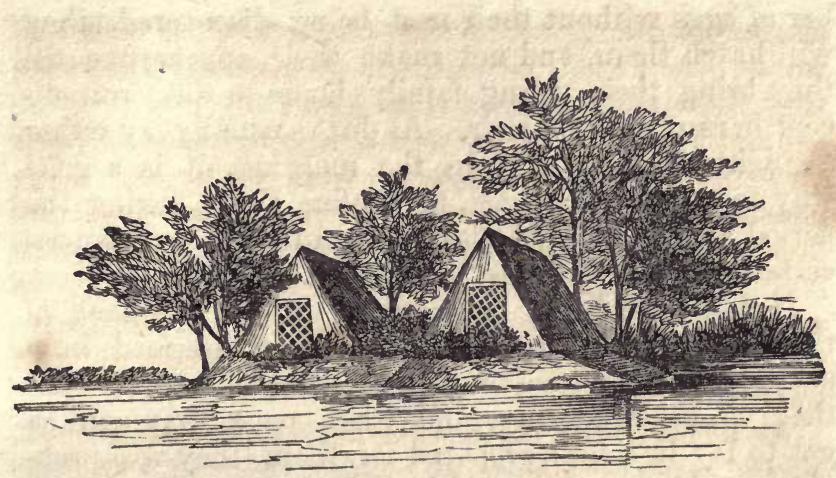

DUCK POND AND HOUSES.

The internal arrangement of these houses may vary, according to the means and taste of the proprietor, only providing the ducks with nests or nest boxes, in order that they may lay and incubate undisturbed, and affording proper protection for the young.

\section{PAIRING AND IAYING.}

ONe drake, according to M. Parmentier, is sufficient for eight or ten ducks, while Columella limits the number of ducks to six; and others to four or five. They begin to lay towards the end of February, and sometimes earlier, but so far from producing the limited number of about sixteen eggs, some will lay as many as fifty, and even nearly double that number. They do not, usually continue to lay, however, later than May or June, unless they are very well fed-the great secret for rendering them prolific, provided they do not become too fat.

At the laying season, ducks require to be closely looked after, inasmuch as they are not so easily brought to lay in the nests prepared for them as common fowls ; but will stray away to hedges and other by-places to lay, and will even sometimes drop their eggs in the water. When they succeed in laying ont their num. 
ber of eggs without their nest being discovered, they will hatch them, and not make their appearance till they bring their young family home to the yard, except in raw, cold weather. As ducks usually lay either at night, or very early in the morning, it is a good way to secure their eggs, to confine them during the period when they must lay, a circumstance easily ascertained by feeling the vent.

It will accordingly be requisite at the approach of the laying season, in spring, to give them food in a particular place three or four times a-day, to prevent them from wandering, and when once they can be got to lay in a nest prepared for them, they will probably continue to do so, without laying elsewhere.

The eggs of the duck are readily known from those of the common fowl by their bluish color and larger size, the shell being smoother, not so thick, and with much fewer pores. When boiled, the white is never curdy like that of a new-laid hen's egg, but transparent and glassy, while the yolk is much darker in color. The flavor is by no means so delicate. For omelets, however, as well as for puddings and pastry, duck eggs are much better than hens' eggs, giving a finer color and flavor, and requiring less butter.

\section{INCUBATION.}

The tame duck is not naturally disposed to incubate, but in order to induce her to do so, towards the end of laying, two or three other eggs may be left in each nest, taking care every morning to take away the oldest laid, that they may not be spoiled. From eight to ten eggs may be given, according to the size of the duck, and her ability to cover them, taking particular care not to sprinkle them with cold water, as some authors wrongly advise. This precaution, at the best, is superfluous, if it be not hurtful. The duck requires some care when she sits; for as she cannot go to her food, attention must be paid to place it before her ; and she will he content with it, whatever be its qual- 
ity; it has even been remarked, that when ducks are too well fed, they will not sit well. The period of incubation is about thirty days, which is somewhat longer than that of the wild species.

The first broods of the season are usually the best, because the-heat of summer helps much to strengthen the ducklings; the cold always preventing the later broods from getting strong.

The duck is apt to let her eggs get cold, when she hatches. Yet Réaumur says, he had one of the common species, which only left the nest once a day, towards eight or nine in the morning; and before leaving it, covered the eggs over with a layer of straw, which she drew from the body of the nest, to screen them from the impression of the air. This layer, above an inch thick, secured the eggs so well, that it was impossible to guess that they were there. But, every duck is far from giving the same proofs of so much foresight for the preservation of the warmth of the eggs, as this one was, and it often happens that they let them cool. The ducklings are no sooner excluded, than the mother takes them to the water, where they dabble and eat at the very first, and many of them perish, if the weather is cold.

All these reasons often induce poultry keepers to have ducks' eggs hatched by hens or turkey hens ; and being more assiduous than ducks, these borrowed mothers take an affection for the young, to watch over, which requires great attention; because, as these are unable to accompany them on the water, for which they show the greatest propensity as soon as they are excluded, they follow the mother hen on dry land, and get a little hardy before they are allowed to take to the water without any guide. Yet, they can do without a mother as soon as they are excluded from the shell.

REARING AND FEEDING THE YOUNG.

The best mode of rearing ducklings depends very much upon the situation in which they are hatched. 
For the first month, the confinement of their mother, under a coop is better than too much liberty. All kinds of sopped food, buckwheat flour, Indian or barley meal and water mixed thin, worms, \&c., suit them. No people are more successful than cottagers, who keep them for the first period of their existence in pens two or three yards square, cramming them night and morning with dried pellets of flour and water, or egg and flour, till they are judged old enough to be turned out with their mother to forage on the common or the village pond.

When ducklings have been hatched under a common hen, or a turkey hen, they are not generally allowed to go to the water till they become a little hardy, by remaining on land; but the moment they see water, they naturally plunge into it, to the great alarm of their fostermother, which cannot follow them; a circumstance which has been remarked by the earliest writers, and is finely depicted by M. Rosset in his "Poëme de l'Agriculture."

It is necessary, to prevent accidents, to take care that such ducklings come regularly home every evening; but precautions must be taken before they are permitted to mingle with the old ducks, lest the latter ill-treat and kill them, though ducks are by no means so pugnacious and jealous of new-comers as common fowls uniformly are.

\section{FATTENING.}

Accordrng to Gervase Markham, pulse, or any kind of grain, will fatten ducks or ducklings in a fortnight; but if he had tried this, he would have found that his receipt was not always successful.

Lawrence says that butchers' offal is excellent for fattening ducks, as it does not give the flesh the rank, disagreeable flavor which it always imparts to pork. Acorns, on the contrary, while they are good for fattening, injure the flavor of the flesh, and barley in 
any form is apt to render the flesh insipid, and woolly, or, as it is termed, "chickeny."

As the duck is both a voracious feeder and fond of liberty, it will fatten very well when allowed to roam about, provided it has abundance of food; but it expedites the process of fattening, to have recourse to coops, quiet, and darkness.

In Lower Normandy, where great numbers of ducks are reared and fattened, the poulterer prepares a paste with the flour of buckwheat, made into gobbets, with which they are crammed thrice a-day, for eight or ten days, when, though not full fat, they are sufficiently marketable to bring a remunerating price.

In Languedoc, when ducks have been rendered tolerably fat by being at large, they are cooped up by eights or tens in a dark place, whence they are taken out morning and evening to be crammed. This is done by a girl, who crosses their wings on her knees, opens their bill with her left hand, while with her right she stuffs them with boiled maize. Many ducks are suffocated by the operation, and killed oatright, but their flesh is not the worse for the table, provided that they be immediately bled. It requires a fortnight to complete the process, which increases the size of their liver enormously, and oppresses their breathing in a distressing manner. The sign of their being sufficiently fat is, when the tail opens like a fan, from the fat pressing on the roots of the feathers. 


\title{
THE DOMESTIC G0OSE.
}

\author{
ORIGIN AND HISTORY.
}

A team of twenty geese, a snow-white train! Fed near the limpid lake with golden grain, Amuse my pensive hours.

Pore.

The domestication of the common goose, like that of the domestic fowl, hides itself, as we pursue it, in the remotest depths, and obscurest mists of ancient history. It has already been hinted that, by the Hebrews, as by many modern naturalists, it would probably be classed generically with the swan, and so be included in their list of unclean birds. Among the Greeks and Romans, it seems to have been the only really domesticated water fowl they possessed; and appears to have held exactly the same place in their esteem, that it still retains with us, after the lapse of two or three thousand years! Indeed, a modern writer may escape great part of the trouble of composing the natural history of the domestic goose, if he will only collect the materials that are scattered amongst ancient authors. A very early notice of them occurs in Homer. Penelope, relating her dream, says, "I have twenty geese at home, that eat wheat out of water, and I am delighted to look at them."

The alarm given at the approach oi the army of the 
Gauls by the geese kept in the capitol of Rome, occurred so long back as A. U. c. 365 , or 388 years before Christ. The passage is worth extracting-

"Thus they were employed at Veii, whilst, in the mean time, the citadel and capitol in Rome were in utmost danger. The Gauls either perceived the track of a human foot, where the messenger from Veii had passed, or, from their own observation, had remarked the easy ascent at the rock of Carmentis ; on a moonlight night, therefore, having first sent forward a person unarmed to make trial of the way, handing their arms to those before them; when any difficulty occurred, supporting and supported in turns, and drawing each other up according as the ground required, they climbed to the summit in such silence, that they not only escaped the notice of the guards, but did not even alarm the dogs, animals particularly watchful with regard to any noise at night. They were not unperceived, however, by some geese, which being sacred to Juno, the people had spared, even in the present great scarcity of food; a circumstance to which they owed their preservation; for the cackling of these creatures, and the clapping of their wings, Marcus Manlius was roused from sleep, - a man of distinguished character in war, who had been consul the third year before ; and snatching up his arms, and at the same time calling to the rest to do the same, he hastened to the spot, where, while some ran about in confusion, he, by a stroke with the boss of his shield, tumbled down a Gaul who had already got footing on the summit; and this man's weight, as he fell, throwing down those who were next, he slew several others, who, in their consternation, threw away their arms and caught hold of the rocks, to which they clung. By this time, many of the garrison had assembled at the place, who, by throwing javelins and stones, beat down the enemy, so that the whole band, unable to keep either their hold or footing, were hurled down the precipice in promiscuous ruin." 
Lucretius, referring to this event, attributes the vigilance of the geese to their fine sense of smell: "The white goose, the preserver of the citadel of the descendants of Romulus, perceives at a great distance the odor of the human race."

Virgil, alluding to the same occurrence, ascribes the preservation of the capitol to a "silver goose." Both these poets, therefore, inform us that the domestic gonse of their days differed as much from the grey-lag or the white-fronted, as it does at present, a circumstance which the reader is requested to bear in mind.

Pliny, about four hundred years later, remarks : "The goose is carefully watchful; witness the defence of the capitol, when the silence of the dogs would have betrayed everything. ***** It is possible, also, that they may have some discernment of wisdom. Thus one is said to have stuck perpetually to the philosopher Lacydis, never leaving him, either in public, in the baths, by night, nor by day. Our folks are wiser, who are aware of the goodness of their liver. In those that are crammed, it increases to a great size; when taken out, it is laid to swell in milk mixed with honey. And it is not without cause that it is a matter of debate who was the first to discover such a dainty, whether Scipio Metellus, of consular dignity, or M. Seius, a Roman knight at the same epoch. But, (what is certain,) Messalinus Cotta, the son of Messala, the orator, discovered the method of cooking the web of their feet, and fricasseeing them in small dishes along with cock's combs. I am ready heartily to attribute the merit to the kitchen of either. It is wonderful that this bird should travel on foot from the Morini, (in the north of France,) to Rome. Those which are tired are carried to the front; so that the rest push them on by a natural crowding. ***** In some places they are plucked twice a year."

It is very natural to inquire whence so remarkable and valuable a bird was originally obtained; but the conclusion generally arrived at appears to be inconsist 
ent, not merely with truth, but even with probability; namely, that it results from the crossing and intermixture of several wild species. None of these ancient accounts indicate any such fact; but on the contrary, declare that the domestic goose was in the earliest ages, (dating. with respect to man,) exactly what it is now. The very same arguments that are used to show that the domesticated goose is a combination of the "grey-legged," (Anser palustris,) "white-fronted," or "laughing goose," (A. albifrons,) and " bean goose," (A. ferus,) would equally prove that the AngloSaxon race of men is derived from a mixture of the Red Indian, the Yellow Chinese, and the tawny Moor.

But the supposition that all our domesticated creatures must necessarily have an existing wild original, is a mere assumption ; and it has misled, and is likely to mislead, investigators, as far from the truth as did the old notion about fossil organic remains, that they were Lithoschemata, as Aldrovandi has it, sketches in stone, abortive efforts of Nature, imperfect embryos, instead of fragmentary ruins of a former state of things. Some naturalists seem already to have had misgivings that such a theory respecting domestic animals is not tenable. According to popular opinion, the domestic goose is usually considered as having been derived from the "grey-legged goose," but such a circumstance is rendered highly improbable from the well-known fact that the common gander, after attaining a certain age is invariably (?) white!

The origin of the domestic goose is indeed unknown if we look to man, or his influence, to have originated so valuable and peculiar a species; but not unknown if we believe it to have been created by the same Almighty Power who animated the Mammoth, the PlesiOsaurus, the Dinornis, and the Dodo. For let us grant that the grey-legged goose is the most probable existing parent to the domestic sort. Now, even that is becoming a rare bird; and the more scarce a creature is in a wild state, the scarcer it is likelv still to be- 
come. Suppose the grey-legged goose extinct; by no means an impossibility. Then those who must have a wild original from which to derive all our domestic animals would be compelled to fall back on some other species still less probable. It is surely a simpler theory to suppose that creatures that were cotemporary with the mammoth, have, like it, disappeared from the earth in their wild state, but have survived as dependents on man, than to engage in attempts at reconciling incongruities and discrepancies, which, after all, cannot satisfy the mind, but leave it in as doubtful a state as ever.

Still less is the "white-fronted," the ancestor of the domestic goose. Entirely white specimens of the Anas albifrons are indeed occasionally hatched in confinement, and the common goose may now and then exhibit traces of an admixture or dash of blood with it, as it certainly does occasionally, of a cross with the China goose (A. cygnoïdes) ; but these are mere impurities which wear out, and the race returns to the well-known domestic type. And it will be allowed by most persons who have possessed a variety of these birds, and who have watched and tended them day by day, that the domestic goose is sufficiently separated from the grey-legged by the color of its feet and legs ; from the white-fronted, by the extreme difference of its voice, manner, time of incubation, color of the eyes, greater thickness of neck, convexity of profile, and - many other particulars that are more easily perceived than described.

It might be urged, as a further essential difference, that the domestic goose is polygamous, whereas all wild geese that we are acquainted with are monogamous. It is true that wild geese, in captivity, will couple with the females of other species, but that takes place by their utterly neglecting their own mate for the time, not by entertaining two or more mistresses at once. It will be replied, that habits of polyamy are the effects of domestication; but what proof have we 
of such an assertion? Domestication has not yet induced the pigeon nor the Guinea fowl to consort with more than one partner, and the swan, called "domestic," by some writers, remains obstinately and even fiercely faithful in its attachments.

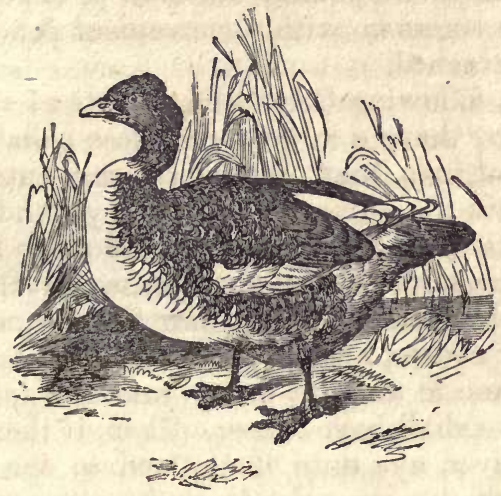

THE DOMESTIC GOOSE.

Srरoкrmes.-Anser palustris (?.,) of Naturalists ; Vie commune, of the Irench ; Gemeine Gans, of the Germans ; Ansa domestica, of the Span. iards ; Goose, Common Goose, of the English and Anglo-Americans.

Of the domestic goose there really is but one variety, individuals of which are found varying from entirely white plumage, through different degrees of patchedness with grey, to entirely grey coloring. The ganders are generally, not invariably white. Such are sometimes called "Embden geese," from a town of Hanover, of that name, famous also for groats. High feeding, care, and moderate warmth, will induce a habit of prolificacy, which becomes, in some measure, hereditary. The season of the year at which the young are hatched, influences their future size and development. After allowing for these causes of diversity, it will be found that the domestic goose constitutes only one species or permanent variety. 
RANGE AND DOMESTIO ACCOMMODATION.

WirH respect to the range and domestic accomsiation of geese, they require a dormitory apart from othar fowls similar to the one shown at p. 203 for the tame duck, or the rustic poultry house at p. 86 , and a green pasture, or common, with a convenient pond or stream of water attached.

Mascall, following Columella, directs as most proper for geese to " have a large court, close paled or walled, of nyne foot hye, that no vermin may enter, and all about within the same to make alleys and galleries, with partitions and chambers for one alone to sleep in and over the same, to set your house for them, made strong with stono or brick four foote square, plaste about your courte, and to eche house a close door for them to come in and out to lay, and also to shut them in when ye shall have cause. Then, if there be not a ponde or river nye unto them, and to the house yee must then make one, else to seeke their water farre off, which is not good, for geese that sitte must have water to bathe them when they rise from their neast, or else, as some say, their egges will.not prosper. If there be no water, must make a ponde, clay it in the bottom for the water to remain; and make it somewhat deep, that they may plunge therein ; for a saying is, a goose will not live withoute bathing and washing her often, no more than a beast without pasture."

"All men," says Markham, "must understand, that, except he have either pond or streame, he can never keepe geese well." Yet if we are to trust M. Parmentier, the vicinity of rivers and ponds is not absolutely necessary to the most successful rearing of geese ; for in districts destitute of these advantages, a small reservoir, where they can bathe, will be quite sufficient.

In France, geese are put up in thirties in the same lodge, with roofs and partitions to separate them, never 
allowing more than eight under one roof. All damp must be avoided, for geese at all times are fond of a clean, dry place to sleep in, however much they may like to swim in water. It is not a good method to keep geese with other poultry ; for when confined in the poultry yard, they become very pugnacious, and will very much harrass the hens and turkeys.

Columella advises to pasture geese in marshy or moist ground, and to sow for them vetches or tares, mellilot, clover, and fenugreek, but more particularly chiccory, and lettuce, of which, he says, they are very fond.

"Grasse, says Markham, "they must necessarily have, and the worst, and that which is the most uselesse, is the best, as that which is moorish and unsavoury for cattell."

In allowing geese to range at large, it is requisite to be aware that they are very destructive to all garden and farm crops, as well as to young trees, and must, therefore, be carefully excluded from orchards and cultivated fields. It is usual to prevent them getting. through the gaps in fences, by hanging a stick or "yoke" across their breasts.

If we traverse a pasture or common, on which geese are kept, we find the flocks of the respective owners keeping together, and if by chance they mingle on the pond or sheet of water, they separate towards evening and retire, each flock to its own domicile. On extensive commons where many thousands of geese are kept, this rule is scarcely ever broken; the flocks of young geese brought up together, as their parents were before them, form a united band, and thus distinct groups herd together, bound by the ties of habit.'

\section{PAIRING.}

IT was ascertained bv M. St. Genis, of France, that geese will pair like pigeons and partridges; and in the course of his experiments, he remarked, that, if the number of the ganders exceed that of the geese by 
two, and even by three, includiug the common father, no disturbance nor disputes occur, the pairing taking place without any noise, and no doubt by mutual choice. Besides the common father, he left two of the young ganders unprovided with female companions; but the couples which had paired, kept constantly together, and the three single ganders did not, during temporary separations of the males and females, offer to approach the latter. He also remarked, that ganders are more commonly white than the females.

Those who breed geese, generally assign one gander to four or five females. M. Parmentier recommends the gander, to be selected, of a large size, of a fine white, with a lively eye, and an active gait; while the breeding goose, he says, ought to be brown, ash-grey, or party-colored, and to have a broad foot. The grey geese are supposed to produce the finest goslings, while the party-colored ones produce better feathers, and are not so apt to stray from home.

Whatever care may be taken in selecting grey geese, with white ganders, Stephanus assures us, that a black sort will frequently be produced, which he says, "are skant so fruitful as the other, nor so good to house; wherefore, nourish as few blacke geese as ye may, for their flesh is not so good, being much dryer." And again: "They are better to be all white than grey, or mixte with two colors, and the blacke color is worste of all, and of leaste goodnesse."

\section{IAYING.}

When well fed, in a mild climate, geese will lay twice or three times a year, from five to twelve eggs each time, and some more, that is, when they are left to their own way; but if the eggs be carefully removed as soon as laid, a goose may be made, by abundant feeding, to lay from twenty to fifty eggs without intermitting. They begin to lay early in the spring, usually in March, and it may be known when an individual is about to lay, by her carrying about straws to 
form her nest with; but, sometimes, she will only throw them about.

When this is observed, the geese should be watched, lest they lay in some by-place, and the eggs be lost. "Wherefore," says.Mascall, "towarde night, ye must take them up, and feele how many be ready to lay, which ye shall perceive if shee be nye laying, yee shall feele the ond of her egge harde at her vent. Then shutte her up, and put her alone in a neast till she have layd, so she will seeke that place agayne to lay."

It is an essential precaution, M. Parmentier says, as soon as it is perceived that geese want to lay, to coop them up under their roof, where nests made of straw have been previously prepared. If they can once be induced to lay in this nest, they will continue to do so till their number of eggs is completed.

In order to have early goslings, geese should be brought to lay early by keeping them in a warm, clean place, and feeding them on stimulant food.

\section{INOUBATION.}

When a goose is observed to keep her nest longer than usual, after laying an egg, it is a pretty sure indication that she is desirous of sitting. The nest for hatching should be made of clean straw, lined with hay, and from fourteen to eighteen eggs will be as many as a large goose can conveniently cover. During the period of incubation, the gander is very attentive to his favorite, sits by her, and is vigilant and daring in her defence.

The goose sits about one month, and requires to have food and water placed near her, that she may not be so long absent as to allow the eggs to cool, which might cause her to abandon her task. It is the practice of some to put vinegar in the water, and of others to lift them off the nests to make them drink, but neither of these is necessary.

It is an economical way of getting a great number of goslings, to employ turkey hens to hatch. The 
common fowl has been equally praised for filling this important function; but the eggs of the goose being very large, and their shell very hard, a hen is not bulky enough to hatch more than eight or ten, even if we employ the Cochin-China, or great Malay. The turkey hen, therefore, deserves to be preferred, because she can hatch twelve or fifteen. This function of the goose being thus filled by another, she is not kept from laying, and yields eggs in great abundance.

In the environs of 'Toulouse, in France, where many hybrid geese are reared, increasing with the common duck and the large musk duck, they give the eggs to the common fowl to hatch; and to these are added two or three of the large-sized goose eggs. The hybrid bird from this crossing conducts the goslings in a superior manner, and always walks at their head.

\section{CARE OF THE GOSLINGS.}

LiKe turkey chickens, goslings are a month in hatching, and must be taken from under the mother, lest, if feeling the young ones under her, she might perhaps leave the rest of the tardy brood still unhatched. After having separated them from her, they may be kept in flat pens, or baskets, covered with a cloth, and lined with wool; and when the whole brood is come forth, the first hatched may be returned to the mother.

On the first day after the goslings are hatched, they may be let out, if the weather be warm, care being taken not to let them be exposed to the unshaded heat of the sun, which might kill them. The food given is prepared with some barley or Indian meal, coarsely ground, bran, and raspings of bread, which are still better, if soaked and boiled in milk, or lettuce leaves, and crusts of bread boiled in milk.

Afterwards, advantage must, be taken of a fine warm sun to turn them out for a few hours; but cold and rain being very hurtful to them, they must in bad weather be cooped up, and prevented from mixing with the larger ones, unless they have strength enough to 
defend themselves against any hostile attack, to which new-comers are usually exposed. To such goslings as are a little strong, bran or Indian-meal dough may be given twice a-day, morning and evening, continuing to give them this food till the wings begin to cross on the back, and after this, green food, which they are particularly fond of, may be mixed with it, such as lettuce, beet leaves, and the like.

\section{FATTENING.}

LiKe other fowls, geese may be brought by proper management to a great degree of fatness; but the period at which they are at the fattest must be chosen to kill them, otherwise they will rapidly become lean again, and many of them would die.

Geese may be fattened at two different periods of their lives, in the young state, when they are termed "green geese," and after they have attained their full growth. The methods at each period are very nearly the same.

The writer of the article on poultry, in Baxter's "Library of Agriculture," recommends steamed potatoes, with a gallon of buckwheat or ground oats to the bushel, mashed up with the potatoes, and given warm. This, it is said, will render geese, cooped in a dark, quiet, cool place, fat enough in three weeks.

M. Parmentier gives very copious details of the French methods of fattening. The whole process, he says, consists in plucking the feathers from under the belly ; in giving them abundance of food and drink, and in cooping them up more closely than is practised with common fowls, cleanliness and quiet being, above all, indispensable. The best time is in the month of November, or when the cold weather begins to set in; if it is longer delayed, the paring season approaches, and prevents them from becoming fat.

When there are not many geese to fatten, they are put into a cask with holes bored in it, through which they may thrust their heads to feed ; and being natur- 
ally voracious, the love of food is greater than the love of liberty, and they fatten rapidly. The food consists of a paste, made of buckwheat, barley or Indian meal, with milk and boiled potatoes.

In Poland, a similar method is practised, the goose being put in an earthen pot without a bottom, and of a size not to allow the bird to move. Similar food as that just mentioned is given in abundance, and the pot is so placed that the dung may not remain in it. The process is completed in a fortnight, and the geese are sometimes so increased in size, that the pots have to be broken to get them out.

When the great number of geese to be fattened renders the preceding plan inconvenient and too expensive, they may be taken from the pasture, and cooped up twelve together, in narrow pens, so low that they can neither stand upright, nor move in any direction. They should be kept scrupulously clean by often renewing the litter of the pens. A few feathers may be previously plucked out from the rump and from under the wings. A quantity of cracked Indian corn, sufficient for once feeding, may be boiled and put into a feeding trough, with clean water in a separate vessel, from which they may be permitted to eat whenever they feel inclined. At the commencement, they eat a great deal constantly, but in about three weeks, their appetite falls off. As soon as this is perceived, they may be crammed, at first twice a-day, and towards the end of the process, thrice a-day. For this purpose, a tin funnel is used, with a pipe five inches and a half in length, and less than an inch in diameter, with the end sloped off like the mouth piece of a flageolet, and rounded at the edge, to prevent it scratching the throat when it is introduced. A small, round bag is adjusted to the pipe, through which grain is introduced into the crop. The operator sits squat on the ground, holds the goose with one hand, introduces the pipe of the funnel into the mouth with the other, and presses in the food till the crop is filled. Water is at the same 
time given to the geese to drink, and must always be left near them, as the cramming renders them very thirsty. A woman who is dexterous will cram ten geese in an hour. In less than a month, a goose may, in this way, be fattened to an enormous bulk.

In Belgium, a lean goose is confined in a small coop made of fir, narrow enough to prevent it from turning, while there is a place behind for passing the dung, and another in front to let out the head. Water is supplied in a trough in front, having some bits of charcoal in it to sweeten it. A bushel of maize is considered enough of food for a month. It is soaked in water the day before it is used; and the goose is crammed morning and evening, while it is allowed, during the day, to eat and drink as much as it chooses. About the twentysecond day, a quantity of poppy oil is mixed with the maize. In a month, it is seized with difficulty of breathing, and a lump of fat under each wing indicates that it is time to kill it, lest it should be choaked with fat, and die.

By this process, the liver of the goose is increased so much, that it will weigh from one to two pounds, and will besides yield about three ounces of fat, which is much employed in French cookery for dressing legumes, \&c.

Among six geese, the fatteners commonly succeed with no more than four, and these generally the youngest. The Romans, who were fond of enlarged goose livers, were very careful to keep them quiet and in the dark. In some places on the continent, they nailed their feet to a board, burnt out their eyes with a hot iron, and kept them before a large fire, allowing them, however, as much water as they chose to drink; but these barbarous practices are now seldom resorted to.

M. Vièle, of France, found, by experiment, that geese fattened without cramming, cannot be brought to weigh above 12 or 13 lbs., while by cramming, they can be made to weigh at least a third more. 


\section{THE CHINA G00SE.}

SrNonrMes.-Anser cygnoides, Anas cygnoudes, Cygnus sinensis, of Naturalists, L'oie de Guinee, of Buffon; Oie de Chine, of the French; Chinesische Gans, Gans von Guinea, of the Germans; Ganso de China, Ganso de Guinea, Ganso de cisne, of the Spaniards ; China Goose, HongKong Goose, Swan Goose, Chinese Swan, Guinea Goose, Spanish Goose, African Goose, and a host of other names, of the English and AngloAmericans

There is a venerable joke told about a Spanish Don who knocked at a cottage door to ask a night's lodging: "Who's there?-what do you want?" demanded the inmates. "Don Juan José Maria Antonio Pedro Alonzo Carlos Geronimo, \&c., \&c., \&c., wants to sleep here to-night." "Get along with you," was the reply, "how should we find room here for so many fellows." It will be seen by the list of names at the head of this article, that the China goose is in the same position as the Spanish Don.

Confusion, therefore, and perplexity are the certain lot of whosoever attempts to trace this bird in our books of natural history. Its place of birth has excluded it from all monographs or limited ornithologies. In very few systematic works is it mentioned at all, which is remarkable of a bird so striking in its appearance, which there is every reason to believe must have been domesticated for a long period. The uncertainty that has existed as to its correct name and really native country may be one cause of this. Like the Jews, or the Gipsies, it has not been allowed to claim a place among the 
natives of any one region; and like many others furnished with a variety of aliases, it ends by being altogether excluded from society.

The old writers call it the Guinea goose, for the excellent reason, as Willughby hints, that in his time it was the fashion to apply the epithet "Guinea" to everything of foreign and uncertain origin. Thus, what at this day is erroneously called the "Muscovy duck," was then called the "Guinea duck." Not long back, it was common to refer every strange or new object to a French source. "Spanish goose" is another title, probably as appropriate as Guinea goose. Bewick has

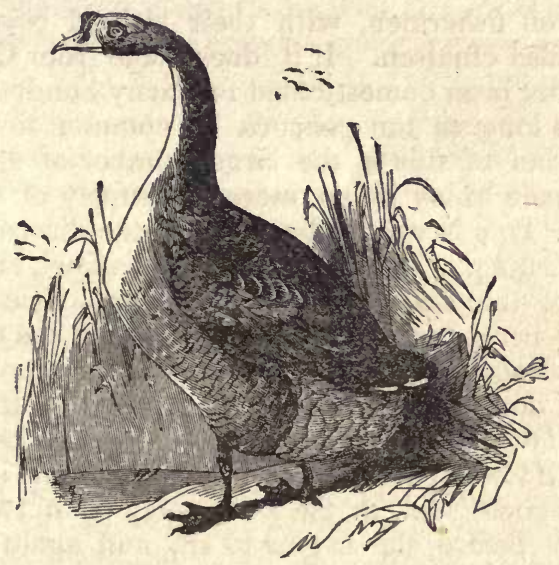

THE CHINA GOOSE.

given an admiral wood cut of this bird, but he has evidently selected the gander, which is taller and more erect than the female, though to both may be applied Willughby's description, "a stately bird, walking with its head and neck decently erected." Bewick calls it the "swan goose." The tubercle at the base of the bill, the unusual length of neck, and its graceful carriage in the water, give it some claim to relationship with the aristocracy of lake and river. Cuvier goes further, calls it at once Cygnus sinensis, (Chinese swan,) and says that 
this and the Canada goose cannot be separated from the true swans. A goose, however, it decidedly is, as is clear from its terrestrial habits, its powerful bill, its thorny tongue, and its diet of grass.

There is something in the aspect of this creature, the dark-brown stripe down its neck, its small bright eye, its harsh voice, its ceremonious strut, and its affectation of seldom being in a hurry, which seem to say that it came from China. It would perfectly harmonise in a picture of Chinese still life; or in a Chinese garden, with artificially-arranged rocks, dwarf trees, crooked trellises, and zigzag pathways; or, in a more extended landscape, it would group well on a broad river, beside a boat filled with shaven fishermen, with their trained cormorants and pig-tailed children. If it does come from China, it has no doubt been domesticated for many hundred years, perhaps as long as the peacock or common fowl. An evident proof of this is the large number of eggs they may be made to lay by an increased supply of nourishing food. This is very different from the disposition to "lay everlastingly," as seen in the Guinea fowl, and some varieties of the domestic hen-the black Spanish, for instance,-because the China goose does, in the end, feel a strong desire to incubate as soon as her protracted laying is done, whereas entire exemption from the hatching fever is the great merit of the "everlasting layers." If liberally furnished with oats, boiled rice, \&c., the China goose will, in the spring, lay from twenty to thirty eggs before she begins to sit, and again in the autumn, after her moult, from ten to fifteen more. It is not, as in the Guinea fowl, a spontaneous flow of eggs, for which the ordinary diet of the creature is sufficient, but is as much dependent on feeding as the fatness to which a bullock is brought. A goose belonging to $\mathrm{Mr}$. Dixon, which he supplied with as much oats as she could eat, besides grass, potatoes, and cabbages, laid eggs larger than ordinary; one of them, with a double yolk, weighed $7 \frac{1}{2} \mathrm{oz}$., or nearly half a pound. Doubleyolked eggs are very rare, except among birds that have been long domesticated.

Another proof is their deficient power of flight com- 
pared with the rest of their congeners, owing to the larger proportionate size of their bodies. The common domestic goose flies inuch more strongly than her sister from China. Indeed, of all geese, these are the worst flyers. There is no occasion to pinion them. While the Canada goose thinks little of a journey from the north pole, or thereabouts, to Carolina; while the Egyptian goose pays an occasional visit from Africa to Great Britain, while the merry little laughing goose, if tamed and allowed the use of its wings, is almost as much at ease in the air as a pigeon, the China goose, to get out of the way of a frisky spaniel can hardly manage to flutter across a lawn.

Said the tame goose to the wild one, "On such a day, I shall fly away." The wild goose replied to the tame one, "On such a day, I shall fly away, too, if it be the will of Allah." At the appointed time, the wild goose performed her annual migration ; the tame one remained, and cannot fly to this day. If China, instead of Egypt, had given rise to the above fable, we should believe that the Anas cygnöides was the vain-boastful bird.

The prevailing color of the plumage of the China goose is a brown, which has aptly been compared to the color of wheat. The different shades are very harmoniously blended, and are well relieved by the black tuberculated bill, and the pure white of the abdomen. Their movements on the water are graceful and swanlike. It is delightful to see them on a fine day in spring lashing the water, diving, rolling over through mere fun, and playing all sorts of antics. Slight variations occur in the color of the feet and legs, some having them of a dull-orange, others black; a delicate fringe of minute white feathers is occasionally seen at the base of the bill. These peculiarities are hereditarily transmitted, but do not amount to more than mere varieties.

The male is almost as much disproportionately larger than the female as the musk drake is in comparison with his mate. He is much inclined to libertine wanderings, without, however, neglecting to pay proper attention at home. If there is any other gander on the same premises, they are sure to disagree; one of the two had $10 *$ 
better be got rid of. Both male and female are, perhaps, the most noisy of all geese; at night, the least footfall or motion in their neighborhood is sufficient to call forth their clanging and resonant trumpetings. This, to a lone country house, is an advantage and a protection. Any fowl stealer would be stunned with their din before he captured them alive, and the family must be deaf indeed that could sleep on through the alarm thus given. But by day it becomes a nuisance to the majority of hearers, and has caused them to be relinquished by many amateurs. One is inclined to address them as O'Connell did the uproarious fellow who was interrupting his speech, "I wish you had a hot potato in your mouth."

\section{BREEDING AND REARING.}

The eggs of the China goose are somewhat less than those of the domestic kind, of a short oval, with a smooth thick shell, white, but slightly tinged with yellow at the smaller end. The goslings, when first hatched, are usually very strong. They are of a dirty-green, like the color produced by mixing Indian ink and yellow ochre, with darker patches here and there. The legs and feet are lead color, but afterwards change to a dull-red. If there is anything like good pasturage for them, they requir no further attention than what their parents will afford them. After a time, a little grain will strengthen and forward them. If well fed, they come to maturity very rapidly. In between three and four months from the time of their leaving the shell, they will be full-grown and ready for the spit. They do not bear being shut up to fatten so well as common geese, and therefore those destined for the table are the better for profuse handfeeding. Their flesh is well-flavored, short and tender; their eggs are excellent for cooking purposes. Hybrids between them and the common goose are prolific; the second and third cross is much prized by some English farmers, particularly for their ganders; and in many flocks, the blood of the China goose may often be traced by the more erect gait of the birds, accompanied by a faint stripe down the back of the neck. With the 
laughing, or white-fronted goose, they also breed freely.

The large number of eggs laid by these birds has, led some persons to imagine that, like Guinea fowls, they were inexhaustible, so that, when at last the goose did make her nest in earnest, (which may be known by her mixing her own down with the straw,) no eggs had been reserved for the poor thing to sit upon. The best plan is to date the eggs with a pencil as they are laid, and consume only those which are more than three weeks old. They are usually very late with their broods, but will rear them well enough if they are allowed to take their own time, and do it after their own manner. Their period of incubation is five weeks. They are steady sitters when they once begin in earnest, and exemplary parents. The goose, on leaving her'nest to feed, covers her eggs carefully. Any difficulty in rearing them results from want of proper management. If, for instance, when the bird does at length sit, she is insufficiently supplied with eggs, or with those which have been kept too long; or if she be permitted to be disturbed by dogs, \&c.; if she be suffered to steal a nest, and sit on more than see can cover-things will go wrong. The great number of eggs laid may perhaps cause an uncertainty that each one is properly fecundated. 


\section{THE WHITE, CHINA GOOSE.}

"Man as he extends his dominion over earth and ocean, is generally a Destroyer, occasionally an Enslaver, and so far a Protector; hence, sometimes, even a Selecter and Improver, but never a Creator.

Drxox.

"Every like is not the same," is a principle that is beginning more and more to influence the reasonings of zoologists, and to effect their conclusions with respect to wild animals. But, according to the prevailing opinion with domestic ones, a diametrically opposite axiom would seem to hold; as the latter are described and catalogued apparently on the rule that "Things may be unlike, and yet the same." The various kinds of domestic fowls are supposed to be "varieties"-by which, it is presumed, is meant transmutable, or at least, transmuted forms - of one, or at most, two or three wild originals; and the history of the common domestic goose is quietly settled by considering it as the result of a fusion of trree or four 'different species melted and mixed into one. Believe it! those who may, and classify it with the marvellous story of the " bernicle goose originating from a worm engendered in the sea from rotten wood!"

But, before finally determining to fix the appellation of species, or variety, to any particular race of animals, it will be necessary first to settle the question of what is meant by the terms Genus, Species, and Variety. They are all understood to denote certain degrees of 
difference, that are made use of to assist in classification; ; but the precise lines of demarcation of each are extremely difficult to define. It is generally assumed that individuals of different genera will refuse to breed together; that the mules between different species are sterile; and that varieties are merely accidental, and recent instances of a slight alteration in the external character of species, which do not affect their continuance as a race, and, perhaps, disappear altogether after a time. But in opposition to this, hybrids have been produced between the Egyptian goose and the penguin duck, also between the common fowl and the Guinea fowl, the siskin and the Canary bird; prolific mules are constantly occurring between all sorts of species of geese; and it is well and practically known, that though varieties breed freely with each other, nothing is so difficult as to establish a cross that shall be a perfect amalgamation of two distinct varieties. Even individual peculiarities are reproduced in the course of generations. For, some breeders of great experience firmly maintain that white pea fowls are not a mere accidental variety of the common kind, but a distinct sort; asserting that the cases, in which white birds are produced from colored parents, are only a breaking out of mixed blood, the " crying back,' in fact, to a cross some generations past. The white pea fowls are certainly of inferior size, and in their proportions bear more resemblance to the Japan breed than to the true Pavo cristatus.

In truth, species and varieties differ only in degree. If we admit that the latter are merely recent changes of organization, we cannot refuse to allow that the former are so likewise; and thence proceeding backwards, we must apply the same view to genera and classes, till we arrive at last at the theory of the development of all animated beings from Monads, as advocated by Lamarck, and more recently by the author of the "Vestiges of Creation," This is one mode of explaining the diversity of Nature; the other is by 
supposing that animals were originally created as we now see them, and that any apparent gaps in the chain or network are caused by the extinction of certain races, not by the uprising of new forms into existence, since the creation of man, at least. Besides, we have records of modern exterminations successively going on, from the Christian era to the present day. No undisputed record, however, is to be found of the sudden emergency into life of a new tribe of creatures. Foreign introductions there have been, but nothing more, that there is any affirmative evidence to prove. I am conscious that I may be contradicted by such instances as the New-Leicester sheep, and the very remarkable rabbits that are now kept in a state of domestication; but Mr. Bakewell is asserted to have studiously concealed and destroyed every trace of the means by which he established his breed," and the secrets of the "rabbit fancy" are as likely to be made available to the elucidation of natural history, as are the Eleusinian Mysteries. But so long as our commercial relations continue as widely extended as they are at present, the sudden and unexplained appearance of any living novelty in Europe or in this country, is by no means of necessity its first appearance on any stage. It may be as old as the hills-not a sudden drop from the clouds in these latter days, nor recently compounded, like Frankenstein's monster, from the members of defunct creatures, not yet electrified into life in a pickle jar, like Mr. Cross' mites.' Milton's noble lines, though true at the Creation, are no longer applicable-

\footnotetext{
"Meanwhile, the tepid caves, and fens, and shores,

Bursting with kindly rupture, forth disolosed

Their callow young; but feathered soon and fledge,

They summed their pens; and, soaring the air sublime,

With clang despised the ground. * * And straight the earth,

Opening her fertile womb, teemed at a birth

Numerojs living creatures, perfect forms

Limbed and full-grown; out of the ground up rose,

As from his lair, the wild beast where he wons

In forest wild, in thicket, brake, or den."
}

If such views be correct, it will follow that those who are searching for the wild originals of many of 
our domestic animals, are altogether pursuing a wrong scent. They might just as well search for the wild original of the Mammoth or the Dodo. It is an assumption, unsupported by any proof, to fix upon the wild creature that nearest resembles any given tame one, and say, "Here is the wild original ; the differences which we see, have been produced by time and domestication ;" or, if there is nothing wild coming within a moderate approach to it, to say, as of the common goose, "it is a combination of three or four other species." This is surely not philosophical reasoning; it is a begging of the question which would not be admitted in the exact sciences. What a daring leap at a conclusion it is, to get from the Asiatic argali, the American argali, or the Corsican mouflon, any or all of them, to the sheep, at a single vault! Such ratiocination is like the knight's move on the chess board, hither and thither, but never straight forward. Nor has the wide gulf between cocks and hens and the jungle fowls been as yet bridged over by any isthmus to me visible. The principle here sought to be indicated as a guide for future research is, that existing varieties and species which cannot be exactly identified in a wild state, are, in all probability, the remains of extinct races, the fragments of a ruin, and not newly-raised "seedlings," the modern sports and freaks of Nature.

And now to the white, China goose, about whose lineage, the reader, it is hoped, by this time, is interested. It was brought into notice, a few years since, by Mr. Alfred Whitaker, of Beckington, in Somerset, England, who speaks of it in the following words :"The white, China goose is of a spotless, pure whitemore swan-like than the brown variety, with a brightorange-colored bill, and a large orange-colored knob at its base. It is a particularly beautiful bird, either in or out of the water, its neck being long, slender, and gracefully arched when swimming. It breeds three or four times in a season, but I was not successfn] 
with them, owing, as I fancied, to my having no water for them, except a rapid running stream. A quiet lake, I believe to be more to their taste, and more conducive to the fecundity of the eggs. I believe my birds are still in the neighborhood, as I lent them to a farmer to try his luck with them. The egg is quite small for the size of the bird, being not more than half the size of that of the common goose. This bird deserves to rank in the first class of ornamental poultry, and would be very prolific under favorable circumstances. You will see both varieties of brown and white, China geese on the water in St. James's Park. My geese were from imported parents, and were hatched on board ship from China."

These geese, it is stated, formerly existed in the aviaries of the London Zoological Society, and were there considered in the light of a variety of the Anser cygnöides; but the head keeper of that establishment speaks most decidedly of his experience of the permanence, not only of this variety, but also of that of the dark-legged sorts of the brown kind, thus indicating three races, which, I repeat, would be considered as species were they now discovered for the first time.

Mr. Dixon, in speaking of these birds, says, "They are larger than the brown, China geese, apparently more terrestrial in their habits; the knob on the head is not only of greater proportions, but of a different shape. If they were only what is commonly meant by a variety of the dark sort, it is a question whether the bill would not retain its original jetty black, whatever change occurred to the feet and legs, instead of assuming a brilliant orange hue. If the bird were an albino, the bill would be flesh-colored, and the eyes would be pink, not blue."

Mr. Knight, of Frome, England, in whose possession they had been for three years, states that he has been unable to obtain any young from the eggs of the goose, but if he supplies her with eggs of the common goose, she invariably hatches and rears the goslings. Separ- 
ate trials of each of the pair with the common goose and gander have been made by him unsuccessfully, although the white, China goose lays four times in the year. Another gentleman, who also had a pair of the same lot, from China, says, "I had one good brood from the young pair which I kept, but since that, they have bred so badly that I have parted with the females and kept a male bird, and now get very good broods. My friends, to whom I have given young birds from my pair, also complain. The geese sit remarkably well, never showing themselves out of the nest by day, but whether they may leave the nests too long in the cold of the night, I cannot tell. The time of incubation I consider to be about four weeks and three days. The young birds of the crossed breed, in appearance, follow the mother, the common English goose, but they do remarkably well." 


\section{THE AMERICAN WILD GOOSE.}

NATURAL HISTORY.

Every portion of it, (the young of the wild goose bred in the inland districts, and procured in September,) is useful to Man; for besides the value of the flesh, as an article of food, the feathers, the quills, and the fat, are held in request.

AUDUBON.

The history of the "Canada" or "wild goose," as it is usually called, both in a state of nature and in captivity, has been so well and so fully delineated by the ablest ornithologists of Europe, as well as of this country, that for me to attempt giving complete details respecting it, would be either to restate the same facts in less appropriate language, perhaps, or to draw too liberally from the stores of those who have written before me; yet, this bird is by far too important, in every respect, to be entirely omitted in the present series; and there are a few points respecting it which ought to be brought into more prominent notice. Most writers on poultry call it a variety of the common goose. But it is no more a variety of goose than the swan is a variety of goose. Cuvier seems to doubt whether it is a goose at all, and says that it cannot be properly separated from the true swans. Audubon kept some three years, and though the old birds refused to breed in confinement, their young, which he had captured together with them, did. He states their period of incubation to be twenty-eight 
days, "which is a shorter time than one would have imagined. That circumstance alone, if correct, marks a wide distinction. At a future time, probably, our scientific naturalists will deem it advisable to institute several new genera, for the reception of various water fowls, that are now huddled into one or two; particularly if they allow the diet and habits of the birds, as well as their external form, to influence the rules of classification.

In a state of nature, the Canada goose eats worms and soft insects, as well as grass and aquatic plants, which the typical, or geese proper, never do. In a domestic or confined state, they do not breed till they are at least two years old, and so far approach the swan, like which, also, the male appears to be fit for reproduction earlier than the female. But Audubon says, "That this tardiness is not the case in the wild state, I feel pretty confident; for I have observed, having broods of their own, many individuals, which, by their size, the dullness of their plumage, and such other marks as are known to the practised ornithologist, I judged to be not more than fifteen or sixteen months old. I have, therefore, thought that in this, as in many other species, a long series of years is necessary for counteracting the original wild and free nature which has been given them; and indeed, it seems probable that our attempts to domesticate many species of wild fowls, which would prove useful to mankind, have often been abandoned in despair, when a few years more of constant care might have produced the desired effect."

The Canada goose, in spite of its original migratory habits, which it appears in almost every case to forget in a reclaimed state, shows much more disposition for true domestication than the swan, and may be maintained in perfect health with very limited opportunities of bathing.

The manner in which these birds are usually kept in Europe and this country, is neither consistent with their natural habits, nor calculated to develope their usefulness and merit. They are mostly retained as ornaments to large parks or inclosures, where there is an 
extensive range of grass and water; so far all is as it should be. But they are there generally associated with other species of geese and water fowls, all being of a sociable disposition, and forming one heterogeneous flock. In the breeding season, they neither can agree among themselves to differ seriously, nor yet live together in peace; the consequence is, that they interrupt each other's love-making, keep up a constant bickering, without coming to the decisive quarrels and battles that would set all right; and in the end, we have birds without mates, eggs unfertilised, and now and then a few monstrous hybrids, which, however much some curious persons may prize them, are as ugly as they are un. natural, and by no means recompense by their rarity for the absence of two or three broods of healthy legitimate goslings. Many writers speak highly of the half-bred Canada goose. They are very large, it is true, and mav merit approbation on the table; but with whatever other species the cross is made, they are hideously displeasing.

The facility with which the Canada goose, captured wild, is tamed, while yet it retains a "trick of the old nature," is well exemplified in a story related by Wilson, on the authority of a correspondent for whose veracity he avouches; which story, he observes, is paralleled by others of the same import. "Mr. Platt, a respectable farmer on Long Island, being out shooting in one of the bays, which, in that part of the country, abound with water fowl, wounded a wild goose. Being wing-tipped and unable to fly, he caught it and brought it home alive. It proved to be a female, and turning it into his yard with a flock of tame geese, it soon became quite tame and familiar, and in a little time its wounded wing entirely healed. In the following spring, when the wild geese migrated to the northward, a flock passed over $\mathbf{M r}$. Platt's barn yard, and just at that moment, their leader happening to sound his bugle note, our goose, in whom its new habits and enjoyments had not quite extinguished the love of liberty, remembering the well-known sound, spread its wings, moved in the air, joined the travellers, and soon disappeared. In the succeeding autumn, the 
wild geese, as was usual, returned from the northward in great numbers to pass the winter in our bays and rivers. Mr. Platt happened to be standing in his yard when a flock passed directly over his barn. At that instant, he observed three geese detach themselves from the rest, and, after wheeling round several times, alight in the middle of the yard. Imagine his surprise and pleasure, when, by certain well-remembered signs, he recognised in one of the three his long-lost fugitive. It was she indeed! She had travelled many hundred miles to the lakes, had there hatched and reared her offspring, and had now returned with her little family to share vith them the sweets of civilized life!"

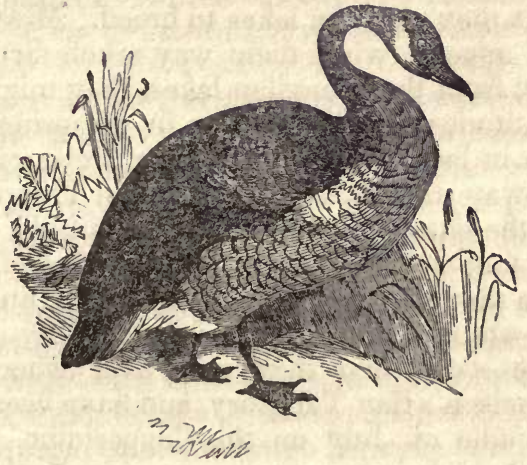

THE AMERICAN WILD GOOSE.

Synonymes.-Anser canadensis, of Naturalists; Oie du Canada, of the French; Canadische Gans, of the Germans; Ansa de Canada, Ansa silvestre americana, of the Spaniards; Wild Goose, Canada Goose, of the English and Anglo-Americans.

The Canada goose is a beautiful species. The head, two thirds of the neck, the greater quills, the rump, and tail, are pitch-black; the back and wings broccoli-brown edged with wood-brown; the base of the neck anteriorly, and the under plumage generally, brownish-grey; a few white feathers are scattered about the eye, and a white cravat, of a kidney shape, forms a conspicuous mark on the throat; upper and under tail coverts, pure white; bill and feet black. 


\section{GEOGRAPHICAL DISTRIBUTION.}

The American wild geese, in a state of nature, make their semi-annual migrations from the north to the south, and vice versî, which are sure signals of the approach of winter, or a returning spring. The tracts of their vast migratory journeys are not confined to the sea coast nor its vicinity, for in their aërial voyages to and from the north, these birds pass over the interior on both sides of the mountains, as far west at least as the Osage River. "I have never," says Wilson, "yet visited any quarter of the country where the inhabitants are not familiarly acquainted with the regular passing and repassing of the wild geese." It is an opinion with many that they visit the lakes to breed. Most, however, it would appear, wing their way much farther northward; for, from the Canadian lakes, they migrate to still higher latitudes on the setting in of spring. Hearne saw them in large flocks within the arctic circle, pushing their way still northward. Captain Phipps observed them on the coast of Spitzbergen in latitude $80^{\circ} 27^{\prime} \mathrm{N}$. Audubon found them breeding on the coast of Labrador, and states that the eggs, six or seven in number, of a greenish white, are deposited in a roughly-made nest. Bonaparte states that they breed everywhere throughout the Hudson's Bay Territory, and have been observed in the middle of July on the Coppermine River, not far from its debouchure, accompanied by their newlyhatched young.

The destruction of the Canada geese during their migrations is enormous; the autumnal flight lasts from the middle of August to the middle of November. Those which are taken in this season, when the frosts begin, are preserved in their feathers, and left to be frozen for the fresh provisions of the winter stock. The feathers constitute an article of commerce, and are sent to England. The vernal flight of these geese lasts from the middle of April until the middle of May. Their arrival in the fur countries, from the south, is impatiently expected; it is the harbinger of spring, and the month is named by the Indians the "goose moon." 
About three weeks after their first appearance, the Canada geese disperse in pairs throughout the country, between the 50 th and 67 th parallels, to breed, retiring at the same time from the shores of Hudson's Bay. They are seldom or never seen on the coasts of the Arctic Sea. In July, after the young birds are hatched, the parents moult, and vast numbers are killed in the rivers and lakes, when, (from the loss of their quill feathers,) they are unable to fly. When chased by a canoe, and obliged to dive frequently, they soon become fatigued, and make for the shore with the intention of hiding themselves, but as they are not fleet they fall an easy prey to their pursuers. In the autumn, they again assemble in flocks on the shores of Hudson's Bay, for three weeks or a month previous to their departure southwards.

The flight of this species is laborious and heavy, and generally in single file, or in the form of two sides of a triangle, the leader, some old gander, being the apical bird. From time to time this leader utters his deep "honk," which is responded to by the rest of the flock, and which may be translated, "What cheer, ho!" "All's well!" Very often, however, all is not well, for the line is scattered by the withering fire of the gunner; often, too, they meet with dense fogs in which they become bewildered, and after wheeling about alight on the ground, where the unerring rifleman gives them a warm reception. In some districts, the sportsmen take with them into the marshes one or two of the domesticated race, which, by their call note, attract the flocks passing over head, and allure them to destruction.

Wilson says, that, except in calm weather, the flocks of Canada geese rarely sleep on the water, generally preferring to roost all night in the marshes. "When the shallow bays are frozen, they seek the mouths of inlets near the sea, occasionally visiting the air or breathing holes in the ice; but these bays are seldom so completely frozen as to prevent their feeding on the bars at the entrance 
PAIRING, BREEDING, AND MANAGEMENT.

In the month of November, it is recommended that every flock of wild geese be reduced to two pairs, (or at least three pairs, ) in order to guard against accidents to one. Such birds should be retained, as differ as much, in age, as may be consistent with their breeding powers; and also, if possible, those should be selected which have been observed to entertain a mutual dislike, in order that they may fix their nests at a distance from each other. They should previously have become attached to their keeper, though not to their co-mates, that they may suffer him to approach and feed them and their goslings liberally, and so bring them into thoroughly good condition by killing time.

The stock bird ought to be well supplied with grain or Indian corn during winter, when the grass grows little or not at all, to promote early laying; but they usually have a few kernels of barley or maize thrown down to them now and then. No one can blame them, if they occasionally stray out of bounds in search of food; but they are then accused of restlessness, shyness, and so on. It is no migratory impulse that sets them on the move, but over-crowding and under-feeding; in proof of which, they will generally return of their own accord. I am speaking of birds that have been bred in captivity for several generations. Give them room and food enough, and they will stay contentedly at home. Curtail their supplies, and they become like "darkness," in Spoffoth's weilknown glee ; "flies away" is ever and again the burden of their song. The Canada goose is a very large bird, and cannot be expected to live and get fat upon air. If a farmer's wife were to treat her turkeys as the Canada goslings are usually served, they would at Christmas be just as tough, stringy, and uneatable, if indeed they survived the pinching regimen so long. The growing goslings must sensibly miss the abundance of their native breeding places, when confined to these short commons; and it is not just in us, after such neglect and penuriousness on our part, to complain that they neither fat well nor reproduce at an early age. 
From each pair of geese, properly looked after, between six and nine goslings may fairly be calculated upon; which, killed in the autumn, when really plump, would be very acceptable at home, or as presents to unprejudiced persons. Managed thus, they would be little, or, according to Audubon, not at all inferior to a fatted cygnet. And their picturesque effect, as accessaries in landscape gardening, would surely be greater in distinct uniformly-tinted groups, moving here and there across the scene with a decided object, namely, the conducting of their young, than as a motley crowd of diversely-colored, variously-shaped creatures, huddled together in unmeaning confusion. The woodland park should be stocked on different principles to the aviary and the menagerie. Thus it is, as a spot of pure white, that the swan gives such a sparkling brilliancy to the picture; and the point of deepest shade, (an adjunct of no less importance to the painter,) may be made more intense and effective by the judicious employment of the Canada goose.

When a pair are received from a distance, the best way of settling them in their new abode is to confine them with hurdles and netting, as near as possible to the spot where it is wished they should eventually make their nest. Those from the hands of dealers will generally be cowed or timidly tame; but young birds fresh taken from their parents, or adult ones that have been removed from their old home to a new one, will sulk and be shy. For the first few hours, they need have nothing to eat, only plenty of water to drink. Their keeper should show himself to them, and speak to them kindly, as often as his leisure will permit; when he guesses that they begin to feel the cravings of hunger, a small handful of grain may be thrown down to them, a cabbage or two, and half a dozen earth worms. It is, of course, supposed that they have been located on the grass. It is likely that, at first, they will not eat in the presence of a stranger; they may be left for an hour or so when, if they have availed themselves of his absence, he may give them a little more from time to time. Proceeding thus by kindness, familiarity, and very frequent 
visits, he will soon secure their confidence, and be able to form his own judgment when they may be suffered to range at large.

The young are active, self-helping little things. Their down is of a dirty-grey, a color very difficult to describe, with darker patches here and there like the young of the China goose. Their bill, eyes, and legs are black. They give no trouble in rearing. The old ones lead them to the places where suitable food is to be obtained. The keeper, by a liberal supply of grain or Indian corn, can bring them forward for the table better than by shutting them up to fat; and before Christmas, the parents should be again alone in their domain. They will continue to increase in size and beauty for some years, and should have been pinioned at the first joint of the wing, reckoning from the tip, in the manner described for the swan; the young that are to be eaten had better remain unmutilated. Old birds, killed in the autumn, after they have recovered from moulting, and before they have begun to think about the breeding time, would make excellent meat if cut into small portions, stewed slowly five or six hours with savory condiments, and made into pies the next day. "'Tis the soup that makes the soldier," say the French. By roasting or broiling similar " joints," we lose the large quantity of nutriment contained in the bones and cartilages, besides having to swallow tough, what we might easily make tender. The young, as well as the old, in some parts of this country, are salted and boiled; they would probably please most palates better, if cooked and served swan fashion. The young male has a frequent disposition to neglect his own mate, and give himself up to unlicenced coinpanionship. Mr. Dixon had one that deserted his partner, to her evident grief, and made most furious love to one of a flock of tame geese, separating her from the rest, not permitting any other water bird to swim near her, stretching out his neck stiffly on a level with the water, opening his red-lined throat to its utmost extent, hissing, grunting, sighing, trumpeting, winking his bright, black eyes, tossing his head madly, and all kinds of folly. Mr. D. did not choose to nermit such conduct; but as often 
as be killed and roasted the object of his affections, the Canadian gander immediately selected another leman, invariably the ugliest of the surviving females. One short, squat, rough-feathered, ill-marked goose, with a thick bill and a great grey topknot, was his special favorite. When the Michaelmas murders had extirpated the whole race he so admired, he returned reluctantly and coldly to his former love. 'The best remedy in such a case is to-divorce them at once, and exchange one out of the pair for another bird.

A similar incident is related in the seventh volume of the "Aınerican Agriculturist," by Col. Minot Thayer, of Braintree, Massachusetts, in the following words :- "A few years since, a neighbor of mine shot at a flock while passing to the south, wounded one in the wing, took him alive, and very soon domesticated him. He soon became very tame, and went with the other geese. I bought him, and kept him three years, and then mated him with an old native goose. They had several broods of young ones, and the old goose became very feeble; so much so, that she could not sit long enough to hatch out her eggs. I accordingly put them under another goose, where they did very well. In the fall of the year, I gave her away, and mated the wild gander with another. In the spring following, about six months after, I heard that the old goose had got better, and was in good health. She was brought home and put into my poultry yard. The wild gander and his new mate were at a distance of about eighty rods, in another pasture. As soon as the old goose was put into the yard, she made a loud noise, which the wild gander heard. He immediately left his new mate, and came down to the yard, recognised his old mate, entered into close conversation, and appeared extremely happy in seeing her again. His other mate followed him, and wished to join the party, but he appeared much offended, treated her with the greatest indifference, and drove her from him. 


\section{THE C $0 M M O N-S W A N$.}

NATURAL HISTORY.

Emblem of modest grace,

Of nnaffected dignity and ease,

Of pure and elegant simplicity.

Eudosra.

The swan, beyond all question, is the bird to place, as a finishing stroke of art, on the smooth lake which expands before our mansions. It is perfectly needless, however delightful, to quote Milton and others, lauding the arched neck, tho white wings, the oary feet, and so on. Its superb beauty is undeniable and acknowledged; and, to borrow an apt, though homely metaphor, I do not wish, if it can conveniently be avoided, in the present volume, "to thresh straw that has been thrice threshed before," to repeat how lovely the swan is on the silver lake, "floating double, swan and shadow ;" for I might thus run, scissors in hand, through the whole Corpus Poetarum; my object being simply to point out the chief features in their natural history, and the best mode of treating them. 


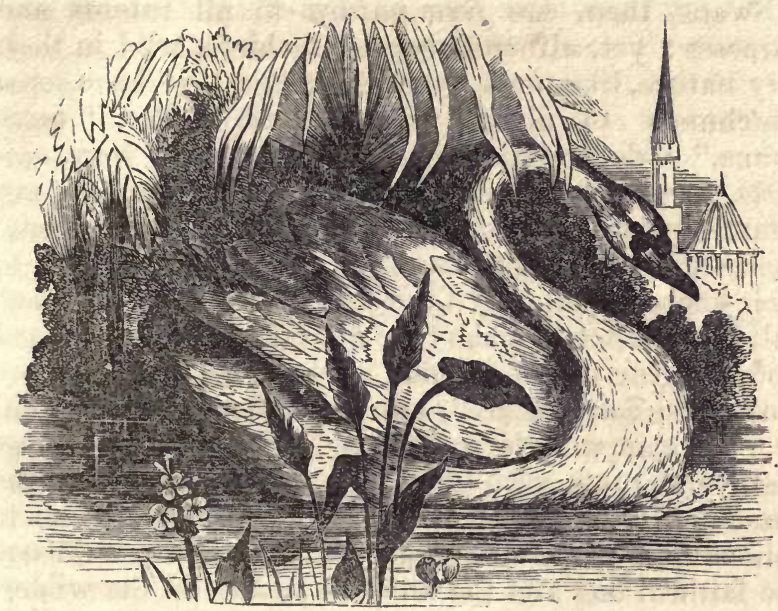

THE COMMON SWAN.

Srnonrmes.-Cygnus olor, of Naturalists ; Cygne commun, Cygne muet, of the French; Gemeiner Schwan, Stummer Scluwan, of the Germans; Cisne comun, Cisne mudo, of the Spaniards; Swan, Common Swan, Mute Swan, Cob, (adult male,) Pen Bird, (adult female,) Cygnet, (young.) of the English and Anglo-Americans.

Those who wish to make themselves acquainted with the habits and dispositions, as well as the mere figures and descriptions of animals, should know that all living creatures cannot be divided into two distinct ranks of wild and tame, but that there is a most perplexing intermediate multitude, neither wild nor yet tameable, but usually spoken of as "familiar," or "half-domesticated," a term without meaning, dodging, like "squatters," on the offskirts of human society, but determined never to enlist in the drilled and disciplined ranks, playing the game of "off and on," but always ending with the "off." Such, among many others, are the partridge, rats and mice, and at a still greater distance, it is believed, is the whole genus of swans. 
Swans, then, are ferce natura to all intents and purposes ; yet, although capricious birds, wild in their very nature, like most living creatures, they have some attachment to place, yet they are called "tame swans," "domestic swans, \&c. ; but never were epithets more inappropriate, unless we agree to say " tame hyæna," "tame wolf," "tame rat," "domestic pheasant," "domestic swallow." They will come to their keeper's call, and take food from his hand; they will keep at home, when they are completely prevented from ranging out of bounds abroad; so far are they tamed and domesticated, but no further, and never will be. To compare the relations which exist between them and man, with those by which we retain the gouse and the common fowl, is about as correct as to believe that the same temper and disposition influence the faithful dog and the wildest jackal of the wilderness. I put the case thus strongly, in order that it may be understood clearly. The comparisons may be a little exaggerated, but they will serve to raise the real truth into higher relief. The period of incubation is about forty days.

\section{PAIRING.}

LIKE mest domesticated animals, as before observed, swans have some attachment to place. The first, therefore, is to settle them, agreeably to their destined home. Old birds are less likely to be contented with a new abode, unless very distant from their former one. Cygnets may be procured every autumn ; if they have been put up to fat for some time so much the better, as they will the sooner become manageable, and content with a small range. The disadvantage of having eygnets to begin swan keeping with, is, that they are less ornamental till they have attained their perfect plumage, and the proper orange color of the bill, and that they do not breed till their third year. It is not, however, generally known that the male is capable of increasing his kind a year earlier than the 
female, so that a brood may be obtained from an old hen, and a cook bird in his second year. In selecting a pair, the great thing is to make sure of having two birds of opposite sexes. Two cock birds will not live together, and their mutual aversion would soon show that all was not right; but two hens will-which is the case also with pigeons.

\section{DISTINOTION BETWEEN THE MALE AND FEMALE.}

IN selecting any water birds whose plumage is alike in both sexes, and which cannot, therefore, be distinguișhed with certainty, the best rule is to see them in the water, and take that which swims deepest for the female; and that which floats with greatest buoyancy for the.male, remembering that, as a general rule, all creatures of the masculine gender have the largest lungs in proportion to their size. The neck of the cock swan is usually thicker. An experienced eye will, besides, detect a certain feminine gentleness and modesty in the one, and an alacrity and boldness in in the other, which is a tolerably safe guide, as well as an appropriate and becoming attribute to the creatures themselves.

FEEDING, MANAGEMENT, ETC.

Supposuvg the reader to have obtained two cygnets that are not mere friends, but actually husband and wife, he will recollect that those reserved for fatting are never pinioned, lest it should check their progress, and he will request the operation to be performed before he has them home, in order that they may have the fewest possible disagreeable reminisences, connected with the spot where they are to spend their lives. The amputation of the part of the wing, which corresponds to our hand, is quite sufficient to prevent the flight of the short-winged species, so far as migration is concerned, disfigures them less than the closer pruning, and still leaves them the means of escape from a 
dog, allows them now and then, in their gambols, to fancy they are free, and to enjoy a sort of half-run, half-fly, from the lawn into the water. Kindness, comfort, and good feeding must be employed to keep them at home as far as possible; but the loss of the last wing will not be enough to prevent their flight. It is recommended that the female be pinioned at the wrist, the male at the elbow, trusting to their mutual attachment to keep the less-maimed bird from deserting her mate. But however it be done, let it be set about in a workmanlike manner; no choppingno hacking-no hewing-nor butchering. Many cygnets are annually killed by the clumsy way in which their wing is lopped off. They suffer from the shock to their nervous system.

A skillful operator will feel for the joint, divide the skin, and turn the bone neatly out of the socket. $\mathrm{He}$ should be allowed to shed just one drop of blood-no more. I would be as hard upon him as Portia was upon the flesh-cutting Jew-

\footnotetext{
"This bond doth give thee here no jot of blood; The words expressly are, a limb of $8 w a n$, Take then thy bond, take thou thy limb of 8 wan; But, in the cutting it, if thou dost shed One drop of cygnine blood, thy clumsiness Shall brand the name of 'Bungler' on thy back. Therefore, prepare thee to ent off the limb, Shed thou no blood; nor cut thou less, nor more But just the very limb; if thou tak'st moro Or less, than just the limb, thou shalt bewail The consequence."
}

If any brook run into and from the pond where they are to remain, their escape through that channel must be prevented by netting, hurdles, pales, or other fencing, which should be continued some distance inland, lest they should walk away, if they cannot swim away. This precaution will be found particularly necessary if there is any main stream in the immediate neighborhood. A feeding trough may be fixed for them in the pond, in the part where it is most desirable that they should be accustomed to display themselves. The trough must be placed in the pond on two firm posts, within arm's length of the shore, raised high 
enough from the water to prevent ducks from stealing the food contained therein, having a cover which lifts up by hinges, and so forms a lid, to keep out rats, and open only in front. Many persons, however, feed their swans by simply throwing the corn, or grain, into shallow water. They will skim the surface for the light grains which float, and then submerge their heads in search of that which has sunk. But it is cruel to locate a pair of swans for the sake of their beauty in a new-made piece of water whose banks and bottom are as barren and bare as the inside of a hand basin. A load or two of water weeds should have been thrown in, the previous spring, to propagate themselves and afford pasturage. Swan food exists in proportion to the shallowness and foulness, not to the extent and clearness of the water. "A yard of margin is worth a mile of deep stream."

In confined waters, swans require a liberal supply of food, in the autumn, when the weeds run short. It should be remembered, that at this season, they have to supply themselves with a new suit of clothes, as well as to maintain their daily strength. If they have not been taught to eat grain, and have not acquired a notion of grazing, they will perish from starvation. Young birds are apt to be fanciful or stupid, and have not sense enough to come to the bank and eat grass, nor pick up the threshed corn, or grain, which may be thrown down to them. Sometimes they may be tempted with a lock of unthreshed barley or oats, thrown; straw and all, into the water, which they will instinctively lay hold of and devour. Cygnets, which have been previously put up to fatten, will give little or no trouble in this respect, besides the advantage of being accustomed to the near approach of their feeder.

The weight of the swan, in the feathers, varies from 25 to $28 \mathrm{lbs}$., and sometimes, though rarely, $30 \mathrm{lbs}$. They are never better than in the month of October, when the gastronomical inquirer, who is as yet unacquainted with their merits, is recommended to give 
them a fair and impartial trial. They may be had till Christmas, after which they are good for nothing. A bird weighing $28 \mathrm{lbs}$. before Christmas, has been known to shrink to 17 or 18 pounds by the end of January, in spite of high feeding. Therefore, "make hay whilo the sun shines," Mr. Epicure. As in the spring, the snowdrop gives way to the primrose and the violet, so, in autumn, the swan yields its place on the board to the turkey and the Guinea fowl. If to-day is lost, tomorrow the opportunity will have flown, in higher concerns than in mere eating and drinking. Now-or, perhaps, never.

The "swan feasts," which sometimes have occurred in England, that seem to have left the most pleasing impressions on the palates of the partakers have been solemnised in the course of the month of September. As to the mode of dressing, those artists, who are skilled in the treatment of venison, will easily cook swan, namely, with a meal crust over it to keep the gravy in. Instead of stuffing it with sage and onions, like goose, (vulgar condiments to vulgar birds,) use rump steak chopped fine, and seasoned with Cayenne and salt. When browned, and served to an admiring circle, let it have rich gravy and currant jelly, the latter hot as well as cold, in respectful attendance. And is that all ? No ; the best remains behind. The hash, next day, is worth riding twenty miles to eat. Nay, more; the giblets make soup before which ox tail sinks into insignificance. The mere writing about it has made me huigry. 


\section{CAPONISING FOWLS.}

\section{EISTORY.}

To my own taste, their flesh is insipid, flavorless, and fulsome, quite inferior to that of other Fowls, as we usually bave them; those who are dissatisfied with a fat Pullet, or a plump Cockerel, must surely want a little wholesome exercise of mind and body to restore a healthy appetite. Fasting, or hard work even, might do no harm in such cases.

Dixon.

THE art of making capons has been practised from the earliest antiquity, in Greece, India, and China, for the purpose of improving the flesh of birds for the table, in tenderness, juiciness, and flavor. But capons, in point of fact, are getting out of date, and are taking rank with oxen roasted whole, and other barbarisms of the middle ages. They are now rarely to be found in the London markets ; and when procurable, are very expensive, but not unjustly so, when it is to be remembered that two or three chickens may have been sacrificed, before ten capons have been nursed into convalescence. That they may be had in considerable abundance, in China, the south of Europe, and in a few instances in our own country, is not to be denied; but wherever they may be found, they cannot be classed otherwise than in the list of uncalled-for luxuries, of unnecessarily unnatural vi nds, such as diseased-goose liver pies, fish crimped al re, or even those frightful and portentous dishes recalled by Dr. Kitchener, in 
the "Cook's Oracle." One thing, however, may be harmlessly resuscitated. As-

\section{"Wears yet a precious jewel in his head,",}

so the capon, which, though ugly, is not half venomous enough, if we can be made to believe all we read, carries a valuable gem in the part that is usually antithetically opposed to the head.

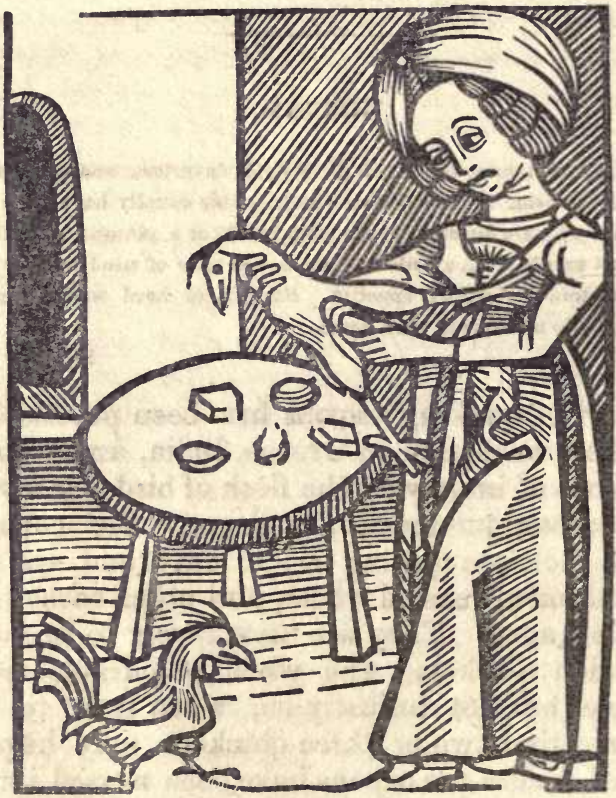

EXTRACTING A CRYSTAL FROM A CAPON'S LIVER.

From a very curious and ancient work on natural history, in my possession, entitled "Ortus Sanitatis," (the garden of health, ) printed and published at Ausburg, in 1485, by Joan. Cuba, a Dutch botanist, who travelled through Greece and the East, I give above, a fac-simile of a wood engraving, representing 
the act of extracting a precious stone from the liver of a capon. "The Allectorius," says the author, "is a stone like a crystal, or limpid water. It is found in the liver of a capon at the age of three years. It is never larger than a bean. After this stone is formed in the capon, he never drinks." The Ortus Sanitatis further informs us that ladies, who wear the jewel Allectorius, are sure to be pleasing in the eyes of their husbands.

Aldrovandi tells us that in capons, which were more the fashion in his day than they are now, the hackle, the tail feathers, and the spurs grew to a much greater length than in cocks.

In England, the art of making capons, it seems, is no new thing, as the business of which formerly devolved upon females ; for old Leonard Mascall, in his minute directions for the operation, uses the feminine gender throughout.

\section{MODE OF MAKING OAPONS AND POULARDES.}

IF young cocks are emasculated, so as to deprive them of their natural reproductive feelings, it has a wonderful effect on their condition, rendering them also more easy to fatten. They are never afterwards subject to the natural process of moulting, and lose their previous strong shrill voice. They become dull and melancholy, are detested by the hens, buffeted about by the other cocks, and would soon fall victims to their enmity, were they not removed to perform the remaining business of their lives, "to eat, drink, sleep, and get fat," with all possible expedition. In this state, they are called "capons."

In a similar manner, young pullets may be caponised, so as to deprive them of their reproductive powers, and render them more easy to fatten. When thus operated upon, they are usually, though improperly, termed "hen capons," but the French word, "poularde," is much to be preferred. 
In performing the operation, the first thing to be considered is the purchase or procurement of the requisite instruments. Those most approved of by skillful operators, consist of two five or seven-pound weights for confining the fowls; a scalpel for cutting open the

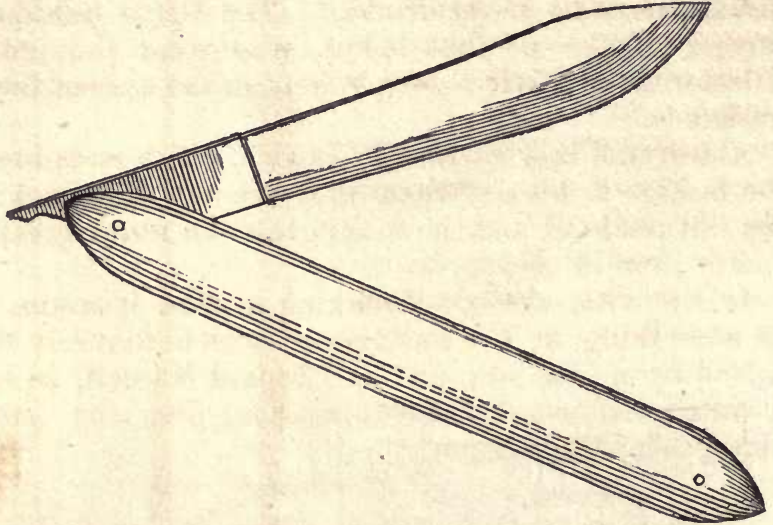

SCALPEL.

thin skin which envelopes the testicles; a silver retractor for stretching open the wound wide enough to ope-

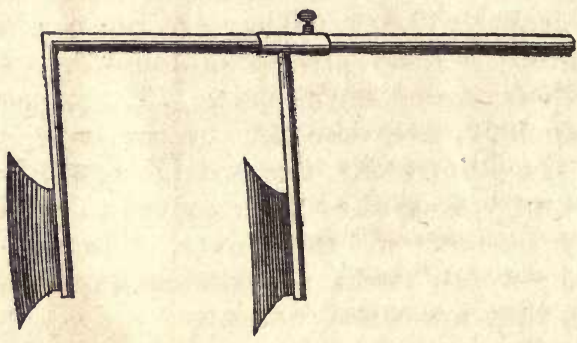

RETRACTOR.

rate within ; a pair of spring forceps, denoted by the letter $a$, in the following page, having a sharp, cutting edge, resembling that of a chisel, with a bevel half an inch in its greatest width, for making the incision, 
and securing the thin membrane co vering the testicles; a spoon-shaped instrument, $b$, with a sharp hook at one end, for pushing and removing the testicles, adjusting the loop, and to assist in tearing open the tender covering of the testicles; and a double silver canula, $c$, for containing the two ends of horse hair or fibre, constituting the loop.

The cost of these instruments in New York, is nearly as follows:-

Scalpel, . . . . $\$ 0.62 \frac{1}{2}$

Silver Retractor, . 1.50

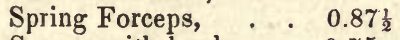

Spoon, with hook, $\quad 0.75$

Double Silver Canula, $\quad 1.75$

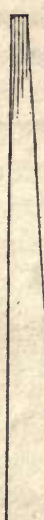
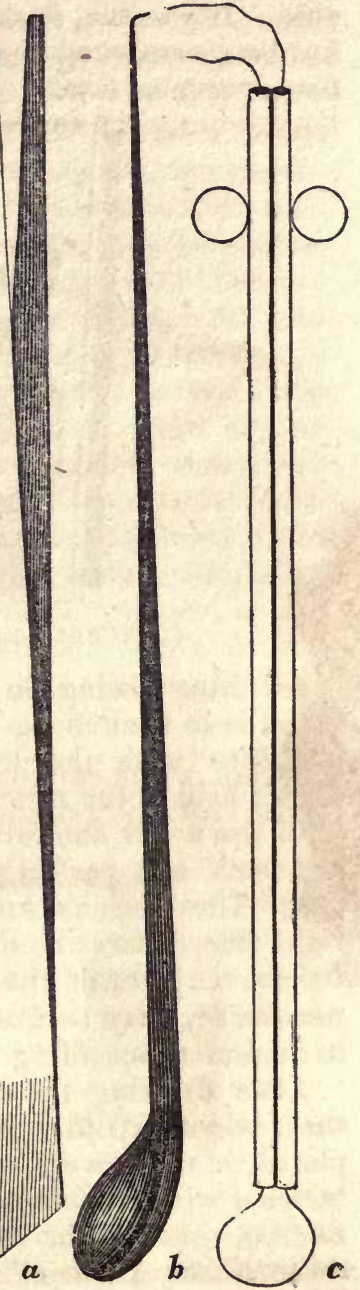

Those who are not particularly nice about the matter, may use a cheap penknife instead of the scalpel, and may obtain the other instruments of a cheaper construction, so that the whole will not cost more than half the sum indicated above.

The cockerels intended for capons should be of the larg. est breeds, as the Dorking, the Bucks-County, CochinChina, or the great Malay. They may be operated upon FORCEPS, SPOON, AND CANULA. at any time after they are a mon th old, though at an 
age of from two to three months is considered preferable. If possible, it should be done before July, as it has been remarked that capons made later than this, never prove so fine.

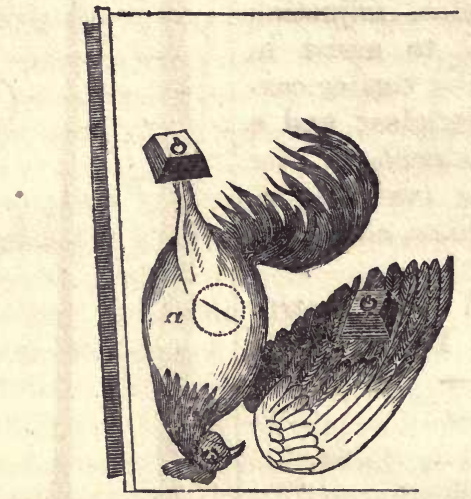

COCKEREL CONFINED FOR CAPONISING.

All things being in readiness, the first step to be taken is to confine the fowl to a table or board by laying him with the left side downward, the wings. drawn behind the rump, the legs extended backward with the upper one furthest drawn out, and the head and neck left perfectly free, as denoted in the above cut. The feathers are next to be plucked from the right side, near the hip joint, on a line with, and between, the joint of the shoulder, as at $a$. The space uncovered, may be from an inch to an inch and a half in diameter, according to the size of the bird.

After drawing the skin off the part, backward, so that, when left to itself when the operation is completed, it will cover the wound in the flesh, make an incision with the bevel-edged knife, at the end of the forceps, between the last two ribs, commencing about an inch from the backbone, and extending it obliquely downward, from an inch to an inch and a half, just cutting deep enough to separate the ribs, taking duo care not to wound the intestines. 
Then, adjust and apply the retractor by means of the small thumb screw, and stretch apart the wound sufficiently wide to afford room to examine the parts to be removed.

Then, with the scalpel or a sharp penknife, carefully cut open the skin, or membrane, covering the intestines, which, if not sufficiently drawn up, in consequence of the previous confinement, may be pushed forward towards the breast bone, by means of the bowl of the spoon-shaped instrument, or, what would answer equally well, with the handle of a teaspoon.

As the testicles are exposed to view, they will be found to be connected with the back and sides by means of a thin membrane, or skin, which passes over them. This tender covering must then be seized with the forceps, and torn open with the sharp-pointed hook, at the small end of the spoon-shaped instrument, after which, with the left hand, introduce the bowl of the spoon under the lower, or left testicle, which is generally a little nearer to the rump than the right one.

Then take the double canula, adjust the hair loop, and, with the right hand, pass the loop over the small hooked end of the spoon, running it down under the bowl of the spoon containing the testicle, so as to bring the loop to act upon the part which connects the testicle to the back. Then, by drawing the ends of the hair loop backward and forward, and at the same time pushing the lower end of the tube, or canula, towards the rump of the fowl, the cord, or fastening of the testicle, is severed.

A similar process is then to be repeated with the uppermost, or right testicle, after which, any remains of the testicles, together with the blood at, or around, the bottom of the wound, must be scooped out with the bowl of the spoon. The reason for cutting out the left testicle first, is to prevent the blood, which may issue, from covering the one remaining, and rendering it more difficult to be seen.

After the preceding operation is performed, which, 
if skillfully done, occupies only a few minutes, the retractor is taken out, the skin of the fowl drawn over the wound, which may be covered with the feathers that were plucked off at the commencement, and the chicken may he released. As soon as it is liberated, it will eagerly partake of grain or other food, and in a few days be restored to health.

In some fowls, the fore part of the thigh covers the two hindmost ribs, in which case, care must be observed to draw the fleshy part of the thigh well back, to prevent it from being cut; as otherwise, the operation to be performed might be liable to lame the fowl, or even cause its death.

For loops, nothing answers better than the fibre of a coco-nut husk, which is rough, and readily separates the testicles by sawing. The next best substance for the purpose, is the hair of a horse's mane or tail.

The usual method of making poulardes, in France, is, to extirpate the egg cluster, or ovaria, in a similar manner as the testicles are extracted from the young cocks; but it has been shown by Mr. Yarrell, in the "Transactions of the Royal Society," that it is quite sufficient merely to cut across the egg tube, or oviduct, with a sharp knife. Poulardes may otherwise be treated in the same manner as the capons.

Capons are fattened precisely in the same manner as other fowls, by keeping them cooped up in a quiet, dark place, and sramming, or otherwise feeding them, abundantly. 


\section{DISEASES OF POULTRY.}

\section{GENERAI REMARRS.}

Although poultry are no less liable to disorders than cattle, or other domestic animals, but very little attention has been paid to them, owing, no doubt, to the small value of individual fowls, compared with sheep or horses ; and frequently it is most economical to kill them at once. These disorders, however, are far from being devoid of interest, not only as sometimes leading to correct views of the diseases of other animals, including man himself; but so far as the saving of even a few dimes, by curing them when that is possible, or of rendering their eggs, or flesh, more wholesome and palatable, as well as the humane motive of adding to the comfort of the creatures, some attention to the subject, more than it usually attracts, is surely desirable.

The following notices, though far from complete, and, not improbably, requiring correction, in several respects, will be found, it is presumed, as full and as perfect as anything hitherto published in treatises on poultry. But let me at once confess my ignorance relative to the treatment of fowls laboring under their various maladies. Their ailments have hitherto failed, with, perhaps, few exceptions, to attract scientific ob- 
servation, and no wonder. Who attends them? What complaint do they make? And when they die, who, acquainted with the symptoms before death, makes post-mortem examinations, and then refers those symptoms to the morbid appearances which his scalpel has revealed? To speak the truth, neither are their diseases well understood, nor is the treatment of them anything but empyrical.

From reading, observation, and conversation, however, with those who profess to be practically acquainted with the diseases of poultry, my attention has only been directed to what may be considered as the proximate causes of their dissolution under the following active forms, namely :-Apoplexy, evinced by inflammation of the membranes of the brain, or by effusion of blood within or upon it; peritoneal inflammation of the mucous membrane of the intestines, or intumescence of the rump gland, symptomatic of a febrile condition. N. B. Do not give salt in any case whatever.

\section{APOPLEXY.}

This is a very frequent disorder among fowls, which makes its attack in most instances without the slightest warning. Mr. Flourens, a very distinguished physiologist, of Paris, and an author, says there are two degrees of apoplexy among fowls, one deep-seated, and the other superficial, each having different symptoms. Deep-seated apoplexy is characterised by complete disorder of movement, while superficial apoplexy is manifested only by deficient muscular energy and instability in walking. Deep-seated apoplexy is accompanied by superficial apoplexy ; but, as the latter is the precursor of the former, it ought to be carefully attended to, in order to prevent its passing to what may be termed the second stage, though both stages are capable of being cured by a natural process, as an individual case proves.

M. Flourens had brought to him, on the 12th of 
April, 1823, a young fowl, whose gait indicated that of a tipsy animal, so much, that the peasants called it the "tipsy hen." Whether standing, walking, or running, it reeled and staggered, advancing always in a zigzag manner, frequently turning to the right, when it wished to turn to the left, and to the left when it wished to turn to the right; and instead of going forward, it went backwards, and backwards instead of forwards. Its legs also often bent under it, so that it fell down; above all, when it flew high up to perch, it could not govern nor regulate its movements, but fell and rolled about on the ground a long while, without being able to get upon its legs or recover its balance. These movements so nearly resembled those which had been produced by experiment, that M. Flourens was impatient to examine the brain. $\mathrm{He}$ found the bone of the skull to be covered with black carious points. On penetrating the dura mater, a quantity of clear water ran out, while the cerebellum was yellowish, with rust-colored streaks on the surface, and in the centre was a mass of purulent coagulated matter, as large as a horse bean, contained in a cavity perfectly isolated, and having its sides very thin and smooth.

Dr. de Sala brought to M. Flourens, from Madame Rousseau, of Pecq, near Paris, a young cock, which had died of a disorder that appeared singular. This cock could not stand upright for any time without reeling on its legs, and it staggered when it attempted to walk or run; its neck always trembled or oscillated, particularly when it stretched it or its body; but when its head or beak were supported, the oscillation ceased.

This is evidently the same disorder which Dr. Bechstein terms epilepsy, and Mr. Clater, the megrims or giddiness. The latter says that "Many promising chickens are lost in this complaint. Without any kind of warning, they fall, roll on their backs, and struggle for a minute or two, when they rise stupid and giddy, and slowly return to their food. One fit having oc. 
curred, is soon followed by others, each more violent than the preceding, until at length, the little animal staggers about half unconscious, refusing to eat, rapidly wasting, and soon dies convulsed. In some cases, the megrims occur when the fowl is poor and halfstarved; but then the food has been improper; it has been watery or disposed to fermentation; diarrhœa has followed, and the fits are the consequence of intestinal irritation. Other young fowls will have occasional fits, from which they will rapidly recover, and appear to be little or nothing the worse. The megrims," he adds, "must be stopped as soon as possible. Castor oil and syrup of ginger will be a very good medicine, and be much improved by syrup of white poppies added to it. The fowl that has once had the megrims should be confined for some days, but in a tolerably large place, where it may obtain some degree of exercise."

This treatment, it may be observed, proceeds upon a total ignorance of the seat of the disease, as so well proved by M. Flourens. Dr. de Sala adopted the best possible method of cure, by applying leeches to the nape of the neck. The food should be light and scanty, and the. affected fowl should be confined in a rather dark coop.

PIP, OR THRUSH.

THis may be regarded as a token of derangement of the mucous membrane of the alimentary canal generally, and not as a local disease. It is considered variously by different writers. Dr. Bechstein describes it as a catarrhal inflammation producing a thickened state of the membrane lining the nostrils and mouth, particularly the tongue. M. Buc'hoz, on the other hand, thinks it caused by want of water, or by bad water, such as the drainings of dunghills, sinks, \&c., which fowls will drink when they can get no other.

The symptoms of the "pip," consist in a thickening 
of the membrane lining the tongue and palate, which causes an obstruction to free inspiration, and makes the poor sufferer gasp for breath; the beak becomes yellow at the base; the tongue dry ; the plumage becomes ruffled, the bird mopes and pines, the appetite gradually declines to extinction, and at last it dies, completely worn out by fever and starvation.

A cure may be effected by a low diet; that is, in the case of common fowls, by an allowance of fresh vegetable food, as lettuce or parsley chopped and mixed with potatoes and a little Indian or oat meal, granting at the same time a plentiful supply of pure water. Give, also, of castor oil, a tea-spoonful, or thereabouts, according to the age and strength of the fowl. Do not scrape the tongue, nor use rough modes of cleaning it; but apply a little borax, (sub-borate of soda,) dissolved in pure water and tincture of myrrh, by means of a camel-hair pencil, two or three times aday.

When chickens are ill with the pip, Dr. Bechstein recommends keeping the fowl in a warm place, and a mixture of butter, pepper, garlic, and scraped horse radish, to be given to it, without stripping the tongue; and, when the nostrils are obstructed, to pass a small feather, dipped in oil, up them. M. Buc'hoz recommends clean water.

\section{GAPES, OR INFLAMMATION OF THE WINDPIPE.}

THrs is a disease to which all our domestic gallinaceous birds are subject, and which often occasions great mortality among them. Wet, ill-feeding, and, ill-ventilated fowl house confinement, or a spot or plot of ground tenanted year after year by fowls, without attention to cleanliness, to renovation of the soil, and a proper allowance of gravel, ashes, fresh vegetables, \&c., are the proximate or remote causes of this, as well as many other complaints of our domestic fowls. At the same time, let it be borne in mind, that the "gapes" is an epidemic disease. 
In the first instance, it appears to arise from a croupy or catarrhal affection, which is indicated by running at the nostrils, watery eyes, alteration of voice, and loss of appetite and spirits. If the trachea, or windpipe, be examined, it will be found replete with narrow worms, about half an inch in length, imbedded in slimy mucus. This singular worm consists of a long and short body united together; the long one is the female, the short one the male, each, were it not that they are permanently united together, being an animal distinct and perfect in itself.

Whether these parasitic worms are the cause or consequence of the disease, it is not easy to say, nor do we know how they become introduced into the trachea ; this, however, seems certain, that their removal is requisite to give the feathered patient a chance of recovery. This can be done by means of a feather, neatly trimmed, which is to be introduced into the windpipe and turned round once or twice and then drawn out; it will dislodge the worms and bring back many of them adhering to it with the slime. This plan requires great dexterity and some knowledge of the anatomy of the parts; a slow unskillful operator may kill the already half-suffocated bird, instead of curing it. Another mode of destroying these worms, is, by putting the birds into a box, and making them inhale the fumes of tobacen, thrown into it through the stalk of a tobacco pipe. Some recommend the forcing of tobacco smoke down the bird's throat, and others that the mouth be crammed with snuff.

Martin, in his "Farmer's Library," recommends the application of a grain of calomel, made up with bread into a pill, or two or three grains of Plummer's pill, (pil. hydr. submur. co., London Pharmacopœia,) after which let flower of sulphur be administered, with a little ginger, in pultaceous food composed of barley meal. Indian meal will do as well. In the meantime let the bird be kept in a dry, warm shed or room, apart from the rest of the fowls, as it is believed 
that the disease is infectious. Let the mouth and beak be washed with a weak solution of chloride of lime.

\section{INFLAMIMATION OF THE LUNGS.}

Fowı, in a state of health, rarely breathe through the mouth as we do, but almost always through the nostrils, which are comparatively large, and communicate backward with the top of the windpipe. The windpipe itself is composed of stiff rings of cartilage, united by strong membranes; and such is the elasticity of these, that the tube is enabled to preserve its cylindrical form, even when it receives considerable pressure, and thereby affords free ingress and egress to the air in breathing.

When the windpipe descends into the chest, it divides into numerous branches called the "bronchial tubes," which gradually becoming smaller, at length terminate in perforations, but neither these branches nor the cells are so small in fowls as in other animals. It is these branchings of the windpipe, however, which, together with numerous blood vessels, make up the substance of the lungs, the interstices being filled with a fine membrane that serves not only to unite them, but likewise to give a uniform appearance to the whole mass. The perforations in which the branches of the windpipe terminate, lead into large air sacks communicating with all parts of the body, and forming an accessary lung.

With reference to a not uncommon disorder among fowls, it is important to mention that the lungs are covered with a fine delicate membrane called the pleura, on every part of which a watery fluid is secreted, for the purpose of preventing a cohesion of the parts.

Inflammation of the lungs, including the bronchial tubes, is not uncommon in fowls. Its symptoms are quick breathing, often with a rattle, or râle, very 
audible, dullness, disorder of plumage, vacancy in the eye, and indisposition to stir. Death is not to be prevented by any remedy we can point out. Human patients can explain their feelings, cattle to a certain degree indicate them; but birds give little indications by voice or manner leading to what the medical man calls a diagnosis. Besides, how are we to bleed a bird? The skin of most birds is very thin, it is unsupported by a thick mass of cellular tissue, and the vessels which ramify upon it are minute, none presenting a fair chance for successful venesection. To cut and wound a bird at random for the purpose of obtaining a flow of blood is barbarous.

\section{OBSTRUCTION OF THE NOSTRILS.}

Fowls, as already remarked, do not in general breathe through the mouth, but through the nostrils, and consequently, when these through any cause become obstructed, the bird may be observed to gape and pant for breath. This is the case in the "pip," as before mentioned and it is also a very common consequence of the wounds received in skirmishing and fighting, the blood from the lacerated comb trickling over, and plugging up the nostril with a hard adherent crust. When this is observed, the parts ought to be washed with warm water till the crust can be loosened.

If the obstruction arise from canker or ulceration of the nostril itself, it may, if recent, be rubbed with a little honey to defend it from the air; but if of long standing, and not seeming likely to heal, it may be touched with a red-hot wire, which will produce a scab, and in most cases be followed by a speedy cure. This may be considered by some a very barbarous remedy; but the pain it produces can only be momentary, and in reality is not so severe an operation as cupping.

In the case of obstructed nestrils from pip or catarrh, bathe them with warm milk and water, or anoint with sweet oil or fresh butter. 
ROUP, OR INFLUENZA.

The term "roup," is in common speaking very indefinite, being applied to the quite dissimilar disorders of poultry, such as to obstruction in the rump gland, the "pip" already described, and to almost every sort of catarrh. The word is supposed to be a corruption of "croup," which appears to be applicable to the "gapes," or inflammation of the windpipe. It will be most advisable, I think, to confine the term to a highly dangerous disorder, caused partly, if not altogether, by cold and moisture, but usually ascribed to improper feeding, uncleanliness, and confinement.

The symptoms most prominent in the roup, is difficult and noisy breathing, beginning with what is termed the gapes, as in the pip. The eyes afterwards become much swollen, and the eyelids livid, with decay of sight, and even total blindness. There is a considerable discharge from the nostrils, and even from the mouth, at commencement, thin and limpid but afterwards becoming thick, purulent, and fetid very similar to the glanders in horses. As secondary symptoms, the appetite is all but lost except for drink, the crop feels hard to the touch, and the feathers are staring, ruffled, and without a healthy gloss. The fowl sits moping and wasting in corners always apparently in great pain. Moubray says, that in a hen, which died of roup, the eggs were black.

The roup affects fowls of all ages, and is either acute or chonic, beginning sometimes suddenly, and sometimes gradually, as the result of neglected colds, or rainy weather and damp lodging. Chronic roup has been known to affect a fowl for two years.

When any fowls or other poultry are observed to be infected with roup, they ought to be kept warm, and have plenty of water and scalded bran, Indian-meal dough, or other light food. The most effectual remedy is said to be antimonial powder or calomel, in grain doses, made into a pill with bread. When it becomes chronic, change of food and of air, if convenient, will be advisable; such as confining the diet to earth worms 
for a week, and then keeping wholly to grain for another week, and again to hot mashed potatoes for a third week.

Cleanliness is no less indispensable than warmth, and it will be convenient to bathe the eyes with warm milk and water, or with Labarraque's disinfecting liquid, which is a solution of chlorinated lime.

\section{COLDS, CATARRHS, AND PULMONARY CONSUMPTION, OR} PHTHISIS,

Hoarseness, sneezing, and other symptoms of cold, are very common among fowls, which are more suscep. tible of cold than might be imagined, when we consider their warm clothing of feathers. When it is considered, however, that the air taken into their lungs is not, as in ourselves, stopped there, but by means of the air cells reaches every part of their body, penetrating even into the interior of their bones, we may wonder the less at their great susceptibility of being affected by changes of temperature. It must be considered, also, that fowls were originally, natives of a warm climate; and though long residents of higher latitudes they still retain so much of their original habits as to influence them in this respect. It is besides, a very common thing for individuals to be rendered more susceptible of changes of remperature than they otherwise would be, by being closely confined in zoops by dealers in the markets; and hence, when purchased and turned out into the fresh air of an open field or of a farm yard, they frequently, to use a common phrase, "catch their death's cold" within a few days.

M. Flourens, has investigated the nature of the disorders produced in fowls, by cold, with great care, and as his observations are not only apposite, I shall give them pretty fully. M. Flourens did not confine his researches to the common dumestic fowl, but experimented likewise on ducks, which he found, conformably to general experience, no less susceptible of catarrhal disorders than fowls, proving that it is not altogether a change of climate which causes such susceptibility.

$M$. Flourens being in the country in the month of 
May, his attention was called to a duckling of a brood newly hatched, which was reported to have swallowed something that stack in its throat, appearing to be on the point of suffocation, continually opening its broad bill, and breathing with extreme difficulty. He examined the fauces, the windpipe, and the gullet, and found nothing; but the struggles of the little creature continued to increase, and it finally died in an hour or two. On opening it, no foreign substance was found, neither in the gullet nor windpipe; but the lungs were of a deep-red, and gorged with blood, showing that its death had been caused by acute inflammation of the lungs.

Another duckling of the same hatch was pointed out to M. Flourens, which had been suddenly seized with symptoms similar to the preceding; and while he was examining this, a third was struck so suddenly with oppression of the chest, that it stood motionless, gasped for breath, had violent palpitation of the heart, left off eating and drinking, and died in two or three hours, as did the second one. He opened both, and found the same inflammatory engorgement of the lungs which he had observed in the first. The disorder indeed was evidently acute inflammation of the lungs.

The terrace where he found the ducklings thus seized, and which was badly situated for rearing poultry, had a northern aspect, and the sun scarcely reached it. It was consequently cold, and cold alone seemed to be the cause of the pulmonary inflammation in the ducklings. To try the effect of a warmer exposure, M. Flourens caused the remaining ducklings of the hatch, seven in number, to be removed to a poultry jard, having a southern aspect, and perfectly exposed to the sun. Upon carefully warming the little creatures, the inflammation disappeared from the chèst, and did not return. All the seven ducklings lived and grew up to adult age.

In the beginning of October, 1826, M. Flourens procured a brood of twenty-three chickens, about a month old. As soon as the cold weather appeared, he placed six of these in a suitable place, where he kept up a mild temperature during the day, and at night made them sleep in baskets warmly covered. None of these six 
chickens, among which were four females and two males, were affected with consumption of the lungs; but one died of a disorder of the eyes, and another lost an eye.

Of eleven chickens which he kept constantly in the poultry yard with a southernly aspect, all, except two, a hen and a cock, died before the end of December, of consumption of the lungs, having first passed through all the stages of this disease.

Those chickens, which, at the end of October, were still lively and gay, lost by little and little their strength and vivacity ; they trailed their wings, ruffled up their feathers, their flanks fell in, they chirped almost incessantly, their voice changed progressively, becoming first hoarse and at length aphonous; they scarcely ate, they grew extremely emaciated, with the skin dry, and as if it were glued to the bones; they endeavored to get in doors for shelter, and when they did get in, they were observed to approach as near as they could to the fire, to sit down even on the cinders and even upon the dogs and cats around the hearth.

On the death of these creatures, M. Flourens found their lungs in different stages of inflammation and of suppuration, For the most part, the larynx, all the windpipe, and its ramifications through the lungs, were filled with purulent matter of a greyish color like mud, and of a fetid smell. This matter was sprinkled all over, (parsemée,) with a multitude of very minute black points, and these when thrown into water, fell to the bottom. The lungs at certain points were gorged with blood, and their tissue, softened as if putrefied, was of the color of wine lees. At other points, particularly the external posterior margin, the pulmonary vesicles presented black points like those in the purulent matter, and in many of these black points he found a very minute substance, hard, crepitating, white, and of a bony or horny appearance. In fine, upon other points, he observed the vesicles corroded, and forming small sacs filled with the pus found in the bronchia, the windpipe, and larynx.

As to the two surviving chickens, they no doubt withstood the cold from being covered with feathers 
than the others, but they remained dwarfea and feeble. There remained six chickens more out of the twentythree on which he had begun his experiments. The following is what he did with these :- He left them at first with the eleven in the poultry yard till they exhibited symptoms, not to be mistaken, of pulmonary consumption more or less advanced. He then took them to the place kept at a mild temperature, where, after marking then with bits of stuff tied to their legs, he united them with the six already there.

Two of these chickens, which would certainly have died the same day or the next, if he had left them in the poultry yard, after having appeared at first to regain a little strength, died, one in about five and the other in about nine days. He found their lungs in a complete state of suppuration or of inflammation.

The four other chickens regained by degrees their vivacity and vigor, recommenced feeding with a good appetite, and appeared completely re-established in health, and in April, 1827, when he released them all from confinement, they appeared as healthy as those which had never been exposed to the cold.

Among these four cured chickens were three cocks which he sacrificed to ascertain both what might be the actual state of their lungs and what could have been the state through which these organs had passed during the evident symptoms of phthisis, which he had previously observed them to present-symptoms of which the most immediate and direct is the purulent matter observed to come from the glottis, on drawing the tongue out from the mouth and pressing upon the larynx or the windpipe.

M. Flourens opened accordingly the chest of the three cocks, and he found in all the three, traces of an old change in the lungs, more or less deep, and now healed. He preserved the hen, which he intended to lay eggs, by means of which he purposed to study the effects which reproduction might have on a pulmonary consumption when cured; but his return to Paris prevented him from putting his design in execution. 
From these observation, M. Flourens concludes, with respect to the effects of cold upon fowls, it follows,

1. That in these creatures, cold - exercises a constant and determined action upon the lungs.

2. That this action is more sudden and more serious in proportion as the creature is of tender age.

3. That when cold does not produce a pulmonary inflammation, acute and speedily fatal, it produces chronic inflammation, which is in fact pulmonary phthisis.

4. That warmth uniformly prevents the access of pulmonary phthisis, and as uniformly suspends its progress when this has commenced; and sometimes even stops it entirely, and effects a complete cure.

5. That this disease, at whatever stage it may have arrived, is never contagious. The chickens affected with phthisis were not only the whole day with the healthy chickens, but roosted at night in the same baskets, without ever having experienced the slightest influence from a communication so intimate and prolonged.

A long series of observations made upon man has unquestionably proved that cold is the most terrible scourge in producing chronic inflammations of the lungs ; while heat, on the contrary, is the most efficacious remedy. The experiments above detailed confirm, in a direct and decisive manner, both the pernicious effects of cold and the salutary effects of heat. In showing this last evidence, accordingly, both where the source of the the evil lies and where is the source of the benefit, the results may not be entirely useless to humanity.

Again, sudden very hot weather produced bad effects on all his chickens, and it being impossible to doctor all, the most advantageous plan, he judged, and the least troublesome, was, to destroy all the sick ones and calculate only on the strong, exercising judgment in the selection; for even when they are cured, they frequently remain not only lean but voracious, destroying a great quantity of food, and showing no signs of thrift till late in autumn. When extensively-spreading disorders attack the chickens of a yard, in this way unless shelter 
and housing prove effectual, little else can be recommended.

In the cure of these disorders in fowls, as well as in man, the most inert and unphilosophical remedies have been recommended. Dr. Handel, of Mentz, for example, recommends, for the pulmonary consumption of fowls, the juice of the white turnip to be given for drink, instead of water, which, of course could have no more effect in curing the corroded lungs, gorged with pus and studded with black points, in chickens, than balsam of hoarhound, pectoral elixir, and all the farrago of stuff lauded for consumption in man. M. Flourens was too sound a reasoner to dream of trying nostrums on his chickens, since temperature alone seems to be the dominant principle to which all attention ought to be paid. After perusing the preceding observations, poultry keepers need not be recommended to take care that their poultry be well sheltered during the colder seasons of the year, and if any appearance of cold or inflammation be observed, to remove them, at least, for a time to some well-sheltered place, or even into some artificial temperature.

ASTHMA.

This is a very common disease among fowls, characterised by their breathing short, opening their beaks often and long, as if to gasp for air, with heaving and panting at the chest, more particularly when agitated or frightened,

There seems to be two species of the disorder. In the first, it frequently happens that, when the action of the blood vessels of the lungs has been increased to a great degree, and the inflammation produced terminates without suppuration or gangrene, phlegm is frequently thrown into and plugs up a part of the air cells, which prevents them from performing their proper functions; and the fowl, not being able to take in the usual quantity of air, is obliged to inspire twice in the time which before only took up one inspiration, causing a double heaving of the chest. The capacity of the lungs being, 
of course, dininished, the membrane which lines the windpipe is much thickened, and many of the finer branches are probably obstructed in a greater or less degree.

In the second variety, by fright, from chasing the fowls to catch them, or by seizing them suddenly, or by their fighting with each other, a blood vessel is not unfrequently ruptured, as is proved by a drop of blood appearing at the beak, speedy death being the usual consequence. If this does not happen, the breathing continues difficult and appareritly painful, and a complete cure is rarely effected. The rupture, not of a blood vessel, but of one or more of the air cells, nccasions considerable vacuities, which are never completely emptied of air on expiration. When this is the case. the fowl not being able to expel the air at one expiration, another immediately takes place, with a short inspiration between, causing the panting and gasping already mentioned.

Confirmed asthma, caused by the bursting of air cells or blood vessels, is of course incurable, though it is not always fatal-fowls so affected often living for several years, otherwise in tolerable health. It certainly, however, injures the utility of cocks, which are the most subject to it from its being brought on by fighting.

\section{FEVER.}

The chief symptom in fever in fowls, is increased rapidity of the current of the blood, and this, of course, may be occasioned by various causes. One of the most common is skirmishing and fighting, by which the creatures are often greatly agitated, and not unfrequently killed outright. This fever is sometimes increased, by buffing the combatants about with a handkerchief, to induce them to leave off.' A more effectual remedy, which at the same time will often stop the fever, is to plunge them over head in cold water, or throw cold water over them from a garden pot, or even from a bucket. If this is done, care must be taken to have them dried as soon as possible, by removing them within doors, should the weather be damp or cold. 
In a case of highly inflammatory fever in a chicken, noticed by Mr. Dickson, supposed to have been caused by sudden hot weather, in May, so that it burned the hand like hot water, a dose of nitre, in milk and water, at night, produced so great a change, that the chicken was cool and brisk in the morning. The dose was repeated, and brought on a cold fever fit, like ague, which, however, changed to an intermittent, and the chicken completely recovered.

\section{THIRST.}

Immoderate thirst is a symptom of fever, though it may also occur when there is no fever, from a long continuance of dry food, and particularly when the crop and gizzard have been distended by over-eating. When fowls are much persecuted by their companions, which is an every-day occurrence in the poultry yard, they may accordingly be observed to drink almost insatiably, for a day or more at a time, eating very sparingly, and sometimes not at all. This appears to operate as a cure for the fever into which they have been thrown.

When immoderate thirst is observed to affect a number of fowls at the same time, they ought to have a good supply of green or moist food, such as cabbage or lettuce leaves, soaked bread, or boiled potatoes, mashed with skimmed milk; taking particular care that this milk be perfectly sweet.

When the thirst arises from fever caused by fighting, the fowl may be soused into a pail of water, in summer; but in winter, this must only be done if there be convenience to let it dry itsell near a fire or a stove.

\section{PAIRING AND HATCHING FEVER.}

THE most decidedly feverish symptoms, very frequently observed in fowls, occur at the period of hatching, when the animal heat becomes so much increased, as to be remarkable to the touch when the hen is caught.

Many methods are adopted to stop this fever, when it is not desirable that the hen should incubate, but continue to lay. It is common, for instance, to turn the hen rapidly round about, to render her giddy, which will of course, for a short time, diminish the velocity of 
the blood, and consequently abate the fever. Others, very improperly plunge the hen several times into cold water, or, let water fall on her from a pump, or otherwise." But what is found to be the most effectual, is cooping the hen up for a few days and nights, on the cold ground, or shutting her out from the nest at night, and compelling her to roost in the yard.

A feverish state also takes place about the time hens begin to lay, but is of little consequence to fowls otherwise healthy, though it will be certain to increase any other disorder which may have previously affected them. If they appear very hot and restless, they may have plenty of green food, Indian-meal dough, scalded bran, or soaked bread, or in more extreme cases, they may be plunged into, or sprinkled with, water to allay the heat.

VORACIOUS APPETITE,

Fows.s which are much emaciated, or affected with loss of feathers, (not moulting, ) often exhibit the most voracious and insatiable appetite, while at the same time they are very ill-tempered and pugnacious. This most probably arises from acidity in the bowels, or some obstruction in the orifices of the veins that open on the inner surface of the intestines, preventing the due passage of the digested aliment into the blood.

Before any proper remedy can be prescribed, the cause ought to be ascertained ; but as this is not always possible, it may be well to try various things at a venture. For instance, as acidity may be presumed to be the cause in a great number of instances, chalk may be mixed up with bread crumbs or mashed potatoes, to neutralise the acid. Again, if costiveness is observed, which may cause obstruction, mashed carrots or boiled cabbages may be given two or three times, till the effect produced be ascertained.

\section{CROPSICK, INDIGESTION, OR WANT OF APPETITE.}

When the food of fowls is suddenly changed, such as from dry to boiled barley, or Indian meal, or to mashed potatoes, they may often be observed to feed badly, and to lose flesh in a surprisingly short space of 
time. It will tend much to prevent this, if care be taken never to give them the boiled barley or potatoes in a cold state, the difference of effect of warm, instead of cold food being quite wonderful; fowls enjoy a hot dinner, and dislike a cold one, (dry grain or meat excepted,) as much as an alderman would enjoy hot, and dislike cold turtle.

But, although change of diet may often produce such temporary fits of indigestion, these are seldom of serious consequence, and usually disappear in a day or two. It is very different, when an individual fowl is affected with indigestion or want of appetite, of some continuance. In that case, the causes ought to be investigated, and remedies given accordingly. A hen of the Spanish breed, about five years old, noticed by Mr. Dickson, was the particular favorite of a cock, which had been confined in consequence of his savage behavior to another hen. From this time, the favorite pined, kept constantly beside the coop of the prisoner, and at length, left off feeding almost entirely. When the cock was liberated, it was supposed the favorite would recover her spirits and appetite; but though the cock was as gallant to her as before, she continued to mope, keep away from the rest, and never took to feeding with any appetite, but only gathered up a few grains of corn, now and then, in a listless manner, as if she cared little about it, and finally in a week or two died. It is not improbable, however, that if she had had active medicine given her, such as pepper or iron rust, mixed with mashed potatoes, or had been well purged with mashed carrots or boiled cabbage, she might have recovered.

Moubray mentions a hen which sat about in corners, and did not eat, drink, nor evacuate, and yet looked full, and not diseased. Her crop being totally obstructed, on an incision being made from the bottom upwards, a quantity of beans was found, which had vegetated there. On the wound being stitched up, it immediately healed, and little inconvenience remained.

Iron rust, (peroxide of iron,) either given in substance mixed with soft food, or diffused in water, is one of the best tonics for fowls, and ought never to be neglected, 
when there is any atrophy or loss of flesh observed. It ought of course to be combined with good barley, oats, Indian meal, or ground malt, and occasionally some good ale, milk warm, to drink. The ale has a very great effect in improving what may be termed the "condition" of fowls.

\section{COSTIVENESS.}

IT is easy to discover the presence of this disease, by the frequent unsuccessful endeavors of the fowl affected with it to relieve itself. It may be caused by a continuance of feeding on dry grain without access to green vegetables, without which, or the occasional substitute of warm boiled potatoes, this disorder is certain to make its appearance. The want of a plentiful supply of good water may also occasion costiveness.

Soaked bread with skimmed milk, if it can be easily had and given warm, is one of the best remedies for the costiveness of fowls, as it does not purge so much as boiled carrots or cabbage, which may be given if the soaked bread fail. A good meal of earth worms, or some chopped suet, may also be useful. Hot potatoes, mashed with dripping or bacon fat, are likewise an excellent remedy.

But should any individual fowl continue costive, notwithstanding these means, a little sweet oil may be introduced in to the anus, by way of clyster, a thing that will rarely fail to effect, at least, temporary relief; and a permanent cure must be sought for by discovering the cause

\section{SCOURING, LOOSENESS, OR DIARRECEA.}

When fowls are observed to dung more loose than natural, in consequence of feeding on green vegetables, bad potatoes, or other soft food, it can scarcely be reckoned a disease, and no treatment will be required, unless it continue or increase, rather than go off. But when it does amount to a confirmed looseness, it ought to be attended to, lest, in the end, it prove fatal, as not unfrequently happens when it is neglected. The worst 
symptom is the voiding of a white calcareous matter, (urate of ammonia,) sometimes streaked with yellow, like the yolk of a stale egg, which sticks to the feathers round the anus, and being very acrid from the ammonia it contains, soon causes inflammation, which extends rapidly upwards into the bowels. When the disorder continues violent for a short time, it rapidly emaciates the fowl, as the same disorder does other animals.

As it is in most, if not all cases, caused by a superabundant acidity, or other irritating matter in the bowels, chalk may be given, mixed with boiled rice and milk, either to neutralise any acid that may be present or to soften any acrid matter. Some people pull out the vent and tail feathers, and then rub the parts with fresh butter; though this is not only a very cruel operation, but one very little likely to prove effectual. Dr. Handel, of Mentz, in France, in cases of chronic, or long-continued looseness, prescribes water in which the rust of iron is diffused, mixed with milk, for drink, and says, it seldom fails to effect a cure. Great care must be taken, however, to have the milk perfectly sweet. The sulphate of iron, or what appears still better, alum, might perhaps be tried with success, dissolved in water, in such proportions as to make it taste a little rough to the tongue.

As looseness may be caused in fowls by an excessive discharge of urine from the kidneys, which, if discovered, must be attacked by giving dry food, such as whole wheat, oats, bran, Indian corn, or buckwheat, and by supplying water sparingly. Boiled rice and milk, which is strongly diuretic, as well as the rust water, will then be improper.

\section{BLOODY FIUX.}

Fows are but rarely affected with this complaint, which not unfrequently proves fatal to parrots. Boiled rice and milk, and mild ale, warm, with a little chalk or magnesia, should be given. Fat broth or sweet milk, warm, should be their only drink. 


\section{INFLAMMATION AND ULCERATION OF THE EYES.}

One of six of the twenty-three chickens which M. Flourens shut up, so as to guard them against cold, was stated in a preceeding page to have died of a disorder of the eyes, and another to have lost an eye. The disorder consisted of small abscesses which were formed on the cornea, containing a whitish sort of pus. Sometimes the inflammation extended to the whole globe of the eye, the eyelids swelling to an enormous size, and then accumulating under them a coagulable albuminous matter, similar to the white of an egg. The cornea subsequently sloughed off, and the eye was consequently emptied of its humors, and vision was destroyed forever, causing in one blindness, and in another death, while in a third, the abscess healed spontaneously.

This disorder of the eyes was no doubt owing to the concentrated vapors of the place where the fowls had been shut up ; but it is also often produced in a manner not less distressing, by cold, and particularly moist cold.

"During the rains in the winter of 1826 and 1827," says M. Flourens, "the poultry yard which furnished my observations was much below the level of the soil, and constantly flooded with water. The greater part of the hens, and particularly the young ones, were affected with abscesses of the cornea, and inflammation of the globe of the eye, to the degree that many of them lost their eyes. The effect of the humidity and cold did not stop here. Along with the abscesses of the cornea, enormous tumors frequently appeared on the head; these tumors broke, and discharged most copiously a sort of sanious pus; and almost uniformly the fowl fell a victim to the disorder. Many fowls were, at the same time, seized with acute rheumatism and sciatica. ${ }^{* \prime}$

\section{RHEUMATISM.}

Thrs affection is often caused by plunging the fowls into cold water, for the hatching fever or for weaning them from sitting. The treatment is the same as that

* Annales des Sciences, Septembre, 1829. 
for "consumption," such as warmth and cooling, opening food.

GOUT.

THis disorder is less common among fowls than it would be, were it not that they are seldom allowed to live long enough for it to make its appearance, since it rarely attacks any except those which are rather old. It manifests itself by swelling of the joints, but it is, in most cases, not worth while to attempt a remedy. Sulphur, mixed with scalded bran, or soaked bread, may be given with advantage.

\section{OBSTRUCTION OF THE RUMP GLAND.}

IT has already been mentioned, under the head of "roup," that this term is sometimes applied improperly to obstruction of the rump gland. Even Moubray says, "imposthume upon the rump is called roup." Before giving the correct view of this gland, it may be as well to state the common and very erroneous notion of it from Clater.

"It is well known," says he, "that there is a little tubercle, or projection, on the rump of every bird, and which is filled with oily matter. Its use is to smooth and give a glossy appearance to the feathers, and more particularly to make them water-tight. When rain is coming, every bird is diligently employed in squeezing out the greasy fluid, and rubbing it over the whole surface of his feathery coat, and then the drops of rain trickle off without penetrating through, or in the slightest degree inconveniencing him."

In order to prove the inaccuracy of this popular and plausible notion, it will scarcely be requisite, as $\mathrm{M}$. Réaumur justly remarks, to show how little the quantity of oil that may be daily supplied by the rump gland is, in proportion to the extent of surfaces resulting from the assemblage of the numberless feathers with which a hen or a duck is covered; nor how long a time would be necessary to enable the gland to supply a quantity of the oil sufficiently to besmear the surface of only one of thase feathers. In order to explode a notion so uni- 
versally believed, it is enough to state, that the feathers of the variety of fowls called "rumkins," which have no rump gland at all, are as much proof against rain as those of other fowls. The fact, notwithstanding, is correct, that fowls are observed pecking about their rumps, and this imposed upon careless observers, who did not consider that the point of the beak could never press out a quantity of oil sufficient to render itself greasy. " So long," says M. Réaumur, " as we shall be ignorant why a secretion is made in our ears of -a certain waxy matter, though in a very small quantity, we shall not think ourselves obliged to give an account why a secretion of a certain matter is in a particular manner effected in a very small quantity on the rump of fowls."

The rump gland frequently becomes obstructed, and in consequence inflames, swells, and of course occasions pain and uneasiness, extending, in bad cases, to the whole rump. Clater says the remedy is simple; it is all loss of time to foment or apply cooling washes; the tumor must be opened at once, and the collected oil, now become purulent and diseased, squeezed out. If the wound does not readily heal, a little tincture of aloes may be applied.

Dr. Bechstein, on the other hand, says that when the rump gland is thus destroyed, the fowls are certain to die the very next moult.

M. Réaumur thinks it will be most rational treatment to clear, if possible, the obstructed outlet or duct of the gland, by means of a tent, or roll of lint, introduced into the orifice.

\section{WOUNDS AND ULCERS.}

From fighting with each other, from having their feet cut with glass or gravel, and not unfrequently from the bites of animals, such as minks, rats, and the like, attacking them at night, serious wounds are sometimes produced, which, if neglected, may canker and produce foul ulcers not easily healed.

In all cases of such injuries, the first requisite is cleanliness. The wound ought to be cleared of all sand or 
dirt, bathed with warm water and milk, and the fowl shut up so as to prevent the others abusing it; for they are always ready to peck at any wound and increase the injury. If it do not readily heal, but go on to ulceration, it may be bathed with alum water or with ointment of creosote, which will be almost certain to heal it, even should it show fungous or "proud flesh."

\section{FRACTURES AND DISLOCATIONS.}

WhEN fowls chance to have their legs broken or dislocated, unless they are of a very peculiar or valuable sort, and wanted for breeding, the best thing is to kill them at once. But in such a case as that recorded in the old song -

I have a hen with a happity leg,

Lass gin ye $10^{\prime} \theta$ me tell me noo,

That every day lays me an egg,

An' I canna' come ilka-day to woo,

it may be worth while to preserve a fowl after an accident of this kind. The case must be treated according to what has already been stated under wounds, and more particularly under inflammation, which will be certain to ensue, more or less severely, both locally and constitutionally.

\section{PARASITIO VERMIN.}

Brrds of all kinds, both wild and tame, are liable, from some unknown causes, to be attacked, as Herod the Jewish tetrarch is said to have been, with a particular sort of lice which are generated on them in myriads. In some instances, théir feathers are so completely covered as to hide their natural color, and in many places the point of a pin cannot be put down without touching some of the vermin.

In the new edition of Clater, it is said, that "vermin are often exceedingly annoying to the poultry, and materially prevent their growing and fattening. They are usually to be traced to evident neglect in the management of the poultry yard. The fowls are half starved, or the place is all over filth, or there is no dry corner 
with plenty of dust or ashes in which the birds may roll themselves." All this is in direct opposition to experience and observation; for the individual fowl infested with vermin rarely communicates these to the rest of the flock in the same yard, though they be fed and lodged alike-unless there be a constitutional disposition in some of the others to become infected, or chickens receiving them from their mothers as soon as they are hatched. As well might it be maintained, because individual humble bees and dung beetles are often found infested with lice, that it is owing to starvation or confinement, though all the other bees in the same nest, and consequently under similar circumstances, as to lodging, shall be free. Is it want of cleanliness, or confinement, which causes so many swallows and other wild birds to be infested with vermin?

In trifling cases, when the infection is not very obvious to casual inspection, no particular attention will be required. In bad cases, the sooner the fowls are killed the better, as there is no certain known remedy; for even were every one of the vermin killed, the evil state of the constitution would soon attract others to breed.

Mascall says, "they get them in scraping abroad among foule strawe, or on dunghills, or when they sit in nests not made cleane, or in the hen house by their dung lying long there, which corruptes their bodyes and breedes lice and fleas." The corrupting of their bodies, seems a much more probable cause than any of the others. "The remedy," adds he, "ye shall take the powder of pepper, mixed with warme water, and therewith bathe them; or take fine powder of stavesacre, (staphisagria,) and mixe it with lye, (urine,) and so washe them therewith, or to bathe them in soap water, which is good to kill lyce, or the fine powder of pryvet mixte with vinegar, and so washe them therewith." These directions are as good as any in the more modern books.

A correspondent of the London "Agricultural Gazette," in speaking of this disgusting affliction, says :- Some time ago I had a beautiful brood of black 
Spanish chickens, and the day after they were hatched, I happened to take one in my hand, and was much struck by observing on the top of its poll five or six large full-grown lice, evidently caught from the mother. I then examined the whole brood, and found them all similarly affected. Knowing that they would not thrive until I had dislodged or destroyed the enemy, the next day I attempted to pick them out; but I found that, having only been left one night, the whole poll was covered with nits, and I could not git rid of them from their hanging so tenaciously to the down. I procured some white precipitate powder, and, with a small camelhair pencil, powdered them over. On examining them the next day, I found the parasites had all disappeared, nor could I detect one in their after growth. They grew and thrived so remarkably afterwards, that I was convinced this was a valuable discovery, and have ever since treated all my broods the same, and have never lost one from sickness. All hens are affected with these parasites, and as they do not dust themselves so frequently during the time of incubation, they are more liable to them. I have ascertained from observation, that as soon as the chickens are hatched, these pests leave the parent for the young, and if they are not destroyed, they weaken the chicken so much, that if any complaint comes on, the poor little thing has not strength to contend with it. The best time to apply the precipitate is when they are two or three days old, and at night after they are gone to roost; but the hen must not be touched with it; as, in pluming her feathers she draws them through her beak, and the precipitate being a strong poison, would no doubt prove fatal to her. In fact, there is no occasion for it ; as I could never detect them in her; they had no doubt left her for the young. A very small quantity should be used; as one pennyworth, purchased at a chemist's, is sufficient for several broods."

A slight application of spirit of turpentine and water, in trifling cases, answers the same purpose, and is preferred by many persons who have a natural dislike to the use of poison. 
There are some startling facts on the subject of parasitic insects, to be found in the "Monographia Anoplurorum Brittanniæ," by the late Henry Denny, a work which, although with a dog-latin title, that has doubtless limited its circulation, is written in such plain and truthful English, as to make the flesh creep on one's bones. It is not easy to enjoy uninterrupted slumber the night after reading Mr. Denny's monograph.

"The author has had to contend with repeated rebukes from his friends for entering upon the illustration of a tribe of insects whose very name was sufficient to create feelings of disgust. 'Why not take up some more interesting or popular department of entomology?' has been the frequent remark made to him. He considered, however, that if he wished to render any service to science, he must not consult popular taste or ephemeral fashion, but must take a page from that part of the great 'Book of Nature,' less generally read, and consequently less understood and appreciated by the world at large."

The number and variety of species given is frightful; some of those which infest poultry are,

"Goniocotes hologaster (Louse of the Domestic Fowl).

" Goniodes falcicornis (Louse of the Peacock).-This beautiful (!) parasite is common upon the peacock, and may be found, after the death of the bird, congregated in numbers about the base of the beak and crown of the head. During the year 1827 , three or fuur specimens of Pavo cristatus having passed through my hands, upon each of which I observed, for the first time, several examples of the large and well-marked parasite of this bird, the Goniodes falcicornis, I was induced to examine whatever other species of birds, \&c. might come in my way, to ascertain whether great diversity in size or appearance existed between the parasites of different species or genera. This I soon found to be so considerable, that I resolved upon forming a collection, and ascertaining what was written upon the parasitic tribes.

" Goniodes stylifer (Louse of the Turkey).-Common upon the turkey, frequenting the head, neck, and breast; a very beautiful species. The males of this and all the 
other species of goniodes use the first and third joints of the antennæ with great facility, acting the part of a finger and thumb.

"Goniodes dissimilis (Louse of the Domestic Fowl). -I suspect this species is of rare occurrence.

"Lipeurus variabilis (Louse of the Domestic Fowl). -Common on the domestic fowl, preferring the primary and secondary feathers of the wings, among the webs of which they move with great celerity.

"Lipeurus polytrapezius (Louse of the Turkey).A common parasite upon the turkey. Their mode of progression, is rather singular, as well as rapid. They slide as it were sideways extremely quick from one side of the fibre of a feather to the other, and move equally well in a forward or retrograde direction, which, together with their flat polished bodies, renders them extremely difficult to catch or hold. I have observed that where two or more genera infest one bird, they have each their favorite localities; for while the Goniodes stylifer will be found on the breast and neck of the bird, the Lipeurus polytrapezius will be congregated in numbers on the webs and shafts of the primary wing feathers.

"Menopon pallidum (Louse of the Domestic Fowl). -Found in great abundance on poultry, running over the hands of those who are plucking fowls, and difficult to brush off, from the smoothness of their bodies."

Those who are desirous of fuller information should consult the work itself.

\section{LOSS OF FEATHERS.}

IT has been observed, that all birds kept in a state of confinement, are particularly subject to an extensive loss of feathers, rendering them naked and deplorable. This is altogether different from moulting, inasmuch as the fall of the feathers in the latter is occasioned by the new ones, shooting out from the skin, and pushing the old ones off, as is the case when young animals shed their teeth. In the disordered state in question, on the other hand, where the feathers fall, no new ones appear, or if they do, they seldom push far 
above the surface of the skin, but remain as mere stumps arrested in their growth. It is a disorder apparently similar to that which, in horses, is termed "out of condition," when the hair becomes shaggy, rough, and staring, and is constantly coming off.

As the disorder, termed "loss of feathers," is evidently a constitutional, and not a local affection, it would be in vain to seek for remedies in external applications, though stimulants might perhaps aid the operation of internal medicines. Amongst the latter, such as are known to act on the skin, particularly sulphur and antimony may be tried. Good keep and cleanliness, plenty of fresh water, and an open range, will do more than any other treatment to restore the loss of feathers. Forge water, or water from the gas works, might probably be of advantage, given as drink.

\section{MOULTING.}

Althovgh moulting is a natural and annual occurrence, it rarely passes without more or less disorder, and not unfrequently proves fatal, so that fowls require to be carefully attended to at the time of their moult. It is most dangerous and most frequently fatal to young chickens, particularly those of late broods, during the occasional cold and rainy weather at the close of autumn, their being late hatched throwing the time of moulting late; whereas, those that are hatched early in spring, moult in the warm days of July and August, and on that account are not so apt to suffer. The summer moult is for the most part gradual, a few feathers falling at a time, and being renewed till the whole plumage undergoes a change. In the autumnal moult, on the contrary, more of the feathers fall off at once, and as the fresh ones do not grow so readily, on account of the weather being colder, the fowls are rendered naked, and exposed to any accidental bad weather which may occur.

Dr. Bechstein judiciously remarks, with respect to wild birds, that their moulting time always happens when their food is most abundant; and as the loss of feathers is likewise attended by a loss of flesh, nature 
points out that they ought to have an additional supply of food till all danger is over.

Warmth is no less necessary than abundant and nourishing food; and when the later broods of chickens fall off, in their appetite, appear moping and inactive, their feathers staring and falling off till their rumps, sides, and thighs show the naked skin, they must be prevented from getting out in cold mornings too early, and not permitted to be abroad after four o clock in the afternoon. M. Chomel, of France, advises, further, to put some sugar in their water, and to give them millet and hemp seed.

After the third year, it has been observed, that fowls begin to moult later every succeeding year, so that it is frequently as late as January before the older fowls come into full feather, and the weather being then cold, they are not in a laying state till the end of March, or later. The time of moulting continues, according to the age and health of the fowls, and also with reference to mild or cold weather, from six weeks to three months.

\section{CHANGE OF COLOR.}

A remarkable peculiarity in the colors of fowls, is, that they frequently change in a very surprising manner, from the time when the chicks cast their down to the annual moult of the full-grown birds. This change, although it may be regarded as a species of disease, in some cases, is, no doubt, the regular process, at least after the second and third moults, as the colors, then, generally continue much the same.

In the physiology of birds, there is, perhaps, nothing more curious than the laws which influence the colors of their feathers. It is asserted, for instance, that, " it is by no means a rare occurrence among game fowls, 'blacks,' 'blues,' and 'reds,' to change their plumage, and become spangles and whites." In the "American Turf Register and Sporting Magazine," it is stated that, in 1807. a case occurred of a milk-white cock, raised by Mr. Phillips, of South Hampton. Virginia, the colors of which changed the next spring to a red spangle. Another instance occurred with $\mathrm{Mr}$ Allen J. Davv, well 
known among the agriculturists and sportsmen of the south, who bred a game cock, in Madison county, Virginia, which, in 1821, was a bluish-grey. In 1822, he was still grey. In 1823, he was milk-white, or "smock" as the English term it. In 1824, he had changed to sky-blue.

We are told by M. Réaumur, that one of his hens which his poultry woman distinguished from the rest by a crooked claw, when her coat began to be taken notice of, had feathers of a ruddy color mixed with the brown so common among dunghill fowls. A year afterwards, this hen was observed to become almost black, with here and there some large white spots. After the second moulting, black was the predominant color on every part of the body; but strange to tell, upon the succeeding moult, white was the predominant color, and only a few black patches about the size of a dollar could be observed. Upon the succeeding moult, all the black spots disappeared, and the hen became uniformly of a pure white like that of a swan- As she was at this time old for a fowl, that is, not less than ten years, it might be thought that old age, which whitens the human hair, likewise whitens the feathers of certain birds ; but, in that case, M. Réaumur says, the transition from the ruddy to the white ought not to have been made, as it really was, through the black; and he was of opinion, as the hen was still vigorous and healthy, that she might again change her color, if she lived, to brown or black.

The same author makes some interesting remarks on a cock which he observed with more attention than the hen, so as to establish proofs, that the white colors of the feathers were not, at least in that instance, caused by age. The owner of the cock was struck, the first time he moulted, with the singular change in his color; and for five successive moults, there was always a considerable change of color. In his first year, he had some ruddy-brown, mixed with white, so common in dunghill cocks; in the second, he was all over ruddy-brown, or rather red, without any white; in the thitd, he became uniformly black; in the fourth, uniformly white; and in the fifth, when he was presented by the prior of Bury to 
M. Réaumur as a curiosity, he had white feathers mixed with a good deal of ruddy color and brown, bordering upon chestnut, his neck, back, wings, and belly, being ruddy; and even where there were white feathers, they were mingled with ruddy ones. During the summer vacation, at Paris, M. Réaumur was two months without seeing the cock; but in this period, he became so changed as not to be recognisable, his feathers having become all over of the finest white. The following year, he had partly white feathers, but the greater portion was ruddy, or rather of a fair red. Here, then, was a transition from white to a light-brown, indicating thai the whiteness of his feathers was not owing to the number of his years.

It has been remarked by several scientific observers, that hen birds of various species, but more particularly hen pheasants, put on, under certain circumstances, the plumage of the male. Hunter, in his work on "Animal Economy," is of opinion that "this change of character takes place at an advanced age of the animal's life, and does not grow up with it from the beginning." Mr. Butler, another English physiologist, expresses a similar opinion still more strongly, namely, that " all hen pheasants, as well as common fowls, would assume the plumage of the cock, to a certain degree, if they were kept to a certain age." Though this, however, to some extent may be true, the reasons, or rather the accompanying circumstances and changes of constitution, were first pointed out, it is believed, by Mr. Yarrell, who seems to have determined that the change of color depends on disease, or removal of the ovarium of the fowl. Among seven hen pheasants, whose plumage more or less resembled that of the male, he found the organ in question diseased, with some variation as to extent, and the progress of change observable in the plumage bore a corresponding analogy. At the commencement of this internal disease, the plumage does not seem to be affected, for "hen pheasants in confinement, and females of the common fowl in the poultry yard, had been known to have ceased producing eggs two years before any change was observed in their 
plumage. When our domestic hens are castrated, or rather, have part of the egg tube cut out, for the purpose of fattening, the plumage undergoes a similar alteration, so as to render it difficult to distinguish the birds from capons.

This change in the color of the plumage of birds, as well as the hair of other animals, is attributed to the influence of some peculiar coloring matter of the system. That singular description of mammalia and birds, usually known under the name of "albinos," I think, with propriety, may be classed among the diseases, as their characteristics appear to arise from a deficiency of the coloring principle common to the skin, hair or feathers, and eyes. Thus, the skin generally has the hue which its cellular and vascular contexture produces; the hair or feathers is produced to its simple organic ground work; and in the eyes, which are entirely destitute of pigmentum, the color of the iris depends on the fine vessels which are so numerous in its composition, and that of the pupil, or the still greater number of capilliaries which almost entirely form the choroid membrane.

The albino or leucœthiopic constitution occurs both in wild and domestic animals as well as in the human sub. ject. It is not only well known in the ferret, mouse, rat, monkey, squirrel, hamster, Guinea pig, mole, opossum, martin, weasel, fox, roe, rhinoceros, elephant, badger, beaver, bear, camel, buffalo, blackbird, crow and partridge, but in the horse, ass, sheep, pig, cow, dog, cat, rabbit, Canary bird, peacock, and the common fowl. In the mammalia and birds just enumerated, the nature and characters of the deviation seem to be perfectly analogous to those in the human albino. The pure whiteness of their skin and other integuments, and the redness of the irides and pu jils mark the same deficiency of coloring matter. 


\section{A P P E N D I X.}





\section{APPENDIX.}

\section{OOMPARATIVE MERITS OF DIFFERENT BREEDS OF FOWLS.}

Having hastily examined the proot sheets of "The American Poultry Yard," written by Mr. D. J. Browne, which you put into my hands, with a request that I should add something from my own experience, I am reminded of an anecdote that took place in this city some years ago. A gentleman being called upon to make the closing speech, at a public meeting, rose and said, he was an unfortunate man; that, since he came into the house, he had been robbed of everything he had intended to say on the subject under discussion, by the speakers who had gone before him; and that nothing was left for him to say which had not already been said. The application is obvious in the case before me.

The breeding of fowls, with many, is more a matter of fancy than of the intrinsic value of the different kinds ; and the safest way of giving advice on this subject is to say, let each individual select that variety which he likes best, breed and compare the merits or demerits of each until his judgment is well founded upon actual experience, holding rigidly to the principle of not crossing different breeds for permanent use, but keeping them, if 
possible, entirely distinct ; for, in no other way, will the test be a fair one.

But, in respect to the comparative merits of the existIng varieties of fowls in this country, I have but little to say. The Cochin-China, Shanghae, great Malay, jago, and other monstrous breeds produced by crossing with one another, in my humble opinion, are not the most desirable kinds for general use ; as their legs are very long and large, which are bad points in a fowl; their flesh coarse; and they are great eaters; besides, they lay comparatively but few eggs, which are very liable to be trodden upon and broken at the time of sitting. I have bred most of them in their so-called purity, as well as many of their crosses, and I am free to say, there is no way to make them profitable except, perhaps, by caponising, and afterwards fattening them for market.

The Dorking is a fowl, all things considered, much to be preferred to all others for profit; but as their good qualities have been so minutely described in the able treatise before me, as well as in the back volumes of the American Agriculturist, it is needless to recapitulate them here. Their scarcity, as well as the high prices at which they are held by those who breed them in their purity, will, for some years, prevent them from coming into general use.

That there is a difference in the number and quality of eggs laid by different hens, I believe is conceded by all. Of these, the Polands stand first in public estimation; but to say or believe, that even these are "everlasting layers," is a great mistake. They are less in. clined to sit, to be sure, and it is on this account that they have obtained the reputation of great layers; and for this reason, if I wanted eggs, only, and not chickens, I would keep this variety.

With most people, an egg is an egg, in the market, as in the old adage, "a pint is a pound, feathers or shot ;" and the buyer seldom stops to think of the weight, although there may be three times the difference in the bulk of those in the same basket or cask. 'Tis not the largest eggs, however, that are the most profitable to the buyer, as the flavor differs not only in the different 
breeds, but with the kind of food on which the hens are fed and the season of the year in which they are laid. Next to the Polands, in point of profit, the eggs of the Dorkings may be considered the best, although those of the Bantams and other small fowls are richer, betterflavored, and larger-yolked in proportion their size.

The Game Fowl, crossed with the Dorking, for the first or second cross, is an excellent bird both in the flavor of the flesh and eggs; but they are objectionable on account of their turbulent dispositions when kept with other fowls.

The little Bantams, however, can only be kept with any advantage as pets within doors, where the climate is severe. If their apartment be kept warm, they will lay abundanly during the winter and spring, producing delicious eggs, though small $\ln$ size, at a time when other hen's eggs are scarce.

The Dominique Fowl is another breed becoming more and more in favor, as they are universally pronounced as being hardy, good layers, careful nurses, and affording excellent eggs and flesh. Besides, their beautiful appearance, when in full plumage, is quite an acquisition to the farm yard or the lawn.

As to the common Turkey, I have but little to say. I prefer the black or dark-colored varieties to all others, as they are generally the largest birds, are more hardy, and equal to the other kinds as to laying, rearing their young, as well as in the flavor of their flesh. Next to the black varieties, I prefer the buff-colored, which are quite as large, and perhaps as good in most of their other qualities; but last of all, I would select the white, which are decidedly less hardy, smaller in size, if they are not even inferior in other respects.

But of all domestic fowls, if not interfered with, the Guinea Hen is the greatest layer, the most faithful nurse, and the best adapted to get its own living when left to herself. These birds are not profitable to keep, how. ever, where there are gardens or cultivated fields, as they will often devour or destroy, in a few hours, more than their eggs and carcasses are worth.

The most showy and magnificent bird of the farm 
yard is the Peacock, which is of no use, except for admiring eyes to look upon. I need not describe the brilliancy of its plumage, the color of its various dyes, nor the unsurpassing elegance of its form. These are familiar to all. To use the words of a writer in the second volume of the "American Agriculturist," it is "idle and vagrant in its habits, mischievious in its propensities, and of little utility either in its carcass or its eggs; it is tolerant alone for its gorgeous display of plumage, and the showy splendor of its attitudes. I have kept them many years, and every year of my observation, only confirms in my mind the truth of the ancient proverb applied to the bird. 'It has the plumage of an angel, the voice of a devil, and the maw of a thief.' They are destructive in the garden, vindictive and quarrelsome among other poultry, without either merit of bravery, or energy of defence. Yet, after all, I like them ; they make a beau. tiful show among the poultry, and add to the infinite and delightful variety of animated creatures, with which a kind Providence has blessed our vision."

Of the kind of Geese, I think the Bremen, crossed with the common China variety, the most profitable. They make a splendid bird; but I would never breed their hybrid progeny, if I could avoid it, beyond the first cross, except for the table.

Geese may be kept to advantage where there is a pond, or plenty of running water; but without these, the rearing of goslings never ought to be attempled, although they have been successfully raised without these-it cost more than it carne to.

I have a few White, China Geese, which, with careful feeding and protection, lay nearly the whole year round. They can only be kept to advantage in a warm climate where the eggs could be hatched under a common hen.

The observation on geese will apply with equal force to Ducks-without a pond or running stream, it is not worth while to keep them; and unless they get some portion of their living out of the water, as cockles, mussels, weeds, \&c., it is doubtful whether they afford much if any profit. Besides the common varieties, I 
think the Muscovy or Musk Duck may be kept with some advantage to cross with them. Their offspring grow to a larger size, and when properly fattened, they are good for the table. Moreover, these birds, from their singular habits and unique appearance, are quite an acquisition to the poultry yard or farm.

It has been said that the Common Swan will not breed in this country, in consequence of the variableness of our climate. But this is an error, probably founded on ignorance of their habits, and the mode of propagation; for they have been successfully bred for a few years past by Mr. Roswell L. Colt, of Paterson, New Jersey, who has, by the by, a fine pond and every other accommodation necessary for rearing them.

Having written to Mr. Colt, a few days since for information on this subject, I have just received ai this moment, the following reply:-

Paterson, December 31st, 1849.

Dear Sir,

You ask me what success I have had with my swans. I got them from France four years ago last spring. The first year, they did not lay. I suppose they were young ones. The second year, I had two eggs which did not hatch. The third year, I had five eggs, four of them hatching out in thirty-nine days. The fourth year, (that is the last summer,) I had six eggs, all of which hatched out on the third of June, also in thirty-nine days. The swan lays an egg every other day, and begins to lay here towards the last of April. I have lost two young ones; but on examination could not discover any cause for death.

Swans must have an abundance of clean water to swim in. I feed mine with Indian corn, rye, oats, and buckwheat, put at the edge of the pond, close to the water, as they like to wash down their food as they partake of it. When the cygnets are young, I give them Indian meal, mixed with water and boiled potatoes, broken up. I throw into the water some clover, green leaves of Indian corn, lettuce, cabbage, spinach, besides 
the corn, oats, \&c. They also come out and eat grass like geese. In fact, they may be fed as you would a favorite goose, and with a fresh, clear pond of water, you will succeed.

$$
\text { Truly yours, }
$$

To Samuel Allen, Ese.,

R. L COLT.

There is one feature in the work before me, although converse to popular opinion, which I think demands the particular attention of those engaged in the breeding and rearing of poultry; that is, the antiquity and permanence of species and varieties in our domestic fowls. We all know of the many attempts that have been made to bring the grouse or partridge, the quail, and the prairie hen into a permanent state of domesticity without success. For instance, the beautiful little Prairie Hens, exhibited at the Fair of the New-York State Agricultural Society, in the autumn of 1848 , were purchased by Mr. Lewis G. Morris, of Mount Fordham, near New-York City, with the view of breeding from thein, but before the return of the next spring they all died. I would not discourage others from trying to domesticate them; for even this, like the turkey, may prove another "exception of the rule."

\section{PROFITS OF POULTRY RAISING.}

As regards the money profits derived from poultry raising, I have but a few words to say. One principle, in fowl-keeping, I think may be laid down as an esiablished truth, which is this: "The more densely poultry are congregated, the less profitable will they be; the more thickly they are crowded, the less will they thrive."

Were it in my power to show by figures, a statement of great profits, derived from keeping a large number of fowls together that would satisfy my own mind, and that I could conscientiously recommend as a guide for others to follow, I would most gladly avail myself of so agreeable a task. But, unfortunately, most of the Debit and Credit accounts of poultry profits, we so often see pub- 
lished, will not bear the close scrutiny of those who have attempted the business on a large scale. I do not wish to be understood to say, that such accounts are heralded to the world with any improper motive, or intention to deceive; but, in general, to use the apt comparison of another," they are no more to be relied on, for practical purposes, than would the ship owner's account of the whale fishery, if it made no allowance for bad luck - the loss of time of the crew, the cost of provisions, and other outfits-worth $\$ 30,000$; to say nothing of wear and tear, and the widows of drowned whalemen to assist." Nothing is more likely to mislead the novice whose experience is insufficient to judge of their incompleteness, leaving error out of the question.

Thus, one writer in the London "Agricultural Gazette," of Sept. 23, 1848, tells us that, by adopting the regimen advised by one good Mrs. Doyley, hens may be made to sit four times in the season. Each time they sit, they are to hatch two broods, (that is, eight broods of three weeks each per annum,) by the withdrawal of the first clutch of chickens, and replacing them with fresh eggs! The kidnapped chicks are to be reared by an artificial mother. Now, if the hen hatches only ten chickens from each set of eggs, which is considered a low estimate, this gives eighty chickens per annum from each hen!! or four hundred in the course of the year, for the expense of maintaining five hens, and, it is supposed, one cock, (though the poor fellow is not mentioned,) or more than one chicken per day!!! But, alas! for such extravagance. Hens are made of flesh, blood, bones and feathers-not of wood, hot water, India rubber, sheepskins, nor iron; and if their incubating powers are overtasked, they will invariably suffer for it afterwards, which will often take them the whole autumn and winter to recover, if they ever recover at all. Accounts like the above, which we often see going the "rounds" in agricultural papers, it is almost needless to say, deserve only to be treated with ridicule and disrespect.

I clip the following egg-laying story, from the fourth volume of the "American Agriculturist," as having oc- 
curred on the farm of Mr. Gerard Carpenter, of Poughkeepsie, New York. He commenced on the first of January, 1844, with sixty-seven hens and three cocks. Out of the flock, were sold and lost, by the 1st of May, - seven hens; from that time up to the 16th of September, he lost two more. The average number of hens remaining, during the year, was estimated at sixty, which laid each month as follows :-

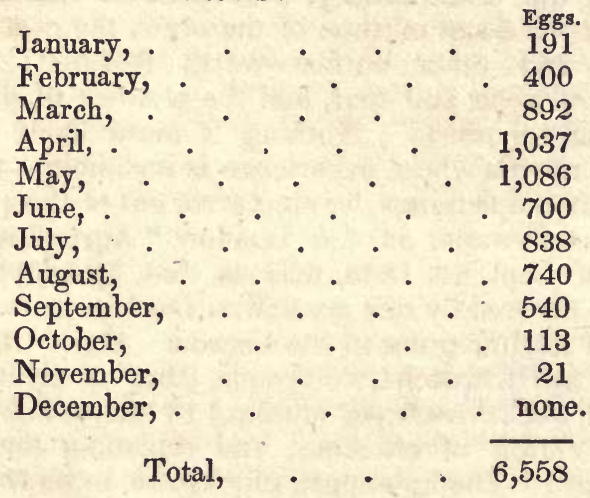

In addition to this number, it was supposed that full 300 eggs were used for sitting, got lost, broken, or spoiled, which are not reckoned in the account above. The food of the hens consisted of as much Indian corn, mixed with a few oats, as they could eat; the grain being placed where they could get at it whenever they felt inclined. In the winter, they had a little meat. They were not confined at all, and had access to lime and gravel, while the ground was covered with snow.

A correspondent, of Rahway, New Jersey, states in the fifth volume of the journal last named above, that he commenced the year 1845 with a stock of poultry, the expenses and profits of which were as follows:-

1845.

Dr.

Jan. 1. To 44 hens, 6 cocks, . at 25cts. . $\$ 12.50$

$\begin{array}{lll}\text { 6 } 6 \text { " } 6 \text { turkeys, . . . at } 62 \frac{1}{2} \text { cts. . } & 3.75 \\ \text { 6 } 4 \text { geese, at } 62 \frac{1}{8} \text { ets. . } & 2.50\end{array}$


Carried up, $\$ 18.75$

Jan. 30. " 22 geese, . . . at 50cts. . 11.00

Feb. 25. " cash for 15 hens, - at 25cts. - 3.75

Aug. 14. " 6 young ducks, . . . . 1.00

Nov. 14. " 5 common ditto, . . . 1.25

"6 " 1 pair Muscovy do. . . . 1.13

Dec. 31. " $61 \frac{1}{2}$ bushels corn, - at $62 \frac{1}{2}$ cts. . 38.44

"6 " Labor in picking geese, 0.83

- Total cost, . . . . $\$ 7 \overline{76.20}$

1845. $\mathrm{Cr}$.

Dec. 31. By 3,660 eggs used or sold, . . $\$ 40.15$

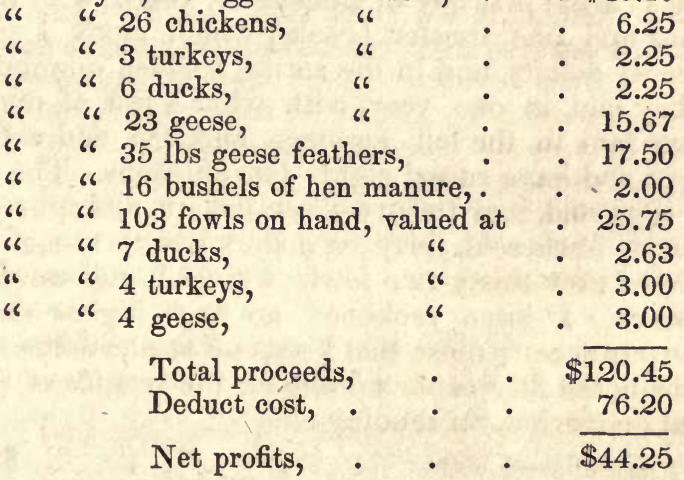

The geese, it is stated, were not the least profitable part of the stock. They were the large, white Bremen variety, weighing, when dressed, from 10 to $15 \mathrm{lbs}$. each. They were confined in a lane, which afforded them access to the different fields, and in which there is a large artificial pond.

Dr. H. S. Chase, of Woodstock, Vermont, makes the following statement on the management and profits of poultry;-On the 27 th of March, 1848, I purchased four hens and one cock, and kept them until the 15th of November, when I killed them. During that time, I received three hundred and eighty-six eggs as the result of their laying. I fed them on grain, I purchasedseven pecks of corn, and one peck of oats. The ac count stands as follows :- 
386 eggs, average price 1 cent each, .

7 pecks corn, at $18 \frac{2}{4}$ cents per peck, $\$ \$ 1.31$

1 peck oats,

$0.12-1.43$

Net profit of four hens for less than eight months,

Average number of eggs laid by each hen, ninety-six.

In the "Boston Cultivator," of Dec. 22, 1849, the following account of poultry raising is given by Mr. Edwin Howard, of Easton, Massachusetts :-I commenced the first day of December, 1848, with nineteen hens and one rooster, [cock,] which stock I valued at twenty dollars, and in the spring I added one more hen. They laid, in one year, with what a few of my pullets have laid in the fall, eighteen hundred and eighty-one eggs, and have raised eighty-two chickens. The amount of eggs sold, was twenty-seven dollars, and ninety-seven cents; fowls sold, forty-six dollars and forty-eight cents. I have now thirty-two fowls, which I call worth thirty dollars. I have reckoned no eggs higher than fifty cents a dozen; those that 1 sent off at one dollar a dozen, I deducted fifty cents a dozen for the trouble of packing and delivering, on sending off.

Eggs sold-1,300 . . . . . . $\$ 27.97$

Eggs not sold-581 at 15 cents per dozen, . 7.27

Fowls sold, . . . . . . 46.48

Value of fowls on hand over last year at this time, .

10.00

91.72

$32 \frac{1}{2}$ bushels of corn and meal, at 75 cents,

24.37

Balance in favor of fowls,

Thus, I might go on with similar accounts almost without end, which show clearly that there is profit attending poultry raising, when undertaken on a moderate scale; but when the business is attempted with a large number of barnyard fowls, obtained at a heavy cost, including the purchase of food, accommodations, \&c., I am free to venture the opinion that, speculations of 
the kind will prove profitless in the end. When geese can be kept in situations where they have proper forage and water accommodation, undoubtedly money could be made on a more extensive scale from the sale of their feathers and flesh. An instance is said to have occurred within two or three years past, in the western part of Pennsylvania or Virginia, in which a farmer raised 2,000 geese in a year, from which he obtained a ton of feathers, valued at $\$ 1,000$. Besides their natural pasturage and range of water, they were allowed to feed until late in autumn or early winter in a large field of standing corn. When sufficiently matured, they were slaughtered solely for their feathers, their carcasses being burned or thrown away.

\section{THE EGG TRADE.}

UNDER the article "Egg Trade," in the "Supplement" to the English "Penny Cyolopædia," we have the fo!lowing estimate given, which will, perhaps, excite some little surprise:- "In 1835, the value of eggs exported from Ireland to Great Britain was $£ 68,687$, and at the present time may exceed $£ 100,000$.* At $4 d$. per dozen, the number of eggs which this sum would purchase would be 72,000,000. From France and Belgium, we imported $96,000,000$ eggs in 1840 , on which the duty of $1 d$. per dozen produced $£ 34,000$. Nine tenths of the foreign eggs are from France. The departments nearest to England, from the Pas de Calais to La Manche, are visited by the dealers, and their purchases often produce a scarcity in the country markets. At most of the ports of these departments, from Calais to Cherbourg, some vessels are employed in the egg trade. The weight of $80,000,000$ eggs, is not far short of 2,500 tons. In the last three years, the importation of foreign eggs were as follow :-

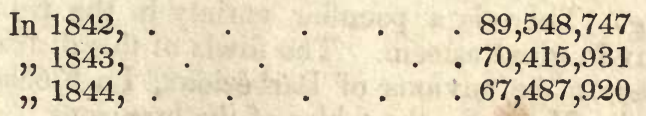

- Mr. M.Culloch says, the price paid hy England to Ireland for eggs and poultry may be estimated at from $£ 200,000$ to $£ 300,000$ a year. 
"The consumption of eggs, at Paris, is estimated a $100,000,000$ of eggs a-year."

Everywhere in France, it is stated, poultry is abundant and cheap, and eggs form an important article of diet. M. Legrand, a member of the French Statistical Society, says " The consumption of eggs in Paris is calculated at $115_{2}^{1}$ eggs per head, or $101,052,400$. The consumption in other parts of France may be reckoned at double this rate, as in many parts of the country dishes composed of eggs and milk are the principal items in all the meals. The consumption of eggs for the whole kingdom, including the capital, is estimated at $7,231,160,000$; add to this number those exported, and those necessary for reproduction, and it will result that 7,380,925,000 eggs were laid in France during the year 1835."

"The exportations from France, in 1835, were as follows :

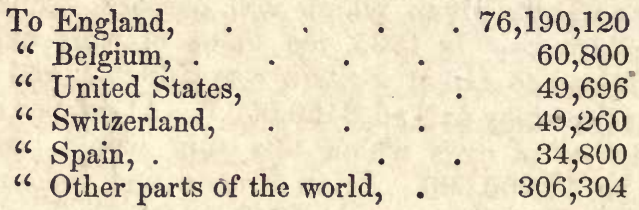

The total amount of the exportation of that year was $3,829,284$ francs $(\$ 76,800)$. France is essentially a fowl-keeping country. The farms, owing to the system of subdivision of landed property among the sons of a proprietor at his decease are small, and poultry constitutes a profitable stock upon them, especially as they will feed but few cattle. Around every farm house, troops of poultry are to be seen. They swarm everywhere, and the markets of every town are abundantly supplied. Much breed does not exist in any of them, but in some parts considerable attention is paid to their rearing. There is a peculiar variety in the peninsula of Caux in great esteem. The fowls of this district are fattened, in the envions of Barbézieux, La Fléche, and especially Mons, for the tables of the luxurious.

The following interesting statistical remarks are taken 
from a paper in the English "Penny Magazine for March, 183\%. After premising that, in the year $183 \%$, the number of eggs imported from France into England amounted to $69,000,000$, the writer says, "These eggs cannot be obtained from much fewer than $\mathbf{5 7 5 , 0 0 0}$ fowls, each producing 120 eggs on an average, all beyond this number being required for domestic consumption. Assuming the grounds of this calculation to be correct, the $55,000,000$ eggs which a writer in a newspaper printed at Arras states to be the amount supplied to England from the Pas de Calais, are the production of 458,333 fowls, each of which furnishes ten dozen eggs, imported at a duty of $10 d$., being a tax to that amount on each fowl. Allowing twelve fowls to each family engaged in supplying the demand for eggs, the number of families thus interested will be 39,861 , representing a population of 198,000 . In the $P$ as de Calais, there can scarcely be a larger population than two families out of every five who are connected with the egg trade; and if this were ascertained to be the real proportion, the population, not directly engaged, would be 457,000 , which, with the 198,000 above mentioned, would comprise a total population of 665,000 , which is the population of the department, the superfices of which being 2,624 square miles. Over this extent of country must those who are engaged in the egg trade keep a vigilant eye, penetrating into every hamlet, and visiting the lone houses which are scattered in this part of France, perhaps more numerously than in any other departments. Some arrangements of a peculiar nature are obviously required to facilitate the transactions of the wholesale dealer, who probably resides at the port whence the eggs are shipped. The services of a subordinate class of dealers are, doubtless, called into activity; and as it would be a waste of time for each of these to visit every week, or at a stated period, every one of the 39,861 houses whence they draw the quantity required, other arrangements of a still more detailed character are necessary, in order to bring the article within grasp."

The British census returns for 1841 present us with an ad-valorem estimate of the poultry, (of all sorts,) kept in Ireland, the pecuniary value of each fowl being 
reckoned at the small sum of $6 d$. This census, however, is only an approximation to the truth; for it is stated, on good authority, that the country people were not unnaturally suspicious of the intertions of the parties employed to ascertain the point in question, and apprehending that the inquiry was only the prelude to some new tax, they gave such statements as seemed most advantageous to their interests; hence their returns were below the mark numerically, and, consequently, also in a pecuniary point of view. The returns were as follows:-

LEINSTER.

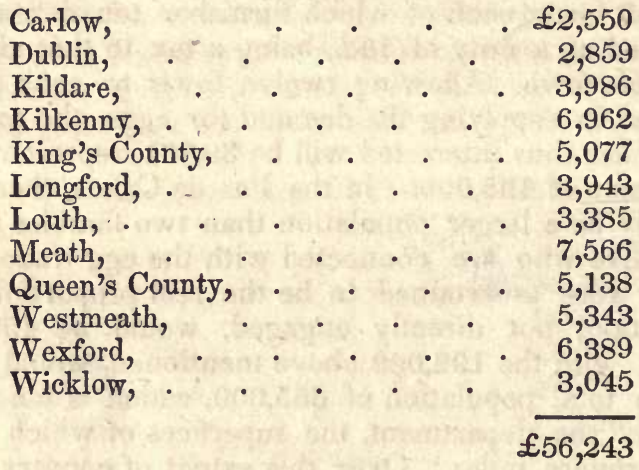

CONNAUGHT.

Galway, - . . . . . $£ 10,753$

Leitrim, . . . . . . 4, 4 4,083

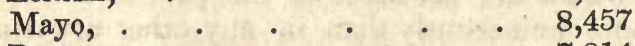

Roscommon; . . . 7,814

Sligo,

4,109

$£ 35,216$

MUNSTER.

Clare,

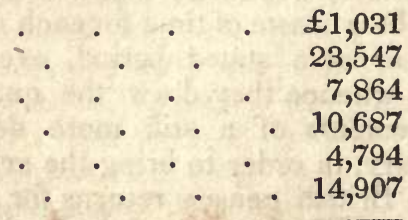

Cork,

Kerry,

Limerick,

7,864

Tipperary,

4,794

Waterford, 


\section{ULSTER.}

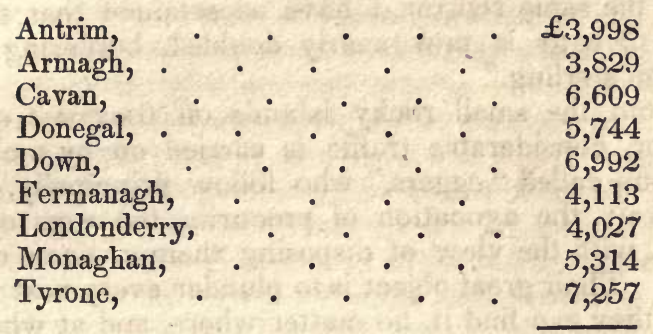

$£ 47,883$

The total sum, according to this estimate, is $£ 202,172$. Hence the number of poultry returned, amounted to $8,088,680$, reckoning them at $6 d$. per head; but, as stated above, this number is far below the mark.

Mr. Richardson, in a little work on "Domestic Fowls," published in Dublin, in 1847, says, "I have had a statement furnished me, by Mr. P. Howell, secretary to the City of Dublin Steam-Packet Company to the following effect:-The number of boxes of eggs shipped by that company's vessels for London, during the year 1844-5, was 8,874 ; about the same number was shipped by the British and Irish Company, making a total of 17,148 boxes. Each contained 13,000 eggs, but occastonally large boxes are used, containing more than four times that number. This gives the result of $23,072,400$ eggs as annually shipped for London. To Liverpool, were shipped 5,135 boxes, containing 25,566,500 eggs, making a total of the shipments from Dublin alone, during the years $1344-5$, to the two ports of London and Liverpool, of $48,639,900$, the value of which, at the average rate of $5 s .6 d$. per every 124 eggs, (the return made,) gives a sum amounting to about $£ 122,500$ as the annual value of the eggs shipped from Dublin alone; and, since this return, the export of eggs has enormously increased. Assuming the export of Dublin to be equal to one fourth of the exports of all Ireland, (a calculation reaching much above the mark,) we have very close on $£ 500,000$, or half a million, as the value of this branch of commerce to Ireland, showing also an increase of 
fourfold since 1835." The same writer adds, in a note, "By the same returns, I have ascertained that the export of eggs is now nearly doubled, bordering on a million sterling."

From the small rocky islands off the coast of Labrador, considerable traffic is carried on by a class of persons called "eggers," who follow principally, or exclusively, the avocation of procuring the eggs of wild birds, with the view of disposing them at some distant port. Their great object is to plunder every nest whenever they can find it, no matter where, and at whatever risk. They not only gather all the eider down they can find; yet so cruel and inconsiderate are they, that they kill every bird that comes in their way. The eggs of gulls, guillemots, and ducks are searched for with care ; and the puffins, and several other birds, they massacre in vast numbers merely for the sake of their feathers.

The business is generally carried on with small dirty, cabinless shallops, of a few tons rurthen, manned with eight hands, who lie and sleep in the hold at the foot of a tottering mast. "Much had been said to me," says Mr. Audubon, from whose work the following graphic sketch is taken, "respecting these destructive pirates before I visited the coast of Labrador, but I could not entirely credit all their cruelties until I had actually witnessed their proceedings, which were such as to inspire no small degree of horror. But you shall judge for yourself.

"There rides the filthy thing! The afternoon is half over. Her crew have thrown their boat overboard; they enter and seat themselves, each with a rusty gun. One of them sculls the skiff towards an island for a century past the breeding place of myriads of guillemots, which are now to be laid under contribution. At the approach of the vile thieves, clouds of birds rise from the rock and fill the air around, wheeling and screaming over their enemies. Yet thousands remain in an erect posture, each covering its single egg, the hope of both parents. The reports of several muskets loaded with heavy shot are now heard, while several dead and wounded birds fell heavily on the rock or into the water. 
Instantly all the sitting birds rise and fly off affrighted to their companions above, and hover in dismay over their assassins, who walk forward exultingly, and with their shouts mingling oaths and execrations. Look at them! See how they crush the chick within its shell, how they trample on every egg in the way, with their huge and clumsy boots. Onward they go, and when they leave the isle not an egg that they can find is left entire. The dead birds they collect and carry to the boat. Now they have regained their filthy shallop; they strip the birds by a single jerk of their feathery apparel, while the flesh is yet warm, and throw them on some coals, where, in a short time, they are broiled. The rum is produced when the guillemots are fit for eating, and after stuffing themselves with this oily fare, and enjoying the pleasures of beastly intoxication, over they tumble on the deck of their crazed craft, where they pass the short hours of night in turbid slumber.

"The sun now rises above the snow-clad summit of the eastern mount-

'Sweet is the breath of morn,'

even in this desolate land. The gay bunting erects his white crest, and gives utterance to the joy he feels in the presence of his brooding mate. The willow grouse on the rock crows his challenge aloud. Each floweret, chilled by the night air, expands its pure petals ; the gentle breeze shakes from the blades of grass the heavy dew drops. On the Guillemot Isles, the birds have again settled, and now renew their loves. Startled by the light of day, one of the eggers springs on his feet and rouses his companions, who stare around them for awhile, endeavoring to recollect their senses. Mark them, as with clumsy fingers they clear away their drowsy eyes! Slowly they rise on their feet. See how the filthy lubbers stretch out their arms and yawn; you shrink back, for verily, 'that throat might frighten a shark.'

"But the master, soon recollecting that so many eggs are worth a dollar or a crown, casts his eye towards the 
rock, marks the day in his memory, and gives orders to depart. The light breeze enables them to reach another harbor a few miles distant, one which, like the last, lies concealed from the ocean by some other rocky isle. Arrived there, they re-act the scene of yesterday, crushing every egg they can find. For a week, each night is passed in drunkenness and brawls, until, having reached the last breeding place on the coast, they return, touch at every isle in succession, shoot as many birds as they need, collect the fresh eggs, and lay in a cargo. At every step, each ruffin picks up an egg, so beautiful that any man with a feeling heart would pause to consider the motive which could induce him to carry it off. But nothing of this sort occurs to the egger, who gathers and gathers, until he has swept the rock bare. The dollars alone chink in his sordid mind, and he assiduously plies the trade which no man would ply who had the talents and industry to procure subsistence by honorable means.

"With a bark nearly half-filled with fresh eggs, they proceed to the principal rock, that on which they first landed. But what is their surprise when they find others there helping themselves as industriously as they can! In boiling rage, they charge their guns, and ply their oars. Landing on the rock, they run up to the eggers, who, like themselves, are desperadoes. The first question is the Nischarge of musketry, the answer another. Now man to man, they fight like tigers. - One is carried to his boat with a fractured skull; another limps with a shot in his leg; and a third feels how many of his teeth have been driven through the hole in his cheek. At last, however, the quarrel is settled; the booty is to be equally divided; and now see them all drinking together. Oaths and curses, and filthy jokes, are all that you hear; but see, stuffed with food and reeling with drink, down they drop one by one; groans and execrations from the wounded mingle with the snorings of the heavy sleepers. There let the brutes lie."

A similar traffic, though less extensive and more peaceable, is carried on among the Keys of Florida, in pro- 
curing wild birds' eggs, and selling them at the adjacent ports.

\section{POULTRY STATISTIES.}

To the Report of the "Committee of Supervision" of - the New-England Convention of Domestic Fowl Breeders, held in Boston on the 15th of November last, I am indebted for the following extract:

"Until quite recently, the breeding and rearing of poultry, in this section of the country, has been considered too insignificant an article of stock to require any, or very little notice.

"The rearing of poultry, as will be shown, is certainly not the least important article of stock to the farmer; and the subject is now beginning to assume an importance which the committee hope may produce an honorable competition at our fairs-for the best stock, that stock whichever it may be, that shall give the best fowl -those giving the greatest anount of meat with the least offal-and which shall at the same time give the largest number of eggs, or return in profit, for the amount invested.

"That the rearing of poultry for market can be made profitable, the committee could produce facts from wellauthenticated sources, which should convince the most incredulous; but they will omit doing so in this report, and confine themselves to a few statistical remarks.

"The article of poultry is readily converted into money, and is probably, quite as readily prepared for market as any other article of stock produced on the farm. The expense of feeding the best stock is no more than would be the expense of feeding and rearing the poorest dunghill fowl, while the return shows a heavy balance in favor of the large-bodied and fine-meated fowl, with little offal.

" Our convenience to the London markets, by the aid of steamers weekly, enables the farmer through the egg merchant, to make sale of his surplus eggs in that quarter.

"The amount of sales of poultry at the Quincy Market. Boston, for the year 1848, was six hundred and 
seventy-four thousand four hundred and twenty three dollars; the average sales of one dealer alone amounting to twelve hundred dollars per week for the whole year. The amount of sales for the whole city of Boston, for the same year, (so far as obtained,) was over one million of dollars.

"The amount of sales of eggs, in and around, the Quincy Market, for 1848, was one million one hundred and twenty-nine thousand, seven hundred and thirty. five dozen, which, at 18 cents per dozen, (the lowest price paid $11_{2}^{1}$ cents, and the highest 30 cents per dozen, as proved by the average purchases of one of the largest dealer's books,) makes the amount paid for eggs to be two hundred and three thousand, three hundred and fifty. two dollars and thirty cents. And from information already obtained from other egg merchants, in the same city, the whole amount of sales will not fall much, if any, short of a million of dollars for 1848 .

"The average consumption of eggs, at three of the hotels, was more than two hundred dozen each day, for the year 1848 .

"The value of eggs brought from the Penobscot and Kennebec Rivers, during the running season of the steamboats, plying between Boston and those two rivers, was more than three hundred and fifty thousand dollars for that season.

"In one day, from Cincinnati, Ohio, it is stated in one of the public journals, there were shipped 500 barrels, containing 47,000 dozen of eggs. One dealer in the egg trade, at Philadelphia, sends to the New-York Market, daily, nearly one hundred barrels of eggs. It is estimated, from satisfactory returns, that the city of New York alone expends nearly a million and a half of dollars per annum, in the purchase of eggs.

"By reference to the agricultural statistics of the United States, published in 1840, it will be seen that the value of poultry in the State of New York, was two million, three hundred and seventy-three thousand and twenty-nine dollars; which was more than the value of its sheep, the entire value of its neat cattle, and nearly five times the value of its horses and mules. 
"The same authority exhibits the total valuation of poultry, in various states and territories of the Union:-

Maine, $\$ 123,171$

New Hampshire, 9 $\quad 97,862$

Vermont, 176,437

Massachusetts, . . 540,295

Rhode Island, . . . . $\quad 61,492$

Connecticut, . . . . 176,659

New York, • . . . 2,373,029

New Jersey, • • • • 412,487

Pennsylvania, . . . . $1,033,172$

Delaware, . . . . 47,465

Maryland, . . • . 219,159

Virginia, . . . . 752,467

North Carolina, • • • . 544,125

South Carolina, . . . 590,594

Georgia, • • • . 473,158

Ohio, • • • • • 734,931

Kentucky, • • • • . 536,439

Tennesee, • . . • . 581,531

Louisiana, • • • • • 273,314

Mississippi, . . . . 369,481

Alabama, • • • • 829,220

Missouri, • • • • 230,283

Indiana, · • • • • 393,228

Illinois, • • • • • $\quad 335,968$

Michigan, • • • • $\quad 82,730$

Arkansas, • • • • 93,549

Florida, • • • • • 61,007

Wisconsin, • • • • 16,167

Iowa, . • • • • 17,101

District of Columbia, . • $\quad 3,092$

Total, . . . $\$ 12,176,170$

"It is probatle that, since 1840 , the value of poultry has doubled."

\section{WEIGHT OF POULTRY.}

As the size and weight ascribed to various breeds of fowls is often greatly exaggerated, I insert for the benefit 
of the curious the following lists from Mr. Dixon's work, which will serve as a guide for about an average weight of poultry in the United States:-

"Wishing to know what truth there was in the unauthentic statement that there were such things as cocks weighing 15lbs., and hens 10lbs., I applied to Mr. Nolan for further information, and not having received any reply, conclude that he is not in a position to supply such birds to his customers-a supposition which has been confirmed by a private letter from a gentleman then staying in the neighborhood of Dublin.

"But the reader will be better able to judge what weights fowls may be reasonably expected to attain, after the inspection of the following lists of the live weights of various poultry, with which I have been obligingly favored. But as the birds are generally out of condition, in consequence of their being mostly now on the moult, and also from the late wet season, the weights are less than they would be under more favorable circumstances. One list gives-

LBs. oz.

Black Polish cock, three years old, - $\quad 53$

Ditto hen, ditto, • . . . 34

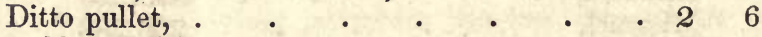

Golden Polish cock, . . . . . . 50

Ditto hen, . . . . . . . 38

Another hen, . • • • • . . 310

Golden Polish pullet, . . . . . 28

Malay hen, • • • • • . . 412

Creole, (silver Hamburgh,) hen, . . . 31

Black nondescript hen, . . . . . 310

Globe-crested Polish hen, . . . . 39

Silver Polish hen, . . . . . . 34

Game cock, . . . . . . . 410

Ditto hen, • • • • . . . 30

Young blue-dun cock, . . . . $\quad$. 36

Blue-dun hen, . • . . . 30

Large dun hybrid hen, . $\quad$. $\quad . \quad 38$

"Among these, the Malay hen was moulting, and not up to her usual weight by nearly a pound. It will be observed that there is a great relative difference between the pullets and the grown hens of the Polish breed. All 
the Polish increase much in size and beauty the second moult."

Another list kindly furnished by Mr. Alfred Whitaker, gives-

Pheasant-Malay cocks, two years old, (average,) ${ }_{7}^{\text {Lss. }}{ }_{0}^{\text {oz. }}$

Ditto cockerel, five months old, . . . 70

Ditto hen, . . . . . . . 51

Ditto pullet, seventeen months old, . . . 53

Ditto, (crossed with Dorking hen,) four years old, $5 \quad 8$

Speckled Surrey hen, two years old, ․ . . 512

Spanish hen, . . . . . . . 50

Two Dorking cocks, each, . . . . . 70

Ditto hens, . . . . . . . 68

Ditto, ditto, . . . . . . . 612

Cock turkey, two years and a half old, . $\quad .17 \quad 12$

Hen ditto, one year and a half old, . . . 100

Ditto, ditto, . . . . . . . 99

Musk drake (moulting) • . . . . 912

Mr. Dixon's own poultry yard gave the following weights:-

Turkey cock, sixteen months old, . $\quad . \quad 16 \stackrel{\text { LBs. }}{0}$

Ditto hen, three or four year old, . . . 86

White, China gander, six years old, . $\quad .12 \quad 13$

White, China goose, . . . . . 1113

Common China goose, (cynoides,) six years old, $10 \quad 10$

Cochin-China cock, about sixteen months old,

moulting, . : • • • . 65

Ditto hen, ditto, ditto, 46

Malay cock, ditto, ditto, $6 \quad 14$

Ditto hen, ditto, ditto, 48

Pheasant-Malay cock, . . . . . 57

Ditto Malay hen, moulting, . $\quad$. 38

Game cockerel, about five months old, . . . 42

Golden Hamburgh cockerel, just arrived from a

long journey; about five months old, . . . 38

Ditto pullet, ditto, ditto, . 24

Cochin-China cockerel, six months old, . . 414

Another, ditto, . . . $4 \quad 13_{2}^{1}$

Silver Hamburgh cockerel, after travelling, about

five months old,

Ditto pullet, ditto, $\quad \begin{array}{llll} & & 3 & 1 \\ \text { ditto, } & \cdot & 2 & 8\end{array}$ 


\begin{abstract}
Black Polish hen, moulting, - . . 30
Golden Hamburgh, ditto . • . . . 23

Andalusian cockerel, four months old $\quad$. 38

Ditto pullet, ditto, . . . . $26_{2}^{1}$

Black Spanish cockerel, ditto, • • . 211

Ditto pullet, ditto, . . . 211

Silver Polish cockerel, four months and a half old, $2 \cdot 14_{2}^{1}$

Golden Poland pullet, about five months old, . 28

White-crested golden Poland pullet, ditto, . $\quad 23$

It will appear from the foregoing, that for a cock, of any breed, to reach $7_{2}^{1}$ lbs., even live weight, he must be an unusually fine bird; but this has to be doubled before we can rival those Cochin-China specimens, in whose existence some persons appear to believe.
\end{abstract}

\title{
SAMUEL ALLEN.
}

Tu C. M. SAXTON.

NEW YoRK, January 2, 1850. 


\section{N DEX.}

A

Albinos

Animals influenced by Food and climate ${ }^{252}$ White ................... 292 "Inferiority of ...... $32,92,297$

\section{B}

Bankiva Fowl Jungle Fowl

Brceding, Reinarks on

\section{C}

Caponising Fowls

166,251

Capons trained to hatch Eggs ........... 119

" employed to nurse Chickens.... 119

Cob (Male Swan) .................. 245

Cock, Dunghill, Selection of ............ 89

" Character of .......... 90

Javan .......................... 19

Jungle $\ldots \ldots \ldots \ldots \ldots \ldots \ldots \ldots \ldots \ldots$ i9, 21

D

Diseases of Poultry . . . . . . . . . . . . 259

Apoplexy .................260

Appetite, Loss of ............. 276

"6 Voracious ..........276

Asthma ................. 273

Bloody Flux ................ 279

Catarrh ................. 268

Change of Color of Feathers.... 289

Colds .................... 268

Consumption, Pulmonary ...... 268

Costiveness ................ 278

Cropsick .................. 276

Diarrhœe ................. 278

Dislocations ............... 283

Feathers, Loss of ............. 287

Fever ................. 274

" Hatching and Pairing.. 275

Fractures $\ldots \ldots \ldots \ldots \ldots \ldots \ldots . . \times 3$
Diseases of Poultry PAars.

Gapes ................... 263

Gout $\ldots \ldots \ldots \ldots \ldots \ldots \ldots \ldots \ldots \ldots \ldots \ldots, 281$

Indigestion................. 276

Inflainmation of the Eyes ...... 280

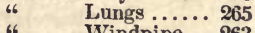

"6 $\quad$ Lungs $\ldots . .2265$

Influenza .................. 267

Lice ......................... 283

Loseness ................... 278

Moulting $\ldots \ldots \ldots \ldots \ldots \ldots \ldots \ldots \ldots \ldots \ldots, 288$

Nostrils, Obstruction of .........266

Parasitic Vermin ............. 283

Pip, or Thrush............. 262

Phthisis ................... 268

Rheumatlsm .................. 280

Roup $\ldots \ldots \ldots \ldots \ldots \ldots \ldots . \ldots 267,281$

Rump Gland, Obstruction of .. 281

Scouring .................... 278

Thrush, or Pip............. 262

Thirst...................... 275

Ulcers ...................... 228

Wounds $\ldots \ldots \ldots \ldots \ldots \ldots \ldots . .289$

Duck, Aylesbury ........................ 197

Marsh .................... 197

Musk, or Muscovy .......... 198, 298

Rouen, or Rhone .............. 197

Tame................. 190, 298

" Choice of varieties of...... 197

" Fattening of $\ldots \ldots \ldots \ldots \ldots, 206$

" Incubation of ................ 204

" Origin and History of...... 190

"Range and Domestic Accomodation of .......... 201

6 Rearing and Feeding of ... 205

wild...................... 191

\section{$\mathbf{E}$}

Excaleobion described $\ldots \ldots \ldots \ldots \ldots \ldots, 112$

Egg Cluster ........................... 100

Eggers, Labrador, described .......... 310

Egg-Hatching Machine, American ..... 116

Egg Trade ....................... 305

Eggs, necessary Temperature for Hatch-

ing $\ldots \ldots \ldots \ldots \ldots \ldots \ldots \ldots \ldots \ldots \ldots \ldots, 112,114$ 
Eggs, Quatities of

PAGES. Preservation of for Cooking .......997 6 6 "6 Hatching ..... 98 « Recipes for Preserving ........ 97, 98

4. Sexes of .................. 95

"6 Structure of ................. 99

46 Weight of................ 41, 224

Everlasting Layers................. 54

\section{F}

Fowl, Domestic, Anomalous Varieties of 81 Antiquity of Varieties of $\ldots \ldots \ldots \ldots \ldots 5,14,73$ Artificial Incubation of 112 66 Mothers in Rearing of........ 120 Bantam ......... 67, 297 " Black....... 70 6. Creeper ...... 71

.6 Jumper......

“ Nankin.....6.67

4 Sebright.....66 68

$4 \quad$ White...... 71

4 Yellow ...... 67

Barn-Door......... 55, 72

Best Food for ......... 125

Black Polish......... 62 "6 Topped White Polish....... 63

4 Spanish....... 26

Blue Dun ........... 80

Bolton Bay ......... 51 " Grey .......... 51

Booby ............. 78 Breeding and Crossing of $\ldots \ldots \ldots \ldots \ldots \ldots$ Buck's-County........ 78 Caponising .......... 251 Chittagong ......... 37 Cheteprats ......... 51 Chittiprats ........... 51 Classification of ....... 25 Cochin-China ........ 33 Comparative Merits of . 295 Cuckoo ............ 55 Coops for ........ 121, 122 Copplecrowns ....... 56, 60 Coral Grey .......... 51 Creole.............. 51

Diseases of .......... 259 Dominica, or Dominique ..........8 80, 297 Dorking $\quad \ldots \ldots \ldots . . .29,296$ Columella......... 32 Duke of Leeds ...... 13, 75 Experiments in Feeding of with boiled Grain ........... 128

Futtelling of ........ 125 Food of, compared ..... 128 found on the Pacific Isles ........... 16, 17

Frizzled........... 81

Game .......... 44, 297

\section{Fowl, Domestic, Geographical Distribu-}

PAGNS.

tion of .......... 15

Golden Hamburgh .... 51 66 Poland .....60, 63 "s spangled ..... 58

Great Malay ......... 37

Immutability of Species of $\ldots \ldots \ldots \ldots \ldots 73,105$

Incubation of ......... 106 Infiuenced by Food and Climate .......... 73

Jago, or St. Jago . . . 39, 74 Jersey-Blue........... 77 Jungle ........... 19, 21

Kuim .............. 37

Killing and Preparing for Market ........ 132

Lark-Crested ......... 56

Lime, Soot, Charcoal, \&c. , for ......... 83, 87

L.ost Varieties of ..... 13

Malay .............. 37

Minorca............... 26

Mongrel............ 72

Negro .............. 81

Nest Boxes for........ 85

Nests of, Materials for making .......... 87

not found in the Atlantic Isles, when discovered by the Moderns .. 8

not mentioned in the Old Testament...... 6

Old Sussex, or Kent ... 31

Origen and History of . 5

Ostrich ........... 33, 78

Paduan ............ 60

Paring of ............ 92

Pencilled Dutch....... 51

Pheasant ............ 40 "6 Breed ....... 40 " Malay ....... 40

Plymouth-Rock ....... 76

Poland, Polander, or Polish............ 60

Portugal................ 26

Range and Domestic Accommodation of.. 81

Rumkin, or Rumpless. 81

Shack-Back, or Shag-

Bag .........663, 75

Shanghae Cochin-China 75

Silky ............ 81

Silver Hamburgh ..... 51 "6 Poland ......... 6n 6 Spangled IIam-

burgh............58 58

Spangied Polish ....... 60

Spanish ........... 26, 75

Topknotted, not mentioned by the Ancients ............. 12

Weight of ... 30, 35, 76, 78,

79,365

White Polish ....... G0, 63

Turkish ............ 
PAGES.

Fowl, Domestic, Young of, Growth in the Egg ........... 108 6 how to feed previous to Weaning 121 Young of, how to nurse 117

Fowl Houses ................ 84, 86 Fowl, Wild ............... 15, 19, 21, 24

Bankiva Jungle ......... 19

Classification of ...........

Geography of ............

Javanese Jungle ...........

Jungle, Sonnerat's ........

6 Stanley's ........... 21

South American ...........

\section{G}

Game Cock, English

Game Fowl

66

Breeding of

Geese, Sandwich-Island .............

Goose, Africun ................. 222

American Wild................. 234

"6 Breeding of ..........240

"Geographical Distribution of ........238

"6 Management of...... 240

"6 Migration of ......... 238

6 Natural History of ... 234

- $6 \quad$ Pairing of .......... 240

Bean .................... 211

Bremen ................... 298

Canada, described ............ 237

China ..................... 222

Domestic Breeding of .......... 226

. 6 Fattening of ............ 219

"6 Incubation of ........217

"6 Laying of ............... 216

"6 Origin and History of... 208

"6 Pairing of ............ 215

"6 Range and Domestic Accomodation of ....214

6 Young of, how to treat. 218

Embden ................ 213

Grey-legged............... 211

Guines................. 222

Hong-Kong ............... 222

Laughing............... 211

Spanish ................. 222

Swan ................... 222

White, China ........ 228, 231, 298

White-Fronted ............. 212

Wild .................. 237

Gninea Fowl ................... 170, 297

Carried from America to Eurce ............. 169

Distinction between the Cock and Hen......... 170

Eggs of .............. 172

Feeding and Management of ............... 174 Geographical Distribution of $\ldots \ldots \ldots \ldots \ldots \ldots \ldots$

Incubation of $\ldots \ldots \ldots \ldots .$.
Guinea Fowl, Laying of ............ PAGs

Origin and History of ...., 167

Pairing of $\ldots \ldots \ldots \ldots \ldots 171$

\section{H}

Hen, Domestic, Character of ......... 91

Choice of ........... 91

Laying Propensities of . 94

Hens, Relative Number to a Cock ..... 92

Hybrid between the Pheasunt and Domestic Fowl................. 41

Hybrid Geese .... 212, 218, 226, 227, 229, 298 Hydro-Incubator ................. 114

\section{I}

Incubation, Period of-

American Wild Goose ..... 234

China Goose............. 227

Common Goose ........... 217

"6 Swan ............246, 229

Domestic Hen .......... 108, 114

Guinea Hen ...................... 173

Musk Duck .............. 200

Pea Hen ................. 188

Tame Duck .............. 205

Turkey Hen .............. 158

White, China Goose ........ 233

Incubation, Periods of, vary according to

Circumstances ........... 200

\section{J}

Javanese J ungle Cock .............. I9

Jungle Cock...................... 21

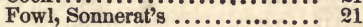

" Stanley's ............. 21

$\mathbf{K}$

Kulm Fowl................... 37

I.

Longevity of Poultry ......... 90, 141, 290

Lost Varieties of Fowls ............. 13

Laying Propensities of Fowls .......... 94

M

Malay Fowl ..................... 37 Meleagris of the Ancients, What ?.. 167,169

167 Nest Boxes for Domestic Fowls

173 Nests, Materials for making ........... 


\section{o}

Ostrich Fowl

PAGRS. 33,78

Ovarium, or Egg Cluster of Fowls...... 100

\section{$\mathbf{P}$}

Pea Fuwl

Feeding and Management of 188

Geographical Distribution of . 181

Japan ................ 182

Laying and Brooding of ..... 187

Origin and History of ...... 178

Queen Victoria's.......... 179

Range and Domestic Accom-

modation of............. 186

Pen Birds (Female Swans) ............ 245

Pheusant-Malay Fowl ............... 40

Fowi .................. 40

Breed.................... 40

Polotokian ....................... 113

Poulardes, how to make .............. 253

Poultry Raising, Profits of........... 300

Statistics .................. 313

Weight of.30 $357678,79,142,152$, $221,249,315$

Q

Queen Victoria's Pea Fowl

\section{$\mathbf{R}$}

Rumkin, or Rumpless Fowl

\section{S}

Sonnerat's Jungle Fowl ............ 21 Stanley's 6 6 $\ldots \ldots \ldots \ldots \ldots \ldots .21$

Swan, Chinese..................... 222

Common ...............245, 299

"Distinction between Sexes 247
PAars. 247,299

"6 Management of ... 247, 299

" Mute............... 245

" Natural History of .... 244

" Pairing of .......... 246

$\mathbf{T}$

Turkey, Domestic ............ 151, 297

Caponising of........ 166

Choice of the Cock .. 153

Eggs of ............ 157

Fattening of ......... 164

Incubation of .......... 158

Laying of ............ 155

Long-Island Dwarf .... 151

Number of Hens to a

Cock.......... 155

Origin and History of 133

Range and Domestic Accommodntion of. 152

Selection of the Hen . 154

Should not roost with other Fowls ....... 152

Topknotted Variety of ........... 152

Story of, in Persia ... 137

Young of, how to treat 160 " injured by

Wet ............. 148

Weight of...... 152, 164 Turkey, wild, described ............ 139

Crossed with Domestic

Breed ............. 142

Eggs of .............. 146

Geographical Distribution of .............. 149

Habits of ............. 143

Honduras ............. 138

Weight of............ 142

When introduced into

Europe............ 136 


\section{IIIUSTRATIONS.}

American Egg-Hatching Machine ................................. 116

" Wild Goose $\ldots \ldots \ldots \ldots \ldots \ldots \ldots \ldots \ldots \ldots \ldots \ldots \ldots \ldots \ldots \ldots \ldots \ldots \ldots \ldots, 237$

Bankiva Jungle Cock ............................ On Frontispiece, and 19

Bantam Cock .............................................. 67

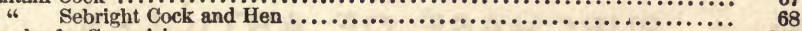

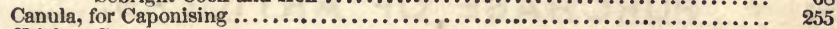

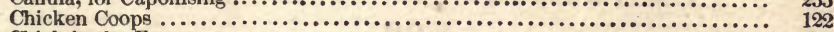

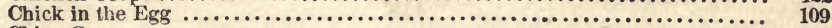

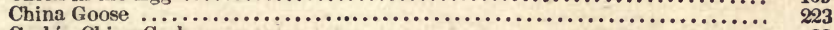

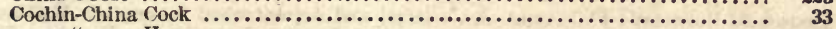

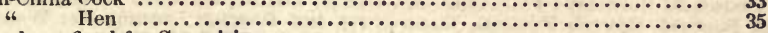

Cockerel, confined for Caponising $\ldots \ldots \ldots \ldots \ldots \ldots \ldots \ldots \ldots \ldots \ldots \ldots \ldots \ldots \ldots \ldots \ldots \ldots, \quad 256$

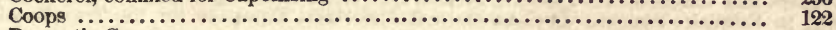

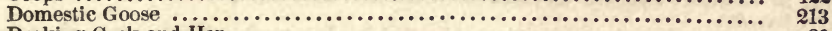

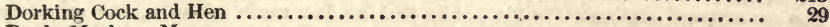

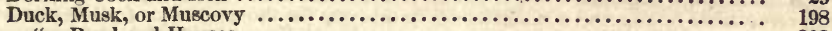

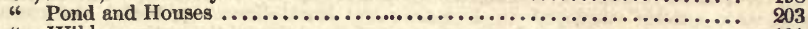

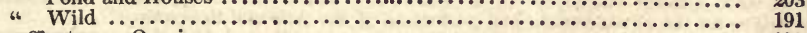

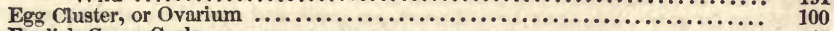

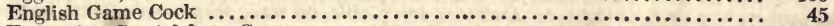

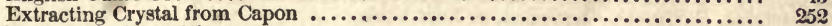

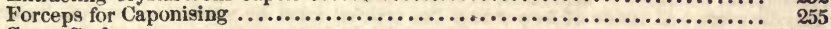

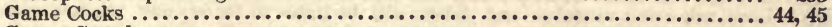

Goose, Canada ................................................. ${ }_{237}$

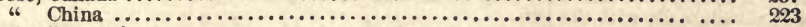

" Domestic .............................................. 213

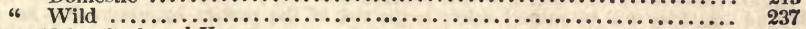

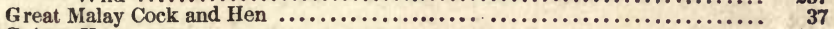

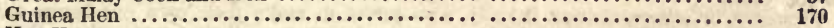

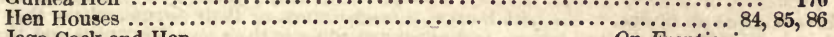

Jago Cock and Hen .............................. On Frontispiece

Javanese Cock ............................. On Frontispiece, and

"Jungle Cock ....................... On Frontispiece, and

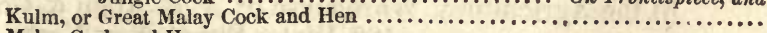

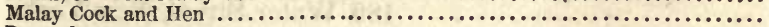

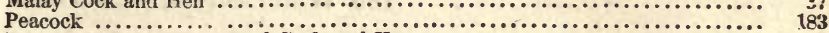

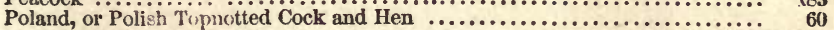

Poultry Houses ..................................... 84, $85,86,122,203$

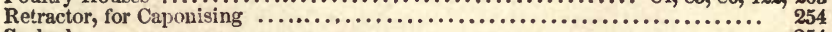

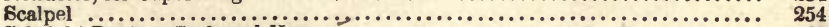

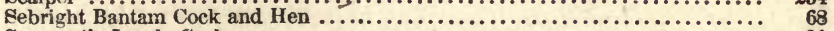

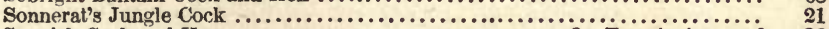

Spanish Cock and Hen ............................ On Frontispiece, and 26

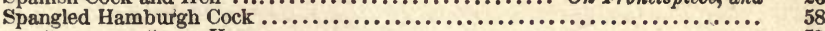

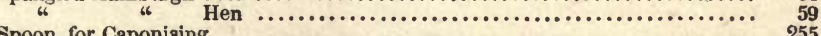

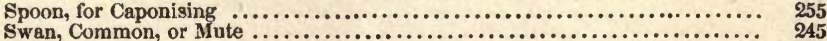

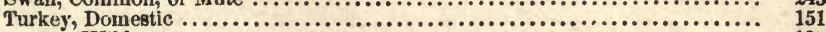

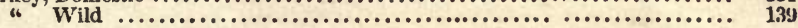




\section{A GEN E \\ FOR THE \\ PURCHASE OF ARTICLES \\ OF}

Household Economy ; Philosophical, Chemical and Astronomical Apparatus; Mathematical, Surgical, Optical, Nautical, Engineering, and Gauging Instruments; Watches, TimeKeepers, and Chronometers ; Books, Stationery, Charts, and Maps; Utensils and Materials used in Printing; Sporting Implements and Materials; Equipage for the Traveller, Voyager, \&c., \&cc.

The undersigned announces to the public that he has made advantageous arrangements with respectable houses and manufacturers in this city for the purchase of all the principal procurable articles employed in Domestic and Rural Economy, useful and ornamental, as well as for the advancement and perfection of the Arts and Sciences.

All orders for goods, \&c., must be addressed, post-paid, and invariably accompanied with the money, or a draft at sight, or otherwise acceptable, on some responsible house in Boston, Philadelphia, Baltimore, Charleston, or New York.

The direction and mode of forwarding the articles must be written out in full, in a clear, legible hand, otherwise mistakes and delays will be-liable to occur; and, whenever practicable, it is desirable that they may be accompanied by a sample, or drawing, or at least, a rude sketch made with the pen.

All articles will be carefully selected, packed, and shipped, or sent, agreeable to direction. Beyond this, they will be subject solely to the risk of the parties by whom they are ordered or conveyed.

Strangers, or others, visiting the city, who prefer to make their own purchases, will be directed, free of charge, to the best houses, manufacturers, or their agents, where they may examine the articles at their leisure, and select according to their own judgment and taste.

D. J. BROWNE,

At the Agricultura: Warehouse of A. B. Allen \& Co., 189 Water Street, New York. 


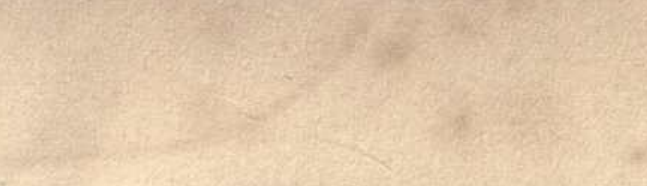

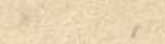

w. 


RETURN TO the circulation desk of any University of California Library or to the

NORTHERN REGIONAL LIBRARY FACILITY Bldg. 400, Richmond Field Station University of California Richmond, CA 94804-4698

ALL BOOKS MAY BE RECALLED AFTER 7 DAYS

- 2-month loans may be renewed by calling (510) 642-6753

- 1-year loans may be recharged by bringing books to NRLF

- Renewals and recharges may be made 4 days prior to due date.

DUE AS STAMPED BELOW

\section{FEB 142002}



